\title{
Sistemas Dinâmicos Não Lineares de Tempo Discreto: Aplicações em Comunicações e Processamento de Sinais
}

Texto que sistematiza criticamente parte da obra do candidato, apresentado ao Departamento de Engenharia de Telecomunicações e Controle - PTC da Escola Politécnica da Universidade de São Paulo para o Concurso 079/2016, visando a obtenção do título de livre-docente na especialidade "Processamento e Análise Digital de Sinais".

\section{Marcio Eisencraft}




\section{Agradecimentos}

Aos professores que, quer seja em salas de aula, quer seja em livros, acompanharam-me ao longo de meus quarenta anos.

Ao meu familiares, em especial a meu tio-avô Prof. Moyses Szajnbok (in memoriam) pelo incentivo, motivação e valiosas discussões.

À todos os colegas, amigos e alunos que direta ou indiretamente colaboraram na realização deste trabalho.

À FAPESP e ao CNPq pelo auxílio financeiro.

À minha maravilhosa esposa Ana Carolina e aos meus queridos filhos David e Beatriz pelo tempo que subtraí em nossa convivência para adicionar a esse trabalho. 


\section{Resumo}

O presente texto sistematiza pesquisas realizadas pelo autor, seus alunos e colaboradores nos últimos dez anos, buscando-se utilizar uma notação única e consistente. Escolheu-se relatar pesquisas que têm como mote comum conseguir resultados relevantes juntando técnicas de duas áreas: Processamento de Sinais e Telecomunicações por um lado e Sistemas dinâmicos, de outro. Especificamente, retratam-se resultados de duas linhas de pesquisa seguidas pelo autor. Na primeira, objetiva-se caracterizar espectralmente sinais gerados por mapas unidimensionais lineares por partes. Na outra, pretende-se adaptar sistemas de comunicação baseados em sincronismo caótico para que possam ser utilizados em aplicações práticas, fazendo frente, por exemplo, a ruído aditivo, canais de banda limitada, distorções e atrasos inerentes a canais de comunicação. Os resultados relatados aqui foram apresentados em 4 dissertações de mestrado e 2 teses de doutorado e publicados em 12 artigos de periódicos listados no Journal Citation Reports, em 6 capítulos de livro e em 22 artigos completos em anais de congressos. 


\section{Sumário}

1 Introdução 1

2 Sinais caóticos de tempo discreto: notação e definições básicas 5

2.1 Conceitos e definições básicas . . . . . . . . . . . . . . 5

2.2 Número e expoente de Lyapunov $\ldots \ldots \ldots \ldots$

2.2 .1 Caso unidimensional . . . . . . . . . . . . . . . . 8

2.2 .2 Caso $M$-dimensional . . . . . . . . . . . . . . . 11

2.3 Sinais caóticos . . . . . . . . . . . . . . . . . . . . . 12

2.4 Alguns geradores de sinais caóticos . . . . . . . . . . . . . . . 13

2.4 .1 Mapa tenda $f_{T}(\cdot) \ldots \ldots \ldots \ldots \ldots \ldots$

2.4 .2 Mapa tenda inclinada $f_{I}(\cdot) \ldots \ldots \ldots \ldots \ldots$

2.4.3 Mapa de Bernoulli com $r$ segmentos $f_{B}(\cdot) \ldots \ldots$. . . . . . 16

2.4 .4 Mapa quadrático $f_{Q}(\cdot) \ldots \ldots \ldots \ldots \ldots$

2.4 .5 Mapa de Hénon $f_{H}(\cdot) \quad \ldots \ldots \ldots \ldots \ldots$

2.4 .6 Mapa de Ikeda $f_{I k}(\cdot) \ldots \ldots \ldots \ldots \ldots$

2.4.7 Mapa de Hénon tridimensional $\boldsymbol{f}_{H 3}(\cdot) \ldots \ldots . \ldots 20$

2.5 Densidade invariante e o operador de Frobenius-Perron . . . . . . . . . . 21

2.6 Conclusões . . . . . . . . . . . . . . . . . . . . . . . . . . . . . . . . . 28 
3.1 Definições básicas . . . . . . . . . . . . . . . . . . . . . 32

3.2 Um estudo das órbitas do mapa tenda inclinada $f_{I}(\cdot) \ldots \ldots . \ldots 33$

3.2 .1 Sequência de autocorrelação . . . . . . . . . . . . . . . 34

3.2 .2 Densidade espectral de potência . . . . . . . . . . . . 38

3.2 .3 Banda essencial . . . . . . . . . . . . . . . . . . 39

3.2 .4 Conclusões . . . . . . . . . . . . . . . . . . . . . 40

3.3 Um estudo das órbitas do mapa de Bernoulli $f_{B}(\cdot) \ldots \ldots$. . . . . . . . . . 41

3.3.1 Sequência de autocorrelação . . . . . . . . . . . . . . . . 4 41

3.3 .2 Densidade espectral de potência . . . . . . . . . . . 45

3.3 .3 Banda essencial . . . . . . . . . . . . . . . . . . . . . . . . . . 45

3.3 .4 Casos particulares . . . . . . . . . . . . . . . . . 46

3.3 .5 Conclusões . . . . . . . . . . . . . . . . . . . . . . 48

3.4 Conclusões, pesquisas em andamento e trabalhos futuros associados . . . . 49

4 Um sistema de comunicação baseado no sincronismo caótico

4.1 Sincronismo mestre-escravo em tempo discreto e o SCBC estudado . . . . 54

4.2 Desempenho em AWGN . . . . . . . . . . . . . . . 58

4.2 .1 Parâmetros das simulações . . . . . . . . . . . . . . 58 58

4.2 .2 Resultados de simulações . . . . . . . . . . . . . . . . . . . 61

4.2 .3 Conclusões . . . . . . . . . . . . . . . . . . 65

4.3 Formatação do espectro do sinal transmitido . . . . . . . . . . . . 66

4.3.1 Condições de sincronismo . . . . . . . . . . . . . . 71

4.3.2 Formatação da mensagem e noise filtering . . . . . . . . . . 78 
4.3 .3 Condições para manutenção do caos . . . . . . . . . . . . . . . 83

4.3 .4 Conclusões. . . . . . . . . . . . . . . . . . . . . . . . . . . 90 90

4.4 Desempenho em canais dispersivos e equalização . . . . . . . . . . . . . . . . . 91

4.4 .1 Formulação do problema de equalização . . . . . . . . . . . . . . 91

4.4 .2 O algoritmo NLMS caótico . . . . . . . . . . . . . . . . . . 93

4.4 .3 Resultados de simulações . . . . . . . . . . . . . . . . . . . 95

4.4.4 Conclusões e outros trabalhos envolvendo equalização . . . . . . . . 105

4.5 Conclusões, pesquisas em andamento e trabalhos futuros associados . . . 106

5 Notas finais

109 



\section{Lista de Figuras}

2.1 Diagrama esquemático do comportamento de uma órbita próxima (a) de um ponto fixo atrator (b) de um ponto fixo estável segundo Lyapunov. Fonte: [67]. . . . . . . . . . . . . . . . . . . . 7

2.2 Evolução de uma esfera centrada na condição inicial $s_{0}$ quando submetida ao mapa (2.1), com $\boldsymbol{f}($.$) diferenciável. Caso bidimensional. Fonte: [67]. . . 11$

2.3 (a) Mapa tenda $f_{T}(s)$; (b) órbita com condição inicial $s_{0}=\sqrt{2} / 2$. Fonte:

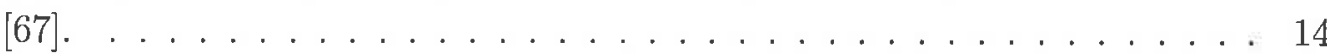

2.4 (a) Mapa tenda inclinada $f_{I}(\cdot)$; (b) trecho da órbita $s(n ; 0)$ para $\alpha=0,8$;

(c) Expoente de Lyapunov do mapa $f_{I}($.$) em função do parâmetro \alpha$. Fonte: $[67]$.

2.5 (a) Exemplo de mapa de Bernoulli, (b) trechos de $s(n ; 0,3)$ (linha contínua) e $s(n ; 0,300000001)$ (em tracejado). Fonte: [31]. . . . . . . . . . 16

2.6 (a) Mapa quadrático $f_{Q}($.$) ; (b) trecho do sinal s(n ; 0,7)$. Fonte: [67]. . . . 17

2.7 Mapa de Hénon $\boldsymbol{f}_{H}(\cdot)$ : (a) e (b) trecho da órbita com condição $s_{0}=\left[\begin{array}{ll}0 & 0\end{array}\right]^{T}$; (c) atrator da órbita. Fonte: $[67] \ldots \ldots \ldots$

2.8 Atratores de $\boldsymbol{f}_{I k}(\cdot)$. A área amarela indica a bacia de atração para o atrator caótico mostrado em preto. Órbitas iniciadas fora da área amarela são levadas para o ponto fixo indicado pela cruz. Fonte: [29]. . . . . . . . . . 19

2.9 Trechos de $s_{1}(n)$ e $s_{2}(n)$ do mapa $\boldsymbol{f}_{I k}(\cdot)$ com os parâmetros (2.23), inicializado com $s(0)=\left[\begin{array}{ll}0 & 0\end{array}\right]^{T}$. Fonte: $[29] . \ldots \ldots \ldots$

2.10 Mapa de Hénon tridimensional $\boldsymbol{f}_{H 3}(\cdot)$ : (a), (b) e (c) trecho da órbita com condição $s_{0}=\left[\begin{array}{lll}0 & 0 & 0\end{array}\right]^{T} ;(\mathrm{d})$ atrator da órbita. Fonte: [67] . . . . . . . . . 21

2.11 Órbitas e histogramas do mapa $f_{Q}($.$) obtidos com K=10^{4}$ pontos, $I=40$ intervalos e condições iniciais (a) $s_{1}(0)=0,7$ e (b) $s_{2}(0)=0,4$. Fonte: [67]. 23 
2.12 Órbitas e histogramas de $f_{Q}($.$) sem comportamento caótico. (a) s_{0}=-\sqrt{\frac{3}{4}}$; (b) $s_{0} \approx 0,809016994$. Foram usados $K=10^{4}$ pontos e $I=40$ intervalos. Fonte: $[67] . \ldots \ldots \ldots \ldots . \ldots \ldots . \ldots \ldots$

2.13 Contraimagem do intervalo $[-1, s]$ por $f_{Q}($.$) representada por linhas grossas$ no eixo das abscissas com $\beta=\sqrt{\frac{1-s}{2}}$. Fonte: [67]. . . . . . . . . . . 24

2.14 (a) Evolução da densidade constante $p_{0}(s)=\frac{1}{2}$ por $f_{Q}($.$) ; (b) Evolução da$ densidade $p_{0}(s)=\frac{3}{2} s^{2}$ por $f_{T}($.$) . Em azul p_{0}(s)$, em verde $\mathbb{P}\left[p_{0}(s)\right]$, em vermelho $\mathbb{P}^{2}\left[p_{0}(s)\right]$ e em preto a densidade invariante, $p_{*}(s)$. Fonte: [67]. . 27

3.1 Iterações do mapa tenda inclinada para $\alpha=0,1$ : (a) $f_{I}(x)$; (b) $f_{I}^{2}(x)$; (c)

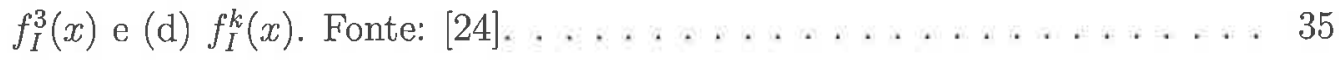

3.2 (a) Trecho de $f_{I}^{k}(\cdot)$ e (b) mesmo trecho após uma iteração. Fonte: [24]. . . 36

3.3 (a) SAC para sinais gerados por $f_{I}(\cdot)$ para alguns valores de $\alpha$; (b) SAC para sinais do mapa tenda inclinada para valores de $\alpha$ no intervalo $(-1,1)$. Fontes: $[24,49] \ldots \ldots \ldots 38$

3.4 (a) DEP para sinais gerados por $f_{I}(\cdot)$ para alguns valores de $\alpha$; (b) comportamento geral da DEP normalizada para os valores admissíveis de $\alpha$. Fontes: $[24,49] \ldots \ldots \ldots$

$3.5 B$ para o mapa $f_{I}(\cdot)$ em função (a) do parâmetro $|\alpha|$ e (b) do expoente de

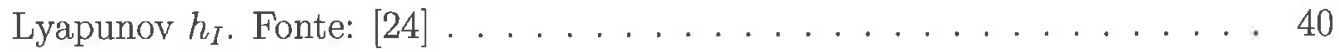

3.6 (a) Mapa $f_{B}(x)$ com $r$ segmentos; (b) $f_{B}^{2}(x)$; (c) $f_{B}^{k}(x)$. Fonte: [31]. . . . . 42

3.7 (a) Gráficos de $f_{B}^{k}(x)$ e (b) $f_{B}^{k+1}(x)$ no intervalo $\left[a_{k}(m-1), a_{k}(m)[\right.$. Fonte:

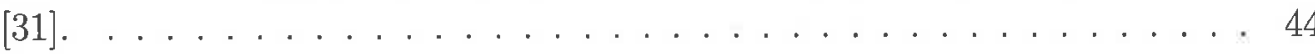

3.8 (a) SAC, (b) DEP e (c) $B$ do sinais caóticos gerados por $f_{B}(\cdot)$ para $r=2 \mathrm{e}$ diferentes valores de $\left|\alpha_{1}\right|$. Os resultados analíticos são mostrados em linhas tracejadas e simulações numéricas em linhas contínuas. Fonte: [31]. . . . . 47

3.9 (a) SAC, (b) DEP e (c) $B$ dos sinais caóticos gerados por $f_{B}(\cdot)$ para $r$ segmentos de mesma inclinação. Os resultados analíticos são mostrados em linhas tracejadas e simulações numéricas em linhas contínuas. Fonte: $[31] \ldots \ldots \ldots \ldots \ldots \ldots \ldots \ldots$

4.1 SCBC de tempo discreto (4.8)-(4.9). Fonte: [23] . . . . . . . . . . . 56

4.2 Exemplos de sinais do SCBC da Figura 4.1 para a condição de canal ideal: (a) $m(n)$, (b) $s(n),($ c) $r(n)$, (d) $\widehat{m}(n)$. A mensagem é recuperada no receptor, após um transitório. Fonte: [52]. . . . . . . . . . . . . . . 57 
4.3 Sinais no transmissor do sistema da Figura 4.1 utilizando-se a função de codificação (4.20) com $\gamma=0,4$. Em todos os casos, considerou-se condições iniciais $\boldsymbol{x}_{0}$ nulas: (a) mensagem $m(n)$ e sinais $s(n)$ transmitidos usando (b) $f_{Q}(\cdot),\left(\right.$ c) $f_{I}(\cdot),\left(\right.$ d) $f_{H}(\cdot)$ e $\left(\right.$ e) $f_{H 3}(\cdot)$. Fonte: $[46] \ldots \ldots 61$

4.4 Sinais $s(n)$ gerados utilizando-se $f_{Q}(\cdot)$ e diversos valores de $\gamma$ em (4.20): (a) mensagem $m(n)$; sinais $s(n)$ com (b) $\gamma=0,9$, (c) $\gamma=0,7$, (d) $\gamma=0,5$, (e) $\gamma=0,4$, (f) $\gamma=0,2$, (g) $\gamma=0,1$, (h) $\gamma=0,01$ e (i) $\gamma=0,001$. Fonte: $[46]$

4.5 BER em função da SNR para o SCBC da Figura 4.1 usando $f_{Q}(\cdot)$ e os valores de $\gamma$ da Figura $4.4 \ldots \ldots \ldots$. . . . . . . . . . . . 63 63

4.6 BER obtida com limiar aplicado diretamente a $s(n)$ em função de $\gamma$. Os sinais gerados pelo mapa $\boldsymbol{f}_{H 3}(\cdot)$ divergem para alguns valores de $\gamma$. Nesses pontos a curva não é mostrada. . . . . . . . . . . . . . . . . . . . . 64

4.7 BER em função da SNR para $\gamma=0,4 \ldots \ldots \ldots \ldots \ldots$

4.8 SCBC de tempo discreto com a inclusão de filtros $H_{S}(\omega)$ no transmissor e receptor. Fonte: [23]. . . . . . . . . . . . . . . . . . . . 6 67

4.9 Exemplos de sinais do SCBC da Figura 4.1 para a condição de canal passabaixas ideal com $\omega_{C}=0,8 \pi$ : (a) $m(n)$, (b) $s(n)$, (c) $r(n)$, (d) $\widehat{m}(n)$. A mensagem não é recuperada no receptor. Fonte: [52]. . . . . . . . . . . . 68

4.10 Exemplos de sinais do SCBC da Figura $4.8 \operatorname{com} \omega_{S}=0,4 \pi$ para a condição de canal passa-baixas com $\omega_{C}=0,8 \pi$ : (a) $m(n)$, (b) $s(n)$, (c) $r(n)$, (d) $\widehat{m}(n)$. A mensagem é recuperada com atraso. Fonte: [52]. . . . . . . . . 69

4.11 Exemplos de sinais do SCBC da Figura 4.8 e respectivas DEPs para $\omega_{C}=$ $0,8 \pi$ : (A) e (B) sem filtro na realimentação;(C) e (D) filtro $H_{S}(\omega)$ com $\omega_{S}=0,7 \pi$. O módulo da resposta em frequência do canal é mostrado em linha tracejada em (B) e (D). Fonte: [23].

4.12 Mensagem $m(n)$ (4.58) para uma sequência $d_{i}$ formada por $+1 \mathrm{~s}$ e $-1 \mathrm{~s}$ alternados com: (a) $L=1$, (b) $L=5$, (c) $L=10$ e (d) $L=20$. Fonte: [65].

4.13 (a) DEP $M(\omega)$ de $m(n)$ e (b) Fração da potência de $m(n), P_{m}$, concentrada no intervalo $\left[0, B_{M}\right]$ em função de $L$. Fonte: [65].

4.14 Exemplo de atuação do filtro sintonizador, eliminando componentes fora da banda de $s(n)$. Fonte: [65].

4.15 SCBC de banda limitada da Figura 4.8 adaptado para mensagens binárias.

Fonte: [65]. 
4.16 (a) BER em função de $\omega_{T}$ para uma SNR de $10 \mathrm{~dB}$; (b) BER em função da SNR para $\omega_{T}=\pi$ (sem sintonizador) e para $\omega_{T}=0,3 \pi$. A curva para o caso ótimo sem caos (4.22) também é mostrada. Fonte: [65] . . . . . . . 82

4.17 Maior expoente de Lyapunov $h$ e diagrama de bifurcação para o mapa (4.68) com $N_{S}=1$ e $\gamma=0$ : (a) em função de $a$ com $c_{0}=1$ e (b) em função de $c_{0}$ com $a=1,4$. Fonte: $[100] . \ldots \ldots \ldots$. . . . . . . . . 84

4.18 Maior expoente de Lyapunov $h$ para (4.68) $\operatorname{com} N_{S}=2, \gamma=0$ e $a=1,4$. As regiões roxas (escuras) representam $h>0$ e as regiões amarelas (claras) representam $h<0$. Nas regiões brancas as órbitas divergem Fonte: [100].

4.19 Maior expoente de Lyapunov $h$ para o sistema (4.68) em função (a) da frequência de corte $\omega_{S}$ e (b) do número de coeficientes $N_{S}$ do filtro. Pontos não marcados indicam que as órbitas divergem para o par $N_{S}, \omega_{S} \ldots \ldots 86$

4.20 Gráficos de $x_{1}(n)$ do sistema (4.68) para duas condições iniciais diferentes e (a) $N_{S}=5, \omega_{S}=0,25 \pi(h \approx-0,02) ;($ b $) N_{S}=10, \omega_{S}=0,25 \pi(h \approx 0)$; (c) $N_{S}=20, \omega_{S}=0,25 \pi(h \approx 0,03)$; e (d) $N_{S}=25, \omega_{S}=0,99 \pi$ (órbitas divergentes). . . . . . . . . . . . . . . . . . . 87

4.21 Maior expoente de Lyapunov para o sistema (4.68) em função de $\gamma$ para:

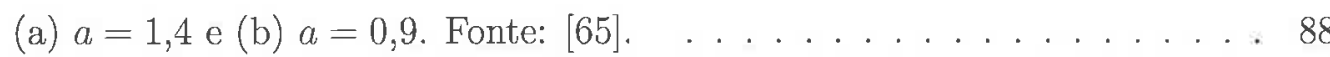

4.22 Gráficos de $x_{1}(n)$ nas condições da Figura 4.21(a) para duas condições iniciais diferentes: (a) $\gamma=0,2(h \approx 0,02)$ e (b) $\gamma=0,3(h \approx-0,08)$. Fonte: [65]. . . . . . . . . . . . . . . . . . . . . . 89

4.23 Maior expoentes de Lyapunov de (4.68), em função de $\gamma$, para $a=0,9 \mathrm{e}$ diversos valores de $N_{S}$ : (a) $\omega_{S}=0,5 \pi$ e $L=8$; (b) $\omega_{S}=0,2 \pi$ e $M=20$. Fonte: [65]. . . . . . . . . . . . . . . . . . . . . . . . . . . . . . . . 89

4.24 Esquema de equalização proposto para o sistema da Figura 4.1. Fonte: [28]. 92

4.25 Atrator no sistema receptor reconstruído utilizando o sinal: (a) transmitido $s(n),(b)$ recebido $r(n)$ (c) recuperado com o equalizador cNLMS $\widehat{s}(n)$ no caso $m(n) \equiv 1 ; N_{e q}=2 ; \Delta=0$; canal $H_{C 1}(z)$. Fonte: [28]. . . . . . . 98

4.26 Mensagem recuperada (a) sem equalizador; (b) com o cNLMS $(\tilde{\mu}=0,005$, $\delta=10^{-5}, \varepsilon=0,1$ ); (c) Média dos coeficientes do cNLMS e solução de Wiener (linhas tracejadas); (d) $y_{1}(n) \times x_{1}(n)$ : pontos em vermelho para $0<n \leq 2000$ e pontos azuis para $n>2000$ (e) EMSE Estimado; média de $10^{3}$ realizações; $N_{e q}=2 ; \Delta=0$; canal $H_{C 1}(z)$. Fonte: [28]. . . . . . 99 
4.27 Mensagem recuperada (a) sem equalizador e (b) usando cNLMS $(\widetilde{\mu}=0,005$, $\delta=10^{-5}, \varepsilon=0,1$; (c) Erro depois da decisão; (d) Média dos coeficientes do cNLMS e solução de Wiener (linhas tracejadas); (e) EMSE estimado; média de $10^{3}$ realizações; $N_{e q}=2 ; \Delta=0$; canal $H_{C 1}(z)$. Fonte: [28] . . . . 100

4.28 Atrator reconstruído usando o sinal: (a) transmitido; (b) recebido e (c) recuperado com o equalizador quando $m(n)$ é uma sequência binária aleatória. Os parâmetros são os mesmos da Figura 4.25. Fonte: [28] . . . . . . . . . . 101

4.29 Mensagem recuperada (a) sem equalizador e (b) com o equalizador cNLMS $\left(\widetilde{\mu}=0,25 ; \delta=10^{-5} ; \varepsilon=0,1 ; N_{e q}=25 ; \Delta=12\right)$; (c) Erro após decisão; (d) Média dos coeficientes do equalizador e solução de Wiener (linhas tracejadas); (e) EMSE estimado; média de $10^{3}$ realizações; variação abrupta do Canal $H_{C 2}(z)$ para o $H_{C 3}(z)$ em $n=30 \times 10^{3}$. Fonte: [28] . . . . . . . 102

4.30 Mensagem recuperada (a) sem equalizador e (b) com o equalizador cNLMS $\left(\widetilde{\mu}=0,1, \delta=10^{-5}, \varepsilon=0,1 ; N_{e q}=5 ; \Delta=3\right.$ ); (c) Erro após decisão; (d) Média dos coeficientes do equalizador e solução de Wiener (linhas tracejadas); (e) EMSE estimado; média de $10^{3}$ realizações; Canal $H_{C 4}(z)$, variante no tempo. Fonte: [28]. . . . . . . . . . . . . . . . . . . . . . 103

4.31 BER para o canal $H_{C 5}(z)$ em função de $h_{0}$ na ausência de ruído; cNLMS com $\widetilde{\mu}=0,05 ; \delta=10^{-5} ; \varepsilon=0,1 ; N_{e q}=21 ; \Delta=11$. Fonte: [28]. . . . . . 103

4.32 BER para o canal $H_{C 5}(z)$ em função de $h_{0}$ com SNR $=60 \mathrm{~dB}$; cNLMS com $\widetilde{\mu}=0,05 ; \delta=10^{-5} ; \varepsilon=0,1 ; N_{e q}=21 ; \Delta=11$. Fonte: [28]. . . . . . . 104

4.33 BER para o canal AWGN não dispersivo e para o Canal $H_{C 5}(z) \operatorname{com} h_{0}=$ 0,25 , em função da SNR; cNLMS com $\widetilde{\mu}=0,05 ; \delta=10^{-5} ; \varepsilon=0,1 ; N_{e q}=$ $21 ; \Delta=11$. Fonte: [28] . . . . . . . . . . . . . . . 104 


\section{Lista de Tabelas}

4.1 Algoritmo cNLMS. Fonte: $[28] . \ldots \ldots$. . . . . . . . . . . . . 96

4.2 Canlais de comunicação utilizados nas simulações. Fonte: [64]. . . . . . . . 97 


\section{Lista de Abreviaturas}

A seguir são listadas as principais abreviações usadas na dissertação. No caso de siglas consagradas na literatura internacional, optou-se por manter as mesmas em inglês.

$\begin{array}{ll}\text { AWGN } & \text { Additive White Gaussian Noise - ruído branco gaussiano aditivo } \\ \text { BER } & \text { Bit Error Rate - taxa de erro de bit } \\ \text { cLMS } & \text { chaotic LMS - LMS caótico } \\ \text { cNLMS } & \text { chaotic NLMS - NLMS caótico } \\ \text { CSK } & \text { Chaos-Shift Keying - comutação caótica } \\ \text { DCSK } & \text { Differential CSK - CSK diferencial } \\ \text { DEP } & \text { Densidade Espectral de Potência } \\ \text { DSCI } & \text { Dependência Sensível com as Condições Iniciais } \\ \text { GSC } & \text { Gerador de Sinais Caóticos } \\ \text { EMSE } & \text { Excess Mean-Square Error - erro médio quadrático em excesso } \\ \text { FIR } & \text { Finite Impulse Response - resposta ao impulso de duração finita } \\ \text { IIR } & \text { Infinite Impulse Response - resposta ao impulso de duração infinita } \\ \text { ISI } & \text { Intersymbol Interference - interferência intersimbólica } \\ \text { JCR } & \text { Journal Citation Reports } \\ \text { LMS } & \text { Least Mean Squares - mínimos quadrados } \\ \text { NLMS } & \text { Normalized LMS - LMS normalizado } \\ \text { SAC } & \text { Sequência de AutoCorrelação } \\ \text { SCBC } & \text { Sistema de Comunicação Baseado em Caos } \\ \text { SNR } & \text { Signal to Noise Ratio - relação sinal ruído } \\ \text { TFTD } & \text { Transformada de Fourier de Tempo Discreto }\end{array}$





\section{Lista de Símbolos}

Neste texto, matrizes são indicadas por letras maiúsculas em negrito e itálico, por exemplo $\boldsymbol{A}$. Vetores-coluna são indicados usando-se letras minúsculas em negrito e itálico, por exemplo $\boldsymbol{r}(n)$ e $\boldsymbol{v}(n)$. Escalares são representados por letras maiúsculas ou minúsculas em itálico, por exemplo $M, \mu$ e $s(n)$. A seguir são listados os principais símbolos utilizados.

\section{Símbolos gerais}

$\begin{array}{ll}\mathbb{N} & \text { conjunto dos números naturais } \\ \mathbb{R} & \text { conjunto dos números reais } \\ \mathbb{R}^{M} & \text { espaço dos vetores-coluna } M \text { dimensionais com elementos reais } \\ U & \text { subconjunto de } \mathbb{R}^{M} \\ \# X & \text { cardinalidade do conjunto X } \\ I_{X}(\cdot) & \text { função indicadora do conjunto X } \\ P(X) & \text { probabilidade do conjunto X } \\ x_{1}, x_{2}, \ldots, x_{M} & \text { elementos do vetor } x \\ \|x\| & \text { norma euclideana ou } l_{2} \text { do vetor } x \\ |x| & \text { módulo do escalar } x \\ f(\cdot) & \text { função com domínio e contradomínio } U \\ f^{k}(\cdot) & k \text {-ésima iterada do mapa } f(\cdot) \\ D f(\cdot) & \text { jacobiano de } f(\cdot) \\ f(\cdot) & \text { função com domínio e contradomínio } U, \text { caso unidimensional } \\ f^{\prime}(\cdot) & \text { derivada de } f(\cdot) \text { com relação ao seu argumento } \\ f^{-1}(X) & \text { contraimagem do conjunto } X \text { sob a operação do mapa } f(\cdot) \\ 0 & \text { vetor-coluna com elementos nulos } \\ \delta(\cdot) & \text { função impulso unitário de tempo contínuo } \\ & \end{array}$




$$
\begin{array}{ll}
\operatorname{sign}(\cdot) & \text { função sinal } \\
* & \text { soma de convolução } \\
\mathbb{E}[\cdot] & \text { operador esperança matemática }
\end{array}
$$

\begin{tabular}{|c|c|}
\hline$n$ & variável independente discreta (tempo), $n \in \mathbb{N}$ \\
\hline$M$ & dimensão do sistema dinâmico \\
\hline$s_{0}$ & condição inicial \\
\hline$E\left(s_{0}\right)$ & hiperesfera de raio unitário com centro em $s_{0}$ \\
\hline$s\left(n ; s_{0}\right)$ & sinal ou órbita com condição inicial $s_{0}$ \\
\hline$S_{s_{0}}$ & trajetória da órbita $s\left(n ; s_{0}\right)$ \\
\hline$\Omega\left(s_{0}\right)$ & conjunto limite da órbita $s\left(n ; s_{0}\right)$ \\
\hline$L\left(s_{0}\right)$ & maior número de Lyapunov do sinal $s\left(n ; s_{0}\right)$ \\
\hline$h\left(s_{0}\right)$ & maior expoente de Lyapunov do sinal $s\left(n ; s_{0}\right)$ \\
\hline$h$ & maior expoente de Lyapunov para um mapa com um único atrator \\
\hline$c$ & ponto fixo de $\boldsymbol{f}(\cdot)$ \\
\hline$p$ & ponto eventualmente periódico de $f(\cdot)$ \\
\hline$C(\cdot)$ & mapa de conjugação \\
\hline$f_{T}(\cdot)$ & mapa tenda \\
\hline$f_{I}(\cdot)$ & mapa tenda inclinada \\
\hline$\alpha$ & parâmetro de $f_{I}(\cdot)$ \\
\hline$h_{I}$ & expoente de Lyapunov do mapa $f_{I}(\cdot)$ \\
\hline$f_{B}(\cdot)$ & mapa de Bernoulli \\
\hline$r$ & número de segmentos do mapa $f_{B}(\cdot)$ \\
\hline$\alpha_{1}, \alpha_{2}, \ldots, \alpha_{r-1}$ & parâmetros de $f_{B}(\cdot)$ \\
\hline$h_{B}$ & expoente de Lyapunov do mapa $f_{B}(\cdot)$ \\
\hline$f_{Q}(\cdot)$ & mapa quadrático \\
\hline$f_{H}(\cdot)$ & mapa de Hénon \\
\hline$f_{H 3}(\cdot)$ & mapa de Hénon tridimensional \\
\hline$a, b$ & parâmetros de $f_{H}(\cdot)$ e $f_{H 3}(\cdot)$ \\
\hline$f_{I k}(\cdot)$ & mapa de Ikeda \\
\hline$C_{1}, C_{2}, C_{3}$ e $R$ & parâmetros do mapa de Ikeda \\
\hline
\end{tabular}

\section{Sistemas dinâmicos}




$\begin{array}{ll}p(s) & \text { função densidade de pontos no intervalo }[-1,1] \\ \mathbb{P}[\cdot] & \text { operador de Frobenius-Perron aplicado sobre } p(s) \\ p_{*}(s) & \text { função densidade invariante }\end{array}$

\section{Caracterização temporal e espectral de sinais caóticos}

$\begin{array}{ll}k & \text { passo da correlação } \\ \omega & \text { frequência discreta em radianos } \\ R(k) & \text { SAC dos sinais gerados por um mapa } \\ P_{\text {med }} & \text { potência média dos sinais gerados por um mapa } \\ \mathbb{F}[\cdot] & \text { operador TFTD } \\ S(\omega) & \text { DEP dos sinais gerados por um mapa } \\ B & \text { Banda essencial } \\ p(x, y) & \text { densidade conjunta }\end{array}$

Sistema de comunicação baseado em caos

$\begin{array}{ll}z^{-1} & \text { operador de atraso, } z^{-1} y(n)=y(n-1) \\ X(\omega) & \text { DEP do sinal } x(n) \\ \boldsymbol{x}(n) & \text { vetor de estados do sistema transmissor } \\ \boldsymbol{y}(n) & \text { vetor de estados do sistema receptor } \\ \boldsymbol{A} & \text { matriz de sincronismo } \\ \lambda_{1}, \lambda_{2}, \ldots, \lambda_{M} & \text { autovalores de } \boldsymbol{A} \\ \boldsymbol{e}(n) & \text { erro de sincronização } \\ d_{i} & \text { sequência de dados binários a ser transmitida } \\ L & \text { comprimento em amostras do intervalo de bit } \\ p(n) & \text { pulso retangular unitário de comprimento } L \\ m(n) & \text { mensagem a ser enviada } \\ B_{M} & \text { banda essencial de } m(n) \\ c(\cdot, \cdot) & \text { função de codificação } \\ d(\cdot, \cdot) & \text { função de decodificação } \\ \gamma & \text { parâmetro da função de codificação linear } \\ s(n) & \text { sinal transmitido } \\ w(n) & \text { AWGN na entrada do receptor }\end{array}$




\begin{tabular}{|c|c|}
\hline$\sigma_{w}^{2}$ & potência média do ruído $w(n)$ \\
\hline$r(n)$ & sinal que chega ao receptor \\
\hline$\widehat{m}(n)$ & mensagem recuperada no receptor \\
\hline$h_{C}(n)$ & resposta ao impulso unitário do canal \\
\hline$N_{C}$ & número de coeficientes de $h_{C}(n)$ \\
\hline$H_{C}(z)$ & função de transferência do canal \\
\hline$H_{C}(\omega)$ & resposta em frequência do canal \\
\hline$\omega_{C}$ & frequência de corte de $H_{C}(\omega)$ \\
\hline$h_{S}(n)$ & $\begin{array}{l}\text { resposta ao impulso unitário dos filtros inseridos nos sistemas trans- } \\
\text { missor e receptor }\end{array}$ \\
\hline$N_{S}$ & número de coeficientes de $h_{S}(n)$ \\
\hline$c_{0}, c_{1}, \ldots, c_{N_{S}-1}$ & coeficientes de $h_{S}(n)$ \\
\hline$H_{S}(\omega)$ & $\begin{array}{l}\text { resposta em frequência dos filtros inseridos nos sistemas transmissor } \\
\text { e receptor }\end{array}$ \\
\hline$\omega_{S}$ & frequência de corte de $H_{S}(\omega)$ \\
\hline$A^{\prime}$ & matriz de sincronismo do sistema com a inclusão dos filtros $H_{S}(\omega)$ \\
\hline$H_{T}(\omega)$ & resposta em frequência do filtro sintonizador \\
\hline$\omega_{T}$ & frequência de corte de $H_{T}(\omega)$ \\
\hline$r(n)$ & vetor regressor de entrada do equalizador \\
\hline $\boldsymbol{R}$ & matriz de autocorrelação do sinal de entrada do equalizador \\
\hline $\boldsymbol{v}(n)$ & vetor de coeficientes do equalizador \\
\hline$\Delta$ & atraso do sistema composto pelo canal e equalizador \\
\hline$\widehat{s}(n)$ & sinal transmitido recuperado na saída do equalizador \\
\hline$N_{e q}$ & número de coeficientes do equalizador \\
\hline$g$ & $\begin{array}{l}\text { vetor de correlação cruzada entre o vetor regressor de entrada e o } \\
\text { sinal de treinamento transmitido }\end{array}$ \\
\hline $\boldsymbol{v}(n)$ & vetor de coeficientes do equalizador \\
\hline $\boldsymbol{v}_{o}$ & vetor de coeficientes ótimos \\
\hline$e_{e q}(n)$ & erro de estimação do equalizador \\
\hline$e_{a}(n)$ & erro a priori do equalizador \\
\hline$e_{p}(n)$ & erro a posteriori do equalizador \\
\hline$\mu$ & passo de adaptação para o algoritmo cLMS \\
\hline$\widetilde{\mu}$ & passo de adaptação para o algoritmo cNLMS \\
\hline$\nabla_{v} \widehat{J}$ & vetor gradiente instantâneo da função custo \\
\hline
\end{tabular}


$\delta, \varepsilon$

$Y$

$h_{0}$ constantes positivas pequenas usadas para evitar divisão por zero no cNLMS

limite superior imposto para $\left|y_{1}(n)\right|$

parâmetro do canal 


\section{Capítulo 1}

\section{Introdução}

O presente texto tem por objetivo sistematizar a pesquisa que o autor e seus colaboradores têm desenvolvido ao longo da última década, envolvendo aplicações da Teoria de Sistemas Dinâmicos e Caos em processamento de sinais e sistemas de comunicações.

De forma simplificada, pode-se dizer que um sinal caótico é limitado em amplitude, aperiódico e apresenta Dependência Sensível com as Condições Iniciais (DSCI) [1]. Essa última propriedade significa que se o sistema que o gerou for iniciado com uma condição ligeiramente diferente, o sinal obtido pode apresentar valores completamente distintos do sinal anterior em curto período de tempo [1].

Em Telecomunicações e Processamento de Sinais, as pesquisas envolvendo aplicações de sinais caóticos iniciaram-se no começo da década de 1990 após os trabalhos seminais $[2,3]$. Desde então, as possibilidades de aplicação da Teoria do Caos nessas áreas vêm aumentando, indo desde modulações analógicas e digitais até criptografia, geração de sequências pseudoaleatórias, marcas d'água e muitas outras (veja, por exemplo, [4-12]). Além disso, mostrou-se que modelos de diversos dispositivos usados em processamento de sinais como equalizadores cegos e redes de phase-locked loops podem apresentar comportamento caótico [13-17].

Especificamente em Telecomunicações, as propostas giram em torno de se transmitir informação digital codificada em um sinal caótico. Dessa forma, cada símbolo é transmitido por uma forma de onda única, diferentemente do que acontece nos sistemas de comunicação digital usuais, em que a cada símbolo da constelação atribui-se uma forma de onda. Essa abordagem não permite, em princípio, utilizar os receptores ótimos baseados em filtros casados [18]. Assim, em um canal não dispersivo, esperam-se taxas de erro de bit (BER - Bit Error Rate) mais altas do que as encontradas em sistemas convencionais. Essa desvantagem pode eventualmente ser compensada por um incremento na segurança [19] e pelo fato dos sinais caóticos serem de banda larga em geral, o que implica em propriedades típicas dos sistemas de espalhamento espectral [7]. 
A grande maioria dos trabalhos na área descreve o desempenho de um Sistema de Comunicação Baseado em Caos (SCBC) em condições ideais de canal. Raramente confrontase estes sistemas com situações usualmente encontradas na prática, como distorção, limitação em banda, ruído aditivo e atrasos inerentes especialmente a canais sem fio

Apesar de ser necessário muita pesquisa para tornar SCBCs efetivamente competitivos, as primeiras implementações práticas vêm surgindo nos últimos anos. Por exemplo, um grupo de pesquisadores do Laboratório de Comunicações Óticas da Universidade de Atenas, na Grécia, implementou recentemente um enlace de $120 \mathrm{~km}$ de fibras ópticas na região metropolitana de Atenas transmitindo na faixa de gigabits por segundo usando portadoras caóticas. O trabalho foi publicado no prestigiado periódico Nature $[19,20]$. Deve-se ressaltar no entanto que as condições do canal utilizado eram bem controladas e ele havia sido equalizado de forma não adaptativa. Caso a mesma filosofia fosse empregada em um canal em que ruído e distorção estivessem presentes de forma mais pronunciada, os resultados possivelmente seriam ruins.

Tendo essa situação em mente, o autor vem estudando, ao longo dos últimos 19 anos, o desempenho de SCBCs em situações realistas e formas de aperfeiçoá-los de modo a atingirem comportamentos aceitáveis em aplicações práticas.

Essas pesquisas tiveram apoio financeiro dos seguintes órgãos de fomento:

- Fundação de Amparo à Pesquisa do Estado de São Paulo (FAPESP)

- Processo 1998/13362-6 - Bolsa de mestrado do autor;

- Processo 2007/04251-7 - Auxílio à Participação em Evento - XXV Simpósio Brasileiro de Telecomunicações - SBrT 2007;

- Processo 2008/05283-2 - Auxílio à Participação em Evento - XXVI Simpósio Brasileiro de Telecomunicações - SBrT 2008;

- Processo 2009/02283-4 - Auxílio à Publicação - Mathematical Problems in Engineering;

- Processo 2013/14911-5 - Auxílio à Participação em Evento - XXXI Simpósio Brasileiro de Telecomunicações - SBrT2013;

- Processo 2014/04864-2 - Projeto de Pesquisa - Regular - Análise Espectral de Sinais Caóticos com Aplicaçôes em Comunicaçôes - Vigência: julho/2014 a junho/2016. Valor total: $\mathrm{R} \$ 43901,51$.

- Conselho Nacional de Desenvolvimento Científico e Tecnológico (CNPq)

- Processo 303926/2010-4- Bolsa de produtividade em pesquisa nível 2 - Engenharia Elétrica - Vigência março/2011 - fevereiro/2014. 
- Processo 4479901/2013-9 - Edital Universal 14/2013 - Faixa A - Aspectos Práticos de Sistemas de Comunicação Baseados em Caos - Vigência: dezembro/2013 - novembro/2017. Valor total: $\mathrm{R} \$ 29939,15$;

- Processo 311575/2013-7- Bolsa de produtividade em pesquisa nível 2 - Engenharia Elétrica - Vigência março/2014 - fevereiro/2017.

- Coordenação de Aperfeiçoamento de Pessoal de Nível Superior (CAPES)

- 2 bolsas para alunos de mestrado e apoios a participações em eventos.

Além disso, contaram com a infraestrutura dos seguintes laboratórios:

- Laboratório de Comunicações e Sinais do Departamento de Engenharia de Telecomunicações e Controle da Escola Politécnica da Universidade de São Paulo (EPUSP);

- Laboratório de Processamento de Sinais do Departamento de Engenharia de Sistemas Eletrônicos da EPUSP;

- Laboratório de Sinais e Sistemas da Universidade Federal do ABC.

Os resultados obtidos em conjunto com orientados de pós-graduação e colaboradores de diversas instituições levou à seguinte produção associada nos últimos 11 anos, ou seja, desde a conclusão do doutorado do autor, em fevereiro de 2006:

- 12 artigos em periódicos listados no Journal Citation Reports (JCR): [13, 21-31]

- 06 capítulos de livro [32-37]

- 09 artigos completos em anais de congressos internacionais [38-46]

- 13 publicações em congressos nacionais [47-59]

- 04 dissertações de mestrado orientadas [60-63]

- 01 tese de doutorado coorientada [64]

- 02 orientações de doutorado em andamento, sendo uma delas [65] depositada em fevereiro de 2017.

Além disso, parte considerável dos esforços da comunidade científica na pesquisa de aplicações realísticas para SCBCs foram publicados em livro coeditado pelo autor [9].

No presente texto, buscando-se utilizar uma notação única e consistente, resumem-se esses resultados. 
No Capítulo 2 são apresentadas definições e notações básicas relacionadas a sistemas dinâmicos em tempo discreto e que são utilizadas em todo o trabalho. Também são apresentados os mapas empregados aqui como Geradores de Sinais Caóticos (GSC). A seguir, no Capítulo 3 discutem-se resultados relacionados à caracterização espectral dos sinais caóticos. No Capítulo 4, uma forma simples de obter o sincronismo entre dois sistemas idênticos de tempo discreto é mostrada. Esse sincronismo é utilizado para a proposta e análise de desempenho de um SCBC em condições encontradas na prática. Por fim, no Capítulo 5 fazem-se algumas observações finais. 


\section{Capítulo 2}

\section{Sinais caóticos de tempo discreto: notação e definições básicas}

Neste capítulo definem-se e comentam-se os principais conceitos relacionados a sistemas dinâmicos não lineares de tempo discreto empregados nos capítulos subsequentes. O texto apresentado é inspirado principalmente em trechos da dissertação de mestrado [66] e da tese de doutorado do autor [67], com as devidas atualizações e padronização de notação.

Na Seção 2.1 define-se a notação utilizada na representação de mapas e sinais. A seguir, na Seção 2.2, são apresentados os conceitos de DSCI e expoentes de Lyapunov. A partir deles, na Seção 2.3, formaliza-se a definição de sinais caóticos e na Seção 2.4 exemplificam-se alguns GSCs. Por fim, na Seção 2.5 expõem-se os conceitos de densidade invariante e operador de Frobenius-Perron e na Seção 2.6 fazem-se algumas conclusões.

\subsection{Conceitos e definições básicas}

Um sistema dinâmico é um conjunto de possíveis estados com uma regra determinística que define o estado presente em função dos anteriores. Neste texto trata-se em particular dos sistemas dinâmicos de tempo discreto, definidos a seguir.

Definição 2.1. Seja $\boldsymbol{f}($.$) uma função cujo espaço de partida U \subset \mathbb{R}^{M}$ (domínio) é igual ao espaço de chegada (contradominio). A equação de diferenças

$$
\boldsymbol{s}(n+1)=\boldsymbol{f}(\boldsymbol{s}(n))
$$

com $n \in \mathbb{N}, \boldsymbol{s}(0)=\boldsymbol{s}_{0} \in U$, representa um sistema dinâmico de tempo discreto ou mapa.

Definição 2.2. A órbita ou sinal correspondente a $\boldsymbol{s}_{\mathbf{0}}$ gerado a partir de $\boldsymbol{f}\left(\right.$ ) e $\boldsymbol{s}_{0}$ fixo é a função $\boldsymbol{s}(n)=\boldsymbol{f}^{n}\left(\boldsymbol{s}_{0}\right)$, em que $\boldsymbol{f}^{k}($.) representa a $k$-ésima aplicação sucessiva de $\boldsymbol{f}($.$) e$ 
$\boldsymbol{f}^{0}\left(\boldsymbol{s}_{0}\right)=\boldsymbol{s}_{0}$. O ponto $\boldsymbol{s}_{0}$ é chamado de condição inicial de $\boldsymbol{s}(n)$. Quando for importante destacar a condição inicial $\boldsymbol{s}_{0}$ de um sinal, ele será indicado por $s\left(n ; \boldsymbol{s}_{0}\right)$.

Definição 2.3. A trajetória da órbita $\boldsymbol{s}\left(n ; \boldsymbol{s}_{0}\right)$ de $\boldsymbol{f}($.$) é o conjunto$

$$
S_{s_{0}}=\left\{\boldsymbol{s}\left(n ; \boldsymbol{s}_{0}\right), n \in \mathbb{N}\right\}
$$

Definição 2.4. Um ponto $\boldsymbol{c}$ é dito ponto fixo do mapa ou de $\boldsymbol{f}($.$) se \boldsymbol{f}(\boldsymbol{c})=\boldsymbol{c}$ e, portanto, $\boldsymbol{s}(n ; \boldsymbol{c})=\boldsymbol{c}, \forall n \in \mathbb{N}$.

A periodicidade e a estabilidade de órbitas periódicas são importantes no estudo de sinais caóticos, pois a ausência de período é uma das principais características desses sinais. Assim, definem-se a seguir periodicidade, estabilidade e conceitos relacionados.

Definição 2.5. Seja o mapa (2.1) e $\boldsymbol{p}$ um ponto do domínio de $\boldsymbol{f}(\cdot)$. O ponto $\boldsymbol{p}$ é dito eventualmente periódico de período $k>0$ se para algum $n_{*} \in \mathbb{N}, \boldsymbol{f}^{n+k}(\boldsymbol{p})=\boldsymbol{f}^{n}(\boldsymbol{p})$ para todo $n \geq n_{*}$ e $k$ é o menor natural que satisfaz essa condição. A órbita $\boldsymbol{s}(n ; \boldsymbol{p})$ é dita eventualmente periódica de período $k$. No caso em que $n_{*}=0, p$ é dito periódico e $s(n ; \boldsymbol{p})$ é periódica de período $k$.

Definição 2.6. Seja o mapa (2.1), com $\boldsymbol{f}(\cdot)$ contínua e diferenciável. Uma órbita $\boldsymbol{s}(n ; \boldsymbol{a})$ é dita assintoticamente periódica se convergir para uma órbita periódica quando $n \rightarrow \infty$; ou seja, existe uma órbita periódica $\boldsymbol{s}(n ; \boldsymbol{p})$ tal que $\lim _{n \rightarrow \infty}\|\boldsymbol{s}(n ; \boldsymbol{a})-\boldsymbol{s}(n ; \boldsymbol{p})\|=0$. O ponto $\boldsymbol{a}$ é dito assintoticamente periódico. Uma órbita (respectivamente, ponto) não assintoticamente periódica (periódico) é chamada de aperiódica (aperiódico).

Definição 2.7. Um ponto fixo $\boldsymbol{c}$ de (2.1) é:

1. atrator se existe $\delta>0$ tal que, para qualquer órbita $\boldsymbol{s}\left(n ; \boldsymbol{s}_{0}\right)$ com $\left\|\boldsymbol{s}_{0}-\boldsymbol{c}\right\|<\delta$, $\lim _{n \rightarrow \infty} s\left(n, s_{0}\right)=c$

2. estável segundo Lyapunov se, dado $\varepsilon>0$, existe um $\delta>0$ tal que se $\left\|s_{0}-c\right\|<\delta$ então $\left\|s\left(n ; s_{0}\right)-c\right\|<\varepsilon$ para todo $n \geq 0 ;$

3. assintoticamente estável se é atrator e estável segundo Lyapunov;

4. instável se não é atrator e nem estável segundo Lyapunov.

As trajetórias que se iniciam próximas de um atrator podem sair de suas proximidades a curto prazo, porém, devem aproximar-se dele a longo prazo. As trajetórias que se iniciam próximas de um ponto fixo estável segundo Lyapunov devem permanecer nas proximidades desse ponto para todo $n \geq 0$, não convergindo, necessariamente, para ele. Essas situações são mostradas de forma esquemática nas Figuras 2.1(a) e (b). As trajetórias próximas 


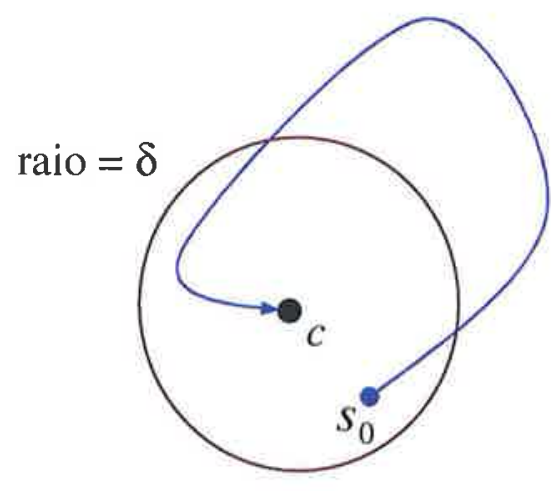

(a)

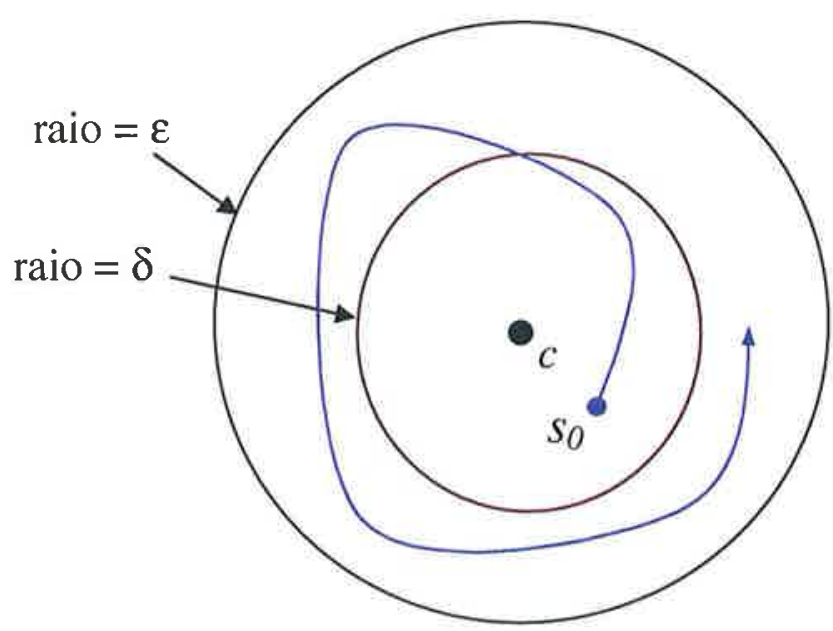

(b)

Figura 2.1: Diagrama esquemático do comportamento de uma órbita próxima (a) de um ponto fixo atrator (b) de um ponto fixo estável segundo Lyapunov. Fonte: [67].

de um ponto fixo assintoticamente estável além de convergirem para ele, permanecem o tempo todo numa vizinhança dele.

Se uma órbita $\boldsymbol{s}(n ; \boldsymbol{p})$ é periódica de período $k$ para o mapa (2.1), $\boldsymbol{p}$ é um ponto fixo do mapa $\boldsymbol{s}(n+1)=\boldsymbol{f}^{k}(\boldsymbol{s}(n))$. Assim, a análise da estabilidade da órbita periódica $\boldsymbol{s}(n ; \boldsymbol{p})$ é feita por meio da análise da estabilidade do ponto fixo $\boldsymbol{p}$ do sistema $\boldsymbol{s}(n+1)=\boldsymbol{f}^{k}(\boldsymbol{s}(n))$.

O conjunto limite de uma órbita é o conjunto de pontos cuja vizinhança é frequentemente visitada por ela. Formalmente, tem-se a definição a seguir.

Definição 2.8. O conjunto limite da órbita $s\left(n ; s_{0}\right)$ de $\boldsymbol{f}(\cdot)$ é dado por

$$
\Omega\left(\boldsymbol{s}_{\mathbf{0}}\right)=\left\{\boldsymbol{s} / \forall\left\{n_{*}, \varepsilon\right\}, \exists n>n_{*},\left\|\boldsymbol{f}^{n}\left(\boldsymbol{s}_{0}\right)-\boldsymbol{s}\right\|<\varepsilon\right\} .
$$

Se $\Omega\left(s_{0}\right)$ é o conjunto limite de um órbita e $\boldsymbol{r}_{\mathbf{0}}$ é uma outra condição inicial, então diz-se que a órbita $\boldsymbol{s}\left(n ; \boldsymbol{r}_{0}\right)$ (ou o ponto $\boldsymbol{r}_{0}$ ) é atraído para $\Omega\left(\boldsymbol{s}_{\mathbf{0}}\right)$ se $\Omega\left(\boldsymbol{r}_{0}\right) \subset \Omega\left(\boldsymbol{s}_{0}\right)$.

Pontos de uma órbita podem ou não estar contidos em seu conjunto limite. O conjunto limitc pode não ter nenhum ponto em comum com a órbita, como no caso do conjunto limite de uma órbita convergindo assintoticamente para um ponto fixo atrator. Nesse caso, o conjunto limite é um único ponto, o ponto fixo atrator. A órbita é atraída para esse ponto fixo.

Definição 2.9. Um atrator é um conjunto limite que atrai um conjunto de condições iniciais de medida não nula. Esse conjunto de condições iniciais é chamado de bacia de atração. 
Um conjunto $A \subset B$ é denso em $B$ se arbitrariamente próximo de cada ponto de $B$ existe um ponto de $A$. Em outras palavras, para cada $s_{*}$ em $B$ e cada $\varepsilon>0$, a vizinhança $\left\{s \in U /\left\|s_{*}-s\right\|<\varepsilon\right\}$ contém um ponto de $A$.

\subsection{Número e expoente de Lyapunov}

Um conceito fundamental para o estudo de sinais caóticos é a DSCI definida a seguir [1].

Definição 2.10. Seja (2.1) um mapa em $U \subset \mathbb{R}^{M}$. Um ponto $s_{0} \in U$ tem DSCI se existe uma distância euclidiana não nula $\varepsilon$ tal que pelo menos algum ponto arbitrariamente próximo de $\boldsymbol{s}_{\mathbf{0}}$ é eventualmente mapeado a pelo menos $\varepsilon$ unidades da imagem correspondente a $s_{0}$. Mais precisamente, existe $\varepsilon>0$ tal que, para qualquer $\delta>0$, a bola aberta de raio $\delta$ centrada em $\boldsymbol{s}_{0},\left\{s \in U /\left\|\boldsymbol{s}-\boldsymbol{s}_{0}\right\|<\delta\right\}$, contém pelo menos um ponto $\mathbf{s}_{*}$ tal que $\left\|\boldsymbol{f}^{n_{*}}\left(\boldsymbol{s}_{*}\right)-\boldsymbol{f}^{n_{*}}\left(\boldsymbol{s}_{0}\right)\right\| \geq \varepsilon$ para algum $n_{*} \in \mathbb{N}$. Nessas condições, a órbita $\boldsymbol{s}\left(n ; \boldsymbol{s}_{0}\right)$ apresenta DSCI.

Valendo-se apenas dessa definição, é difícil verificar essa propriedade para uma dada órbita, exceto em casos excepcionais.

A seguir definem-se os expoentes de Lyapunov que representam taxas de divergência exponencial média entre duas órbitas suficientemente próximas e que possibilitam a verificação da DSCI de forma operacional. Daí a importância do estudo de sua definição e de métodos numéricos para o seu cálculo. Inicia-se com o caso unidimensional e, a seguir, passa-se ao caso $M$-dimensional.

\subsubsection{Caso unidimensional}

O comportamento das órbitas do mapa unidimensional de tempo discreto

$$
s(n+1)=f(s(n))
$$

nas proximidades de um ponto fixo é fortemente influenciado pela derivada de $f(\cdot)$ nesse ponto, supondo que ela exista. Por exemplo, se $c$ é um ponto fixo de $f(\cdot)$ e o módulo da derivada nesse ponto obedece $\left|f^{\prime}(c)\right|=\ell>1$, então toda órbita $s\left(n ; s_{0}\right)$ com $s_{0}$ suficientemente próximo de $c$ afasta-se de $c$ com uma taxa multiplicativa de aproximadamente $\ell$ por iteração, até mover-se para longe de $c$. Isto pode ser visto pela expansão em série de Taylor de $f\left(s_{0}\right)$ em torno de $c$ :

$$
\begin{aligned}
f\left(s_{0}\right) & \approx f(c)+f^{\prime}(c)\left(s_{0}-c\right) \Rightarrow f\left(s_{0}\right)-f(c) \approx f^{\prime}(c)\left(s_{0}-c\right) \Rightarrow \\
& \Rightarrow\left|f\left(s_{0}\right)-c\right| \approx \ell\left|s_{0}-c\right| .
\end{aligned}
$$


Para um ponto periódico $p$ de período $k$, essa informação pode ser obtida olhando-se a derivada da $k$-ésima iteração de $f(\cdot)$ já que $p$ é ponto fixo de $f^{k}(\cdot)$. Pela regra da cadeia,

$$
\begin{aligned}
f^{k \prime}(p) & =f^{\prime}\left(f^{k-1}(p)\right) \cdot f^{\prime}\left(f^{k-2}(p)\right) \cdot f^{\prime}\left(f^{k-3}(p)\right) \cdot \ldots \cdot f^{\prime}(p) \Rightarrow \\
f^{k \prime}(p) & =\prod_{n=0}^{k-1} f^{\prime}(s(n ; p)),
\end{aligned}
$$

ou seja, $f^{k \prime}(p)$ é o produto das derivadas de $f(\cdot)$ calculadas nos $k$ pontos distintos de $S_{p}$. Suponha que o módulo desse produto seja $\ell>1$. Pelo mesmo raciocínio utilizado para pontos fixos, uma órbita com condição inicial próxima de $p$ separa-se de $s(n ; p)$ a uma taxa de aproximadamente $\ell$ depois de $k$ iterações. Faz sentido então descrever a taxa multiplicativa média de separação por iteração entre as duas órbitas como sendo $L=(\ell)^{1 / k}$.

O número de Lyapunov generaliza as taxas obtidas acima para o caso em que os pontos não são necessariamente periódicos.

Definição 2.11. Seja o mapa unidimensional (2.4). Se $f(\cdot)$ for diferenciável nos pontos da trajetória da órbita $s\left(n ; s_{0}\right)$, o seu número de Lyapunov é

$$
L\left(s_{0}\right)=\lim _{N \rightarrow \infty}\left(\prod_{n=0}^{N-1}\left|f^{\prime}(s(n))\right|\right)^{1 / N}
$$

se o limite existir. O expoente de Lyapunov $h\left(s_{0}\right)$ é definido como

$$
h\left(s_{0}\right)=\ln \left(L\left(s_{0}\right)\right),
$$

se $L\left(s_{0}\right)$ existir.

Segue da definição que o número de Lyapunov de um ponto fixo $c$ do mapa (2.4) é $\left|f^{\prime}(c)\right|$ e o expoente de Lyapunov de um ponto periódico $s_{0}=p$ de período $k$ desse mesmo mapa é

$$
h(p)=\frac{\sum_{n=0}^{k-1} \ln \left|f^{\prime}(s(n ; p))\right|}{k} .
$$

A Definição 2.11 permite algumas considerações sobre estabilidade:

- um ponto fixo ou uma órbita periódica que tenha expoente de Lyapunov negativo será assintoticamente estável pelo argumento apresentado em (2.5), já que nesse caso $\ell<1$

- também de (2.5), conclui-se que expoente de Lyapunov positivo indica que o ponto fixo ou a órbita periódica é instável, pois nesse caso $\ell>1$. 
Esses fatos são relevantes por causa do seguinte teorema, cuja demonstração é apresentada em [1]:

Teorema 2.1. Seja o mapa (2.4). Se a órbita $s\left(n ; s_{0}\right)$ satisfaz $f^{\prime}(s(n)) \neq 0$ para todo $n \in \mathbb{N}$ e é assintoticamente periódica tendo como limite a órbita periódica $s(n ; p)$, então as duas órbitas têm expoentes de Lyapunov idênticos, assumindo que ambos estejam definidos.

Conclui-se assim que se uma órbita limitada possui expoente de Lyapunov positivo ela não pode ser assintoticamente periódica tendo como limite uma órbita periódica assintoticamente estável ou convergir para um ponto fixo assintoticamente estável. Assim, restam duas possibilidades para esse tipo de órbita

- ou ela é assintoticamente periódica convergindo para uma órbita periódica instável, caso pouco provável em geral; ou

- ela é aperiódica.

Essa conclusão é fundamental para a classificação de uma órbita como "caótica", como será visto na Seção 2.3 .

É comum um mapa ter um único atrator estável que atrai quase todas ${ }^{1}$ as condições iniciais. Nesse caso, quase todas as órbitas terão mesmo expoente de Lyapunov $h$ que é igual ao de uma órbita que se inicia dentro do atrator. Para esses mapas, toma-se a liberdade de escrever que $h$ é o expoente de Lyapunov do mapa, como é usual na literatura.

Finalmente, outro conceito que é conveniente definir neste ponto é o de mapas conjugados. O número de Lyapunov é simples de ser calculado, por exemplo, para sinais gerados por mapas lineares por partes, já que esses apresentam derivada constante em cada trecho. Porém para mapas mais genéricos, a determinação desse número e das propriedades associadas a ele tornam-se mais difíceis. A conjugação permite deduzir propriedades das órbitas de um mapa a partir da "parecença" dele com outro eventualmente mais simples.

Definição 2.12. Seja $C(\cdot)$ um mapa contínuo e injetor. Os mapas $f(\cdot)$ e $g(\cdot)$ são conjugados se eles estão relacionados por uma mudança de coordenadas $C(\cdot)$ tal que $C \circ f(\cdot)=g \circ C(\cdot)$. A notação $C \circ f(\cdot)$ significa $C(f(\cdot))$ e $C(\cdot)$ é chamado de mapa de conjugação.

O mapa $C(\cdot)$ indica uma correspondência entre pontos dos mapas $f(\cdot)$ e $g(\cdot)$. O seguinte teorema, demonstrado em [1] resume a relevância da conjugação no estudo de sistemas dinâmicos não lineares.

\footnotetext{
${ }^{1} \mathrm{O}$ termo quase toda $(0) s$ neste texto é usado no sentido de que existe apenas um conjunto de medida nula que não satisfaz a propriedade.
} 
Teorema 2.2. Considere os mapas $f(\cdot)$ e $g(\cdot)$ conjugados por $C(\cdot)$. Pode-se afirmar que:

1. se $p$ é um ponto periódico de período $k$ de $f(\cdot)$, então $C(p)$ é um ponto periódico de período $k$ de $g(\cdot)$;

2. se a derivada de $C(\cdot)$ é não nula em todos os pontos da órbita $s\left(n ; s_{0}\right)$ de $f(\cdot)$ então existe uma órbita correspondente $C\left(s\left(n ; s_{0}\right)\right)$ de $g(\cdot)$ com mesmo número de Lyapunov.

Esse teorema expressa que dados dois mapas conjugados, a cada órbita de um corresponde uma órbita do outro com mesmo período e mesmo número de Lyapunov.

\subsubsection{Caso $M$-dimensional}

Em sistemas discretos $M$-dimensionais, a cada órbita estão associados $M$ expoentes de Lyapunov.

Seja o mapa (2.1) com $\boldsymbol{f}: U \subset \mathbb{R}^{M} \rightarrow \mathbb{R}^{M}$ diferenciável e seja $\boldsymbol{J}_{k}=\boldsymbol{D} \boldsymbol{f}^{k}\left(\boldsymbol{s}_{0}\right)$ o jacobiano de $f^{k}(\cdot)$ calculado em $s_{0}$. Para $m=1,2, \ldots, M$, seja $r_{k}^{(m)}$ o comprimento do $m$-ésimo maior semieixo do elipsoide $\boldsymbol{J}_{k} \boldsymbol{E}\left(\boldsymbol{s}_{0}\right)$ para uma órbita com condição inicial $\boldsymbol{s}_{0}$ em que $\boldsymbol{E}\left(\boldsymbol{s}_{0}\right)$ é uma hiperesfera de raio unitário centrada em $\boldsymbol{s}_{0}$. A notação $\boldsymbol{J}_{k} \boldsymbol{E}\left(\boldsymbol{s}_{0}\right)$ representa o produto dos versores que descrevem a hiperesfera $\boldsymbol{E}\left(\boldsymbol{s}_{0}\right)$ pelo jacobiano $\boldsymbol{J}_{k}$. Então $r_{k}^{(m)}$ mede a contração ou expansão próximo à órbita de $\boldsymbol{s}_{0}$ durante as primeiras $k$ iterações na direção do $m$-ésimo maior eixo do elipsoide $\boldsymbol{J}_{k} \boldsymbol{E}$, que é representada pelo versor $\boldsymbol{u}_{k}^{(m)}$.

A Figura 2.2 ilustra esses conceitos no caso bidimensional.
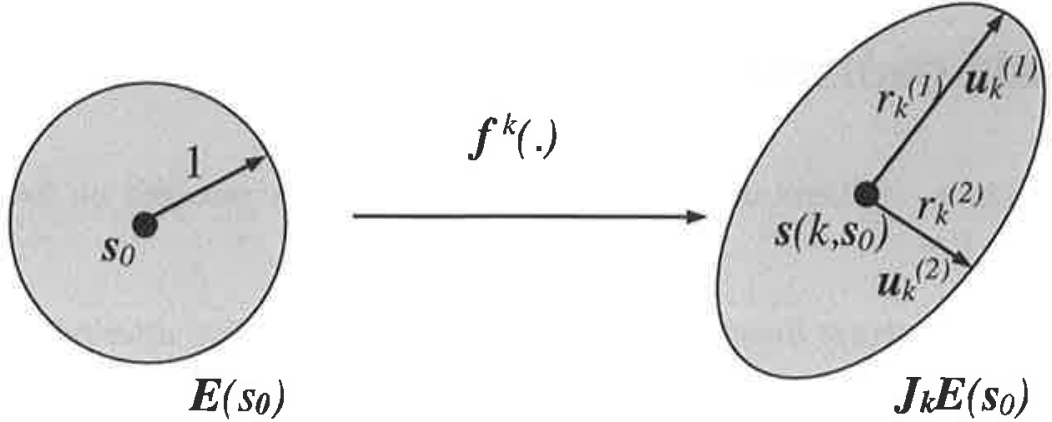

Figura 2.2: Evolução de uma esfera centrada na condição inicial $\boldsymbol{s}_{0}$ quando submetida ao mapa (2.1), com $\boldsymbol{f}($.$) diferenciável. Caso bidimensional. Fonte: [67].$ 
Definição 2.13. O $m$-ésimo número de Lyapunov, $m=1,2, \ldots, M$, de $\boldsymbol{s}\left(n ; \boldsymbol{s}_{0}\right)$ é dado por

$$
L^{(m)}\left(s_{0}\right)=\lim _{k \rightarrow \infty}\left(r_{k}^{(m)}\right)^{1 / k}
$$

se o limite existir. Nesse caso, o $m$-ésimo expoente de Lyapunov de $\boldsymbol{s}\left(n ; \boldsymbol{s}_{0}\right)$ é $h^{(m)}\left(\boldsymbol{s}_{0}\right)=$ $\ln L^{(m)}\left(s_{0}\right)$.

Note que a definição assegura que, para uma certa órbita, os números e expoentes de Lyapunov obedecem $L^{(1)}\left(\boldsymbol{s}_{0}\right) \geq L^{(2)}\left(\boldsymbol{s}_{0}\right) \geq \ldots \geq L^{(M)}\left(\boldsymbol{s}_{0}\right)$ e $h^{(1)}\left(\boldsymbol{s}_{0}\right) \geq h^{(2)}\left(\boldsymbol{s}_{0}\right) \geq \ldots \geq$ $h^{(M)}\left(s_{0}\right)$, respectivamente.

Pode-se demonstrar [1] que todas as considerações feitas no caso unidimensional continuam válidas para o caso multidimensional, inclusive o Teorema 2.1 e as observações que o seguem, devendo-se considerar nas análises o sinal do maior expoente de Lyapunov $h^{(1)}\left(s_{0}\right)$ da órbita. Ou seja, a existência de um único expoente de Lyapunov positivo já impede a órbita de convergir para um ponto fixo atrator ou para uma órbita periódica atratora.

No restante do trabalho, para facilidade de notação, o maior expoente de Lyapunov de uma órbita $h^{(1)}\left(s_{0}\right)$ será denotado por $h\left(s_{0}\right)$. Quando o mapa tem um único atrator que atrai quase todas as órbitas, representa-se os expoentes de Lyapunov do atrator simplesmente por $h^{(m)}, m=1,2, \ldots, M$, que são ditos expoentes de Lyapunov do mapa, como é usual na literatura.

Existem diversas técnicas para o cálculo numérico dos expoentes de Lyapunov para os sinais gerados por um dado mapa. Nos experimentos numéricos descritos nos demais capítulos desse trabalho, utilizou-se a clássica abordagem do mapa tangente (veja, por exemplo, [1, p. 199-203]). Outra técnica especialmente útil no caso de mapas não suaves é o das dinâmicas clonadas, recentemente proposto em [68].

\subsection{Sinais caóticos}

A definição de sinais caóticos utilizada aqui é a introduzida por [69] na forma como foi expressa em [1].

Definição 2.14. Um sinal limitado em amplitude é caótico se é aperiódico e apresenta DSCI.

Uma órbita com DSCI, pela própria Definição 2.10, é instável já que é sempre possível encontrar um ponto arbitrariamente próximo de sua condição inicial cuja órbita relacionada estará distante após algumas iterações. É exatamente aí que reside a "imprevisibilidade" característica dos GSCs. Como, numa situação prática, muitas vezes não se sabe 
com toda a precisão a condição inicial de uma órbita, é impossível prever o valor assumido pelo sinal gerado após certo tempo (conhecido como tempo de horizonte) dependente da incerteza na condição inicial.

Como foi visto, os expoentes de Lyapunov funcionam como uma quantificação da DSCI. O seguinte teorema garante esse fato [1].

Teorema 2.3. Suponha que um sinal $s\left(n ; s_{0}\right)$ tenha maior número de Lyapunov $L\left(s_{0}\right)$ e maior expoente de Lyapunov $h\left(\boldsymbol{s}_{0}\right)$. Esse sinal apresentará DSCI se $L\left(\boldsymbol{s}_{0}\right)>1$ ou $h\left(s_{0}\right)>0$.

Esse teorema é bastante intuitivo considerando-se que os expoentes de Lyapunov medem a divergência exponencial de órbitas próximas. Como existem algoritmos disponíveis para o cálculo numérico dos expoentes de Lyapunov [1,68], tem-se uma forma quantitativa para se determinar se uma órbita apresenta DSCI. Desse teorema, segue que

Corolário 2.1. Um sinal $\boldsymbol{s}\left(n ; \boldsymbol{s}_{0}\right)$ limitado em amplitude, aperiódico e satisfazendo $h\left(s_{0}\right)>0$ é caótico.

A determinação da periodicidade ou não de um sinal não é simples. Nos procedimentos numéricos nesse trabalho usa-se a condição $h\left(\boldsymbol{s}_{0}\right)>0$ como "suficiente" para considerar um sinal como caótico, como é adotado usualmente na literatura focada em aplicações. Essa escolha é numericamente justificável pelo fato de que apenas sinais periódicos instáveis possuem $h\left(\boldsymbol{s}_{\mathbf{0}}\right)>0$, como visto na Seção 2.3. Esses sinais têm, em geral, probabilidade nula de serem obtidas num experimento numérico.

Outra definição usual na literatura é a de atrator caótico [1].

Definição 2.15. Seja o sistema dinâmico $\boldsymbol{s}(n+1)=\boldsymbol{f}(\boldsymbol{s}(n))$ e um sinal caótico $\boldsymbol{s}\left(n ; \boldsymbol{s}_{\mathbf{0}}\right)$ gerado por esse sistema. O conjunto $\Omega\left(s_{0}\right)$ dessa órbita é chamado de conjunto caótico se $s_{0} \in \Omega\left(s_{0}\right)$. Um atrator caótico é um conjunto caótico que também é um atrator.

Em outras palavras, um conjunto caótico é o conjunto limite de uma órbita caótica que está contida no seu conjunto limite. A exigência de que a órbita caótica esteja contida no seu próprio conjunto limite garante que o conjunto caótico tenha uma órbita densa e que, portanto, seja irredutível.

\subsection{Alguns geradores de sinais caóticos}

Nesta seção apresentam-se alguns mapas utilizados nos capítulos seguintes como GSCs. Inicia-se com mapas unidimensionais, incluindo-se os mapas tenda, tenda inclinada e quadrático. Em seguida, passa-se a mapas multidimensionais, especificamente os mapas de Hénon, de Ikeda e uma versão tridimensional do mapa de Hénon. 


\subsubsection{Mapa tenda $f_{T}(\cdot)$}

O mapa tenda unidimensional é dado por

$$
f_{T}(s)=1-2|s|
$$

definindo o sistema dinâmico

$$
s(n+1)=f_{T}(s(n)),
$$

com condição inicial $s(0)=s_{0} \in U=[-1,1]$. Na Figura 2.3 mostram-se um gráfico de $f_{T}(s)$ e uma órbita gerada a partir de (2.12).
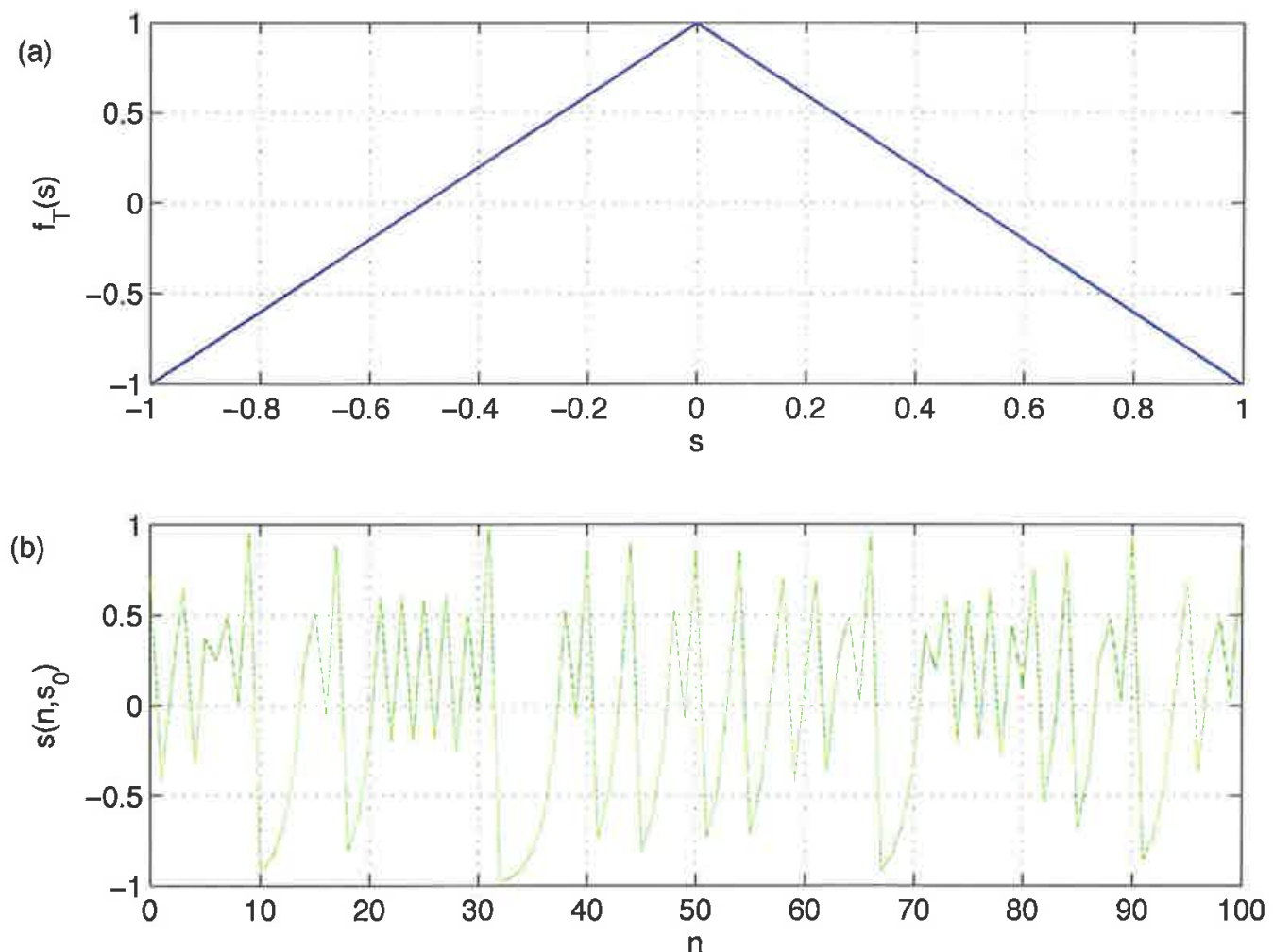

Figura 2.3: (a) Mapa tenda $f_{T}(s)$; (b) órbita com condição inicial $s_{0}=\sqrt{2} / 2$. Fonte: [67].

Para $s \neq 0,\left|f_{T}^{\prime}(s)\right|=2$ e portanto $L\left(s_{0}\right)=2$ e $h\left(s_{0}\right)=\ln 2$ para todas as órbitas com condição inicial $s_{0}$ cuja trajetória não inclua $s=0$. O fato de que $h>0$ implica no provável aparecimento de órbitas caóticas nesse sistema. Na verdade, utilizando-se a teoria de dinâmica simbólica, pode-se mostrar que existe uma quantidade não enumerável de condições iniciais que geram órbitas caóticas para esse mapa, sendo seu atrator caótico o intervalo $U[70]$.

É importante ressaltar que, para qualquer condição inicial $s_{0}$ racional, a órbita $s\left(n ; s_{0}\right)$ converge para o ponto fixo $c=-1$. Assim, o comportamento caótico das órbitas desse mapa não pode ser observado em simulações computacionais por meio de iterações de 
(2.12). Nos trabalhos descritos aqui, para simular a utilização de condições iniciais irracionais utilizou-se a abordagem de sistemas lineares alimentados por entradas aleatórias descrita em [71].

\subsubsection{Mapa tenda inclinada $f_{I}(\cdot)$}

O mapa tenda inclinada é definido por

$$
s(n+1)=f_{I}(s(n))= \begin{cases}\frac{2}{\alpha+1} s(n)+\frac{1-\alpha}{\alpha+1}, & -1 \leq s(n)<\alpha \\ \frac{2}{\alpha-1} s(n)-\frac{\alpha+1}{\alpha-1}, & \alpha \leq s(n) \leq 1\end{cases}
$$

com parâmetro $-1<\alpha<1$ e $s(0)=s_{0} \in U=[-1,1]$. Um gráfico de $f_{I}(\cdot)$ para $\alpha=0,8$ é mostrado na Figura 2.4(a) e a órbita $s(n ; 0)$ na Figura 2.4(b).

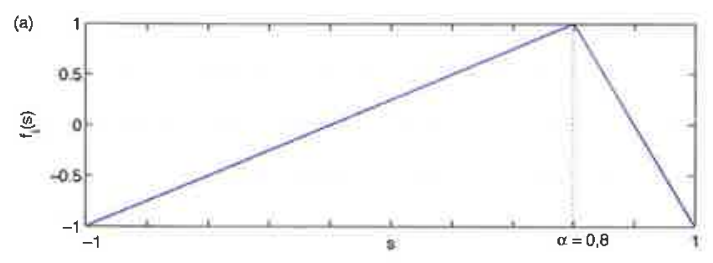

(b)

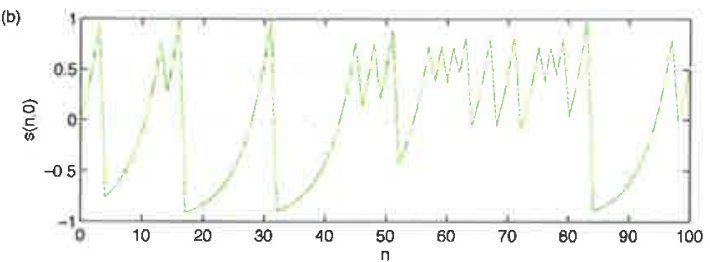

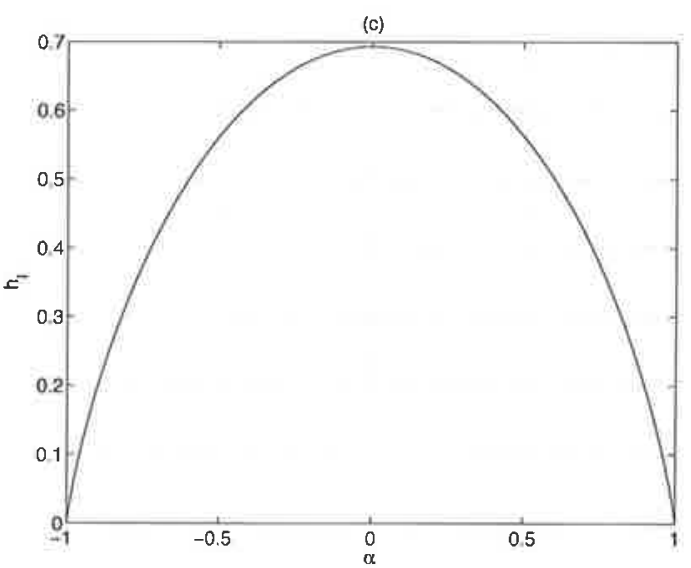

Figura 2.4: (a) Mapa tenda inclinada $f_{I}(\cdot)$; (b) trecho da órbita $s(n ; 0)$ para $\alpha=0,8$; (c) Expoente de Lyapunov do mapa $f_{I}($.$) em função do parâmetro \alpha$. Fonte: [67].

O número de Lyapunov $L\left(s_{0}\right)$ para quase todas as órbitas $s\left(n ; s_{0}\right)$ é a média geométrica do módulo da derivada dos dois trechos lineares do mapa, ponderada pelo comprimento de cada um dos segmentos [72]. Assim, o expoente de Lyapunov de quase todas as órbitas de $f_{I}(\cdot)$ é

$$
h_{I}=\frac{1+\alpha}{2} \ln \left(\frac{2}{1+\alpha}\right)+\frac{1-\alpha}{2} \ln \left(\frac{2}{1-\alpha}\right) .
$$

Na Figura 2.4(c) mostra-se a variação de $h_{I}$ com $\alpha$. Observa-se que, para os valores de $\alpha$ admissíveis $h_{I}>0$ e, portanto, os sinais aperiódicos gerados são caóticos. O valor máximo é $h_{I \max }=\ln 2$ e ocorre para $\alpha=0$, que corresponde ao mapa tenda $f_{T}().(2.11)$.

Um resultado interessante proveniente da teoria da dinâmica simbólica [1] é que para qualquer $-1<\alpha<1, f_{I}($.$) apresenta órbitas caóticas densas em U$ sendo esse seu atrator caótico. 


\subsubsection{Mapa de Bernoulli com $r$ segmentos $f_{B}(\cdot)$}

Seja $r$ um inteiro com $r \geq 2$ e $-1=\alpha_{0}<\alpha_{1}<\alpha_{2}<\ldots<\alpha_{r}=1$ uma partição do intervalo $U=[-1,1]$. O mapa de Bernoulli com $r$ segmentos $f_{B}:[-1,1[\rightarrow[-1,1[$ é definido por

$$
s(n+1)=f_{B}(s(n))=\frac{2}{\alpha_{j}-\alpha_{j-1}} s(n)-\frac{\alpha_{j}+\alpha_{j-1}}{\alpha_{j}-\alpha_{j-1}}, \text { para } s(n) \in\left[\alpha_{j-1}, \alpha_{j}[.\right.
$$

Na Figura 2.5(a) mostra-se um exemplo de $f_{B}(s)$ para $r=7$ e a partição definida por $\alpha_{1}=-0,5, \alpha_{2}=-0,3, \alpha_{3}=-0,1, \alpha_{4}=0,2, \alpha_{5}=0,7$ e $\alpha_{6}=0,8$. Na Figura 2.5(b) são mostrados trechos dos sinais $s(n ; 0,3)$ e $s(n ; 0,300000001)$. Nota-se claramente que esses sinais são aperiódicos e apresentam a DSCI característica dos sinais caóticos.
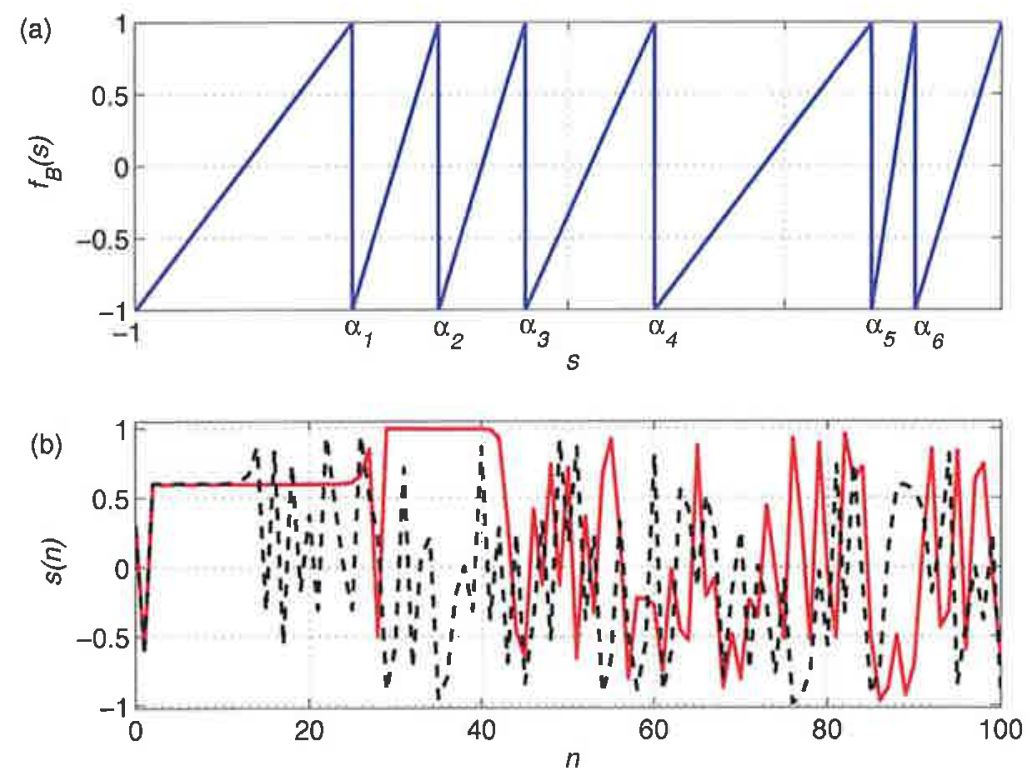

Figura 2.5: (a) Exemplo de mapa de Bernoulli, (b) trechos de $s(n ; 0,3)$ (linha contínua) e $s(n ; 0,300000001)$ (em tracejado). Fonte: [31].

Pode-se mostrar [63] que o expoente de Lyapunov para quase todas as órbitas de $f_{B}(\cdot)$ é dado por

$$
h_{B}=\sum_{j=1}^{r} \frac{\alpha_{j}-\alpha_{j-1}}{2} \ln \left(\frac{2}{\alpha_{j}-\alpha_{j-1}}\right)>0
$$

sendo $U$ seu atrator. 


\subsubsection{Mapa quadrático $f_{Q}(\cdot)$}

O mapa quadrático $f_{Q}($.$) e o sistema dinâmico associado são definido por$

$$
s(n+1)=f_{Q}(s(n))=-2 s^{2}(n)+1
$$

para condições iniciais $s_{0} \in U=[-1,1]$.

Um gráfico de $f_{Q}($.$) é mostrado na Figura 2.6(a) e a órbita s(n ; 0,7)$ na Figura 2.6(b). Este mapa tem dois pontos fixos instáveis,

$$
c_{1}=-1 \text { e } c_{2}=0,5
$$
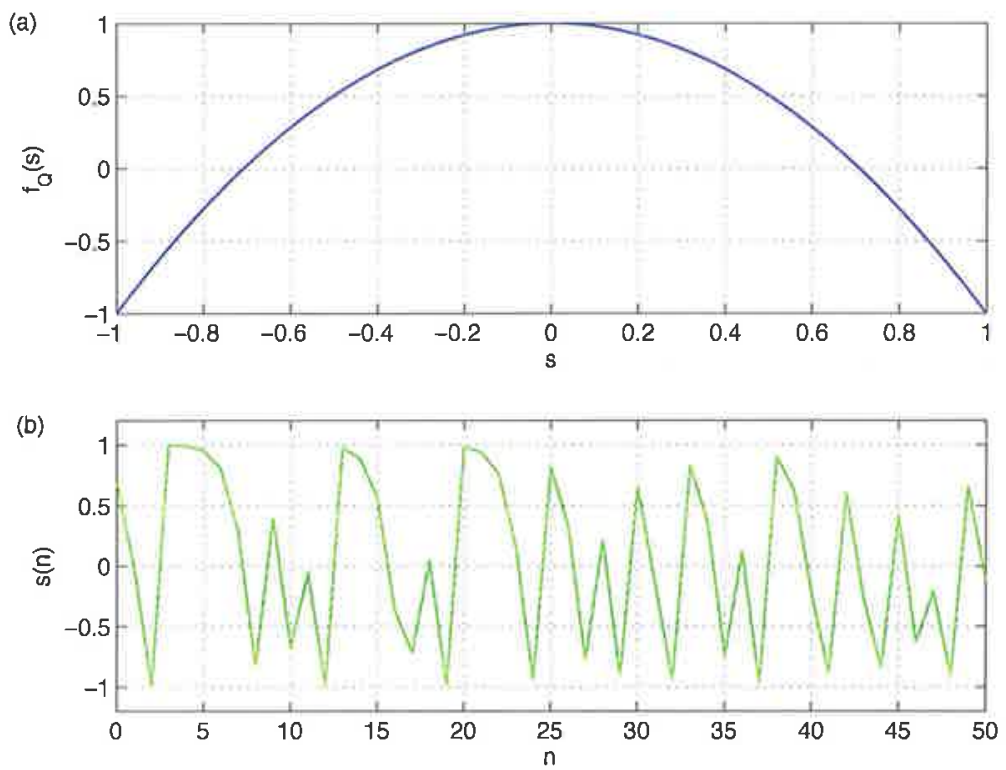

Figura 2.6: (a) Mapa quadrático $f_{Q}($.$) ; (b) trecho do sinal s(n ; 0,7)$. Fonte: [67].

A derivada de $f_{Q}($.$) varia ponto a ponto sendo mais difícil o cálculo do expoente de$ Lyapunov e a consequente análise da dinâmica das órbitas desse mapa. Para resolver esse problema, pode-se utilizar o conceito de mapa de conjugação, visto na Definição 2.12, página 10. Pode-se mostrar que os mapas $f_{T}($.$) e f_{Q}($.$) são conjugados com mapa de$ conjugação [1]

$$
C_{T Q}(s)=-\cos \frac{\pi(s+1)}{2}
$$

Assim, usando o Teorema 2.2 pode-se afirmar que a cada uma das não enumeráveis órbitas caóticas de $f_{T}($.$) corresponde uma órbita caótica de f_{Q}($.$) com expoente de Lya-$ punov $h_{Q}=h_{T}=\ln 2$. É interessante ressaltar que algumas condições iniciais irracionais de $f_{T}($.$) são mapeadas em condições iniciais racionais de f_{Q}($.$) . Dessa forma, nesse caso, o$ comportamento caótico pode ser observado diretamente por meio de iterações de (2.17). 
O conjunto atrator de todas as órbitas caóticas de $f_{Q}($.$) é novamente U$.

A seguir, exemplificam-se dois mapas bidimensionais e um mapa tridimensional.

\subsubsection{Mapa de Hénon $f_{H}(\cdot)$}

O mapa de Hénon, proposto originalmente em [73], é definido por

$$
\boldsymbol{s}(n+1)=\boldsymbol{f}_{H}(\boldsymbol{s}(n))=\left[\begin{array}{l}
s_{1}(n+1) \\
s_{2}(n+1)
\end{array}\right]=\left[\begin{array}{c}
s_{2}(n)+1-a s_{1}^{2}(n) \\
b s_{1}(n)
\end{array}\right]
$$

sendo $\{a, b\} \subset \mathbb{R}$ parâmetros. Por exemplo, para $a=1,4$ e $b=0,3$ verifica-se que esse sistema é um GSC.

Nos gráficos (a) e (b) da Figura 2.7 mostra-se um trecho da órbita obtida com condição inicial $s_{0}=\left[\begin{array}{ll}0 & 0\end{array}\right]^{T}$ para esses valores dos parâmetros. O atrator, obtido desprezando-se as primeiras $10^{3}$ iterações, é mostrado no gráfico (c).
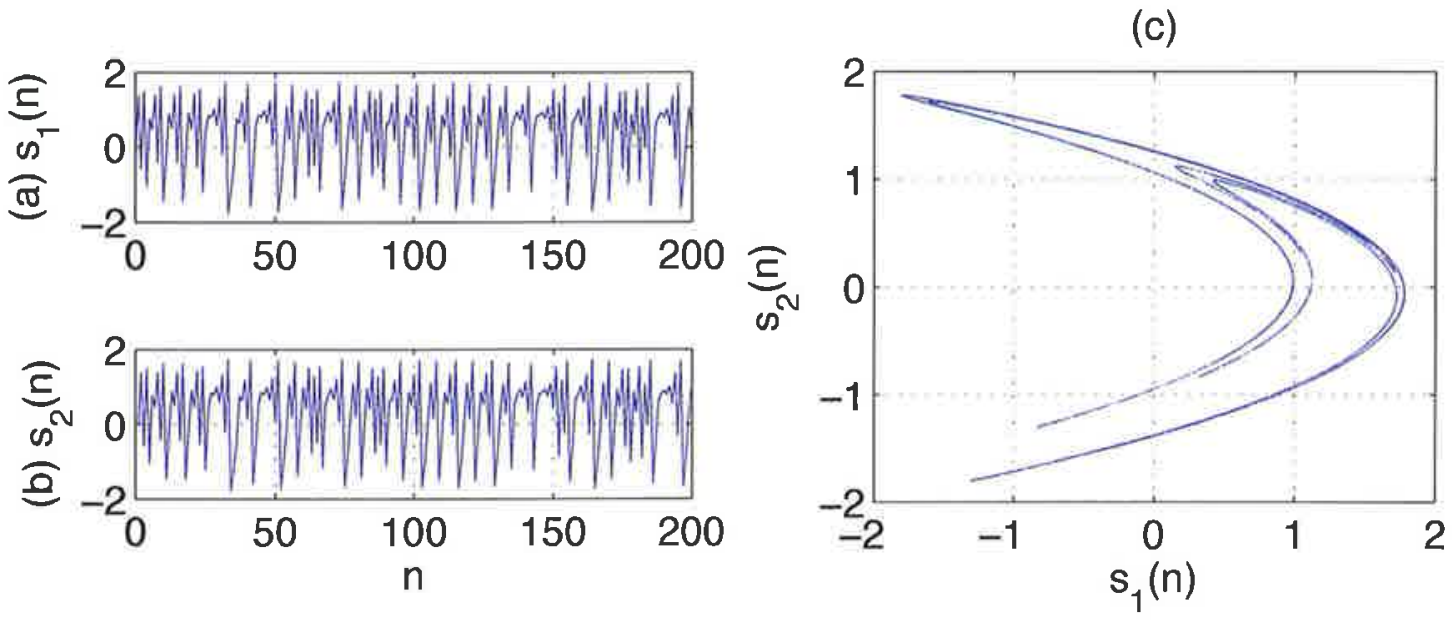

Figura 2.7: Mapa de Hénon $\boldsymbol{f}_{H}(\cdot)$ : (a) e (b) trecho da órbita com condição $s_{0}=\left[\begin{array}{ll}0 & 0\end{array}\right]^{T}$; (c) atrator da órbita. Fonte: [67].

Os expoentes de Lyapunov das órbitas que são atraídas para o atrator na Figura 2.7(c) podem ser obtidos numericamente resultando $h^{(1)}=0,42$ e $h^{(2)}=-1,62[1$, p. 201]. Esses expoentes e o aspecto aperiódico da órbita observada levam a concluir que ela é caótica.

\subsubsection{Mapa de Ikeda $f_{I k}(\cdot)$}

Usando algumas hipóteses simplificadoras, o mapa de Ikeda é um modelo para um tipo de célula que pode ser utilizado em computadores ópticos $[1,74]$. É um mapa bidimensional dado por 


$$
\boldsymbol{s}(n+1)=\boldsymbol{f}_{I k}(\boldsymbol{s}(n))=\left[\begin{array}{c}
s_{1}(n+1) \\
s_{2}(n+1)
\end{array}\right]=\left[\begin{array}{c}
R+C_{2}\left(s_{1}(n) \cos \tau(n)-s_{2}(n) \sin \tau(n)\right) \\
C_{2}\left(s_{1}(n) \sin \tau(n)-s_{2}(n) \cos \tau(n)\right)
\end{array}\right]
$$

sendo

$$
\tau(n)=C_{1}-\frac{C_{3}}{1+\left(s_{1}(n)\right)^{2}+\left(s_{2}(n)\right)^{2}}
$$

e $R, C_{1}, C_{2}$ e $C_{3}$ parâmetros reais.

Considerando-se os parâmetros usuais $[1$, p. 202]

$$
C_{1}=0,4, \quad C_{2}=0,9, \quad C_{3}=6 \quad \text { e } \quad R=1,
$$

o mapa de Ikeda apresenta um atrator caótico com expoentes de Lyapunov $h^{(1)} \approx 0,51 \mathrm{e}$ $h^{(2)} \approx-0,72$ e um ponto fixo localizado em $c \approx\left[\begin{array}{ll}2,97 & 4,15\end{array}\right]^{T}$ com expoentes de Lyapunov $h^{(1)} \approx-0,11 \mathrm{e} h^{(2)} \approx-0,10$. Para esse conjunto de parâmetros, as órbitas de (2.21) podem apresentar dois comportamentos distintos: (i) convergência para o ponto fixo $\boldsymbol{c}$ ou (ii) convergência para o atrator caótico.

Na Figura 2.8 são mostrados ambos os atratores no plano $s_{1}(n) \times s_{2}(n)$ assim como trechos de suas bacias de atração. O atrator caótico é mostrado em preto e o ponto fixo atrator é indicado pela cruz. A área em amarelo indica a bacia de atração para o atrator caótico. Os pontos fora dessa área levam a órbita para o ponto fixo. Na Figura 2.9, são mostrados trechos de $s_{1}(n)$ e $s_{2}(n)$ ao longo das iterações para $s_{0}=\left[\begin{array}{ll}0 & 0\end{array}\right]^{T}$.

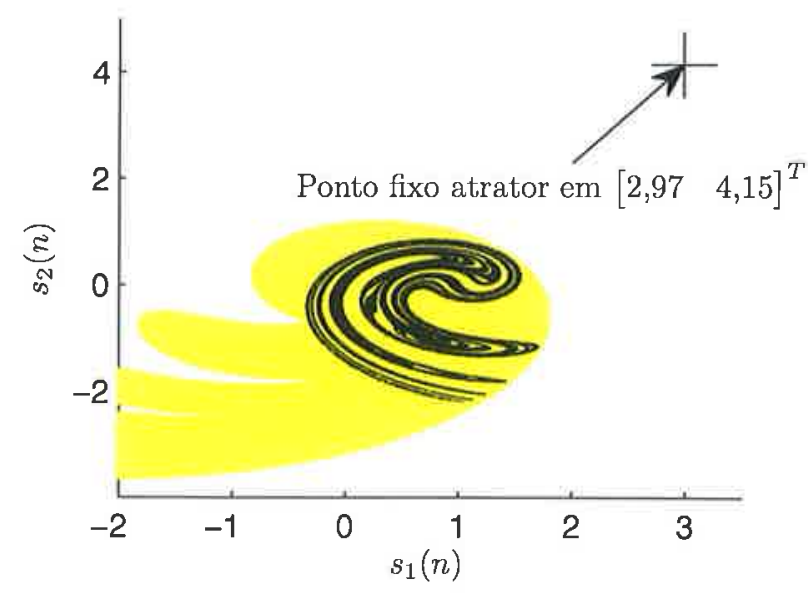

Figura 2.8: Atratores de $\boldsymbol{f}_{I k}(\cdot)$. A área amarela indica a bacia de atração para o atrator caótico mostrado em preto. Órbitas iniciadas fora da área amarela são levadas para o ponto fixo indicado pela cruz. Fonte: [29]. 

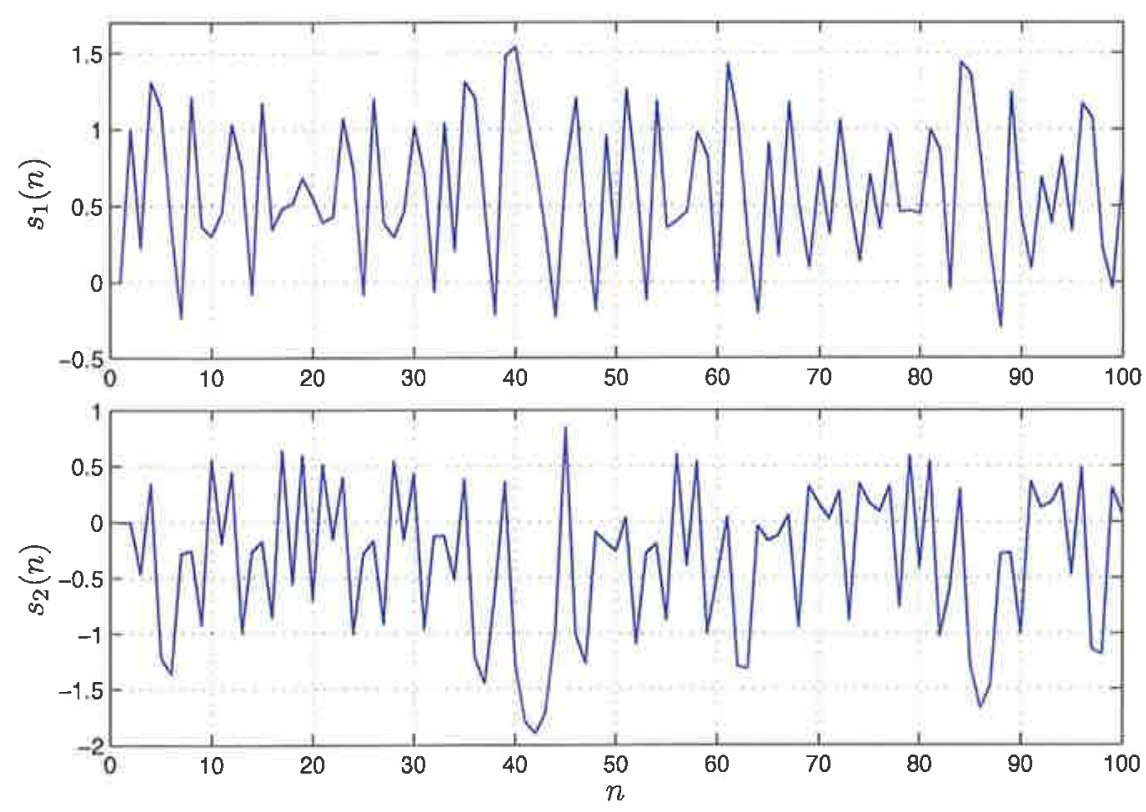

Figura 2.9: Trechos de $s_{1}(n)$ e $s_{2}(n)$ do mapa $\boldsymbol{f}_{I k}(\cdot)$ com os parâmetros $(2.23)$, inicializado com $s(0)=\left[\begin{array}{ll}0 & 0\end{array}\right]^{T}$. Fonte: $[29]$.

\subsubsection{Mapa de Hénon tridimensional $\boldsymbol{f}_{H 3}(\cdot)$}

Uma generalização para três dimensões do mapa de Hénon foi proposta em [75]. Ela é dada por

$$
\boldsymbol{s}(n+1)=\boldsymbol{f}_{H 3}(\boldsymbol{s}(n))=\left[\begin{array}{c}
s_{1}(n+1) \\
s_{2}(n+1) \\
s_{3}(n+1)
\end{array}\right]=\left[\begin{array}{c}
-a s_{1}^{2}(n)+s_{3}(n)+1 \\
-b s_{1}(n) \\
b s_{1}(n)+s_{2}(n)
\end{array}\right]
$$

sendo $\{a, b\} \subset \mathbb{R}$ parâmetros. Para $a=1,07$ e $b=0,3$ verifica-se que quase todas as condições iniciais dentro da esfera unitária geram sinais caóticos cujo maior expoente de Lyapunov é $h \approx 0,23$.

Nos gráficos (a)-(c) da Figura 2.10 mostra-se um trecho da órbita obtida com condição inicial $s_{0}=\left[\begin{array}{lll}0 & 0 & 0\end{array}\right]^{T}$ para esses valores dos parâmetros. O atrator é mostrado na Figura $2.7(\mathrm{~d})$, desprezando-se as primeiras $10^{3}$ iterações. 


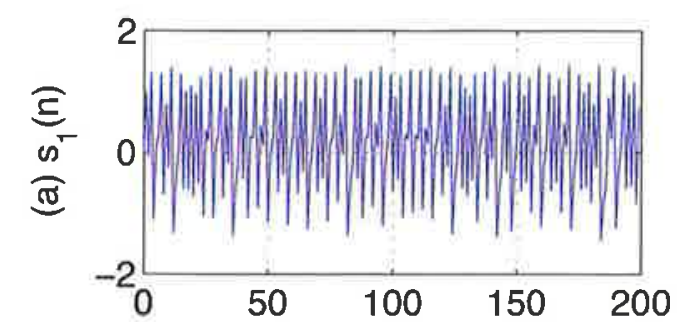

(d)
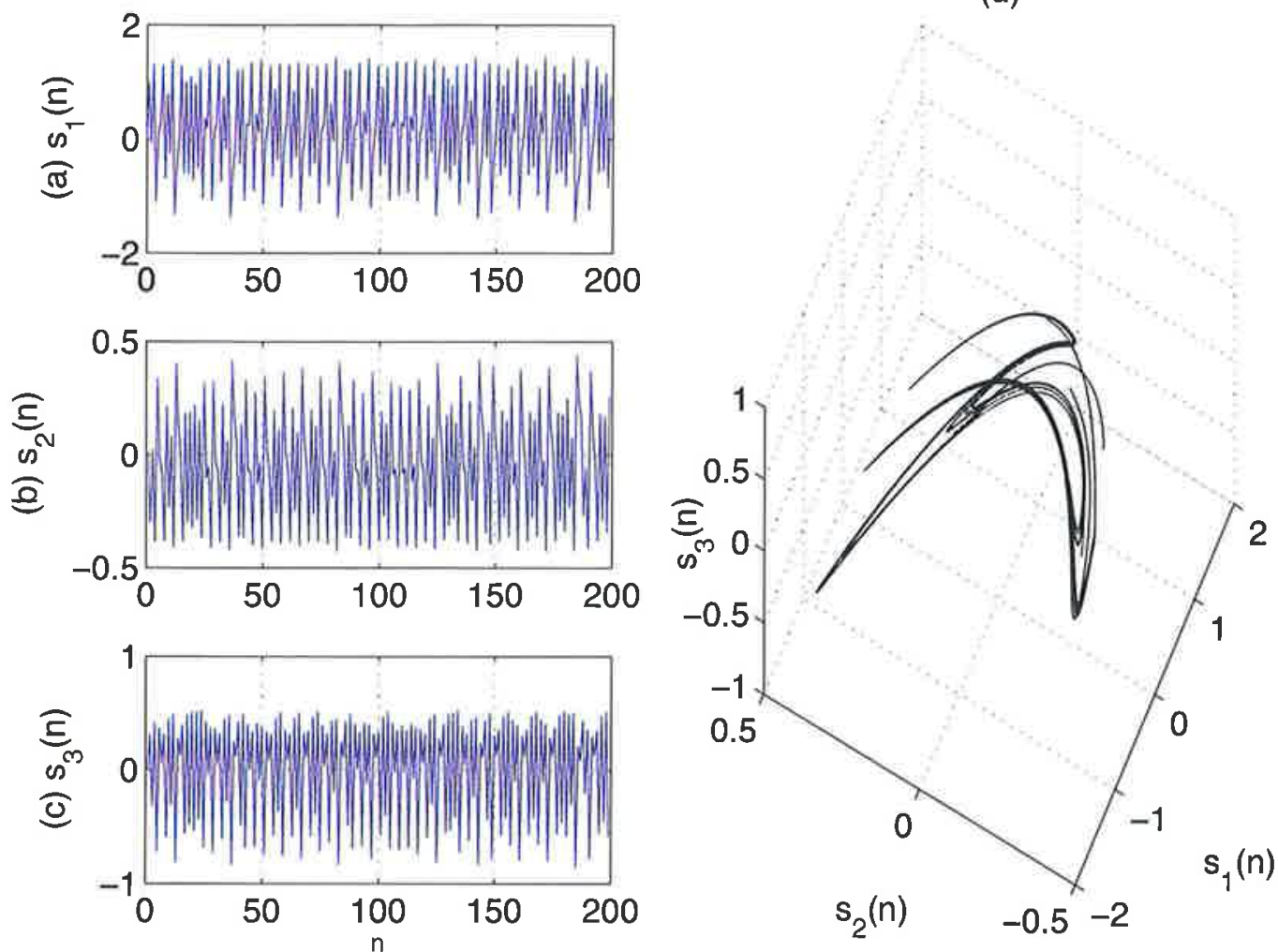

Figura 2.10: Mapa de Hénon tridimensional $f_{H 3}(\cdot)$ : (a), (b) e (c) trecho da órbita com condição $s_{\mathbf{0}}=\left[\begin{array}{lll}0 & 0 & 0\end{array}\right]^{T} ;(\mathrm{d})$ atrator da órbita. Fonte: [67].

\subsection{Densidade invariante e o operador de Frobenius- Perron}

O estudo de órbitas caóticas em sistemas discretos pode ser facilitado, analisando-se como seus mapas atuam sobre conjuntos de pontos, descritos por densidades, ao invés de sobre uma única condição inicial $[76,77]$.

Quando um dado mapa opera sobre uma densidade como condição inicial ao invés de sobre um único ponto, então as densidades sucessivas são dadas por um operador conhecido como operador de Frobenius-Perron. O objetivo aqui é fornecer uma interpretação intuitiva desse operador, que é necessária nos capítulos seguintes. Restringe-se a discussão aos mapas unidimensionais.

Órbitas caóticas são difíceis de serem caracterizadas individualmente. Considerandose, por exemplo, o mapa $f_{Q}($.$) , suas órbitas têm como atrator todo o intervalo U=[-1,1]$ e, devido à DSCI, seu comportamento de longo termo é imprevisível, caso não se conheça sua condição inicial com precisão absoluta.

Pode-se construir um histograma para mostrar a frequência com que os pontos ao 
longo de uma trajetória caem em dadas regiões do domínio $U$. Esse histograma é obtido dividindo-se $U$ em $I$ intervalos disjuntos de forma que o $i$-ésimo intervalo, (negligenciando o ponto +1 ) é dado por

$$
U_{i}=\left[\frac{2(i-1)}{I}-1, \frac{2 i}{I}-1\right), i=1, \ldots, I
$$

A seguir, toma-se uma condição inicial $s_{0}$ e calcula-se uma longa trajetória de comprimento $K \gg I$. Assim, é imediato estimar a probabilidade $P\left(s(n) \in U_{i}\right)$ como a fração dos $K$ pontos, chamada aqui de $P_{i}$, que estão no $i$-ésimo intervalo

$$
P_{i} \approx \frac{\#\left\{f^{k}\left(s_{0}\right) \in U_{i}, k=0,1, \ldots K-1\right\}}{K},
$$

em que \#A representa a cardinalidade do conjunto $A$.

Nos histogramas da Figura 2.11 mostram-se os resultados desse procedimento, tomando-se como condições iniciais $s_{1}(0)=0,7$ e $s_{2}(0)=0,4$, utilizando-se $I=40$ intervalos e $K=10^{4}$ pontos. Nesses histogramas, a área do retângulo sobre o intervalo $U_{i}$ é a aproximação para $P_{i}$ de (2.26).

Existe uma simetria interessante no resultado já que os pontos concentram-se claramente próximos de -1 e 1 com mínimo próximo de $s=0$, apesar das órbitas ponto a ponto serem bastante diferentes. Repetindo o procedimento para outras condições iniciais chega-se, em geral, ao mesmo resultado. Assim, apesar da DSCI das órbitas individualizadas, essa sensibilidade não se reflete na distribuição dos pontos ao longo da trajetória.

Nota-se que para algumas condições iniciais selecionadas, comportamentos diferentes podem ocorrer. Por exemplo, algumas condições iniciais geram sinais que são atraídos para um dos pontos fixos (2.18) de $f_{Q}($.$) . Quando isso ocorre a órbita assume um va-$ lor constante $\left(c_{1}\right.$ ou $c_{2}$ ) após algumas amostras, como exemplificado na Figura 2.12(a). Para outras condições iniciais, a órbita é eventualmente periódica e também não exibe o comportamento irregular das órbitas da Figura 2.11. Essa situação é ilustrada na Figura $2.12(\mathrm{~b})$.

O problema da descrição dos comportamentos esperados para órbitas de um mapa pode ser parcialmente resolvido abandonando-se o estudo de órbitas individuais em favor do exame do fluxo de densidades.

Considere um mapa $f($.$) definido em U$ e tome-se um grande número $Q$ de condições iniciais $s_{01}, s_{02}, \ldots, s_{0 Q}$. A cada uma dessas condições iniciais aplica-se o mapa $f($.$) ,$ obtendo-se $Q$ novos pontos $s\left(1 ; s_{01}\right) \equiv s_{11}, s\left(1 ; s_{02}\right) \equiv s_{12}, \ldots, s\left(1 ; s_{0 Q}\right) \equiv s_{1 Q}$.

Para definir a densidade inicial e final desses pontos, é interessante introduzir o con- 


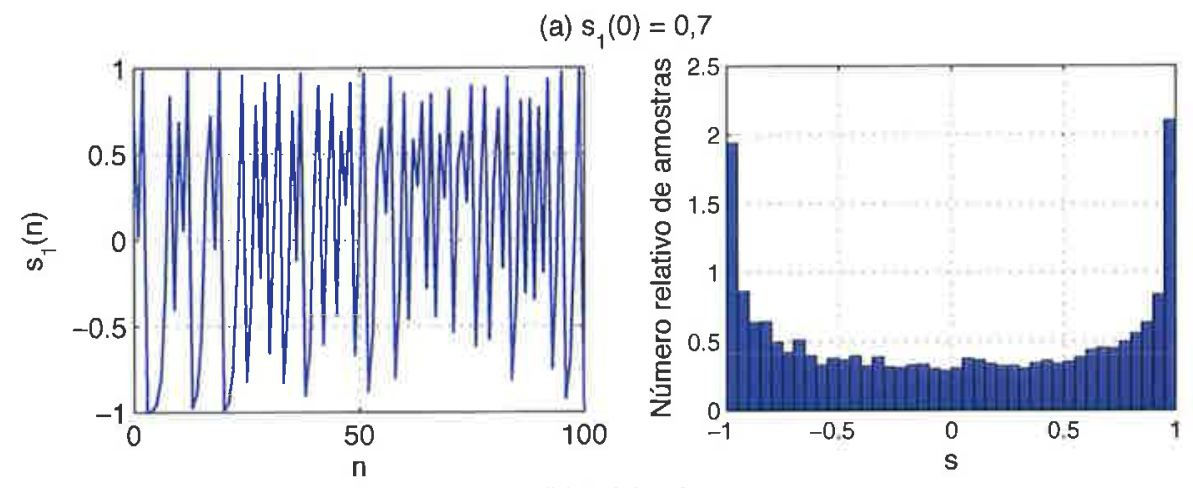

(b) $s_{2}(0)=0,4$
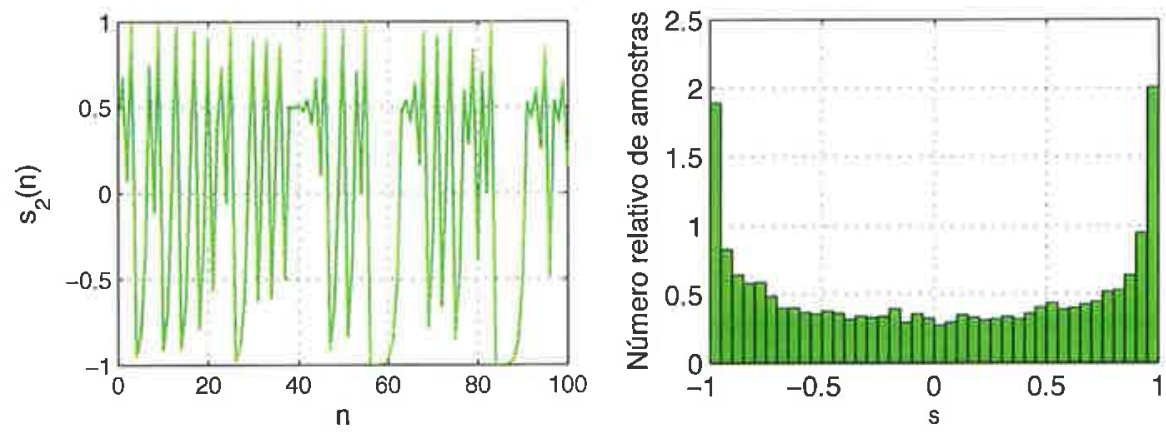

Figura 2.11: Órbitas e histogramas do mapa $f_{Q}($.$) obtidos com K=10^{4}$ pontos, $I=40$ intervalos e condições iniciais (a) $s_{1}(0)=0,7$ e (b) $s_{2}(0)=0,4$. Fonte: [67].

ceito de função indicadora de um conjunto $A$. Ela é simplesmente definida por

$$
I_{A}(s)= \begin{cases}1, & \text { se } s \in A \\ 0, & \text { caso contrário. }\end{cases}
$$

Considere-se um intervalo $A_{0} \subset U$ e um conjunto de $Q$ condições iniciais $s_{01}, s_{02}, \ldots$, $s_{0 Q}$. Pode-se estimar a função densidade $p_{0}(s)$ desses pontos para qualquer $A_{0}$ pela relação $[76]$

$$
\int_{A_{0}} p_{0}(u) d u \approx \frac{1}{Q} \sum_{k=1}^{Q} I_{A_{0}}\left(s_{0 k}\right) .
$$

Considere então que a função densidade $p_{1}(s)$ dos pontos $s_{11}, s_{12}, \ldots, s_{1 Q}$ satisfaz

$$
\int_{A} p_{1}(u) d u \approx \frac{1}{Q} \sum_{q=1}^{Q} I_{A}\left(s_{1 q}\right)
$$

para $A \subset U$.

Deseja-se obter uma relação entre $p_{1}$ e $p_{0}$. Para fazê-lo é necessário introduzir o 
(a) $s_{0}=-0,86602540378444 \ldots$
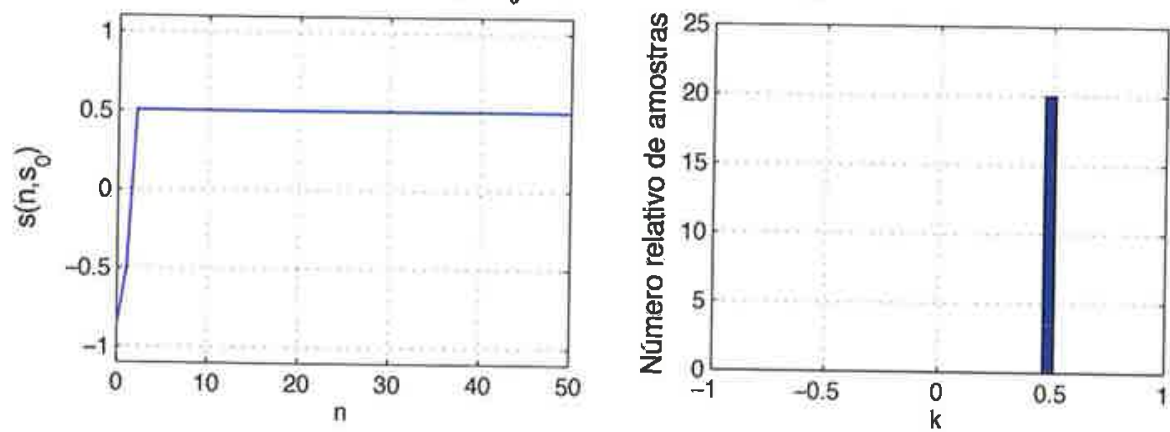

(b) $s_{0}=0,809016994 \ldots$
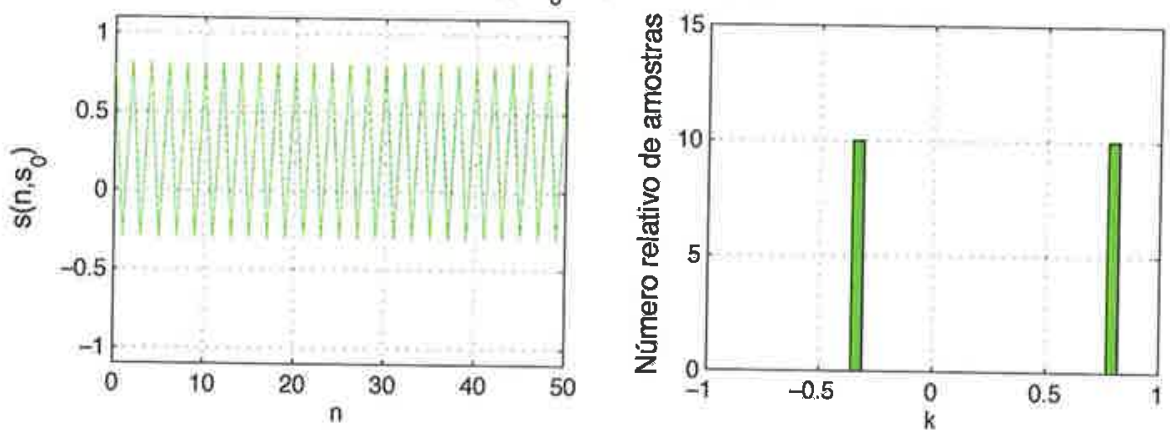

Figura 2.12: Órbitas e histogramas de $f_{Q}\left(\right.$.) sem comportamento caótico. (a) $s_{0}=-\sqrt{\frac{3}{4}}$; (b) $s_{0} \approx 0,809016994$. Foram usados $K=10^{4}$ pontos e $I=40$ intervalos. Fonte: [67].

conceito de contraimagem de um intervalo $A \subset U$ sob a operação do mapa $f($.$) ou$

$$
f^{-1}(A)=\{s \in U / f(s) \in A\} .
$$

Como ilustrado na Figura 2.13, para o mapa $f_{Q}($.$) a contraimagem de um intervalo é a$ união de dois intervalos.

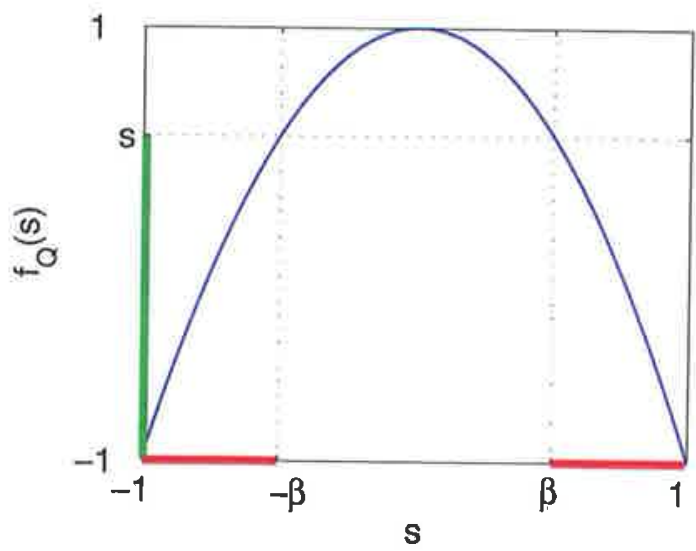

Figura 2.13: Contraimagem do intervalo $[-1, s]$ por $f_{Q}($.$) representada por linhas grossas$ no eixo das abscissas $\operatorname{com} \beta=\sqrt{\frac{1-8}{2}}$. Fonte: [67]. 
Note que para qualquer $A \subset U$,

$$
s_{1 q} \in A \Leftrightarrow s_{0 q} \in f^{-1}(A)
$$

para $q=1,2, \ldots, Q$. Assim, tem-se a seguinte relação útil

$$
I_{A}(f(s))=I_{f^{-1}(A)}(s) .
$$

Com (2.32) pode-se reescrever (2.29) como

$$
\int_{A} p_{1}(u) d u \approx \frac{1}{Q} \sum_{q=1}^{Q} I_{f^{-1}(A)}\left(s_{0 q}\right) .
$$

Tomando-se $A_{0}=f^{-1}(A)$, os membros direitos de (2.28) e (2.33) são iguais e, portanto

$$
\int_{A} p_{1}(u) d u=\int_{f^{-1}(A)} p_{0}(u) d u
$$

Essa é a relação desejada entre $p_{0}($.$) e p_{1}($.$) . Dela percebe-se como a densidade inicial$ de estados $p_{0}($.$) é transformada por um dado mapa f($.$) em uma nova densidade p_{1}($.$) .$

Supondo $A=[a, s]$ obtém-se uma representação explicita para $p_{1}($.$) reescrevendo-se$ (2.34) como

$$
\int_{a}^{s} p_{1}(u) d u=\int_{f^{-1}([a, s])} p_{0}(u) d u
$$

Diferenciando os dois membros em relação a $s$, obtém-se

$$
p_{1}(s)=\frac{d}{d s} \int_{f^{-1}([a, s])} p_{0}(u) d u \text {. }
$$

Fica claro que $p_{1}($.$) depende de p_{0}($.$) . Na literatura, esse fato é usualmente indicado$ por $p_{1}=\mathbb{P}\left[p_{0}\right][76]$, de forma que (2.36) torna-se

$$
\mathbb{P}[p(s)]=\frac{d}{d s} \int_{f^{-1}([a, s])} p(u) d u
$$

em que se retirou o subscrito de $p_{0}$. Essa expressão define explicitamente o operador de Frobenius-Perron $\mathbb{P}[\cdot]$ correspondente à transformação $f($.$) ; esse operador é útil no estudo$ da evolução de densidades.

Uma densidade $p^{*}(s)$ que seja ponto fixo do operador $\mathbb{P}[\cdot]$ para um dado $f(\cdot)$ é chamada de densidade invariante para esse mapa. Em outras palavras, $p^{*}(s)$ é uma densidade 
invariante do mapa $f(\cdot)$ se e somente se

$$
\mathbb{P}\left[p^{*}(s)\right]=p^{*}(s)
$$

Exemplo 2.1 (Densidade invariante do mapa $f_{Q}(\cdot)$ ). Para ilustrar o conceito do operador de Frobenius-Perron retorna-se ao mapa quadrático $f_{Q}($.$) , aplicando-se (2.37) a$ uma fórmula analítica da contraimagem do intervalo $[-1, s]$.

Da Figura 2.13, nota-se que os pontos extremos dos dois intervalos constituintes de $f_{Q}^{-1}([-1, s])$ podem ser calculados resolvendo-se uma equação quadrática. Procedendo dessa forma, chega-se a

$$
f_{Q}^{-1}([-1, s])=\left[-1,-\sqrt{\frac{1-s}{2}}\right] \cup\left[\sqrt{\frac{1-s}{2}}, 1\right] .
$$

Com isto, (2.37) pode ser escrita como

$$
\mathbb{P}[p(s)]=\frac{d}{d s} \int_{-1}^{-\sqrt{\frac{1-s}{2}}} p(u) d u+\frac{d}{d s} \int_{\sqrt{\frac{1-s}{2}}}^{1} p(u) d u .
$$

Realizando-se as diferenciações chega-se a

$$
\mathbb{P}[p(s)]=\frac{1}{2 \sqrt{2(1-s)}}\left[p\left(-\sqrt{\frac{1-s}{2}}\right)+p\left(\sqrt{\frac{1-s}{2}}\right)\right] .
$$

Essa equação é uma fórmula explícita para o operador de Frobenius-Perron correspondente ao mapa $f_{Q}($.$) e mostra como ele transforma uma dada densidade p($.$) em outra \mathbb{P}[p()$.$] .$

Por exemplo, tome-se uma densidade inicial

$$
p_{0}(s)=\frac{1}{2}
$$

para $s \in[-1,1]$. Então, como os termos dentro dos colchetes em (2.41) são constantes, um cálculo simples fornece:

$$
\mathbb{P}\left[p_{0}(s)\right]=\frac{1}{2 \sqrt{2(1-s)}} .
$$

Pode-se então substituir essa expressão para $\mathbb{P}\left[p_{0}().\right]$ no lugar de $p($.$) no segundo membro$ 
de (2.41) obtendo-se

$$
\begin{aligned}
\mathbb{P}\left[\mathbb{P}\left[p_{0}(s)\right]\right] & =\mathbb{P}^{2}\left[p_{0}(s)\right]=\frac{1}{2 \sqrt{2(1-s)}}\left[\frac{1}{2 \sqrt{2\left(1+\sqrt{\frac{1-s}{2}}\right)}}+\frac{1}{2 \sqrt{2\left(1-\sqrt{\frac{1-s}{2}}\right)}}\right] \\
& =\frac{1}{4 \sqrt{2(1-s)}}\left[\frac{1}{\sqrt{2+\sqrt{2(1-s)}}}+\frac{1}{\sqrt{2-\sqrt{2(1-s)}}}\right] .
\end{aligned}
$$

Na Figura 2.14(a) são mostrados gráficos de $p_{0}(s), \mathbb{P}\left[p_{0}(s)\right]$ e $\mathbb{P}^{2}\left[p_{0}(s)\right]$. Nela vê-se que essas densidades aproximam-se de uma densidade limite. Essa é dada por

$$
p_{*}(s)=\left\{\begin{array}{ll}
\frac{1}{\pi \sqrt{1-s^{2}}}, & -1 \leq s \leq 1 \\
0, & \text { caso contrário }
\end{array},\right.
$$

como pode ser verificado substituindo-se $p_{*}(s)$ em (2.38) para o $\mathbb{P}[p(s)]$ de (2.41). Sendo assim, $p_{*}(s)$ é uma densidade invariante.

\section{Evolução de densidades - Aplicação do operador de Frobenius-Perron}

(a) Mapa $f_{Q}($.

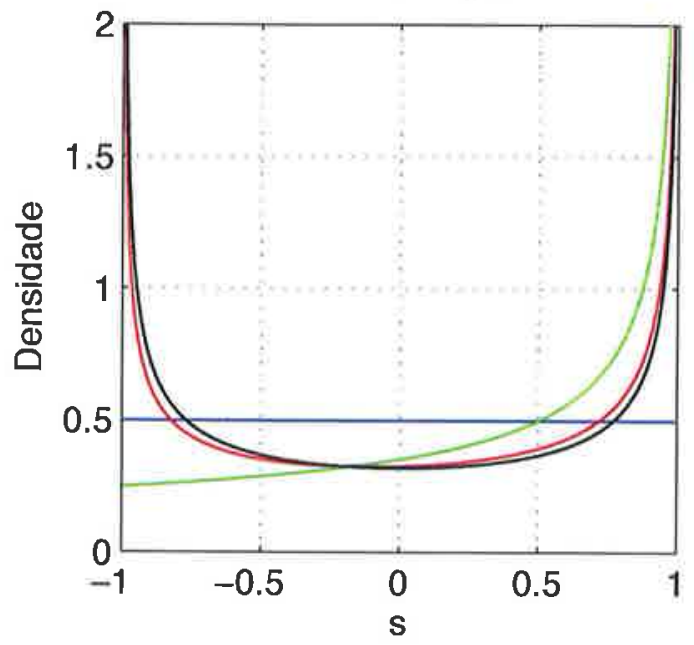

(b) Mapa $\mathrm{f}_{\mathrm{T}}(\cdot)$

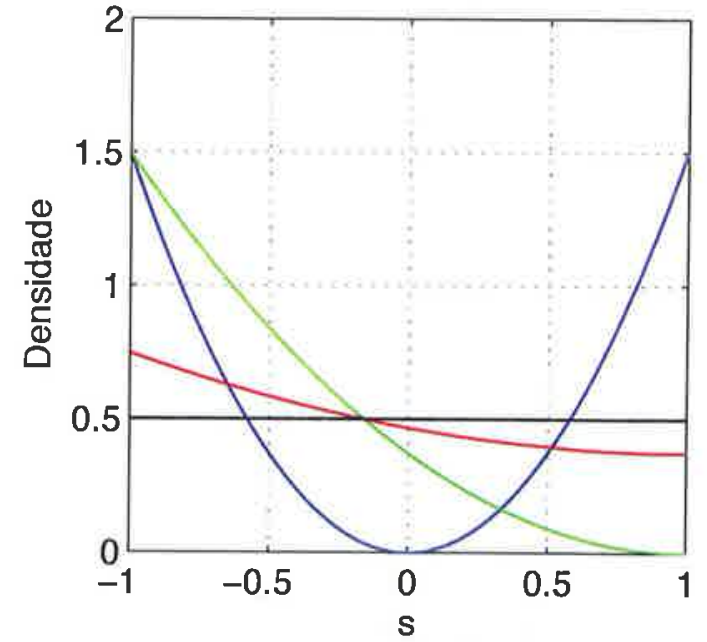

Figura 2.14: (a) Evolução da densidade constante $p_{0}(s)=\frac{1}{2}$ por $f_{Q}($.$) ; (b) Evolução da$ densidade $p_{0}(s)=\frac{3}{2} s^{2}$ por $f_{T}($.$) . Em azul p_{0}(s)$, em verde $\mathbb{P}\left[p_{0}(s)\right]$, em vermelho $\mathbb{P}^{2}\left[p_{0}(s)\right]$ e em preto a densidade invariante, $p_{*}(s)$. Fonte: [67].

Note-se a semelhança entre o gráfico de $p_{*}(s)$ da Figura 2.14(a) com os histogramas da Figura 2.11. Na verdade, pode-se mostrar que, para o mapa quadrático, a distribuição dos pontos ao longo de uma órbita típica aproxima-se de $p_{*}(s)$ da mesma forma que as iterações de densidades [76], propriedade que pode ser reconhecida como uma forma de ergodicidade desse mapa [4]. 
Exemplo 2.2 (Densidade invariante do mapa $f_{I}(\cdot)$ ). Tome-se um intervalo $[-1, s] \subset$ $[-1,1]$ cuja contraimagem sob $f_{I}($.$) é dada por$

$$
f_{I}^{-1}([-1, s])=\left[-1, \beta_{1}\right] \cup\left[\beta_{2}, 1\right]
$$

sendo $\beta_{1}=-\frac{(\alpha+1) s+(\alpha-1)}{2}$ e $\beta_{2}=\frac{(\alpha-1) s+\alpha+1}{2}$. Sendo assim, o operador de Frobenius-Perron é

$$
\mathbb{P}[p(s)]=\frac{d}{d s}\left(\int_{-1}^{\beta_{1}} p(u) d u+\int_{\beta_{2}}^{1} p(u) d u\right)=\frac{1}{2}\left[(\alpha+1) p\left(\beta_{1}\right)+(1-\alpha) p\left(\beta_{2}\right)\right] .
$$

Observa-se na Figura 2.14(b) que também nesse caso as densidades $p($.$) são levadas$ por $\mathbb{P}[\cdot]$ a uma densidade invariante. Nessa figura, tomou-se $\alpha=0$ e considerou-se como densidade inicial $p_{0}(s)=\frac{3}{2} s^{2}$ que é levada a $\mathbb{P}\left[p_{0}(s)\right]=\frac{3}{8}(s-1)^{2}$ e $\mathbb{P}^{2}\left[p_{0}(s)\right]=\frac{3}{32}\left(s^{2}-\right.$ $2 s+5)$.

Como $\mathbb{P}\left[\frac{1}{2}\right]=\frac{1}{2}$ em (2.47), é fácil ver que a densidade invariante para o mapa $f_{I}(\cdot)$ é uniforme,

$$
p_{*}(s)=\left\{\begin{array}{ll}
\frac{1}{2}, & -1 \leq s \leq 1 \\
0, & \text { caso contrário }
\end{array} .\right.
$$

A ergodicidade observada para o mapa quadrático também se verifica nesse exemplo.

A densidade invariante é um primeiro exemplo de como um sistema claramente determinístico pode ser tratado formalmente como um processo estocástico, em que as condições iniciais definem as funções amostras, para se obter propriedades relevantes do comportamento assintótico das órbitas. Essa visão está refletida no título da reconhecida obra de A. Lasota and M. MacKey, Probabilistic properties of deterministic systems [76]. Também é a base para se definir Sequências de AutoCorrelação (SAC) e Densidade Espectral de Potência (DEP) de um GSC no Capítulo 3.

\subsection{Conclusões}

Neste capítulo foram definidos e exemplificados conceitos fundamentais da teoria de sistemas dinâmicos não lineares de tempo discreto necessários para o desenvolvimento dos resultados nos capítulos subsequentes. Entre eles destacam-se os de órbita caótica, número de Lyapunov, densidade invariante e o operador de Frobenius-Perron.

Essa rápida revisão pretendeu estabelecer uma notação coerente tornando os resultados descritos acessíveis mesmo a leitores que não sejam especialistas.

Além disso, com relação a caos, órbitas e sistemas caóticos, diversos autores usam de- 
finições levemente diferentes. Assim, o autor considerou relevante explicitar as definições utilizadas no presente texto. 


\section{Capítulo 3}

\section{Caracterização temporal e espectral de sinais caóticos}

O autor deste texto vem estudando há vários anos o problema da definição e determinação da DEP de sinais caóticos. Esse estudo foi instigado por pergunta que lhe foi dirigida, quando da sua defesa de doutorado, em 2006, pelo Prof. José R. C. Piqueira, da EPUSP. O Prof. Piqueira indagou ao autor sobre a banda necessária para a transmissão dos sinais caóticos dos SCBCs então apresentados [67].

Era do conhecimento do autor que muitos trabalhos citavam "banda larga" como uma propriedade dos sinais caóticos $[7,78]$. No entanto, essa caracterização está longe do que é necessário em sistemas de comunicação práticos. Como os canais físicos são sempre de banda limitada, é necessário conhecer exatamente qual a largura de banda ocupada por um sinal caótico transmitido e, preferencialmente, ser capaz de controlá-la. Dessa forma, essa lacuna precisaria ser preenchida para viabilizar o emprego prático dos SCBCs.

Utilizando sobretudo técnicas descritas no trabalho de Sakai e Tokumaru [79], o autor juntamente com orientados e colaboradores vem conseguindo obter de forma analítica a DEP associada com os sinais caóticos gerados por mapas lineares por partes.

Nesse capítulo resumem-se alguns desses resultados. Na Seção 3.1 fazem-se as definições básicas necessárias para a caracterização temporal e espectral de sinais caóticos. $\mathrm{Na}$ Seção 3.2, trata-se das órbitas do mapa $f_{I}(\cdot)$, que foi definido na Seção 2.4.2. Esse foi o tema da dissertação de mestrado de Daniela M. Kato [60], orientada pelo autor e que resultou nos artigos $[22,24]$. Em seguida, na Seção 3.3 trata-se da DEP do mapa $f_{B}(\cdot)$, definido na Seção 2.4.2, que foi tema da dissertação de mestrado de Rafael A. da Costa [63], também orientada pelo autor e que originou o artigo [31]. 


\subsection{Definições básicas}

A definição de DEP para sinais caóticos não é evidente. Esses sinais são determinísticos, por definição, porém um mesmo mapa gera uma infinidade de sinais diferentes associados com diferentes condições iniciais. Como então associar uma DEP ao conjunto de sinais gerados por um dado mapa?

Uma solução eficaz para esse problema é aplicar a sinais caóticos a notação formalmente utilizada para sinais e sistemas aleatórios, como expresso no título da obra de Lasota e MacKey Probabilistic properties of deterministic systems [76]. A ideia básica é simples: da mesma forma como um processo estocástico é um conjunto de funções-amostras, cada uma delas determinística, um mapa é tratado como um conjunto de sinais, cada um determinístico, associado a condições iniciais diferentes. As médias amostrais são substituídas por médias sobre os sinais gerados por condições iniciais diferentes. Da mesma forma como nos processos aleatórios ergódicos, nos sistemas dinâmicos ergódicos pode-se substituir médias amostrais por médias no tempo.

Usando a analogia entre mapa e processo estocástico, define-se a SAC $R(k)$ das órbitas de um mapa $f(\cdot)$ ergódico como

$$
R(k) \triangleq \mathbb{E}[s(n) s(n+k)],
$$

sendo $k$ um número inteiro que representa o passo da correlação e $n$ qualquer. A esperança matemática $\mathbb{E}[\cdot]$ é tomada sobre todas as condições iniciais que geram sinais caóticos. Neste cálculo, considera-se que $s(n)=0$ para $n<0$. Em particular, define-se a potência média dos sinais caóticos gerados como

$$
P_{\text {med }} \triangleq R(0)=\mathbb{E}\left[s(n)^{2}\right]
$$

Para processos estocásticos estacionários, a DEP $S(\omega)$ é obtida calculando-se a Transformada de Fourier de Tempo Discreto (TFTD) de $R(k)$, considerando-se $k$ a variável temporal $[80$, p. 6]. Seguindo a analogia entre sinais caóticos definidos por um mapa e sinais aleatórios definidos por um processo estocásticos, utiliza-se a mesma definição aqui, ou seja,

$$
S(\omega)=\mathbb{F}[R(k)] \triangleq \sum_{k=-\infty}^{\infty} R(k) e^{-j \omega k},
$$

sendo $\mathbb{F}[\cdot]$ o operador TFTD.

Como qualquer TFTD, $S(\omega)$ é periódica com período $2 \pi$. Além disso, devido à simetria par de $R(k)$, ela é real e par. Dessa forma, nos gráficos desse texto, sempre 
apresenta-se $S(\omega)$ no intervalo $0 \leq \omega<\pi$. Também, pode-se mostrar que [80, p. 5-7]

$$
\frac{1}{\pi} \int_{0}^{\pi} S(\omega)=P_{\mathrm{med}}
$$

justificando assim $S(\omega)$ ser uma densidade de potência.

Muitos sinais, apesar de terem DEP näo nula sobre todo o intervalo $0 \leq \omega<\pi$, apresentam uma concentração de sua potência numa certa faixa de frequências. A banda essencial $B$ é uma medida dessa faixa efetivamente ocupada pelo sinal. Existem diversas definições formais possíveis para $B$ [81]. Nessa tese, $B$ será definida como o comprimento do intervalo de frequências em que $p=95 \%$ da potência do sinal está concentrada [81]. Para um sinal passa-baixas,

$$
\int_{0}^{B} S(\omega) d \omega \triangleq p \int_{0}^{\pi} S(\omega) d \omega=p \pi P_{\mathrm{med}}
$$

Usando essas definições, nas próximas seções exploram-se as propriedades temporais e espectrais das órbitas dos mapas tenda inclinada $f_{I}(\cdot)$ e de Bernoulli $f_{B}(\cdot)$.

\subsection{Um estudo das órbitas do mapa tenda inclinada $f_{I}(\cdot)$}

Escolheu-se inicialmente tratar dos sinais gerados por $f_{I}(\cdot)$, definida na Seção 2.4.2, pagina 15, porque eles apresentam comportamento rico e variado, mas ainda assim de fácil esquematização. Pelo fato destes mapas serem lineares por partes e suas órbitas apresentarem densidade invariante uniforme, as deduções tornam-se tratáveis analiticamente. Além disso, nessa família está incluso o mapa $f_{T}(\cdot)(2.11)$, cujos sinais gerados possuem características espectrais que já eram bem conhecidas [82] quando se iniciou o estudo.

Usando o fato de que a densidade invariante $p_{a s t}(s)$ de $f_{I}(\cdot)$ é uniforme no intervalo $U=[-1,1]$, vide (2.48), conclui-se que quase todas as suas órbitas possuem média nula e potência média

$$
P_{\text {med }}=\mathbb{E}\left[s(n)^{2}\right]=\int_{-1}^{1} s^{2} p_{*}(s) d s=\frac{1}{3},
$$

para qualquer valor de $\alpha$. 


\subsubsection{Sequência de autocorrelação}

A partir da definição (3.1), obtém-se a seguir a SAC das órbitas do mapa $f_{I}(\cdot)$. Para facilitar a notação definem-se

$$
x \triangleq s(n) \text { e } y \triangleq s(n+k)=f_{I}^{k}(x)
$$

Como $y$ é completamente determinado por $x$, a densidade conjunta $p(x, y)$ é dada por

$$
p(x, y)=p_{*}(x) \delta\left(y-f_{I}^{k}(x)\right)
$$

em que $p_{*}(\cdot)$ é a densidade invariante do mapa $f_{I}(\cdot)$ e $\delta(\cdot)$ representa a função impulso unitário de tempo contínuo [83, p. 22]. Dessa forma, usando-se (2.48) e (3.7) em (3.1), tem-se

$$
\begin{aligned}
R(k) & =\mathbb{E}[x y]=\int_{-1}^{1} \int_{-1}^{1} x y p(x, y) d x d y=\int_{-1}^{1} \int_{-1}^{1} x y p_{*}(x) \delta\left(y-f_{I}^{k}(x)\right) d x d y \\
& =\frac{1}{2} \int_{-1}^{1} x f_{I}^{k}(x) d x .
\end{aligned}
$$

Assim, para encontrar $R(k)$ é necessário obter uma expressão para $f_{I}^{k}(\cdot)$.

O mapa $f_{I}(\cdot)$ é constituído de dois segmentos de reta de inclinações de sinais opostos. A imagem de cada um desses segmentos é igual ao domínio $U$ do mapa. Consequentemente, $f_{I}^{k}(\cdot)$ consiste de $2^{k}$ segmentos. Esse fato é ilustrado na Figura 3.1. Em (a) mostra-se o mapa $f_{I}(x)$ para $\alpha=0,1$, em (b) $f_{I}^{2}(x)$ e em (c) $f_{I}^{3}(x)$. Em (d) é mostrado um trecho do gráfico de $f_{I}^{k}(x)$ para um $k$ genérico. Representa-se a $m$-ésima solução da equação $f_{I}^{k}(\cdot)=1$ por $a_{k}(m)$, em que $1 \leq m \leq 2^{k-1}$ e a $m$-ésima solução da equação $f_{I}^{k}(\cdot)=-1$ por $b_{k}(m)$, com $0 \leq m \leq 2^{k-1}$.

As equações dos segmentos que constituem o mapa $f_{I}^{k}(x)$ são:

- segmento que passa por $\left(b_{k}(m-1),-1\right)$ e $\left(a_{k}(m), 1\right)$ :

$$
y=\frac{2}{a_{k}(m)-b_{k}(m-1)}\left(x-b_{k}(m-1)\right)-1=\frac{2 x-a_{k}(m)-b_{k}(m-1)}{a_{k}(m)-b_{k}(m-1)} ;
$$

- segmento que passa por $\left(a_{k}(m), 1\right)$ e $\left(b_{k}(m),-1\right)$ :

$$
y=\frac{-2}{b_{k}(m)-a_{k}(m)}\left(x-a_{k}(m)\right)+1=\frac{2 x-a_{k}(m)-b_{k}(m)}{a_{k}(m)-b_{k}(m)} .
$$



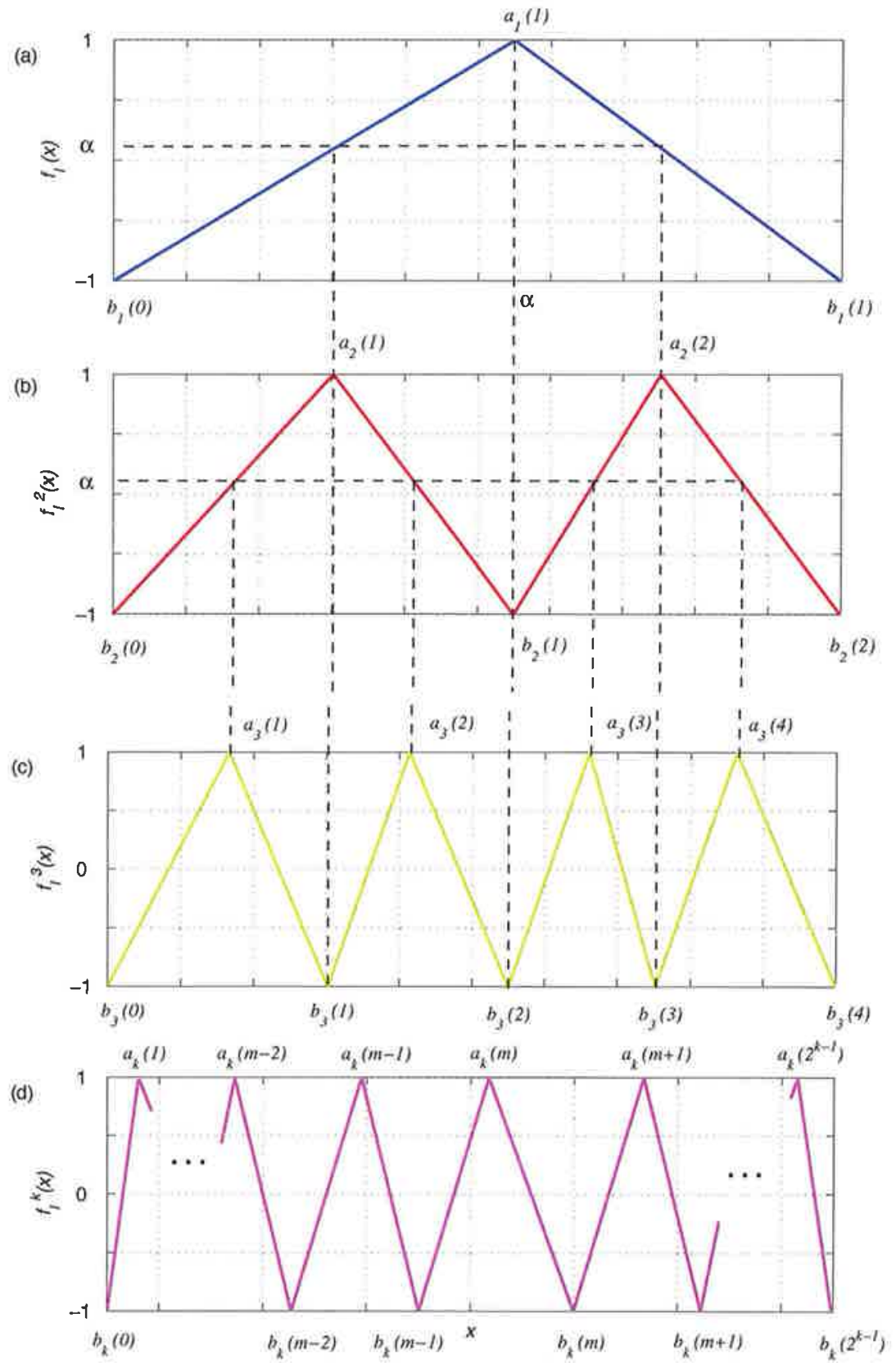

Figura 3.1: Iterações do mapa tenda inclinada para $\alpha=0,1$ : (a) $f_{I}(x)$; (b) $f_{I}^{2}(x)$; (c) $f_{I}^{3}(x)$ e $(\mathrm{d}) f_{I}^{k}(x)$. Fonte: [24].

Substituindo-se (3.10) e (3.11) em (3.9),

$$
\begin{aligned}
R(k)= & \frac{1}{2} \sum_{m=1}^{2^{k-1}} \underbrace{\int_{b_{k}(m-1)}^{a_{k}(m)} x\left(\frac{2 x-a_{k}(m)-b_{k}(m-1)}{a_{k}(m)-b_{k}(m-1)}\right) d x}_{I_{1}}+ \\
& \underbrace{\int_{a_{k}(m)}^{b_{k}(m)} x\left(\frac{2 x-a_{k}(m)-b_{k}(m)}{a_{k}(m)-b_{k}(m)}\right) d x}_{I_{2}} .
\end{aligned}
$$


Calculando-se as integrais $I_{1}$ e $I_{2}$ em (3.12) separadamente, obtém-se

$$
I_{1}=\frac{\left(a_{k}(m)-b_{k}(m-1)\right)^{2}}{6} \mathrm{e} I_{2}=-\frac{\left(a_{k}(m)-b_{k}(m)\right)^{2}}{6} .
$$

Assim,

$$
R(k)=\frac{1}{12} \sum_{m=1}^{2^{k-1}}\left[\left(a_{k}(m)-b_{k}(m-1)\right)^{2}-\left(a_{k}(m)-b_{k}(m)\right)^{2}\right] .
$$

Visando uma fórmula mais simples para $R(k)$, busca-se uma forma recursiva para $R(k+1)$ em função de $R(k)$. Calculando-se $R(k+1)$ a partir de (3.14), obtém-se

$$
R(k+1)=\frac{1}{12} \sum_{m=1}^{2^{k}}\left[\left(a_{k+1}(m)-b_{k+1}(m-1)\right)^{2}-\left(a_{k+1}(m)-b_{k+1}(m)\right)^{2}\right] .
$$

Separando-se as parcelas de índices pares e ímpares, tem-se

$$
\begin{array}{r}
R(k+1)=\frac{1}{12} \sum_{m=1}^{2^{k-1}}\left[\left(a_{k+1}(2 m)-b_{k+1}(2 m-1)\right)^{2}-\left(a_{k+1}(2 m)-b_{k+1}(2 m)\right)^{2}+\right. \\
\left.\left(a_{k+1}(2 m-1)-b_{k+1}(2 m-2)\right)^{2}-\left(a_{k+1}(2 m-1)-b_{k+1}(2 m-1)\right)^{2}\right] .
\end{array}
$$

Ao iterar uma vez o mapa, passa-se de $f_{I}^{k}(x)$ para $f_{I}^{k+1}(x)$, o que pode ser visualizado nas Figuras 3.2(a) e 3.2(b), em que $w$ e $z$ são raízes da equação $f_{I}^{k}(x)=\alpha$.
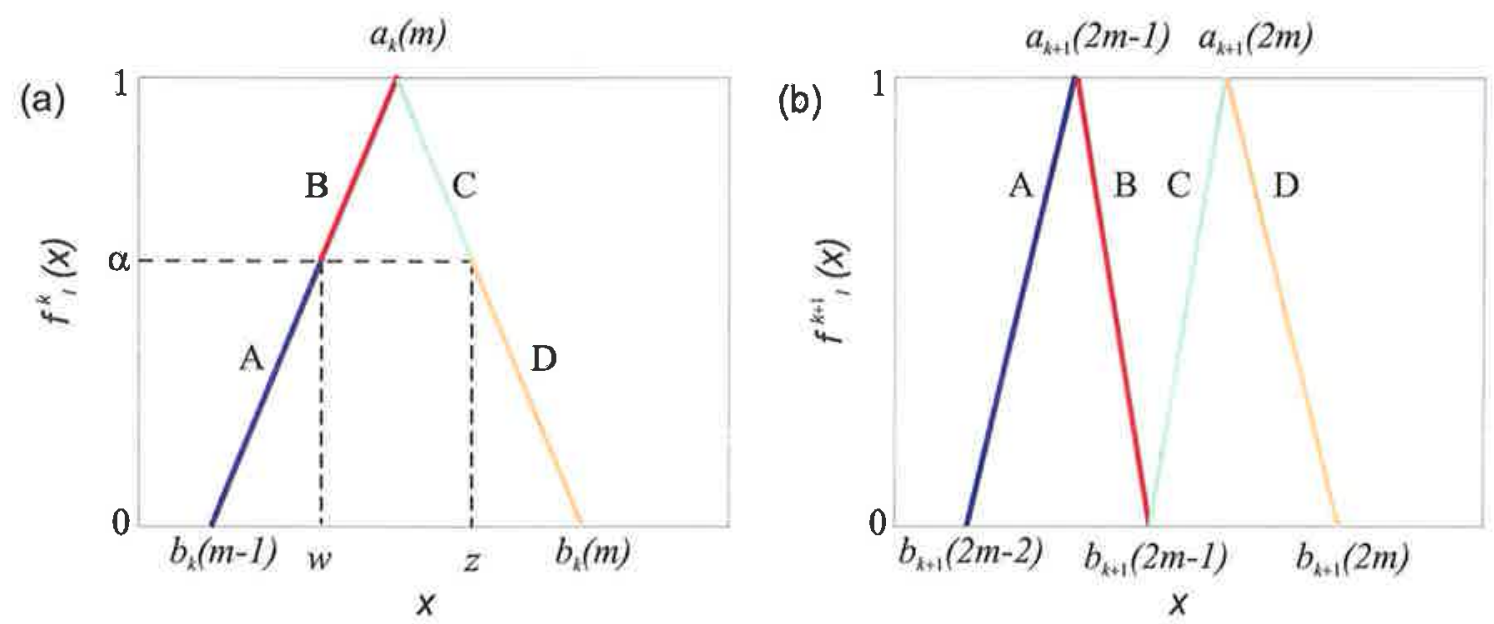

Figura 3.2: (a) Trecho de $f_{I}^{k}(\cdot)$ e (b) mesmo trecho após uma iteração. Fonte: [24]. 
Dos gráficos da Figura 3.2, observa-se que

$$
\begin{cases}b_{k+1}(2 m-2) & =b_{k}(m-1) \\ a_{k+1}(2 m-1) & =w \\ b_{k+1}(2 m-1) & =a_{k}(m) \\ a_{k+1}(2 m) & =z \\ b_{k+1}(2 m) & =b_{k}(m)\end{cases}
$$

Para determinar $w$ e $z$, substitui-se $y$ por $\alpha$ em (3.10) e (3.11), respectivamente e isola-se $x$. Desta forma, obtém-se

$$
\left\{\begin{array}{l}
w=\frac{\alpha+1}{2}\left(a_{k}(m)-b_{k}(m-1)\right)+b_{k}(m-1) \\
z=\frac{\alpha+1}{2}\left(a_{k}(m)-b_{k}(m)\right)+b_{k}(m)
\end{array}\right.
$$

Substituindo-se (3.18) e (3.19) em (3.17) e realizando-se algumas manipulações, chegase a

$$
\begin{aligned}
R(k+1) & =\frac{1}{12} \sum_{m=1}^{2^{k-1}}\left\{\left[\frac{\alpha+1}{2}\left(a_{k}(m)-b_{k}(m)\right)+b_{k}(m)-a_{k}(m)\right]^{2}-\left[\frac{\alpha+1}{2}\left(a_{k}(m)-b_{k}(m)\right)\right]^{2}\right. \\
& \left.+\left[\frac{\alpha+1}{2}\left(a_{k}(m)-b_{k}(m-1)\right)\right]^{2}-\left[\frac{\alpha+1}{2}\left(a_{k}(m)-b_{k}(m-1)\right)+b_{k}(m-1)-a_{k}(m)\right]^{2}\right\} .
\end{aligned}
$$

Expandindo-se os termos quadráticos do somatório e agrupando-se termos comuns, finalmente obtém-se

$$
R(k+1)=\frac{\alpha}{12} \sum_{m=1}^{2^{k-1}}\left[\left(a_{k}(m)-b_{k}(m-1)\right)^{2}-\left(a_{k}(m)-b_{k}(m)\right)^{2}\right] .
$$

Comparando (3.14) e (3.21), observa-se que

$$
R(k+1)=\alpha R(k) .
$$

De (3.6), a condição inicial dessa equação de diferenças é $R(0)=\mathbb{E}\left[s(n)^{2}\right]=\frac{1}{3}$. Assim, resolvendo-se (3.22), obtém-se

$$
R(k)=\frac{1}{3} \alpha^{|k|} \text {. }
$$

Na Figura 3.3(a) mostram-se gráficos de (3.23) para alguns valores de $\alpha$. Na Figura 3.3(b) é ilustrado o comportamento geral da SAC para os valores admissíveis de $\alpha$.

Observa-se que para $\alpha>0, R(k)$ decai monotonicamente com $|k|$ e que para $\alpha<0$, 


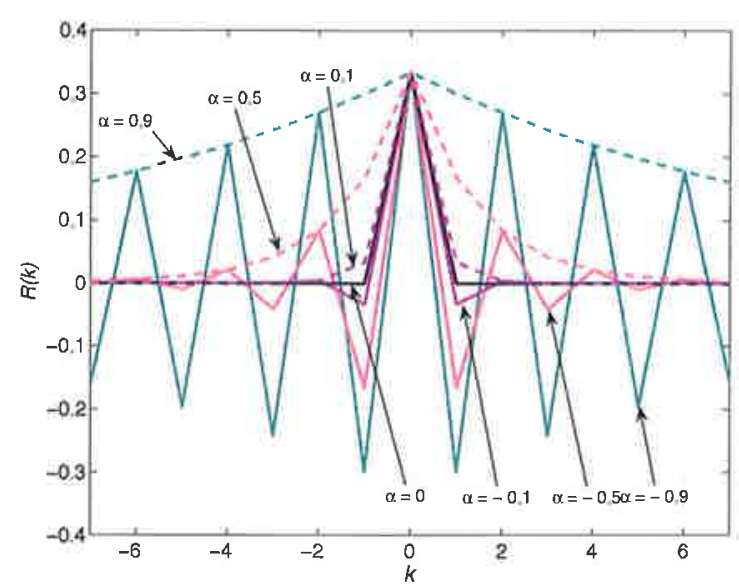

(a)

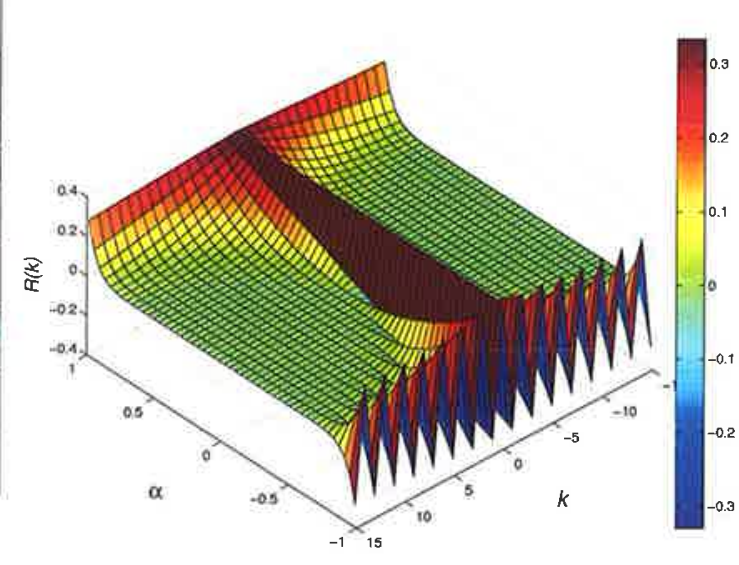

(b)

Figura 3.3: (a) SAC para sinais gerados por $f_{I}(\cdot)$ para alguns valores de $\alpha$; (b) SAC para sinais do mapa tenda inclinada para valores de $\alpha$ no intervalo $(-1,1)$. Fontes: [24, 49].

$R(k)$ alterna de sinal a cada $k$, indicando que, neste caso, para quase quaisquer $n$ e $s_{0}$, os pontos $s\left(n ; s_{0}\right)$ e $s\left(n+1, s_{0}\right)$ têm sinais diferentes. Nota-se que, se $R_{\alpha_{1}}(k)$ é a SAC para o mapa tenda $\operatorname{com} \alpha=\alpha_{1}, R_{\alpha_{2}}(k)$ é SAC para $\alpha=\alpha_{2}$ e $\alpha_{1}=-\alpha_{2}$, então

$$
R_{\alpha_{2}}(k)=(-1)^{k} R_{\alpha_{1}}(k)
$$

Estes resultados mostram que sinais caóticos nem sempre possuem SAC na forma impulsiva. Neste caso, obtém-se esta forma apenas para $\alpha=0$, coincidindo com o resultado obtido em [82] para $\beta=2$.

\subsubsection{Densidade espectral de potência}

Aplicando-se a TFTD aos dois membros de (3.23) e usando a definição (3.3),

$$
S(\omega)=\frac{1}{3}\left[\sum_{k=0}^{\infty} \alpha^{k} e^{-j \omega k}+\sum_{k=-\infty}^{-1} \alpha^{-k} e^{-j \omega k}\right]=\frac{1}{3}\left(\frac{1}{1-\alpha e^{-j \omega}}+\frac{1}{1-\alpha e^{j \omega}}-1\right)
$$

ou

$$
S(\omega)=\frac{1-\alpha^{2}}{3\left(1+\alpha^{2}-2 \alpha \cos (\omega)\right)}
$$

Na Figura 3.4(a) são mostrados gráficos de (3.26) para alguns valores de $\alpha$ e na Figura 3.4(b) é apresentado, de forma normalizada, o comportamento geral para todos os valores de $\alpha$.

De (3.26) e pelos gráficos apresentados, observa-se que o parâmetro da família controla 


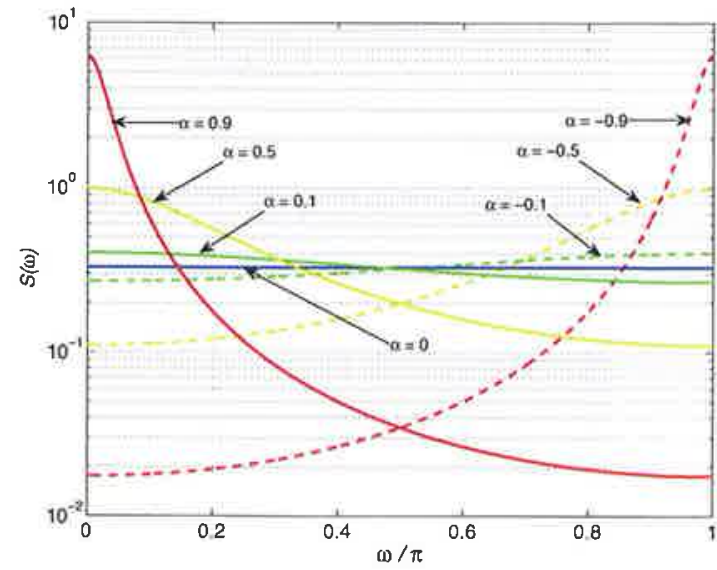

(a)

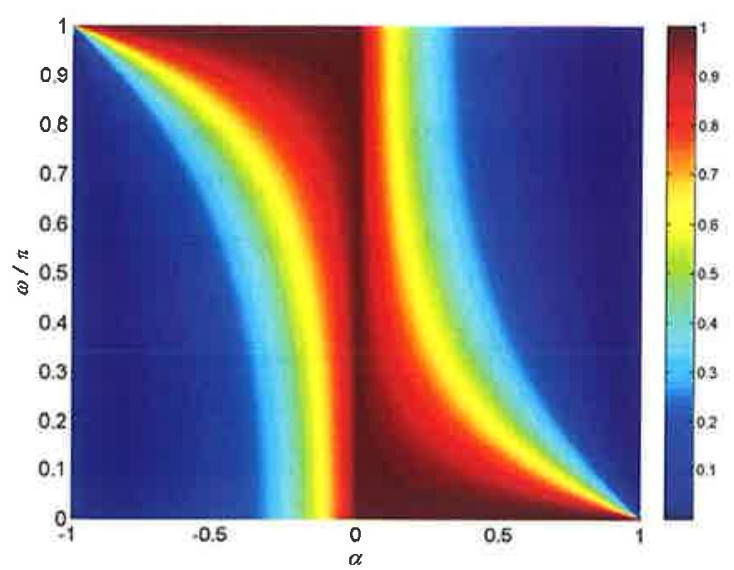

(b)

Figura 3.4: (a) DEP para sinais gerados por $f_{I}(\cdot)$ para alguns valores de $\alpha$; (b) comportamento geral da DEP normalizada para os valores admissíveis de $\alpha$. Fontes: [24, 49].

a forma como a potência está distribuída na frequência. Quanto maior o módulo de $\alpha$, menor a faixa de frequências em que está concentrada a potência do sinal resultante. Além disso, o sinal de $\alpha$ define se a potência está concentrada nas altas ou baixas frequências.

Pode-se observar na Figura 3.4 que as DEPs de sinais gerados por mapas com valores de $\alpha$ opostos apresentam simetria em relação a $\omega=\pi / 2$, ou seja, se $\alpha_{1}=-\alpha_{2}, S_{\alpha_{1}}(\omega)=$ $S_{\alpha_{2}}(\omega+\pi)$, em que $S_{\alpha_{1}}(\omega)$ é a DEP das órbitas geradas quando $\alpha=\alpha_{1}$ e $S_{\alpha_{2}}(\omega)$ é a DEP das órbitas geradas quando $\alpha=\alpha_{2}$. Esse resultado é esperado devido à relação (3.24) e à propriedade do deslocamento em frequência da TFTD [84, p. 59].

\subsubsection{Banda essencial}

Para valores de $\alpha$ opostos, devido às simetrias ilustradas na Figura 3.4 e justificadas na seção anterior, as bandas essenciais dos sinais gerados são iguais. Assim, no desenvolvimento seguinte, considera-se apenas valores positivos de $\alpha$.

De (3.26),

$$
\int_{0}^{B} S(\omega) d \omega=\frac{2}{3} \arctan \left[\left|\frac{\alpha+1}{\alpha-1}\right| \tan \left(\frac{B}{2}\right)\right] .
$$

Substituindo (3.6) e (3.27) na definição (3.5) e isolando-se $B$, obtém-se

$$
B=2 \arctan \left[\tan \left(\frac{p \pi}{2}\right)\left|\frac{\alpha-1}{\alpha+1}\right|\right]
$$

Na Figura 3.5 mostram-se gráficos de $B$ em função do módulo de $\alpha$ e do expoente de Lyapunov $h_{I}$ dado por (2.14). Como $B=p \pi$ para $\alpha=0$ e levando-se em conta a 
densidade invariante uniforme (2.48), obtém-se, neste caso, sinais que se comportam em termos temporais e espectrais como um ruído branco uniforme. Já para $|\alpha| \approx 1$, as órbitas comportam-se como funções-amostras de um processo com banda extremamente estreita. É importante ressaltar que, em todos os casos, o expoente de Lyapunov é positivo e assim, os sinais gerados são caóticos para todos os valores de $\alpha$.

(a)

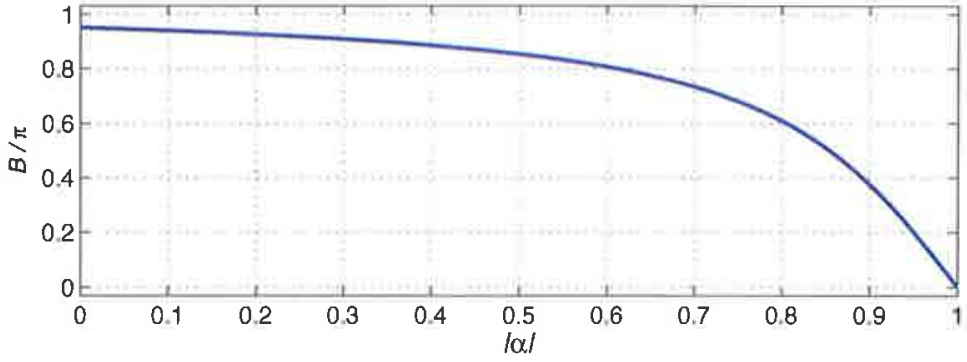

(b)

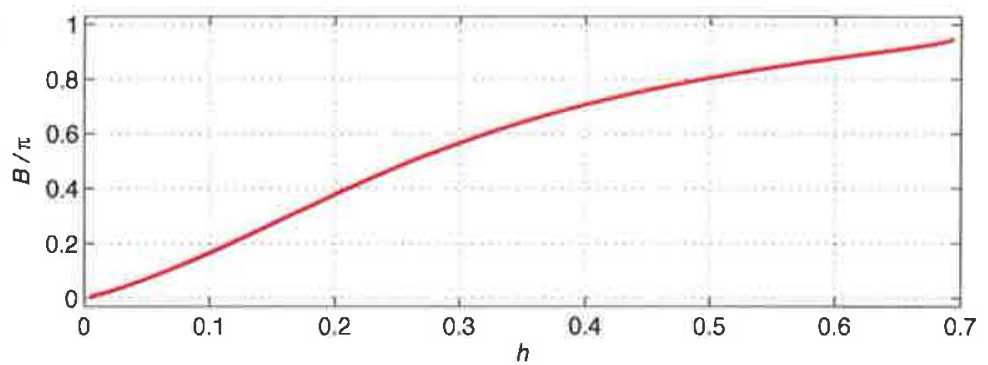

Figura 3.5: $B$ para o mapa $f_{I}(\cdot)$ em função (a) do parâmetro $|\alpha|$ e (b) do expoente de Lyapunov $h_{I}$. Fonte: [24]

\subsubsection{Conclusões}

Os resultados obtidos mostram que, escolhendo-se um $\alpha$ adequado, pode-se utilizar o mapa $f_{I}(\cdot)$ para se obter um sinal caótico banda larga ou estreita, com sua potência concentrada nas frequências altas ou baixas e com a banda essencial bem definida.

É importante realçar, portanto, que sinais caóticos não implicam, necessariamente, banda larga e SAC impulsiva.

Em $[39,47]$ mostram-se resultados numéricos que concordam perfeitamente com os resultados teóricos descritos aqui. Com a possibilidade de se gerar sinais caóticos banda estreita, propôs-se em [22] a multiplexação e desmultiplexação de sinais caóticos em frequência, de forma similar ao que se faz em sistemas de modulação em frequência convencionais.

Usando técnicas similares às apresentadas aqui, diversos autores propuseram resultados para diversas famílias de mapas lineares por partes. Veja, por exemplo, [85, 86]. Em particular, o autor juntamente com seu orientado de mestrado Rafael A. Costa e o cola- 
borador Murilo B. Loiola obtiveram recentemente resultados bastante interessantes para o mapa de Bernoulli com $r$ inclinações, $f_{B}(\cdot)$, descrito na Seção 2.4.3. Eles são detalhados a seguir.

\subsection{Um estudo das órbitas do mapa de Bernoulli $f_{B}(\cdot)$}

O mapa de Bernoulli com $r$ inclinações $f_{B}(\cdot)$ foi definido na Seção 2.4.3, 16. Diferentemente do mapa $f_{I}(\cdot)$ que possui um único parâmetro $\alpha$, o mapa de Bernoulli possui $r-1$ parâmetros diferentes, o que torna o problema, em princípio, bem mais desafiante. Por outro lado, pode-se mostrar [31] que a densidade invariante para $f_{B}(\cdot)$ é uniforme, dada por

$$
p_{*}(s)=\frac{1}{2},-1 \leq s<1,
$$

o que torna o problema tratável. Assim, escolheu-se determinar suas características temporais e espectrais como um segundo problema após os resultados obtidos para $f_{I}(\cdot)$, mostrados na seção anterior.

Da mesma forma que para $f_{I}(\cdot)$, quase todas as suas órbitas possuem média nula e potência média

$$
P_{\text {med }}=\mathbb{E}\left[s(n)^{2}\right]=\int_{-1}^{1} s^{2} p_{*}(s) d s=\frac{1}{3},
$$

para quaisquer valores de $r \geq 2$ e $\alpha_{j}, 1 \leq j<r-1$.

\subsubsection{Sequência de autocorrelação}

O procedimento utilizado para o cálculo da SAC para o mapa $f_{B}(\cdot)$ segue de perto o utilizado para o mapa $f_{I}(\cdot)$ na Seção 3.2.1.

Para facilitar a notação, definem-se

$$
\left\{\begin{array}{l}
x \triangleq s(n) \\
y \triangleq s(n+k)=f_{B}^{k}(x) .
\end{array}\right.
$$

Como $y$ é completamente determinado por $x$, a densidade invariante conjunta de $x$ e $y, p(x, y)$, pode ser escrita como

$$
p(x, y)=p_{*}(x) \delta\left(y-f_{B}^{k}(x)\right)
$$


Substituindo (3.31) e (3.32) na definição (3.1) e usando-se (3.29) pode-se escrever

$$
\begin{aligned}
R(k) & =\mathbb{E}[x y]=\int_{-1}^{1} \int_{-1}^{1} x y p(x, y) d x d y=\int_{-1}^{1} \int_{-1}^{1} x y p_{*}(x) \delta\left(y-f_{B}^{k}(x)\right) d x d y \\
& =\frac{1}{2} \int_{-1}^{1} x f_{B}^{k}(x) d x
\end{aligned}
$$

Para obter uma fórmula fechada para (3.33) é necessária uma expressão para $f_{B}^{k}(x)$, a $k$-ésima iteração de $f_{B}(\cdot)$.

O mapa $f_{B}(\cdot)$ é constituído de $r$ segmentos de reta. A imagem de cada um desses segmentos é igual ao domínio $U=\left[-1,1\left[\right.\right.$ do mapa. Consequentemente, $f_{B}^{k}(\cdot)$ consiste de $r^{k}$ segmentos. Esse fato é ilustrado na Figura 3.6. Mostra-se um exemplo de $f_{B}(x), f_{B}^{2}(x)$ e $f_{B}^{k}(x)$, para um $k$ genérico. Representa-se a $m$-ésima solução da equação $f_{B}^{k}(\cdot)=-1$ por $a_{k}(m-1)$, para $k=1,2, \ldots$ e $m=1,2, \ldots, r^{k}$. Define-se $a_{k}\left(r^{k}\right)=1$.

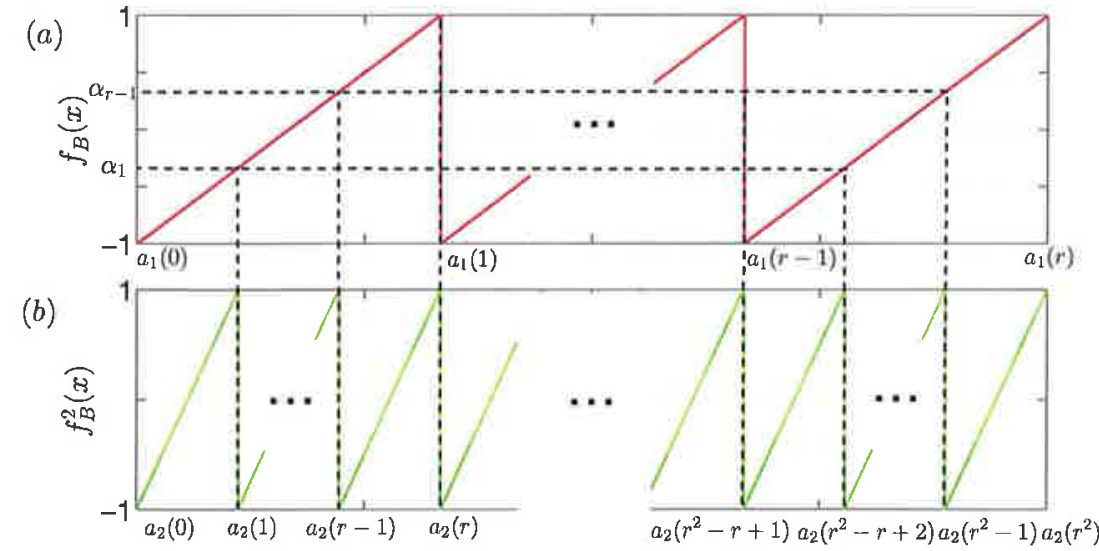

$(c)$

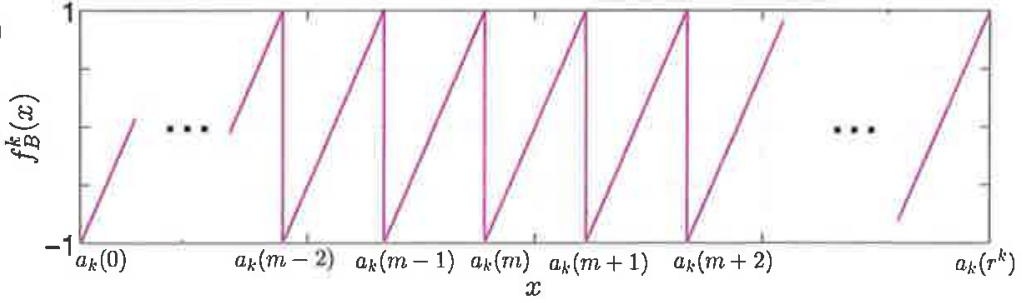

Figura 3.6: (a) Mapa $f_{B}(x)$ com $r$ segmentos; (b) $f_{B}^{2}(x)$; (c) $f_{B}^{k}(x)$. Fonte: [31].

Da Figura 3.6, nota-se que $f_{B}^{k}(x)$ no intervalo $\left[a_{k}(m-1), a_{k}(m)\right.$ [ é dado por

$$
f_{B}^{k}(x)=\frac{2 x-a_{k}(m)-a_{k}(m-1)}{a_{k}(m)-a_{k}(m-1)}, \quad a_{k}(m-1) \leq x<a_{k}(m) .
$$


Substituindo (3.34) em (3.33),

$$
R(k)=\frac{1}{2} \sum_{m=1}^{r^{k}} \underbrace{\int_{a_{k}(m-1)}^{a_{k}(m)} x \frac{2 x-a_{k}(m)-a_{k}(m-1)}{a_{k}(m)-a_{k}(m-1)} d x}_{I} .
$$

Resolvendo-se a integral $I$,

$$
\begin{aligned}
I & =\left[\frac{2 x^{3}}{3\left(a_{k}(m)-a_{k}(m-1)\right)}-\frac{\left(a_{k}(m)+a_{k}(m-1)\right) x^{2}}{2\left(a_{k}(m)-a_{k}(m-1)\right)}\right]_{a_{k}(m-1)}^{a_{k}(m)} \\
& =\frac{a_{k}^{3}(m)-3 a_{k}^{2}(m) a_{k}(m-1)+3 a_{k}(m) a_{k}^{2}(m-1)-a_{k}^{3}(m-1)}{6\left(a_{k}(m)-a_{k}(m-1)\right)} \\
& =\frac{\left(a_{k}(m)-a_{k}(m-1)\right)^{2}}{6} .
\end{aligned}
$$

Em seguida, substituindo esse resultado em (3.35), obtém-se

$$
R(k)=\frac{1}{12} \sum_{m=1}^{r^{k}}\left(a_{k}(m)-a_{k}(m-1)\right)^{2}
$$

Assim como foi feito no caso do mapa $f_{I}(\cdot)$, pode-se buscar uma forma recursiva para $R(k+1)$ em função de $R(k)$. De (3.37), $R(k+1)$ é dada por

$$
R(k+1)=\frac{1}{12} \sum_{m=1}^{r^{k+1}}\left(a_{k+1}(m)-a_{k+1}(m-1)\right)^{2} .
$$

Pode-se reescrever (3.38) como um somatório de $r^{k}$ somas de $r$ parcelas, ou seja,

$$
R(k+1)=\frac{1}{12} \sum_{m=1}^{r^{k}} \sum_{j=1}^{r}\left(a_{k+1}(r(m-1)+j)-a_{k+1}(r(m-1)+j-1)\right)^{2}
$$

É necessário então encontrar relações entre os valores de $a_{k+1}$ e $a_{k}$. O processo de obter $f_{B}^{k+1}(x)$ a partir de $f_{B}^{k}(x)$ é ilustrado na Figura 3.7 , em que $w_{m, j}$ satisfaz

$$
f_{B}^{k}\left(w_{m, j}\right)=\alpha_{j}
$$

no intervalo $\left[a_{k}(m-1), a_{k}(m)[, 0 \leq j \leq r\right.$.

Da Figura 3.7,

$$
a_{k+1}(r(m-1)+j)=w_{m, j}
$$



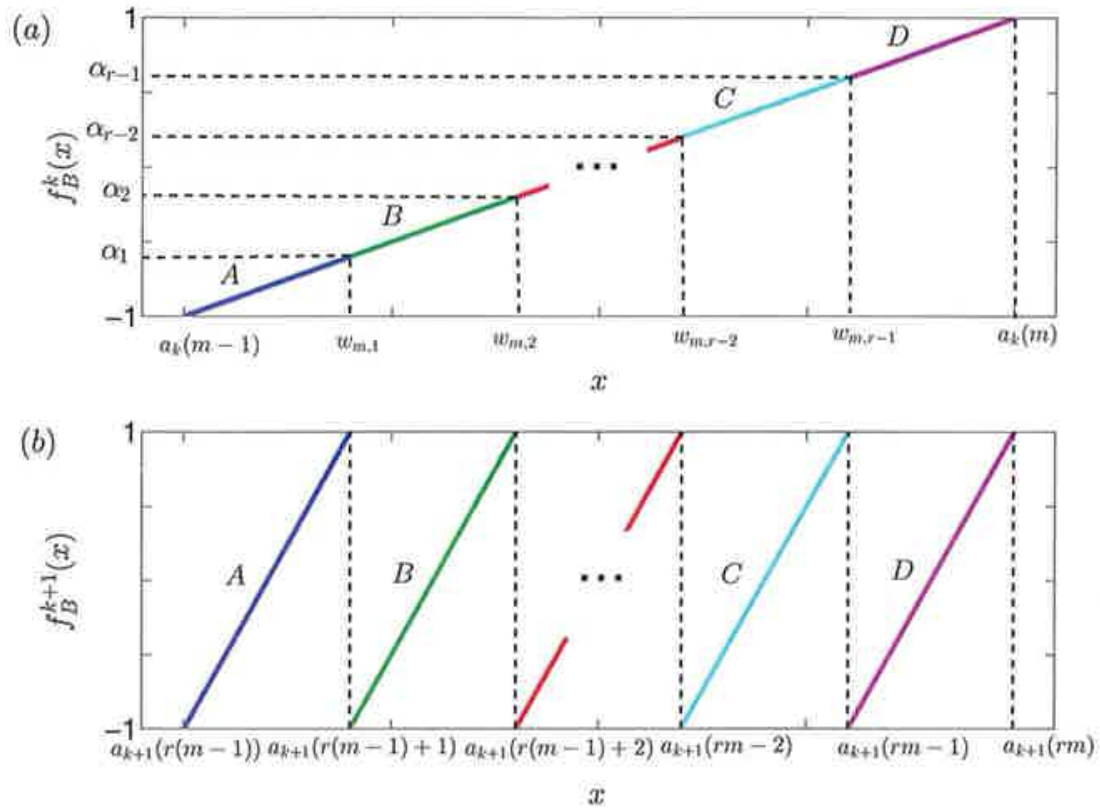

Figura 3.7: (a) Gráficos de $f_{B}^{k}(x)$ e (b) $f_{B}^{k+1}(x)$ no intervalo $\left[a_{k}(m-1), a_{k}(m)[\right.$. Fonte: [31].

para $0 \leq j \leq r$. Usando esse resultado em (3.39), tem-se

$$
R(k+1)=\frac{1}{12} \sum_{m=1}^{r^{k}} \sum_{j=1}^{r}\left(w_{m, j}-w_{m, j-1}\right)^{2} .
$$

Os valores de $w_{m, j}$ podem ser obtidos substituindo-se (3.40) em (3.34). Obtém-se

$$
w_{m, j}=\frac{\left(a_{k}(m)-a_{k}(m-1)\right) \alpha_{j}+a_{k}(m)+a_{k}(m-1)}{2} .
$$

Substituindo em (3.42),

$$
\begin{aligned}
R(k+1) & =\frac{1}{12} \sum_{m=1}^{r^{k}} \sum_{j=1}^{r}\left(\left(a_{k}(m)-a_{k}(m-1)\right) \frac{\alpha_{j}-\alpha_{j-1}}{2}\right)^{2} \\
& =\frac{1}{12} \sum_{m=1}^{r^{k}}\left(a_{k}(m)-a_{k}(m-1)\right)^{2} \sum_{j=1}^{r}\left(\frac{\alpha_{j}-\alpha_{j-1}}{2}\right)^{2} .
\end{aligned}
$$

Assim, $R(k+1)$ pode ser escrita como

$$
R(k+1)=\frac{\psi}{12} \sum_{m=1}^{r^{k}}\left(a_{k}(m)-a_{k}(m-1)\right)^{2},
$$


com

$$
\psi=\frac{1}{4} \sum_{j=1}^{r}\left(\alpha_{j}-\alpha_{j-1}\right)^{2} .
$$

Comparando (3.37) e (3.45), observa-se que

$$
R(k+1)=\psi R(k)
$$

De (3.30), a condição inicial para a equação de diferenças (3.47) é $R(0)=P_{\text {med }}=1 / 3$. Resolvendo (3.47) com essa condição inicial, obtém-se a expressão geral

$$
R(k)=\frac{1}{3} \psi^{|k|}
$$

para qualquer inteiro $k$. Chama a atenção a forma compacta desse resultado e a semelhança com (3.23). Para o mapa $f_{B}(\cdot), \psi$ substitui formalmente o parâmetro $\alpha$ do mapa $f_{I}(\cdot)$.

\subsubsection{Densidade espectral de potência}

Aplicando-se a TFTD a ambos os membros de (3.48) obtém-se

$$
S(\omega)=\frac{1-\psi^{2}}{3\left(1+\psi^{2}-2 \psi \cos (\omega)\right)} \text {, }
$$

que tem a mesma forma de (3.26). No entanto, diferentemente do que ocorre com $\alpha$ no mapa $f_{I}(\cdot)$, o parâmetro $\psi$ é sempre positivo, como se conclui de (3.46). Consequentemente, $S(\omega)$ tem máximo em $\omega=0$ e mínimo $\mathrm{em} \omega=\pi$ para quaisquer $r$ e $\alpha_{j}$, $1 \leq j \leq r-1$, resultando em sinais passa-baixas para todos os mapas da família.

\subsubsection{Banda essencial}

Procedendo de forma análoga ao que foi feito na Seção 3.2.3, obtém-se

$$
B=2 \arctan \left(\tan \left(\frac{p \pi}{2}\right)\left|\frac{\psi-1}{\psi+1}\right|\right) \text {. }
$$

De forma a ilustrar de forma mais concreta os resultados obtidos, a seguir consideramse dois casos particulares. 


\subsubsection{Casos particulares}

Consideram-se dois casos particulares: o caso $r=2$ e o caso de $r$ segmentos com inclinações iguais.

Caso $r=2$

Nesse caso, $f_{B}(\cdot)$ é formado por apenas 2 segmentos com um único ponto de descontinuidade $\alpha_{1}$. Esse caso foi estudado numericamente em detalhes no artigo [87]. Usando (3.46),

$$
\begin{aligned}
\psi & =\frac{1}{4} \sum_{j=1}^{2}\left(\alpha_{j}-\alpha_{j-1}\right)^{2}=\frac{1}{4}\left(\left(\alpha_{1}-\alpha_{0}\right)^{2}+\left(\alpha_{2}-\alpha_{1}\right)^{2}\right) \\
& =\frac{1}{4}\left(\left(\alpha_{1}+1\right)^{2}+\left(1-\alpha_{1}\right)^{2}\right)=\frac{\alpha_{1}^{2}+1}{2}
\end{aligned}
$$

Assim, de (3.48),

$$
R(k)=\frac{1}{3}\left(\frac{\alpha_{1}^{2}+1}{2}\right)^{|k|} .
$$

Substituindo (3.51) em (3.49), tem-se

$$
S(\omega)=\frac{3-\alpha_{1}^{4}-2 \alpha_{1}^{2}}{3\left(5+\alpha_{1}^{4}+2 \alpha_{1}^{2}-4\left(\alpha_{1}^{2}+1\right) \cos (\omega)\right)} .
$$

Finalmente, substituindo-se (3.51) em (3.50),

$$
B=2 \arctan \left(\tan \left(\frac{p \pi}{2}\right)\left|\frac{\alpha_{1}^{2}-1}{\alpha_{1}^{2}+3}\right|\right) .
$$

Na Figura 3.8 mostram-se gráficos de $R(k), S(\omega)$ e $B$ para diversos valores de $\alpha_{1}$. As linhas tracejadas indicam os resultados analíticos de (3.52) e (3.53) e as linhas contínuas estimativas numéricas de $R(k)$ a partir de um conjunto de sinais $s(n)$, como detalhado em [63].

Observa-se que para $k$ positivo, $R(k)$ decai monotonicamente de forma mais rápida para $\left|\alpha_{1}\right| \approx 0$ e mais lentamente para $\left|\alpha_{1}\right| \approx 1$. A DEP está sempre concentrada nas baixas frequências e nunca chega a ser plana. Os resultados numéricos coincidem com os teóricos.

Esses resultados estão de acordo com o estudo realizado para esse caso particular publicado em [87]. 

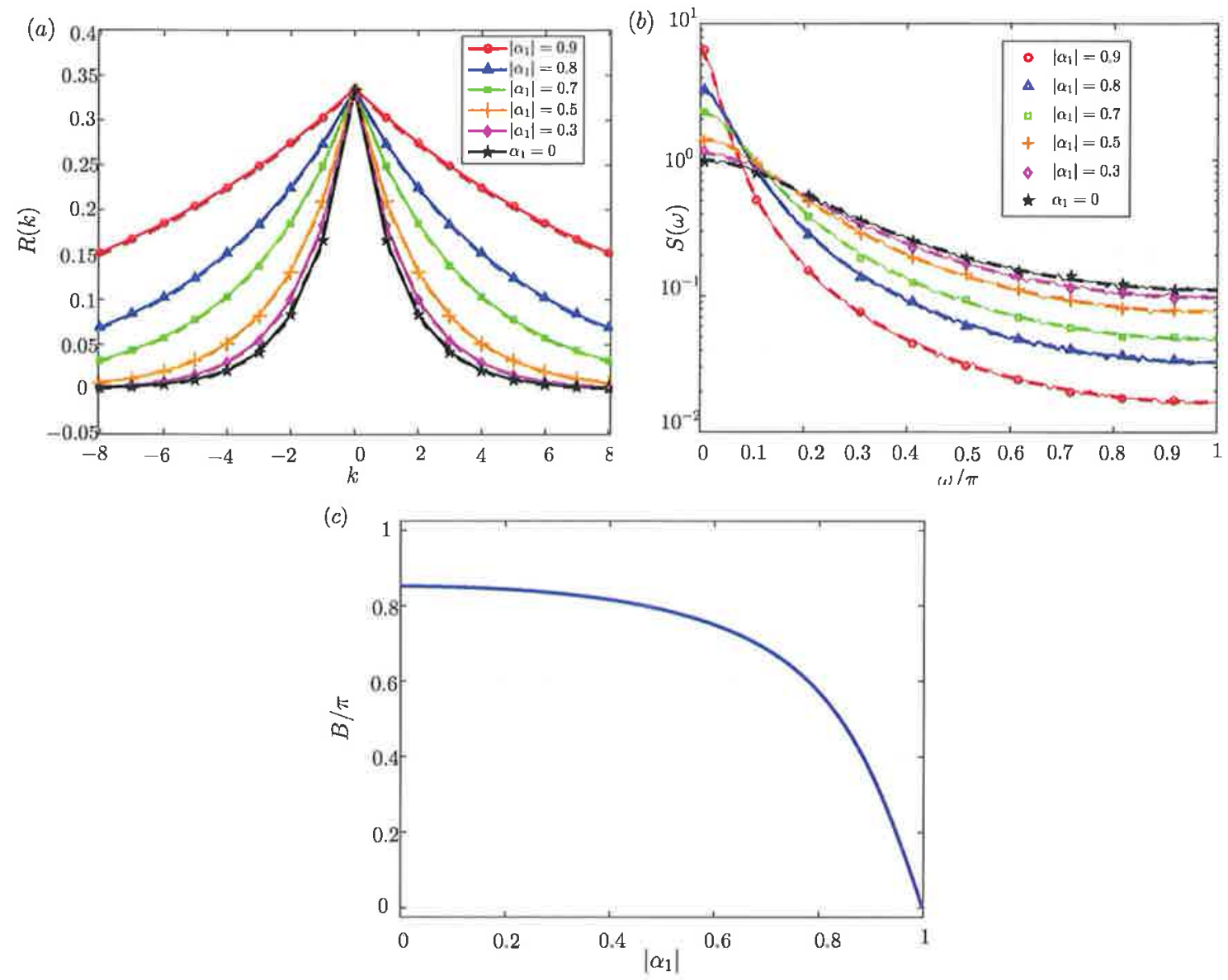

Figura 3.8: (a) SAC, (b) DEP e (c) $B$ do sinais caóticos gerados por $f_{B}(\cdot)$ para $r=2$ e diferentes valores de $\left|\alpha_{1}\right|$. Os resultados analíticos são mostrados em linhas tracejadas e simulações numéricas em linhas contínuas. Fonte: [31].

\section{Caso $r$ segmentos com inclinações iguais}

Nesse caso, $\alpha_{j}=-1+\frac{2}{r} j$, para $j=0,1, \ldots, r$. Assim,

$$
\psi=\frac{1}{4} \sum_{j=1}^{r}\left(\alpha_{j}-\alpha_{j-1}\right)^{2}=\frac{1}{4} \sum_{j=1}^{r}\left(\left(-1+\frac{2}{r} j\right)-\left(-1-\frac{2}{r}+\frac{2}{r} j\right)\right)^{2}=\frac{1}{r}
$$

que substituído na (3.48) resulta

$$
R(k)=\frac{1}{3}\left(\frac{1}{r}\right)^{|k|}
$$

Substituindo (3.55) em (3.49) e (3.50), obtém-se

$$
S(\omega)=\frac{r^{2}-1}{3\left(1+r^{2}-2 r \cos (\omega)\right)},
$$


$\mathrm{e}$

$$
B=2 \arctan \left(\tan \left(\frac{q \pi}{2}\right)\left|\frac{1-r}{1+r}\right|\right)
$$

respectivamente.

Na Figura 3.9 mostram-se curvas de $R(k), S(\omega)$ e $B / \pi$ para diferentes valores de $r$. Nota-se que com o aumento de $r, S(\omega)$ aproxima-se de um espectro plano. Novamente são mostrados resultados analíticos em tracejado e estimativas espectrais baseadas em um conjunto de órbitas de $f_{B}(\cdot)$ são mostrados em linha cheia. Os detalhes da simulação numérica estão descritos em [63]. Claramente, os resultados numéricos coincidem com os cálculos teóricos.
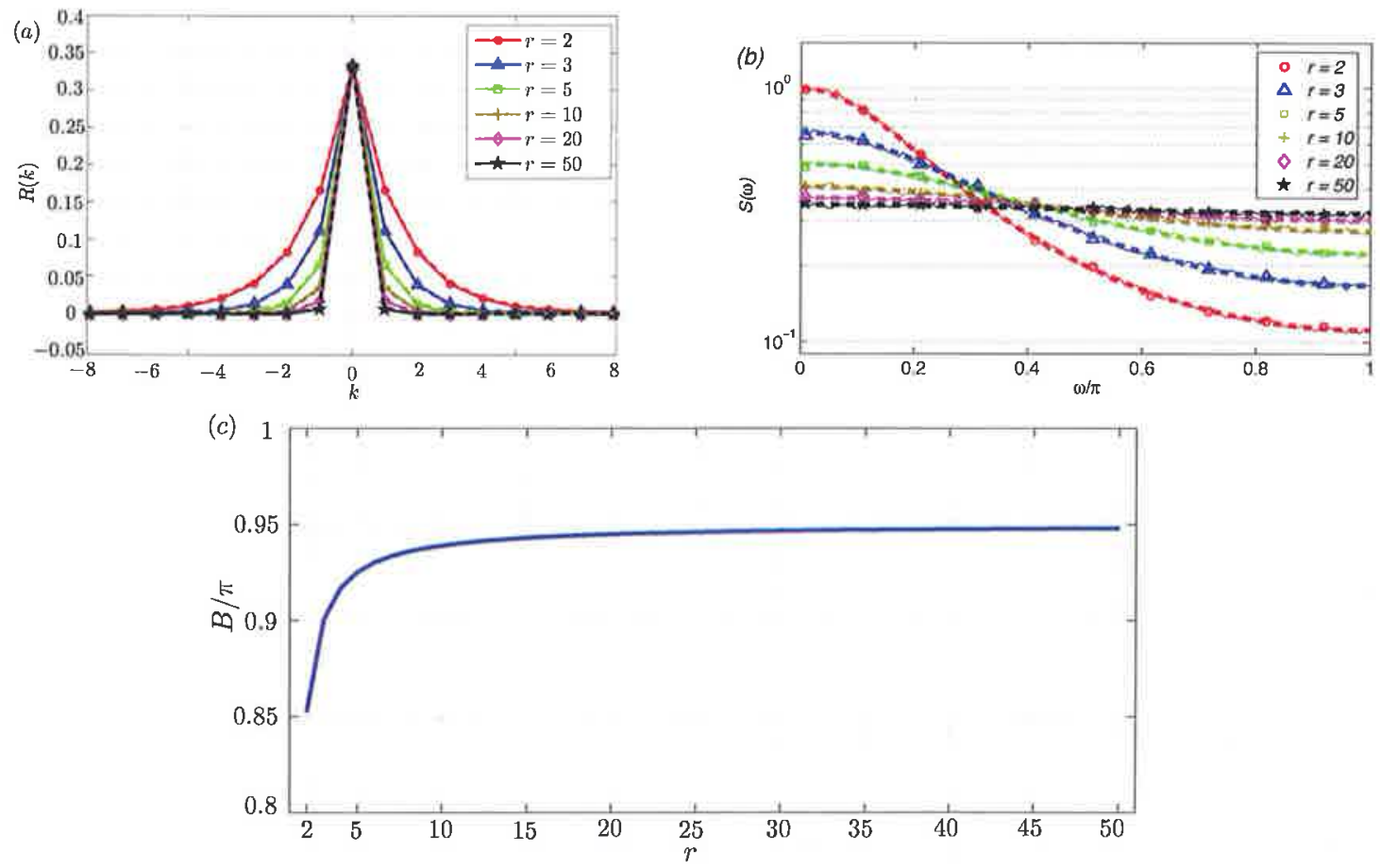

Figura 3.9: (a) SAC, (b) DEP e (c) $B$ dos sinais caóticos gerados por $f_{B}(\cdot)$ para $r$ segmentos de mesma inclinação. Os resultados analíticos são mostrados em linhas tracejadas e simulações numéricas em linhas contínuas. Fonte: [31].

Os resultados apresentados aqui a partir do mapa geral corroboram os deduzidos para esse caso particular em [57].

\subsubsection{Conclusões}

Os resultados fechados obtidos para o mapa $f_{B}(\cdot)$, expressos em $(3.48),(3.49)$ e (3.50) foram possíveis pela estrutura linear por partes desses mapas e pela sua densidade invariante 
uniforme.

Para esse mapa, diferentemente do que ocorre com $f_{I}(\cdot)$, todos os conjuntos de parâmetros levam a DEPs concentradas nas baixas frequências. Essa diferença ocorre basicamente porque todos os segmentos de $f_{B}(\cdot)$, da forma como ele foi definido, apresentam inclinação positiva.

Está em fase de finalização um trabalho em colaboração com o aluno de doutorado Rafael A. Costa em que se estuda a DEP de um mapa semelhante a $f_{B}(\cdot)$, mas que também permita inclinações negativas. Esse novo mapa é uma generalização que inclui $f_{B}(\cdot)$ e $f_{I}(\cdot)$ e os resultados deverão ser publicados em breve.

\subsection{Conclusões, pesquisas em andamento e trabalhos futuros associados}

Nesse capítulo apresentou-se resultados associados a determinação da SAC e DEP para sinais caóticos. Inspirando-se em técnica utilizada por [79], obteve-se fórmulas fechadas para a DEP das órbitas dos mapas $f_{I}(\cdot)$ e $f_{B}(\cdot)$ em função de seus parâmetros.

Esses resultados, além da relevância matemática, tem um interesse prático importante. Como discutido na introdução do capítulo, não se pode projetar um sistema de comunicação sem se conhecer a banda essencial dos sinais envolvidos. Assim, a viabilidade de qualquer SCBC passa necessariamente pela precisa definição e determinação da DEP de sinais caóticos.

Os trabalhos de pesquisa seguem nessa área, em várias frentes, resumidas a seguir.

\section{Generalizações para mapas lineares por partes mais gerais}

Desde o início das pesquisas envolvendo o mapa $f_{I}(\cdot)$, tem-se buscado caminhar no sentido de generalizar os resultados para mapas lineares por parte quaisquer. O próximo passo, que está atualmente em fase de finalização, é propor um mapa que admita $f_{I}(\cdot)$ e $f_{B}(\cdot)$ como casos particulares. Dessa forma, ele tem um número arbitrário de segmentos que se estendem por toda a imagem do mapa, com inclinações positivas ou negativas. Novamente, a densidade invariante uniforme torna o problema tratável.

O próximo passo seria passar a mapas lineares por parte gerais no intervalo $[-1,1]$. Nesse caso, a situação parece mais delicada já que as órbitas não tem necessariamente densidade invariante uniforme. $\mathrm{Na}$ verdade, podem nem ter uma densidade invariante bem definida. 
Esses estudos fazem parte da tese de doutorado de Rafael A. Costa que o autor está orientando no Programa de Pós-graduação em Engenharia Elétrica da EPUSP.

\section{Uso da representação linear de caos}

Drake e Williams [71] propuseram uma representação alternativa para sinais caóticos de tempo discreto. Ao invés de utilizar mapas não lineares, eles mostraram que é possível gerar sinais caóticos a partir de filtros lineares não causais alimentados por sequências aleatórias. Esse resultado surpreendente pode ser útil na determinação da DEP desses sinais. Conhecendo-se o sistema linear equivalente a um dado mapa, é possível utilizar a resposta em frequência do filtro e a DEP da sequência aleatória de entrada juntamente com a teoria de sistemas lineares [88, Cap. 8] para se obter a DEP do sinal caótico gerado.

Essa abordagem, que parece inédita, pode gerar resultados interessantes. Por exemplo, utilizando os filtros propostos em [71], já obteve-se uma expressão para a DEP do mapa $f_{B}(\cdot) \operatorname{com} r$ segmentos de inclinações iguais, equivalente a (3.57). A exploração das possibilidades envolvidas está apenas no início e também devem fazer parte do doutoramento de Rafael A. Costa.

\section{Mapas com outras não linearidades e multidimensionais}

Uma vez que se tenha conseguido obter expressões fechadas para famílias de mapas lineares unidimensionais, o próximo alvo são os mapas com não linearidades mais gerais e mapas multidimensionais.

O autor em conjunto com seus orientados e colegas explorou numericamente alguns casos, como o mapa de Maneville [51], o mapa quadrático [63] e o mapa de Hénon [89].

Uma possibilidade que está em estudo para se obter resultados analíticos é usar aproximações lineares por trechos para mapas gerais. Em particular, algumas experiências numéricas iniciais com mapas quadráticos mostraram que essas aproximações, no limite, mantém propriedades temporais e espectrais das órbitas geradas [63].

\section{Aplicações}

Uma vez bem definida e determinada a DEP de sinais caóticos, pode-se passar ao problema de determinar analiticamente a banda ocupada pelos sinais transmitidos por diversos SCBCs. Em sistemas que transmitem trechos de sinais caóticos associados a cada símbolo, como a comutação caótica (CSK - Chaos-Shift Keying) e a CSK diferencial (DCSK -Differential CSK) [90], sabendo-se a DEP do GSC, pode-se utilizar a teoria de comunicações para obter a banda do sinal transmitido, como se faz usualmente em 
sistemas de comunicação digital convencionais [81, Cap. 7].

Além disso, pode-se pensar o problema no outro sentido: dado uma banda essencial que o sistema deverá ocupar, projetar os mapas a serem utilizados de forma a se garantir que a DEP dos sinais transmitidos não ultrapassem essa banda.

São problemas ainda em estudo e que, como já escrito, fundamentais quando se pensa em possíveis implementações práticas de SCBCs.

Uma outra possibilidade de aplicação prática da obtenção da DEP de sinais caóticos é utilizar sua medida na estimação de uma grandeza associada com o mapa ou com o modelo que ele representa. Por exemplo, em [51] usa-se a banda essencial para estimar o intervalo entre intermitências e o parâmetro do mapa de Mannevile [91].

Espera-se que todas essas possibilidades gerem resultados relevantes nos próximos anos. 


\section{Capítulo 4}

\section{Um sistema de comunicação baseado no sincronismo caótico}

O autor iniciou seus estudos sobre sincronismo de GSCs ainda no mestrado, em 1998. Nessa fase, estudou sobretudo sistemas de tempo contínuo, motivado pelo trabalho seminal de Pecora e Carroll [2] e suas promessas de interessantes aplicações em Telecomunicações. Estudou detalhadamente as técnicas de sincronização propostas em [2] e também as ideias de Wu e Chua [92]. Com o objetivo sempre de verificar a viabilidade de SCBCs que utilizam o sincronismo caótico em canais práticos, estudou a robustez do sincronismo em relação a ruído aditivo e limitação de banda pelo canal de comunicação. Os principais resultados dessa fase estão resumidos em [93].

Após dedicar-se a SCBCs que não utilizam o sincronismo na recuperação da informação durante o doutorado, retomou o assunto do sincronismo caótico em 2009, dedicando-se a versões em tempo discreto dos sistemas estudados no mestrado. A partir do sistema de Wu e Chua [92], propôs sua versão em tempo discreto no artigo [23] que representaria um equivalente passa-baixas de tempo discreto [18] do sistema de comunicação.

A partir daí, começa a analisar formas de adaptar esse SCBCs de tempo discreto para canais práticos, tendo em mente principalmente os seguintes pontos:

1. Desempenho em canal com ruído branco gaussiano aditivo (AWGN - Additive White Gaussian Noise) e a influência dos mapas e funções de codificação nesse desempenho. Nesse contexto orientou a dissertação de mestrado de Greta A. Abib [62] e relatou os principais resultados em $[35,43,46,54,55,94-96]$.

2. Formatação do espectro do sinal transmitido para que esse possa ser enviado em canal limitado em banda. Nesse cotexto orientou a tese de doutorado de Rodrigo T. Fontes, que será defendida no primeiro semestre de 2017. Os principais resultados 
foram publicados em $[23,30,34,45,52,59,97-100]$.

3. Desempenho em canais dispersivos e equalização. Nesse contexto coorientou a tese de doutorado de Renato Candido [64] juntamente com o Prof. Magno T. M. Silva, especialista na área de equalização. Os principais resultados foram publicados em $[28,29,37,44,53,56,101]$.

Nesse capítulo resumem-se os principais resultados associados com essas pesquisas. $\mathrm{Na}$ Seção 4.1 descreve-se o método de sincronização e o SCBC estudado. Resultados associados ao desempenho desse sistema em canal AWGN são relatados na Seção 4.2. O problema da formatação do sinal transmitido para canais de banda limitada é tratada na Seção 4.3. A questão da equalização em canais dispersivos é abordada na Seção 4.4 e, por fim, discutem-se conclusões e possíveis trabalhos futuros na Seção 4.5.

\subsection{Sincronismo mestre-escravo em tempo discreto e o SCBC estudado}

Nesta seção descreve-se a adaptação para tempo discreto do SCBC proposto em [92] e que serve de base para os estudos desse capítulo. Esse SCBC foi apresentado originalmente em [23].

Considere dois sistemas de tempo discretos que podem ser escritos como

$$
\begin{aligned}
& \boldsymbol{x}(n+1)=\boldsymbol{A} \boldsymbol{x}(n)+\boldsymbol{b}+\boldsymbol{f}(\boldsymbol{x}(n)) \\
& \boldsymbol{y}(n+1)=\boldsymbol{A} \boldsymbol{y}(n)+\boldsymbol{b}+\boldsymbol{f}(\boldsymbol{x}(n))
\end{aligned}
$$

A matriz quadrada $\boldsymbol{A}_{M \times M}$ e o vetor coluna $\boldsymbol{b}_{M \times 1}$ são constantes.

O sistema descrito por (4.1) é autônomo e, portanto, chamado de mestre; o sistema descrito por (4.2) depende de $\boldsymbol{x}(n)$ e é chamado de escravo.

O erro de sincronização é definido por

$$
\boldsymbol{e}(n) \triangleq \boldsymbol{y}(n)-\boldsymbol{x}(n)
$$

Subtraindo-se (4.2) de (4.1), obtém-se

$$
\boldsymbol{e}(n+1)=\boldsymbol{A e}(n)
$$

Os sistemas estão completamente sincronizados [102] se $\boldsymbol{e}(n) \rightarrow \mathbf{0}$ quando $n$ cresce. 
De (4.4), uma condição necessária e suficiente para que isso ocorra é [103]

$$
\left|\lambda_{m}\right|<1,1 \leq m \leq M
$$

em que $\lambda_{m}$ são os autovalores de $\boldsymbol{A}$. Dado que os autovalores da matriz $\boldsymbol{A}$ determinam se os sistemas (4.1) e (4.2) sincronizam, $\boldsymbol{A}$ é chamada de matriz de sincronismo.

Esse esquema de sincronização pode ser facilmente adaptado para transmissão unidirecional de uma mensagem $m(n)$, tomando-se o mestre como sistema transmissor e o escravo como receptor. Para tanto, considera-se que $\boldsymbol{f}(\cdot)$ depende apenas da componente $x_{1}$ de $\boldsymbol{x}$ e pode ser escrita como

$$
\boldsymbol{f}(\boldsymbol{x}(n))=\left[\begin{array}{llll}
f\left(x_{1}(n)\right) & 0 & \ldots & 0
\end{array}\right]^{T}
$$

O sinal transmitido $s(n)$ é gerado misturando-se a mensagem $m(n)$ com $x_{1}(n)$ por meio de uma função de codificação invertível $c(\cdot)$; isto é

$$
s(n)=c\left(x_{1}(n), m(n)\right)
$$

Além de ser transmitido, $s(n)$ também é realimentado no GSC como argumento de $f(\cdot)$.

Seja $r(n)$ o sinal que chega ao receptor que, em geral, difere de $s(n)$. Nesse SCBC, os dois nós são então dados por

$$
\begin{aligned}
& \boldsymbol{x}(n+1)=\boldsymbol{A} \boldsymbol{x}(n)+\boldsymbol{b}+\boldsymbol{f}(s(n)) \\
& \boldsymbol{y}(n+1)=\boldsymbol{A} \boldsymbol{y}(n)+\boldsymbol{b}+\boldsymbol{f}(r(n)) .
\end{aligned}
$$

As únicas diferenças entre (4.1)-(4.2) e (4.8)-(4.9) são os argumentos de $\boldsymbol{f}(\cdot)$.

Para um canal ideal, isto é, $s(n)=r(n),(4.8)$-(4.9) tornam-se

$$
\begin{aligned}
& \boldsymbol{x}(n+1)=\boldsymbol{A} \boldsymbol{x}(n)+\boldsymbol{b}+\boldsymbol{f}(s(n)) \\
& \boldsymbol{y}(n+1)=\boldsymbol{A} \boldsymbol{y}(n)+\boldsymbol{b}+\boldsymbol{f}(s(n)) .
\end{aligned}
$$

Assim, a dinâmica do erro é ainda governada por (4.4). Dessa forma, se a condição (4.5) é válida, $\boldsymbol{y}(n) \rightarrow \boldsymbol{x}(n)$ e, em particular, $y_{1}(n) \rightarrow x_{1}(n)$.

No receptor, estima-se a mensagem enviada como

$$
\widehat{m}(n)=d\left(y_{1}(n), r(n)\right)
$$

em que $d(\cdot, \cdot)=c^{-1}(\cdot, \cdot)$, é a inversa de $c(\cdot, \cdot)$ com relação à primeira variável. Assim, de 
$(4.12)$

$$
\widehat{m}(n)=d\left(y_{1}(n), r(n)\right) \rightarrow d\left(x_{1}(n), s(n)\right)=m(n) .
$$

Portanto, quando os valores dos parâmetros de mestre e escravo estão perfeitamente casados e o canal é ideal, a mensagem é recuperada sem degradação no escravo, exceto durante um transitório necessário para a sincronização.

O diagrama do SCBC de tempo discreto descrito é mostrado na Figura 4.1. O operador $z^{-1}$ é o atraso unitário, ou seja, $z^{-1} \boldsymbol{x}(n) \triangleq \boldsymbol{x}(n-1)$.

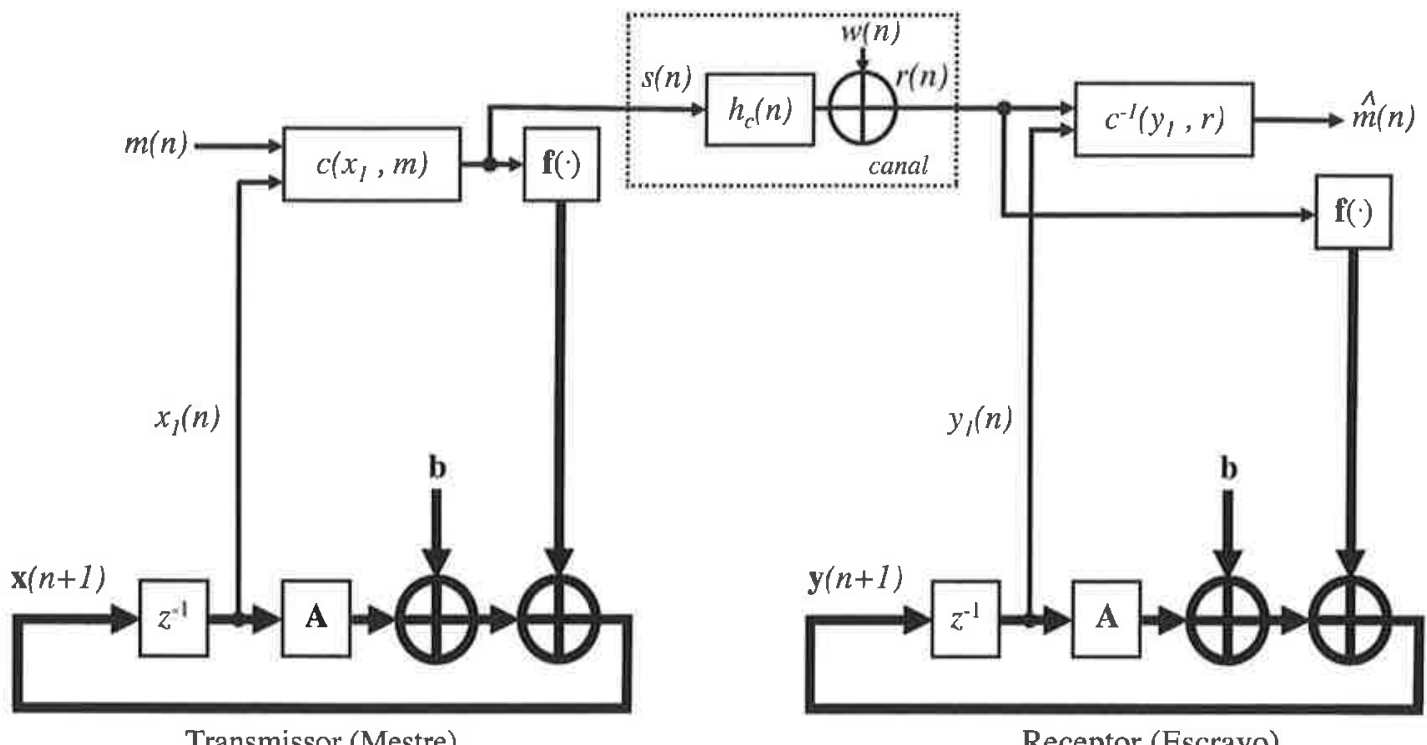

Transmissor (Mestre)

Receptor (Escravo)

Figura 4.1: SCBC de tempo discreto (4.8)-(4.9). Fonte: [23].

Vale ressaltar que, com a inclusão da mensagem, não se tem nenhuma garantia sobre a natureza dos sinais transmitidos. Em outras palavras, a inclusão da mensagem pode fazer com que o sinal transmitido deixe de ser caótico, tornando-se periódico ou mesmo divergir. Essa situação é mostrada em [29] para o mapa $f_{I k}(\cdot)$. Garante-se apenas que os sistemas mestre e escravo sincronizam e, portanto, a mensagem é recuperada em um canal ideal após um transitório.

Exemplo 4.1 (SCBC com o mapa $\left.f_{H}(\cdot)\right)$. Um GSC que pode ser escrito na forma (4.1) com $\boldsymbol{f}(\cdot)$ no formato (4.6) é o mapa $f_{H}(\cdot)(2.20)$. Nesse caso, $M=2 \mathrm{e}$

$$
\boldsymbol{A}=\left[\begin{array}{ll}
0 & 1 \\
b & 0
\end{array}\right], \boldsymbol{b}=\left[\begin{array}{l}
1 \\
0
\end{array}\right] \text { e } \boldsymbol{f}(\boldsymbol{x}(n))=\left[\begin{array}{c}
-a x_{1}^{2}(n) \\
0
\end{array}\right]
$$

Como os autovalores da matriz $\boldsymbol{A}$, são $\lambda_{1}=-\lambda_{2}=\sqrt{b},(4.1)$ e (4.2) sincronizam para $|b|<1$. 
Como função de codificação considera-se

$$
c\left(x_{1}(n), m(n)\right)=x_{1}(n)+0,001 m(n),
$$

toma-se $m(n)$ uma sequência aleatória equiprovável de $\pm 1 \mathrm{~s}, a=1,4$ e $b=0,3$. Nesse caso, como sabe-se que a mensagem é binária, utiliza-se um limiar de decisão no receptor de modo que

$$
\widehat{m}(n)=\operatorname{sign}\left(d\left(y_{1}(n), r(n)\right)\right),
$$

sendo $\operatorname{sign}(\cdot)$ a função que retorna 1 se o argumento é positivo ou -1 se o argumento é negativo.

Na Figura 4.2 mostram-se exemplos dos sinais do SCBC da Figura 4.1 para essas escolhas e para a condição de canal ideal, ou seja, $r(n)=s(n)$.
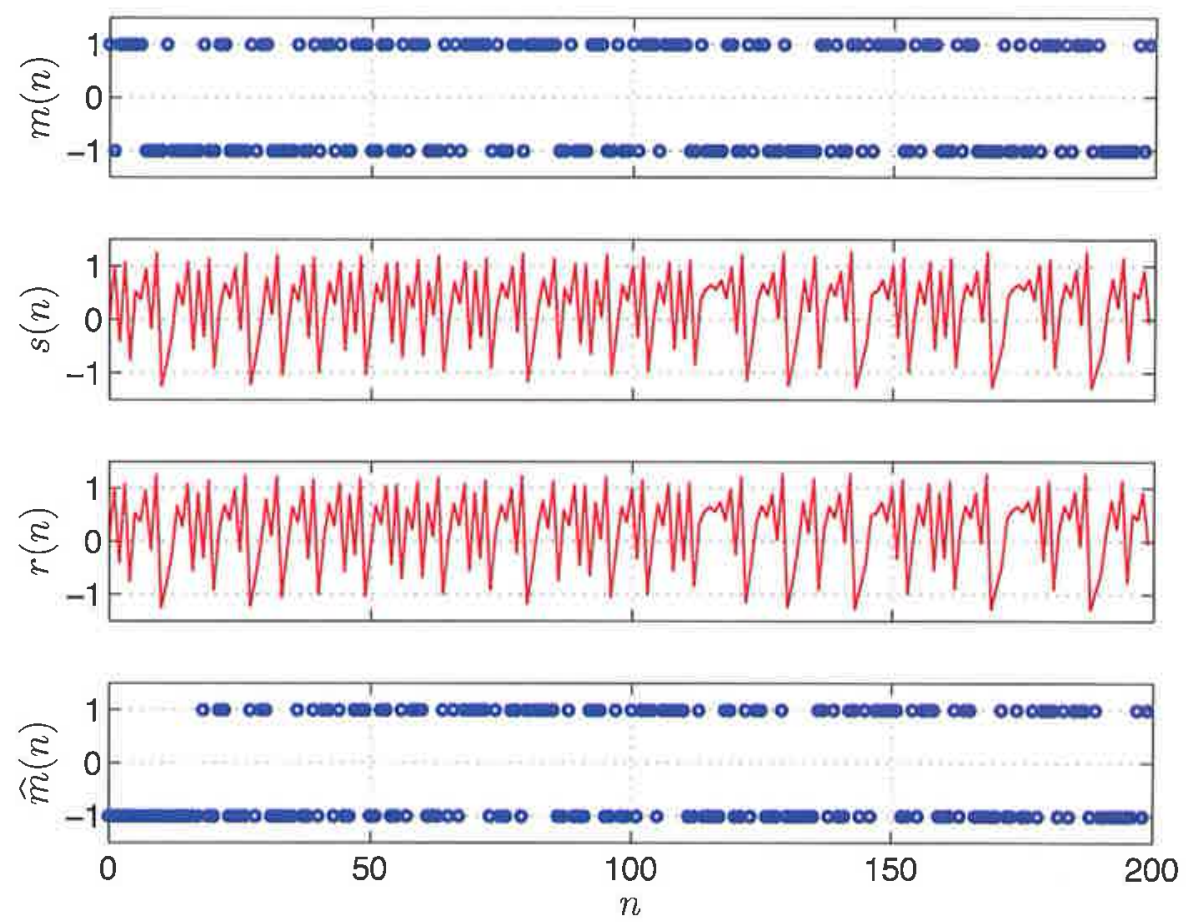

Figura 4.2: Exemplos de sinais do SCBC da Figura 4.1 para a condição de canal ideal: (a) $m(n)$, (b) $s(n),($ c) $r(n)$, (d) $\widehat{m}(n)$. A mensagem é recuperada no receptor, após um transitório. Fonte: [52].

Nota-se claramente que a mensagem $m(n)$ é recuperada no receptor após um transitório, como o esperado.

Quando o canal é não ideal, ou seja, $r(n) \neq s(n)$, a dinâmica do erro torna-se mais complicada e, em geral, não se garante que $\widehat{m}(n) \rightarrow m(n)$.

Como mostrado na Figura 4.1, modela-se o canal de comunicação como sendo um sistema linear com resposta ao impulso $h_{C}(n)$ causal e resposta em frequência $H_{C}(\omega)$. 
Além disso, considera-se que um AWGN $w(n)$ corrompe o sinal na entrada do receptor. Assim,

$$
r(n)=s(n) * h_{C}(n)+w(n),
$$

sendo “*” o símbolo da operação de soma de convolução [84].

Nas seções seguintes estuda-se o comportamento do SCBC da. Figura 4.1 em condições não ideais, procurando-se formas de tornar seu desempenho ainda aceitável. Começa-se considerando um canal AWGN, ou seja, com $H_{C}(\omega)=1$, na Seção 4.2. Depois considerase o caso de um canal ideal, mas de banda limitada, na Seção 4.3. Por fim, considera-se canais dispersivos e equalização na Seção 4.4.

\subsection{Desempenho em AWGN}

Junto com a aluna de mestrado Greta A. Abib [62] e outros colaboradores, o autor estudou o comportamento do SCBC da Figura 4.1 em canal AWGN. Ou seja, toma-se

$$
h_{c}(n)= \begin{cases}1, & n=0 \\ 0, & n \neq 0\end{cases}
$$

de modo que (4.17) torna-se

$$
r(n)=s(n)+w(n) .
$$

Os principais resultados dessa seção foram publicados em $[35,43,54,55,94-96]$.

\subsubsection{Parâmetros das simulações}

$\mathrm{Na}$ análise numérica relatada aqui, considera-se como funções de codificação e decodificação (4.7) e (4.12), o par

$$
\left\{\begin{array}{l}
s(n)=c\left(x_{1}(n), m(n)\right)=(1-\gamma) x_{1}(n)+\gamma m(n) \\
\widehat{m}(n)=d\left(y_{1}(n), r(n)\right)=\frac{r(n)-(1-\gamma) y_{1}(n)}{\gamma}
\end{array},\right.
$$

em que $0<\gamma \leq 1$ é uma constante. Essa escolha é um refinamento da mistura (4.15) usualmente utilizada em trabalhos anteriores, em que se considera o sinal transmitido como uma soma de uma das variáveis de estado do transmissor com uma versão atenuada da mensagem $[23,104,105]$. O parâmetro $\gamma$ permite controlar as intensidades relativas da mensagem e do sinal caótico no sinal transmitido.

Como mensagem, toma-se o sinal digital binário $m(n)= \pm 1$ para cada $n$ de forma 
equiprovável. Esse sinal pode ser interpretado como o equivalente passa-baixas de tempo discreto de um código de linha polar [81]. Como sabe-se que a mensagem enviada é binária, adiciona-se um limiar na estimação da mensagem transmitida, como feito em (4.16), de modo que

$$
\widehat{m}(n)=\operatorname{sign}\left(r(n)-(1-\gamma) y_{1}(n)\right)
$$

Para efeito de comparação com sistemas convencionais, considera-se também a transmissão direta do sinal $m(n)$ através do canal, i.e. $s(n)=m(n)$. Esse caso é chamado aqui de sem caos. Definindo-se a relação sinal-ruído (SNR - Signal to Noise Ratio) como a potência média do sinal transmitido pela potência de $w(n), \sigma_{w}^{2}$, pode-se mostrar [81, p. 649] que, quando se utiliza o receptor ótimo, a BER é dada por

$$
\mathrm{BER}_{\mathrm{sc}}=Q(\sqrt{\mathrm{SNR}})
$$

em que

$$
Q(y)=\frac{1}{\sqrt{2 \pi}} \int_{y}^{\infty} e^{-x^{2} / 2} d x .
$$

É usual representar a SNR em decibels $(\mathrm{dB})$,

$$
\operatorname{SNR}(\mathrm{dB})=10 \log (\mathrm{SNR})
$$

\section{GSCs avaliados}

Escolheram-se mapas bem conhecidos na literatura e de diferentes dimensões, de forma a se testar a influência desta escolha no desempenho em termos de BER. Os mapas utilizados devem satisfazer os seguintes pré-requisitos:

1. devem gerar sinais caóticos. Os mapas escolhidos satisfazem essa condição, como mostram os expoentes de Lyapunov calculados na Seção 2.4;

2. deve ser possível reescrevê-los como (4.1) com $\boldsymbol{f}(\cdot)$ na forma (4.6);

3. devem levar ao sincronismo mestre-escravo entre (4.1) e (4.2). Para isso, os autovalores da matriz de sincronismo devem satisfazer (4.5).

Dessa forma, considerou-se os seguintes mapas:

A. Mapa tenda inclinada $f_{I}(\cdot)$

Descrito na Seção 2.4.2, o mapa $f_{I}(\cdot)$ pode ser escritos na forma (4.1) com $M=1$, $\boldsymbol{A}=[0], \boldsymbol{b}=[0]$ e $\boldsymbol{f}(\boldsymbol{x}(n))=\left[f_{I}\left(x_{1}(n)\right)\right]$. Assim, $\lambda_{1}=0$ e a condição (4.5) é 
satisfeita. Portanto, um sistema mestre-escravo formado usando este mapa atinge o sincronismo. Para as simulações apresentadas foi considerado o parâmetro $\alpha=0,1$.

B. Mapa quadrático $f_{Q}(\cdot)$

Descrito na Seção 2.4.4, esse mapa pode ser colocado na forma (4.1) com $M=1$, $\boldsymbol{A}=[0], \boldsymbol{b}=[1]$ e $\boldsymbol{f}(\boldsymbol{x}(n))=\left[-2 x_{1}^{2}(n)\right]$. Para esse sistema, o autovalor da matriz $\boldsymbol{A}$ é novamente $\lambda_{1}=0$ e, assim, a condição (4.5) é satisfeita. Portanto, um sistema mestre-escravo formado usando esse mapa, atinge o sincronismo.

Cabe observar que, de fato, qualquer mapa unidimensional na forma (2.4), pode ser utilizado no esquema proposto com $M=1, \boldsymbol{A}=[0]$ e $\lambda_{1}=0$. Para esses mapas, o sincronismo é trivial já que a única variável de estado é transmitida e, portanto, diretamente recuperada no escravo.

C. Mapa de Hénon $\boldsymbol{f}_{H}(\cdot)$

Descrito na Seção 2.4.5, mostrou-se no Exemplo 4.1, página 56, que ele pode ser utilizado no sincronismo mestre-escravo estudado para $|b|<1$. Em particular, para as simulações dessa seção, utiliza-se os parâmetros $a=1,4$ e $b=0,3$.

D. Mapa de Hénon tridimensional $\boldsymbol{f}_{H 3}(\cdot)$

O mapa de Hénon tridimensional $\boldsymbol{f}_{H 3}(\cdot)$, descrito na Seção 2.4 .7 foi utilizado no artigo [23] em que se propôs o SCBC da Seção 4.1 e também no artigo [26] sobre sincronismo baseado em mapas acoplados em rede.

Ele pode ser escrito na forma (4.1) $\operatorname{com} M=3$,

$$
\boldsymbol{A}=\left[\begin{array}{ccc}
0 & 0 & 1 \\
-b & 0 & 0 \\
b & 1 & 0
\end{array}\right]
$$

$\boldsymbol{b}=\left[\begin{array}{lll}1 & 0 & 0\end{array}\right]^{T}$ e $\boldsymbol{f}(\boldsymbol{x}(n))=b=\left[\begin{array}{lll}-a x_{1}^{2}(n) & 0 & 0\end{array}\right]^{T}$. Para as simulações foram utilizados os valores $a=1,07$ e $b=0,3[23,26]$. Com esses valores de parâmetros, os autovalores de $\boldsymbol{A}$ são $\lambda_{1,2}=0,4084 \pm j 0,4477$ e $\lambda_{3}=-0,8169$. Como $\left|\lambda_{m}\right|<1, m=1,2,3$, (4.5) é satisfeita.

Nos gráficos (b) a (e) da Figura 4.3 são mostrados exemplos de trechos de sinais transmitidos $s(n)$ para os mapas testados. Em cada caso, a mensagem $m(n)$ é a mesma sequência mostrada no gráfico (a). 

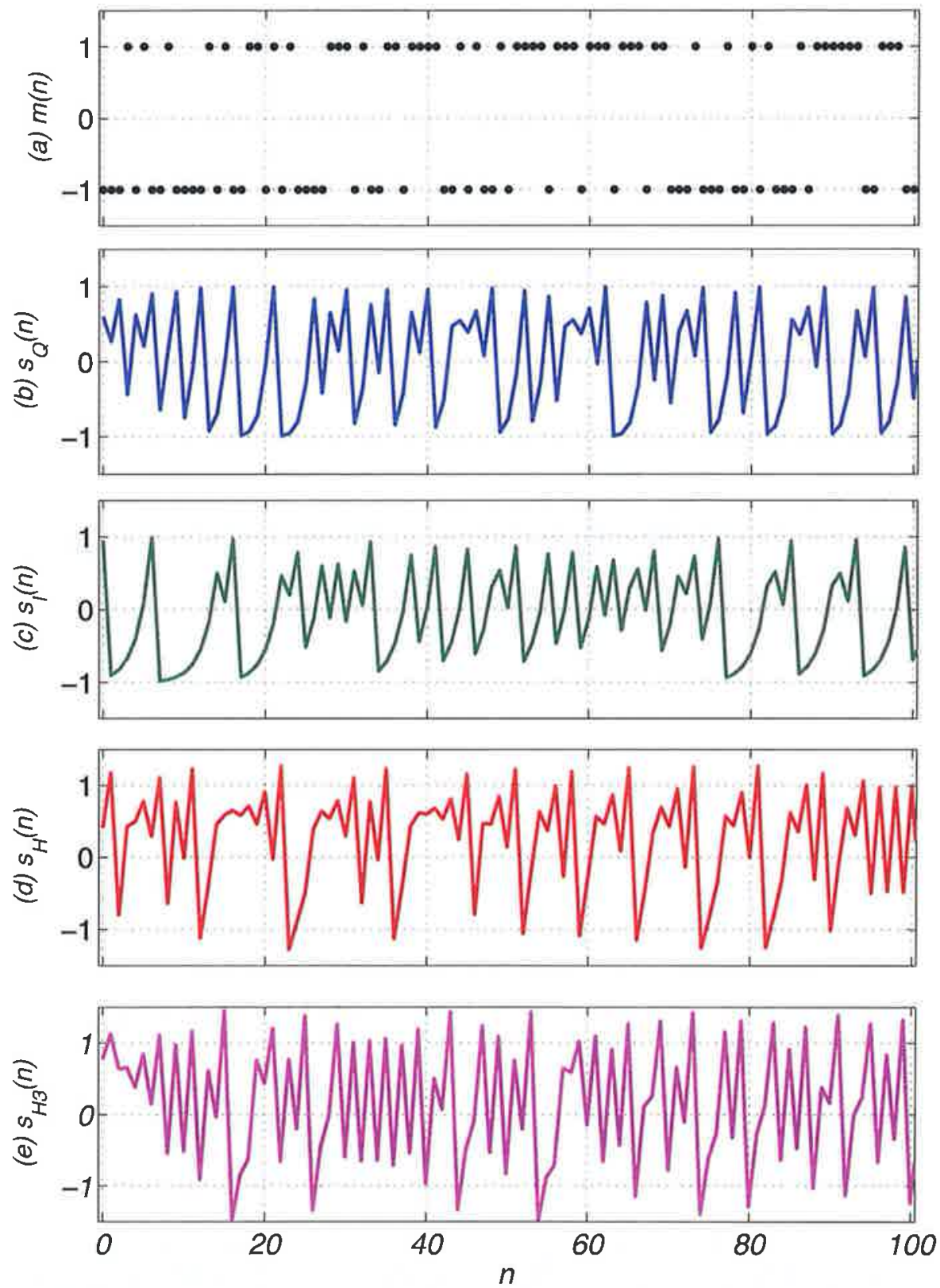

Figura 4.3: Sinais no transmissor do sistema da Figura 4.1 utilizando-se a função de codificação (4.20) com $\gamma=0,4$. Em todos os casos, considerou-se condições iniciais $x_{0}$ nulas: (a) mensagem $m(n)$ e sinais $s(n)$ transmitidos usando (b) $f_{Q}(\cdot),\left(\right.$ c) $f_{I}(\cdot),\left(\right.$ d) $\boldsymbol{f}_{H}(\cdot)$ e (e) $\boldsymbol{f}_{H 3}(\cdot)$. Fonte: [46].

\subsubsection{Resultados de simulações}

Utilizando-se o sistema de comunicação com os mapas e as funções de codificação e decodificação descritos na. Seção 4.2.1, foram realizadas diversas simulações apresentadas resumidamente aqui.

Para exemplificar a influência do parâmetro $\gamma$ na "segurança" do sinal transmitido, 
mostra-se na Figura 4.4 uma mesma mensagem codificada utilizando $f_{Q}(\cdot)$ para diferentes valores do parâmetro de codificação $\gamma$. É possível notar que, para os valores de $\gamma$ próximos de 1 , o sinal codificado é similar à mensagem enviada. Para valores de $\gamma$ próximos de 0 existe uma influência maior da componente caótica e o sinal codificado distancia-se da mensagem.
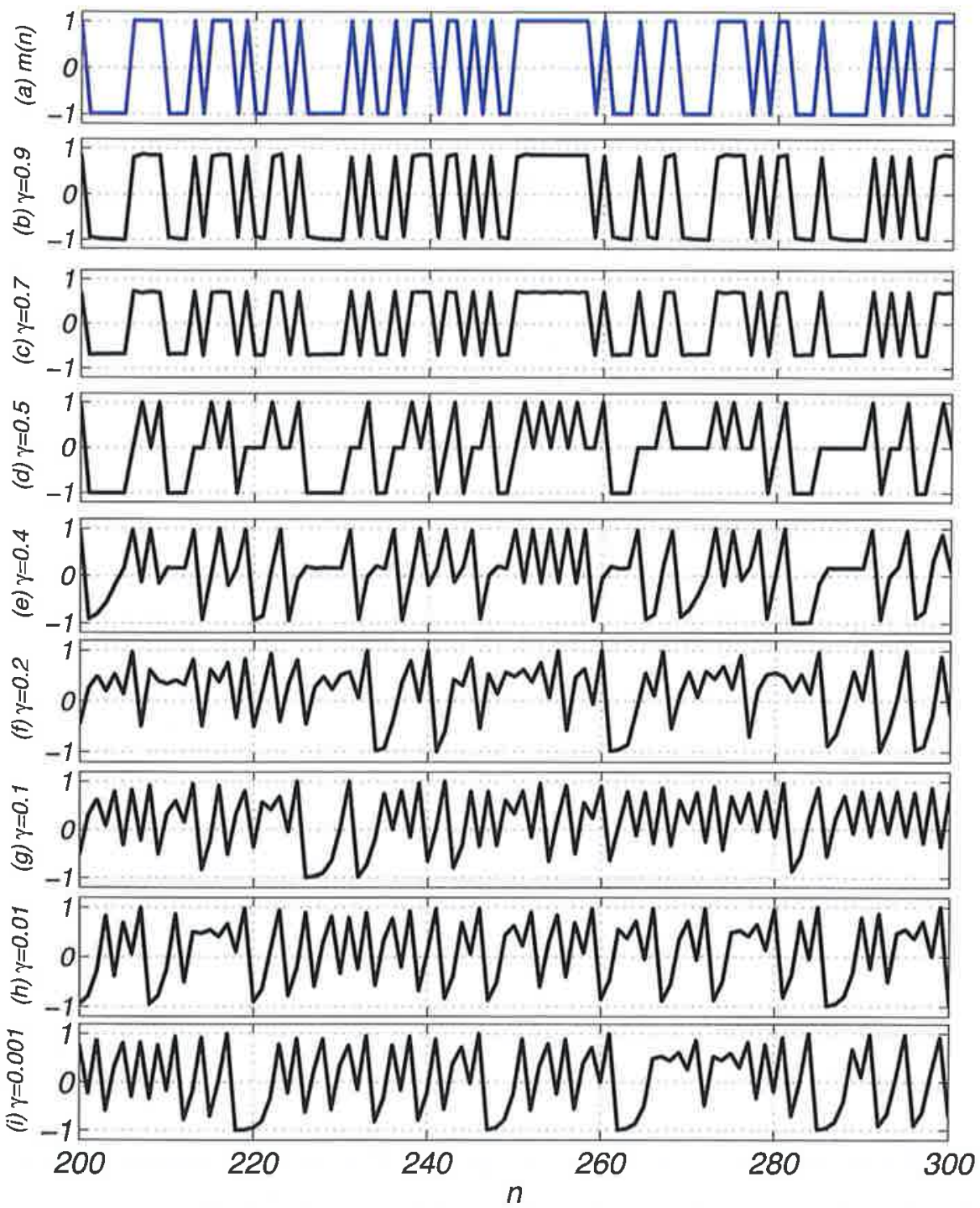

Figura 4.4: Sinais $s(n)$ gerados utilizando-se $f_{Q}(\cdot)$ e diversos valores de $\gamma$ em (4.20): (a) mensagem $m(n)$; sinais $s(n)$ com (b) $\gamma=0,9$, (c) $\gamma=0,7$, (d) $\gamma=0,5$, (e) $\gamma=0,4$, (f) $\gamma=0,2$, (g) $\gamma=0,1$, (h) $\gamma=0,01$ e (i) $\gamma=0,001$. Fonte: [46].

Já na Figura 4.5 são mostradas as curvas de BER em função da SNR no canal para o GSC $f_{Q}(\cdot)$ e diversos valores de $\gamma$. Para cada valor de SNR simulou-se a transmissão de $10^{8}$ bits. Para eliminar o efeito de transitório, os primeiros 200 bits foram descartados.

Analisando-se essa figura, é possível notar como os valores de $\gamma$ influenciam na robustez do sincronismo caótico em relação ao ruído no canal. Quando $\gamma$ assume valores 


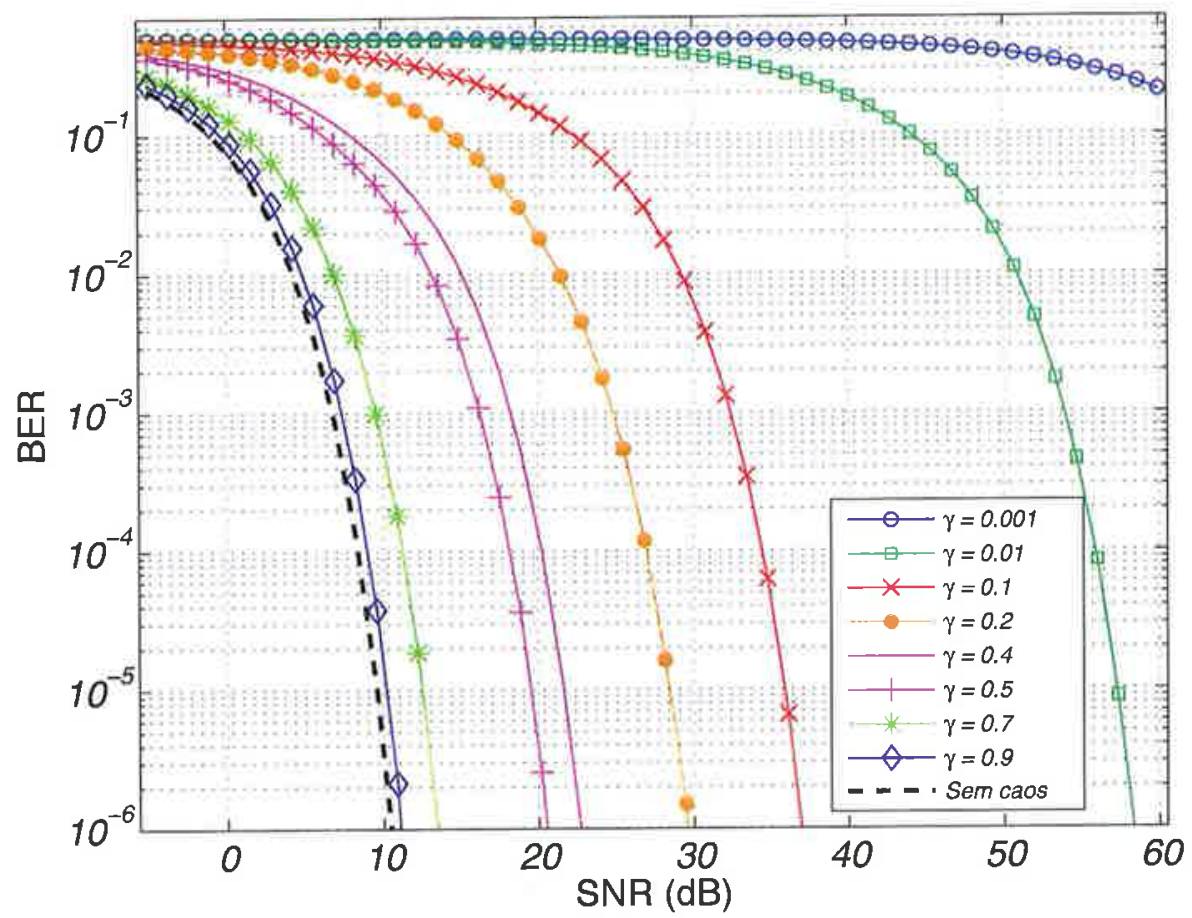

Figura 4.5: BER em função da SNR para o SCBC da Figura 4.1 usando $f_{Q}(\cdot)$ e os valores de $\gamma$ da Figura 4.4.

próximos de 0, a BER só atinge valores razoáveis em canais praticamente ideais. Em contrapartida, para $\gamma$ próximo de 1, obtém-se melhores resultados em termos de BER, próximos do caso ótimo sem caos.

Assim, das Figuras 4.4 e 4.5, observa-se que o valor de $\gamma$ representa um compromisso entre o quanto o sinal transmitido é parecido com a mensagem e a BER. O valor ideal de $\gamma$ é o mais próximo da unidade possível, para se obter menor BER, mas de forma que a mensagem não fique evidente no sinal transmitido $s(n)$.

Como forma inicial de mensurar o quão aparente está a mensagem $m(n)$ em $s(n)$, utiliza-se como parâmetro a BER que é obtida aplicando-se um limiar de decisão diretamente sobre o sinal que sai do transmissor $s(n)$, sem decodificação. Se $s(n) \approx m(n)$, como nos primeiros gráficos da Figura 4.4, espera-se uma. BER próxima de zero e pode-se concluir que a mensagem é completamente aparente em $s(n)$, i.e., não há qualquer tipo de "segurança" embutida. Porém, se $m(n)$ não é aparente em $s(n)$, como nos últimos gráficos da Figura 4.4, espera-se uma BER próxima de 0,5.

Na Figura 4.6 mostram-se os valores de BER obtidos dessa forma, em função de $\gamma$, para os diversos mapas testados aqui. Para a realização dessa simulação foram utilizados $10^{6}$ bits para cada valor de $\gamma$, condições iniciais aleatórias e os primeiros 200 bits foram descartados. Note-se que para o mapa $f_{H 3}(\cdot)$, para $0<\gamma \leq 0,01$ e $0,05<\gamma<0,35$, os sinais gerados divergem, o que inviabiliza a escolha desses intervalos de $\gamma$ para esse mapa 
em particular.

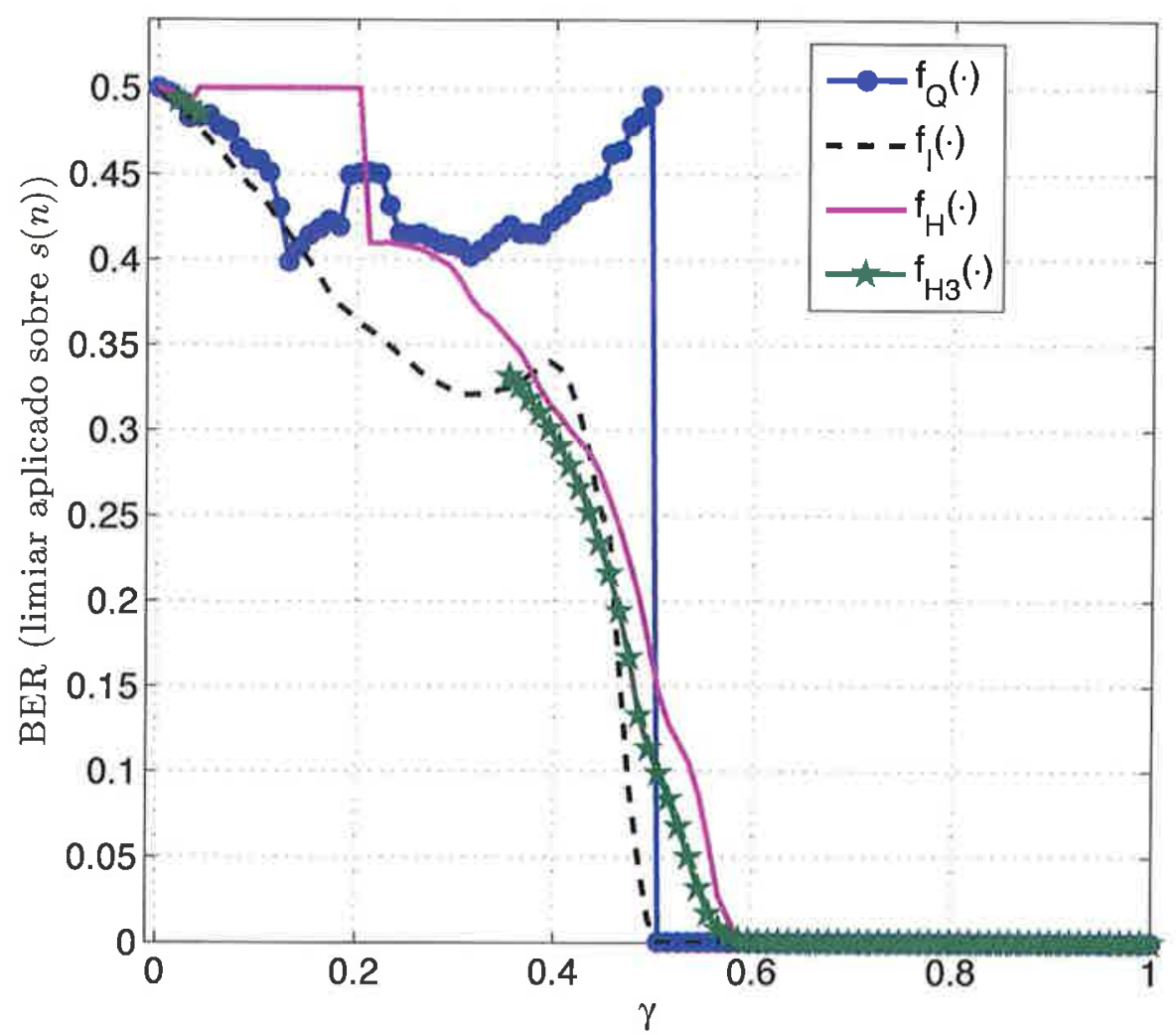

Figura 4.6: BER obtida com limiar aplicado diretamente a $s(n)$ em função de $\gamma$. Os sinais gerados pelo mapa $\boldsymbol{f}_{H 3}(\cdot)$ divergem para alguns valores de $\gamma$. Nesses pontos a curva não é mostrada.

Da Figura 4.6, $\gamma=0,4$, é um valor interessante a ser considerado, já que a BER obtida apenas com um limiar sobre $s(n)$ é superior a $30 \%$ para todos os mapas considerados. Assim, tem-se $m(n)$ suficientemente "escondida" e ainda assim, desempenho em canal AWGN razoável, como mostrado na Figura 4.5. É interessante notar que trabalhos anteriores que tratam de SCBCs similares, por exemplo $[23,104,105]$, tendem a considerar valores menores para $\gamma$. Isso justifica-se pelo fato de que, em geral, há preocupação apenas com a "segurança" do sistema, sem se levar em conta a robustez do SCBC em relação ao ruído no canal.

Na. Figura 4.7 são mostradas as curvas de BER para os diferentes mapas considerados para $\gamma=0,4$. Para essa simulação foram utilizados $10^{8}$ bits para cada valor de SNR, desprezou-se um transitório de 200 amostras e foram utilizadas condições iniciais aleatórias.

Por essa figura, nota-se que, para $\gamma=0,4$, o uso do mapa $f_{I}(\cdot)$ resulta em valores de BER inferior ao dos demais mapas para SNR elevada. Usando a função de codificação com um valor adequado de $\gamma$, as curvas ficam bem mais próximas do resultado ótimo sem 


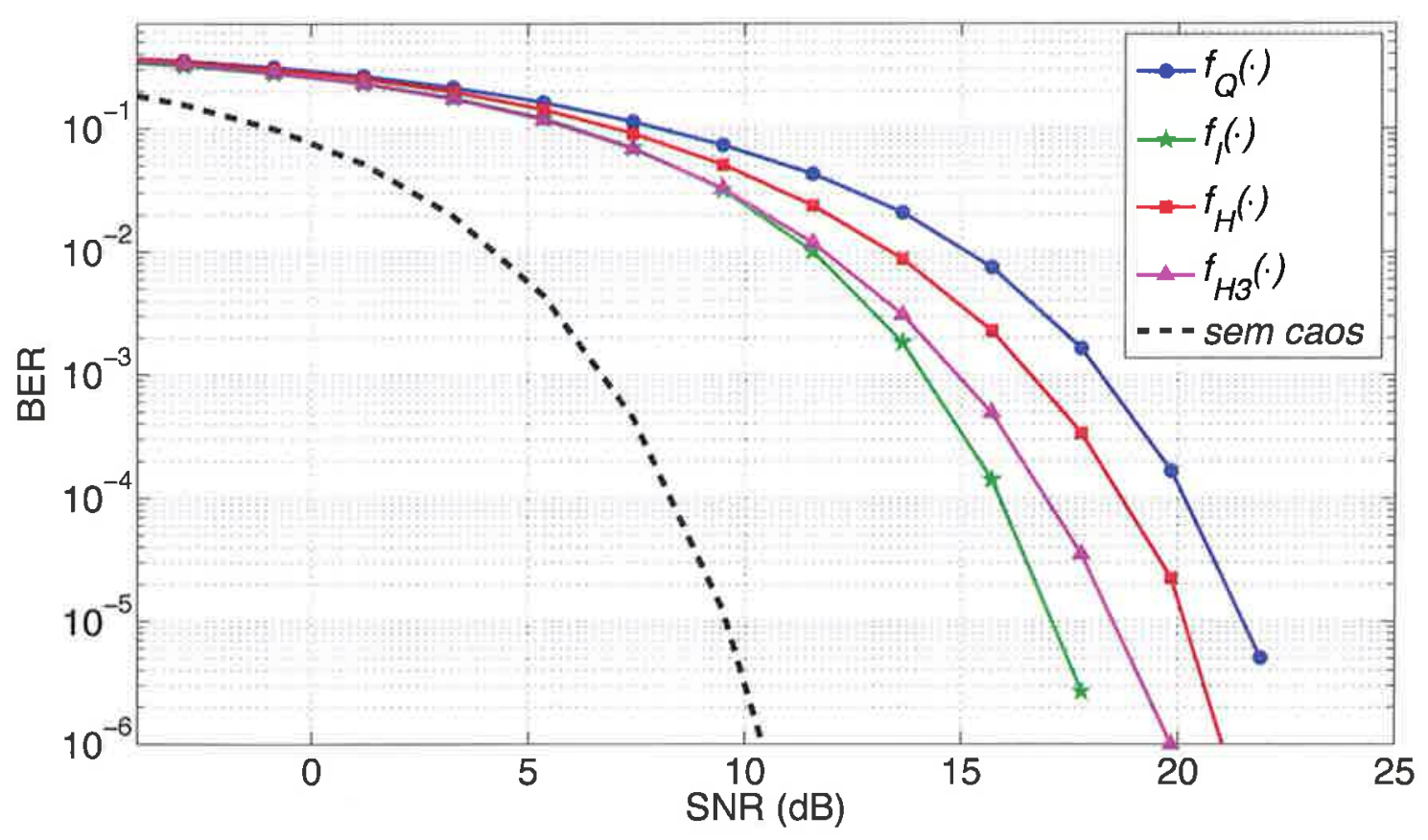

Figura 4.7: BER em função da SNR para $\gamma=0,4$.

caos do que os descritos anteriormente na literatura, que usam valores de $\gamma$ mais baixos, e.g. [106].

\subsubsection{Conclusões}

Nessa seção, faz-se uma analise numérica do desempenho em termos de BER do SCBC da Figura 4.1 em canal AWGN.

Foram testados quatro GSCs diferentes e uma função de codificação-decodificação que permite dosar a intensidade da mensagem e do sinal provindo do GSC. Dessa forma é possível controlar o compromisso entre o quão aparente é a mensagem no sinal transmitido e a BER. Verificou-se numericamente que é possível escolher um valor para o parâmetro $\gamma$ da função de codificação de forma que a mensagem não seja aparente e o valor de BER em canal AWGN seja adequado.

Os resultados ainda estão aquém dos sistemas convencionais, pelo menos em termos de BER em canal AWGN. Como alternativas para melhorar a robustez ao ruído da sincronização caótica face a ruído e, consequentemente, melhorar as taxas de erro, tem-se estudado o uso de algoritmos bioinspirados [43], reservoir dynamics [107] e redes de mapas $[26]$.

Outro tema que parece fundamental aqui é definir em termos mais precisos os ganhos de segurança em se utilizar uma técnica baseada em caos. A forma usada aqui para 
mensurar esse ganho, ou seja, a BER obtida ao se aplicar um limiar diretamente em $s(n)$ é um tanto rudimentar e precisa ser aperfeiçoada. Apesar de diversos artigos citarem o aumento da segurança na camada física pelo uso de sinais caóticos, e.g. [19], esse aumento ainda necessita de melhor fundamentação.

\subsection{Formatação do espectro do sinal transmitido}

O SCBC da Figura 4.1 é um equivalente passa-baixas de tempo discreto [18]. Assumese que, numa implementação prática, o sinal de tempo contínuo a ser transmitido será interpolado a partir das amostras de $s(n)$. Caso utilize-se um meio cabeado, esse sinal de tempo contínuo poderá ser diretamente transmitido. Caso se utilize um meio sem fio, ainda será necessário um processo de modulação para transformá-lo em um sinal na banda adequada.

De qualquer forma, como os canais práticos são limitados em frequência, é relevante analisar o que ocorre com os sinais caóticos transmitidos por um canal com essa característica. No modelo passa-baixas de tempo discreto da Figura 4.1, essa limitação em frequência é modelada tomando-se $H_{C}(\omega)$ como um filtro passa-baixas.

Como os sistemas são não lineares, uma modificação em qualquer componente espectral de $s(n)$ pode provocar mudanças em todas as componentes de $\widehat{m}(n)$. Simulações mostradas em diversos trabalhos, e.g. [30, 34, 52] confirmam que o desempenho do sistema da Figura 4.1 é extremamente sensível à eliminação mesmo de pequenas porcentagens do espectro do sinal transmitido.

Uma forma de contornar essas dificuldades é ajustar o espectro de $s(n)$ à largura de banda do canal. Essa ideia, proposta para sistemas de tempo contínuo em [93, 108] foi estendida para o caso de tempo discreto em [23]. Um diagrama de blocos do sistema proposto é mostrado na Figura 4.8.

A ideia básica é incluir um filtro $H_{S}(\omega)$ no transmissor de forma que o espectro dos sinais do GSC tenham uma conformação espectral que não seja afetada significativamente pelo canal. Para que o sincronismo caótico ainda possa ser obtido no receptor, um filtro idêntico é acrescentado a esse.

$\mathrm{Na}$ presente seção discute-se o funcionamento e diversos aspectos desse SCBC de banda limitada. Os principais resultados relatados aqui foram publicados em $[23,25,27$, $30,34,45,52,59,97-100]$.

Considera-se que $H_{S}(\omega)$ é um filtro causal de resposta ao impulso finita (FIR - Finite Impulse Response), ou seja, sua resposta ao impulso $h_{S}(n)$ tem um número finito $N_{S}$ de amostras não nulas [84] $c_{0}, c_{1}, \ldots, c_{N_{S}-1}$. Além disso, considera-se que $H_{S}(\omega)$ tem 


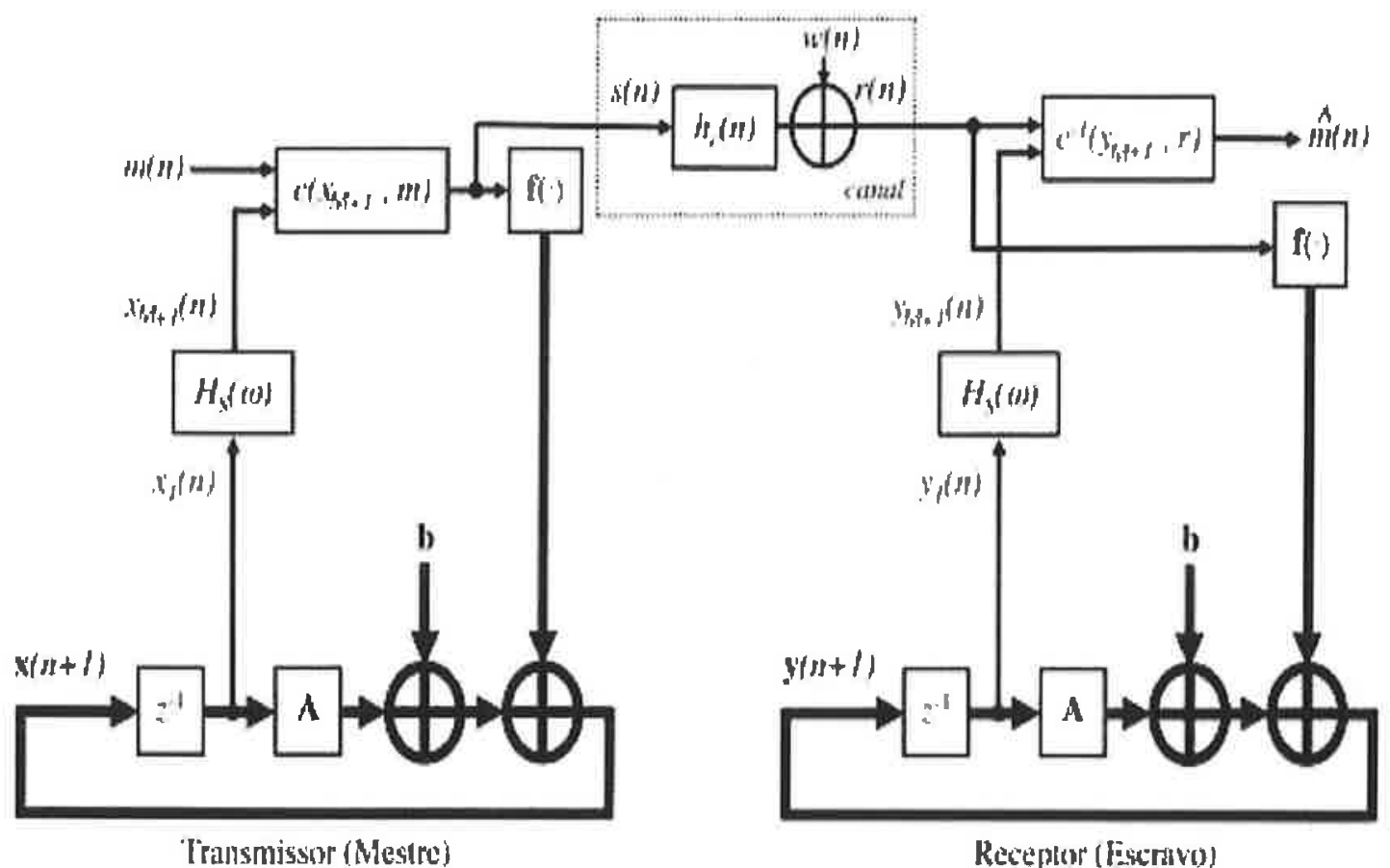

Figura 4.8: SCBC de tempo discreto com a inclusão de filtros $H_{S}(\omega)$ no transmissor e receptor. Fonte: [23].

fase linear de modo que apenas a amplitude das componentes em frequência dos sinais transmitidos sofrem alterações [84].

A vantagem de se considerar filtros FIR aqui é a possibilidade de se obter filtros com fase exatamente linear, o que não é possível com filtros com resposta ao impulso de duração infinita (IIR - Infinite Impulse Response), ou com realimentação [84]. A não ser que se faça menção em contrário, todos os filtros foram projetados utilizando-se a técnica do janelamento por uma janela de Hamming [84, Cap. 7], por meio da rotina fir1 do Matlab $^{\circledR}[109$, Cap. 7].

A entrada do filtro $H_{S}(\omega)$ no transmissor é $x_{1}(n)$. Assim, sua saída $x_{M+1}(n)$ é expressa como

$$
x_{M+1}(n)=\sum_{j=0}^{N_{S}-1} c_{j} x_{1}(n-j) .
$$

No SCBC da Figura 4.8, o sinal transmitido $s(n)$ passa a ser

$$
s(n)=c\left(x_{M+1}(n), m(n)\right) .
$$

ao invés de (4.7). 
O mesmo filtro é colocado no receptor, tendo como entrada $y_{1}(n)$. Assim, a saída desse outro filtro é

$$
y_{M+1}(n)=\sum_{j=0}^{N_{S}-1} c_{j} y_{1}(n-j)
$$

e a mensagem transmitida é estimada como

$$
\widehat{m}(n)=d\left(y_{M+1}(n), r(n)\right)
$$

Exemplo 4.2 (Transmissão de mensagem digital em canal limitado em frequência). Na Figura 4.9 considera-se a mesma mensagem e transmissor do Exemplo 4.1, página 56. Porém agora o canal filtra as altas frequências de $s(n)$. Mais precisamente, $H_{C}(\omega)$ é um filtro FIR passa-baixas com $N_{C}=50$ coeficientes e frequência de corte $\omega_{C}=0,8 \pi$. Em outras palavras, cerca de $20 \%$ do espectro do sinal foi afetado. Note que a mensagem é completamente perdida no receptor.

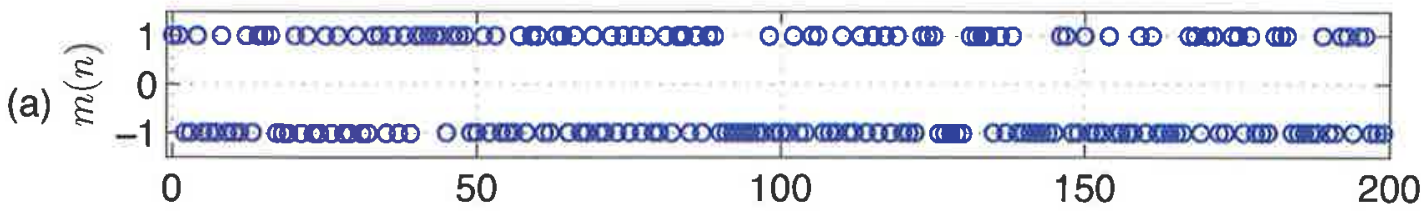
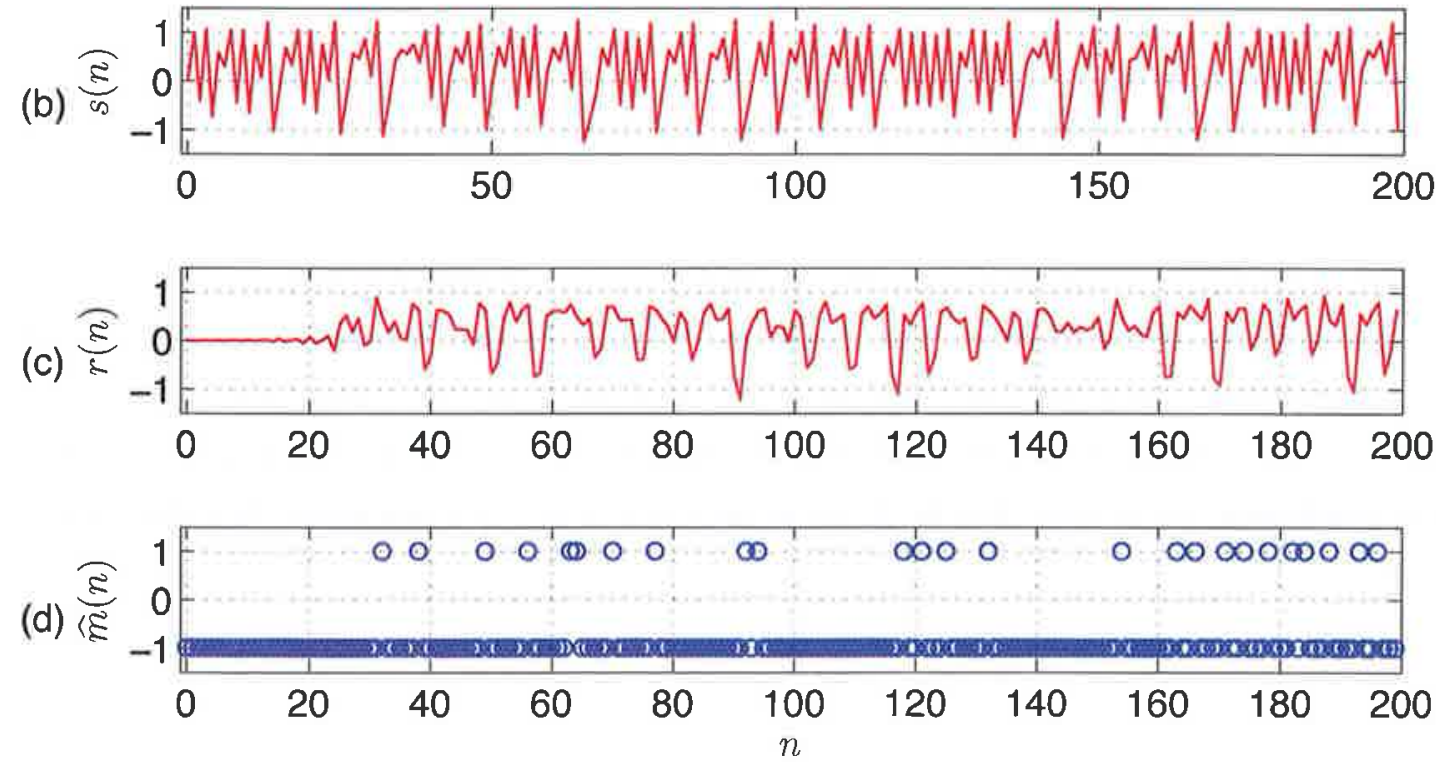

Figura 4.9: Exemplos de sinais do SCBC da Figura 4.1 para a condição de canal passabaixas ideal com $\omega_{C}=0,8 \pi$ : (a) $m(n)$, (b) $s(n)$, (c) $r(n)$, (d) $\widehat{m}(n)$. A mensagem não é recuperada no receptor. Fonte: [52].

Na Figura 4.10 repete-se a simulação da Figura 4.9, com a introdução de filtro $H_{S}(\omega)$ de ordem $N_{S}=30$ e frequência de corte $\omega_{S}=0,4 \pi$. Como o canal é passa-baixas com 
frequência de corte $\omega_{C}=0,8 \pi, s(n)$ é pouco afetado e a mensagem é recuperada com um atraso de $N_{C} / 2=25$ amostras. Alguns erros ainda ocorrem porque, como será discutido na Seção 4.3, é necessário formatar o espectro de $m(n)$ e não só do GSC para que $s(n)$ tenha banda efetivamente limitada e não seja afetado pelo canal.

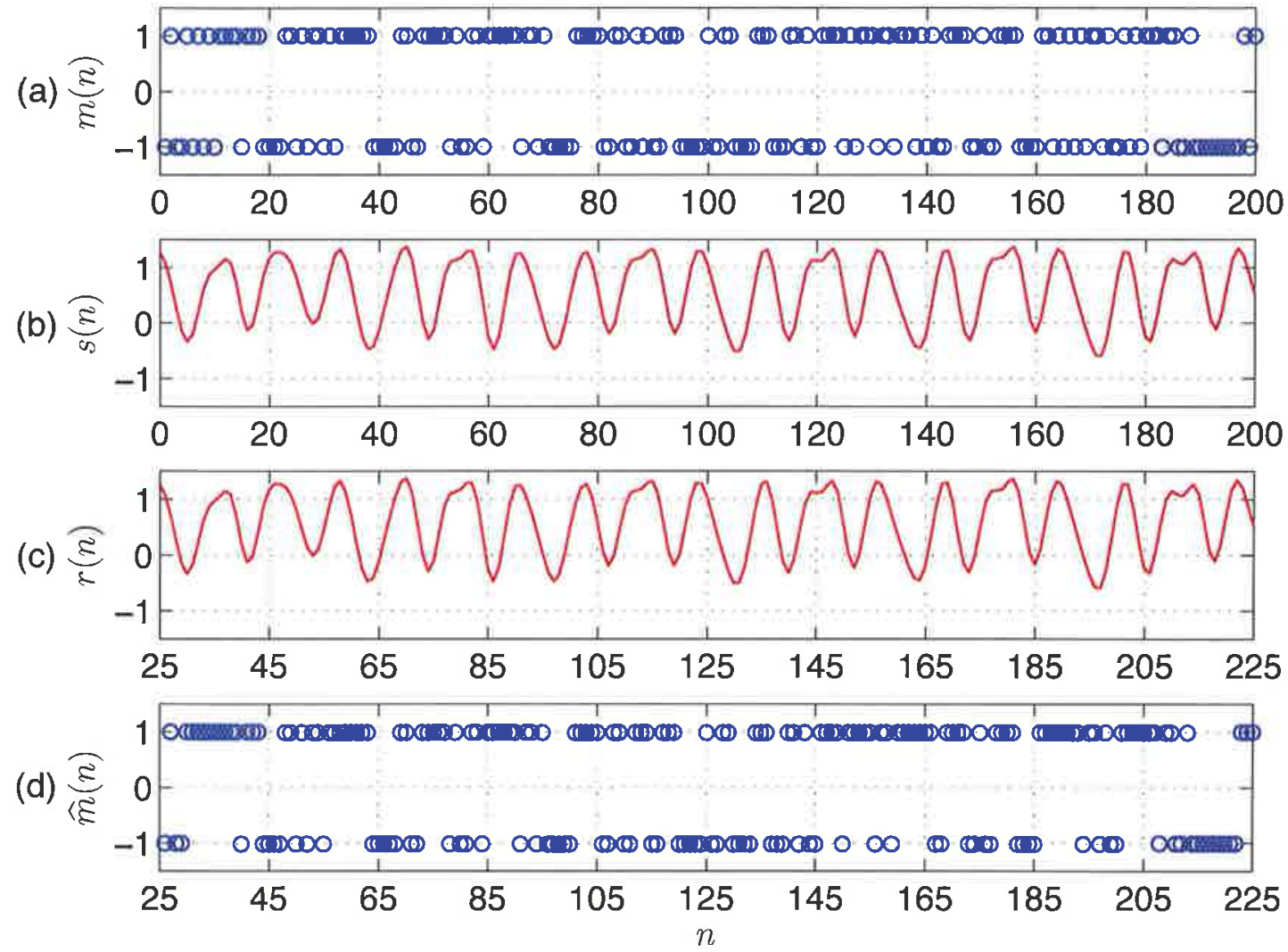

Figura 4.10: Exemplos de sinais do SCBC da Figura $4.8 \operatorname{com} \omega_{S}=0,4 \pi$ para a condição de canal passa-baixas com $\omega_{C}=0,8 \pi$ : (a) $m(n)$, (b) $s(n),($ c) $r(n),($ d) $\widehat{m}(n)$. A mensagem é recuperada com atraso. Fonte: [52].

Exemplo 4.3 (Transmissão de mensagem senoidal em canal limitado em frequência). Um outro exemplo de operação do sistema é mostrado na Figura 4.11, agora na transmissão do sinal analógico $m(n)=\sin (0,2 \pi n)$ e utilizando-se o mapa $\boldsymbol{f}_{H 3}(\cdot)$ como GSC [23]. Nos gráficos (A) e (B), mostram-se a $m(n), s(n), r(n)$ e $\widehat{m}(n)$ e suas respectivas DEPs, no caso em que não se usa os filtros $H_{S}(\omega)$ e o canal é passa-baixas com $\omega_{C}=0,8 \pi$. Claramente a mensagem perde-se e não é recuperada no receptor. Nos gráficos (C) e (D) mostramse os sinais associados quando $H_{S}(\omega)$ é passa-baixas com $\omega_{S}=0,7 \pi$, de forma que $o$ sinal transmitido não é afetado significativamente pelo canal. Nesse caso, a menos de um transitório $\widehat{m}(n) \approx m(n)$.

Para verificar como a introdução dos filtros altera a condição para o sincronismo, é necessário reescrever o sistema da Figura 4.8 na forma (4.8)-(4.9) e verificar quais 
(A)

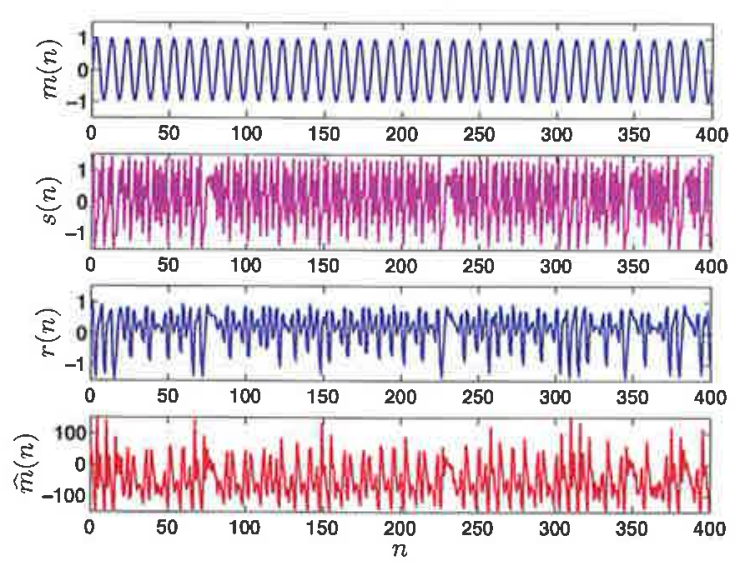

(C)
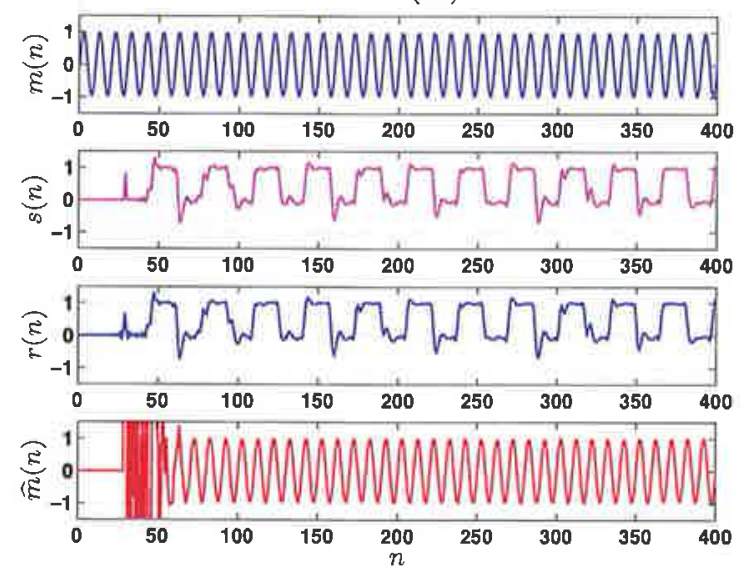

(B)

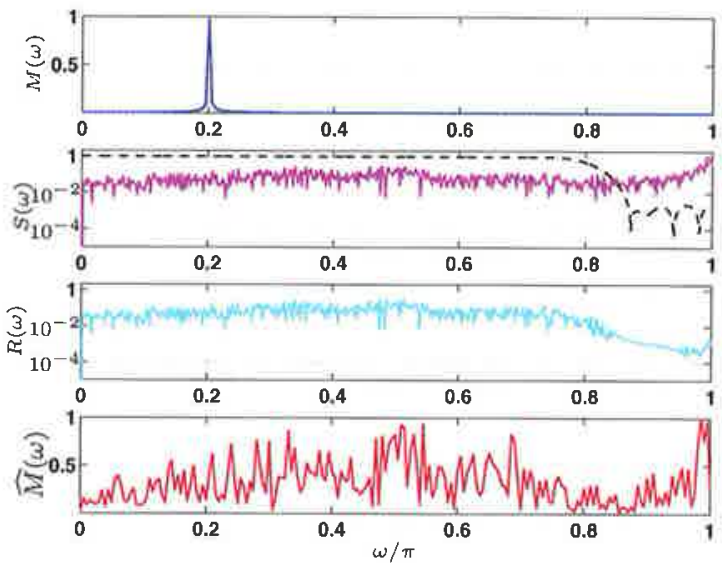

(D)
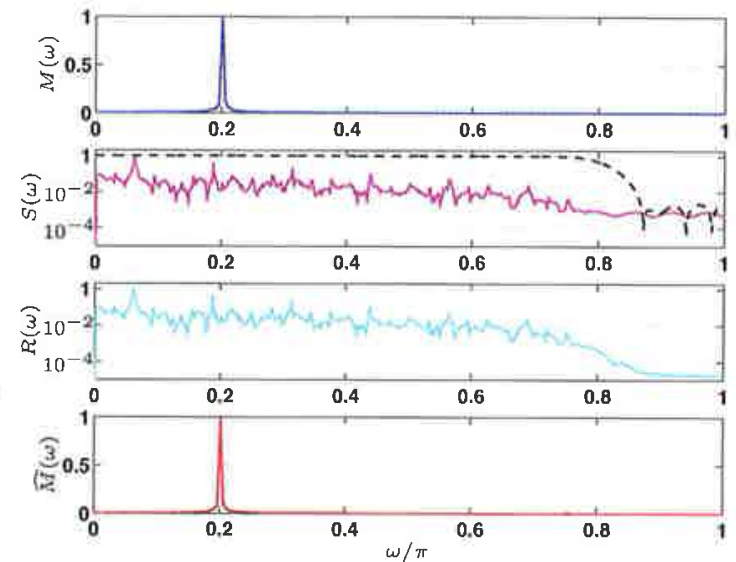

Figura 4.11: Exemplos de sinais do SCBC da Figura 4.8 e respectivas DEPs para $\omega_{C}=$ $0,8 \pi$ : (A) e (B) sem filtro na realimentação;(C) e (D) filtro $H_{S}(\omega)$ com $\omega_{S}=0,7 \pi$. O módulo da resposta em frequência do canal é mostrado em linha tracejada em (B) e (D). Fonte: [23].

condições os coeficientes dos filtros devem satisfazer de forma que (4.5) seja válida. Essa análise para um mapa genérico foi publicada em [30, 59] e é apresentada na Seção 4.3.1.

Quando se pensa em $m(n)$ digital e canal AWGN algumas questões relevantes precisam ser consideradas para se empregar de forma eficiente o SCBC da Figura 4.8. Do lado transmissor, $m(n)$ precisa ser formatada de forma a manter o sinal $s(n)$ dentro da faixa de passagem do canal. Caso contrário, haverá erros na recepção mesmo no caso sem ruído, como mostrado no Exemplo 4.2. Do lado receptor, dado que o sinal transmitido é limitado em banda, pode-se utilizar um filtro sintonizador de forma a eliminar as componentes do ruído fora da faixa do sinal, melhorando-se assim a SNR e reduzindo a BER. Essas análises foram apresentadas em [30, 45] e são resumidas na Seção 4.3.2.

Por fim, a introdução dos filtros na realimentação do sistema transmissor afeta significativamente o GSC original. Os sinais transmitidos podem deixar de ser caóticos, 
tornando-se periódicos, ou mesmo divergirem. Uma análise numérica inicial desse problema, considerando-se como GSC o mapa $\boldsymbol{f}_{H}(\cdot)$ foi apresentada nos trabalhos $[25,34,100]$ e é resumida na Seção 4.3.3.

\subsubsection{Condições de sincronismo}

Para se obter as condições sobre os coeficientes dos filtros para que o sistema mestreescravo da Figura 4.8 sincronize, é necessário obter a nova matriz de sincronismo $\boldsymbol{A}^{\prime}$ associada ao sistema com os filtros, de forma que ele possa ser descrito como

$$
\begin{aligned}
& \boldsymbol{x}(n+1)=\boldsymbol{A}^{\prime} \boldsymbol{x}(n)+\boldsymbol{b}+\boldsymbol{f}(s(n)) \\
& \boldsymbol{y}(n+1)=\boldsymbol{A}^{\prime} \boldsymbol{y}(n)+\boldsymbol{b}+\boldsymbol{f}(r(n))
\end{aligned}
$$

A partir daí, basta verificar as condições para que os autovalores de $\boldsymbol{A}^{\prime}$ satisfaçam (4.5).

Considere o sistema mestre original, ou seja, sem a presença dos filtros. Ele é expresso pelo sistema de $M$ equações (4.8). Seja $\boldsymbol{A}=\left\{a_{i j}\right\}, 1 \leq i, j \leq M$ a matriz de sincronismo do GSC original, ou seja, sem os filtros. O filtro $H_{S}(\omega)$ é FIR com $N_{S}$ coeficientes.

A seguir demonstra-se o seguinte teorema que foi enunciado originalmente em [30]:

Teorema 4.1. O sistema representado na Figura 4.8 pode ser representado na forma (4.30)-(4.31). Além disso, a matriz de sincronismo $\boldsymbol{A}^{\prime}$ tem $M$ autovalores iguais aos da matriz $\boldsymbol{A}$ do GSC original. Todos os seus demais autovalores são nulos.

Demonstração. A introdução do filtro $H_{S}(\omega)$ acrescenta (4.26) ao sistema (4.8) que passa a ter $M+1$ equações. O sistema transmissor completo é representado pelo sistema de equações

$$
\left\{\begin{array}{l}
x_{1}(n+1)=a_{11} x_{1}(n)+a_{12} x_{2}(n)+\cdots+a_{1 K} x_{K}(n)+b_{1}+f(s(n)) \\
x_{2}(n+1)=a_{21} x_{1}(n)+a_{22} x_{2}(n)+\cdots+a_{2 K} x_{K}(n)+b_{2} \\
\vdots \\
x_{M}(n+1)=a_{M 1} x_{1}(n)+a_{M 2} x_{2}(n)+\cdots+a_{M M} x_{M}(n)+b_{M} \\
x_{M+1}(n+1)=c_{0} x_{1}(n+1)+c_{1} x_{1}(n)+\cdots+c_{N_{S}-1} x_{1}\left(n-N_{S}+2\right)
\end{array}\right.
$$

com $s(n)$ dado por (4.27).

O problema de encontrar a matriz de sincronismo $\boldsymbol{A}^{\prime}$ para esse novo sistema e determinar seus autovalores é tratado a seguir separadamente para $N_{S}=1, N_{S}=2, N_{S}=3 \mathrm{e}$ $N_{S} \geq 3$. 


\section{Caso $N_{S}=1$}

Nesse caso, o filtro $H_{S}(\omega)$ é um simples ganho e (4.26) torna-se

$$
x_{M+1}(n+1)=c_{0} x_{1}(n+1) \text {. }
$$

Assim, (4.32) é dada por

$$
\left\{\begin{array}{l}
x_{1}(n+1)=a_{11} x_{1}(n)+a_{12} x_{2}(n)+\ldots+a_{1 M} x_{M}(n)+b_{1}+f(s(n)) \\
x_{2}(n+1)=a_{21} x_{1}(n)+a_{22} x_{2}(n)+\ldots+a_{2 M} x_{M}(n)+b_{2} \\
\vdots \\
x_{M}(n+1)=a_{M 1} x_{1}(n)+a_{M 2} x_{2}(n)+\ldots+a_{M M} x_{M}(n)+b_{M} \\
x_{M+1}(n+1)=c_{0} a_{11} x_{1}(n)+c_{0} a_{12} x_{2}(n)+\ldots+c_{0} a_{1 M} x_{M}(n)+c_{0} b_{1}+c_{0} f(s(n))
\end{array}\right.
$$

e, portanto, pode ser escrita na forma (4.30) com matriz de sincronismo de dimensão $M+1 \times M+1$

$$
\boldsymbol{A}_{1}^{\prime}=\left[\begin{array}{ccccc}
a_{11} & a_{12} & \cdots & a_{1 M} & 0 \\
a_{21} & a_{22} & \cdots & a_{2 M} & 0 \\
\vdots & \vdots & \cdots & \vdots & \vdots \\
a_{M 1} & a_{M 2} & \cdots & a_{M M} & 0 \\
c_{0} a_{11} & c_{0} a_{12} & \cdots & c_{0} a_{1 M} & 0
\end{array}\right] .
$$

Os autovalores $\lambda_{i}^{\prime}, 1 \leq i \leq M+1$, de $\boldsymbol{A}_{1}^{\prime}$, são as raízes da equação em $\lambda$

$$
\operatorname{det}\left(\lambda \boldsymbol{I}-\boldsymbol{A}_{1}^{\prime}\right)=\left|\begin{array}{ccccc}
\left(\lambda-a_{11}\right) & a_{12} & \cdots & a_{1 M} & 0 \\
a_{21} & \left(\lambda-a_{22}\right) & \cdots & a_{2 M} & 0 \\
\vdots & \vdots & \cdots & \vdots & \vdots \\
a_{M 1} & a_{M 2} & \cdots & \left(\lambda-a_{M M}\right) & 0 \\
c_{0} a_{11} & c_{0} a_{12} & \cdots & c_{0} a_{1 M} & \lambda
\end{array}\right|=0,
$$

sendo $\boldsymbol{I}$ a matriz identidade de dimensão $M+1$.

Calculando o determinante a partir da expansão por cofatores [110, Cap. 3] da última coluna, (4.36) torna-se

$$
\operatorname{det}\left(\lambda \boldsymbol{I}-\boldsymbol{A}_{1}^{\prime}\right)=\lambda\left|\begin{array}{cccc}
\left(\lambda-a_{11}\right) & a_{12} & \cdots & a_{1 M} \\
a_{21} & \left(\lambda-a_{22}\right) & \cdots & a_{2 M} \\
\vdots & \vdots & \cdots & \vdots \\
a_{M 1} & a_{M 2} & \cdots & \left(\lambda-a_{M M}\right)
\end{array}\right|=\lambda \operatorname{det}(\lambda \boldsymbol{I}-\boldsymbol{A})=0 .
$$

Portanto, os $M+1$ autovalores de $\boldsymbol{A}_{1}^{\prime}$ são $\lambda_{m}^{\prime}=\lambda_{m}, 1 \leq i \leq M$, e $\lambda_{M+1}^{\prime}=0$. Assim, 
o Teorema 4.1 está demonstrado para $N_{S}=1$.

Caso $N_{S}=2$

Nesse caso, (4.32) é dada por

$$
x_{M+1}(n+1)=c_{0} x_{1}(n+1)+c_{1} x_{1}(n)
$$

e assim (4.32) torna-se

$$
\left\{\begin{array}{l}
x_{1}(n+1)=a_{11} x_{1}(n)+a_{12} x_{2}(n)+\ldots+a_{1 M} x_{M}(n)+b_{1}+f(s(n)) \\
x_{2}(n+1)=a_{21} x_{1}(n)+a_{22} x_{2}(n)+\ldots+a_{2 M} x_{M}(n)+b_{2} \\
\vdots \\
x_{M}(n+1)=a_{M 1} x_{1}(n)+a_{M 2} x_{2}(n)+\ldots+a_{M M} x_{M}(n)+b_{M} \\
x_{M+1}(n+1)=\left(c_{0} a_{11}+c_{1}\right) x_{1}(n)+c_{0} a_{12} x_{2}(n)+\ldots+c_{0} a_{1 M} x_{M}(n)+c_{0} b_{1}+c_{0} f(s(n))
\end{array}\right.
$$

A matriz de sincronismo associada, de dimensão $M+1 \times M+1$ é dada por

$$
\boldsymbol{A}_{2}^{\prime}=\left[\begin{array}{ccccc}
a_{11} & a_{12} & \cdots & a_{1 M} & 0 \\
a_{21} & a_{22} & \cdots & a_{2 M} & 0 \\
\vdots & \vdots & \cdots & \vdots & \vdots \\
a_{M 1} & a_{M 2} & \cdots & a_{M M} & 0 \\
\left(c_{0} a_{11}+c_{1}\right) & c_{0} a_{12} & \cdots & c_{0} a_{1 M} & 0
\end{array}\right] \text {. }
$$

Procedendo de forma análoga ao que foi feito no caso $N_{S}=1$, conclui-se que os $M+1$ autovalores de $\boldsymbol{A}_{2}^{\prime}$ são novamente $\lambda_{m}^{\prime}=\lambda_{m}, 1 \leq i \leq M$, e $\lambda_{M+1}^{\prime}=0$. Assim, o Teorema 4.1 está demonstrado para $N_{S}=2$.

\section{Caso $N_{S}=3$}

Para $N_{S}=3$, o filtro é dado por

$$
x_{M+1}(n+1)=c_{0} x_{1}(n+1)+c_{1} x_{1}(n)+c_{2} x_{1}(n-1) .
$$

Definindo-se a variável de estado auxiliar

$$
x_{M+2}(n+1)=x_{1}(n) \text {, }
$$


pode-se reescrever (4.32) como

$$
\left\{\begin{array}{l}
x_{1}(n+1)=a_{11} x_{1}(n)+a_{12} x_{2}(n)+\ldots+a_{1 M} x_{M}(n)+b_{1}+f(s(n)) \\
x_{2}(n+1)=a_{21} x_{1}(n)+a_{22} x_{2}(n)+\ldots+a_{2 M} x_{M}(n)+b_{2} \\
\vdots \\
x_{M}(n+1)=a_{M 1} x_{1}(n)+a_{M 2} x_{2}(n)+\ldots+a_{M M} x_{M}(n)+b_{M} \\
x_{M+1}(n+1)=\left(c_{0} a_{11}+c_{1}\right) x_{1}(n)+c_{0} a_{12} x_{2}(n)+\ldots+c_{0} a_{1 M} x_{M}(n)+c_{2} x_{M+2}(n)+c_{0} b_{1}+ \\
\quad c_{0} f(s(n)) \\
x_{M+2}(n+1)=x_{1}(n)
\end{array}\right.
$$

A matriz de sincronismo $A_{3}^{\prime}$ de dimensão $M+2 \times M+2$ associada a (4.43) é dada por

$$
\boldsymbol{A}_{3}^{\prime}=\left[\begin{array}{cccccc}
a_{11} & a_{12} & \cdots & a_{1 M} & 0 & 0 \\
a_{21} & a_{22} & \cdots & a_{2 M} & 0 & 0 \\
\vdots & \vdots & \cdots & \vdots & \vdots & \\
a_{M 1} & a_{M 2} & \cdots & a_{M M} & 0 & 0 \\
\left(c_{0} a_{11}+c_{1}\right) & c_{0} a_{12} & \cdots & c_{0} a_{1 M} & 0 & c_{2} \\
1 & 0 & \cdots & 0 & 0 & 0
\end{array}\right]
$$

Os autovalores $\lambda_{m}^{\prime}, 1 \leq m \leq M+2$, de $\boldsymbol{A}_{3}^{\prime}$, são as raízes da equação em $\lambda$

$$
\operatorname{det}\left(\lambda \boldsymbol{I}-\boldsymbol{A}_{3}^{\prime}\right)=\left|\begin{array}{cccccc}
\left(\lambda-a_{11}\right) & a_{12} & \cdots & a_{1 M} & 0 & 0 \\
a_{21} & \left(\lambda-a_{22}\right) & \cdots & a_{2 M} & 0 & 0 \\
\vdots & \vdots & \cdots & \vdots & \vdots & \vdots \\
a_{M 1} & a_{M 2} & \cdots & \left(\lambda-a_{M M}\right) & 0 & 0 \\
\left(c_{0} a_{11}+c_{1}\right) & c_{0} a_{12} & \cdots & c_{0} a_{1 M} & \lambda & c_{2} \\
1 & 0 & \cdots & 0 & 0 & \lambda
\end{array}\right|=0 .
$$

Calculando o determinante a partir da expansão por cofatores da penúltima coluna da matriz, (4.45) torna-se

$$
\operatorname{det}\left(\lambda \boldsymbol{I}-\boldsymbol{A}_{3}^{\prime}\right)=\lambda\left|\begin{array}{ccccc}
\left(\lambda-a_{11}\right) & a_{12} & \cdots & a_{1 M} & 0 \\
a_{21} & \left(\lambda-a_{22}\right) & \cdots & a_{2 M} & 0 \\
\vdots & \vdots & \cdots & \vdots & \vdots \\
a_{M 1} & a_{M 2} & \cdots & \left(\lambda-a_{M M}\right) & 0 \\
1 & 0 & \cdots & 0 & \lambda
\end{array}\right|=0 .
$$


Usando novamente a expansão por cofatores, agora pela última coluna,

$$
\operatorname{det}\left(\lambda \boldsymbol{I}-\boldsymbol{A}_{3}^{\prime}\right)=\lambda^{2}\left|\begin{array}{cccc}
\left(\lambda-a_{11}\right) & a_{12} & \cdots & a_{1 M} \\
a_{21} & \left(\lambda-a_{22}\right) & \cdots & a_{2 M} \\
\vdots & \vdots & \cdots & \vdots \\
a_{M 1} & a_{M 2} & \cdots & \left(\lambda-a_{M M}\right)
\end{array}\right|=\lambda^{2} \operatorname{det}(\lambda \boldsymbol{I}-\boldsymbol{A})=0
$$

Portanto, os $M+2$ autovalores de $\boldsymbol{A}_{2}^{\prime}$ são $\lambda_{i}^{\prime}=\lambda_{i}, 1 \leq i \leq M$, e $\lambda_{M+1}^{\prime}=\lambda_{M+2}^{\prime}=0$. Assim, o Teorema 4.1 está demonstrado para $N_{S}=3$.

Caso $N_{S} \geq 3$

Finalmente, considera-se o caso $N_{S} \geq 3$, generalização do caso anterior. Agora, o filtro é dado por (4.26), ou seja,

$x_{M+1}(n+1)=c_{0} x_{1}(n+1)+c_{1} x_{1}(n)+c_{2} x_{1}(n-1)+c_{3} x_{1}(n-2)+\ldots+c_{N_{S}-1} x_{1}\left(n-\left(N_{S}-2\right)\right)$

e o sistema com a inclusão do filtro é dado por (4.32).

Definem-se as $N_{S^{\prime}}-2$ variáveis de estado auxiliares

$$
\left\{\begin{array}{l}
x_{M+2}(n+1)=x_{1}(n) \\
x_{M+3}(n+1)=x_{M+2}(n)=x_{1}(n-1) \\
x_{M+4}(n+1)=x_{M+3}(n)=x_{1}(n-2) \\
\vdots \\
x_{M+N_{S}-1}(n+1)=x_{M+N_{S}-2}(n)=x_{1}\left(n-\left(N_{S}-3\right)\right)
\end{array}\right.
$$

Substituindo-se $x_{1}(n+1)$ em (4.48) e utilizando-se (4.49), pode-se reescreve-se o sistema 
mestre como

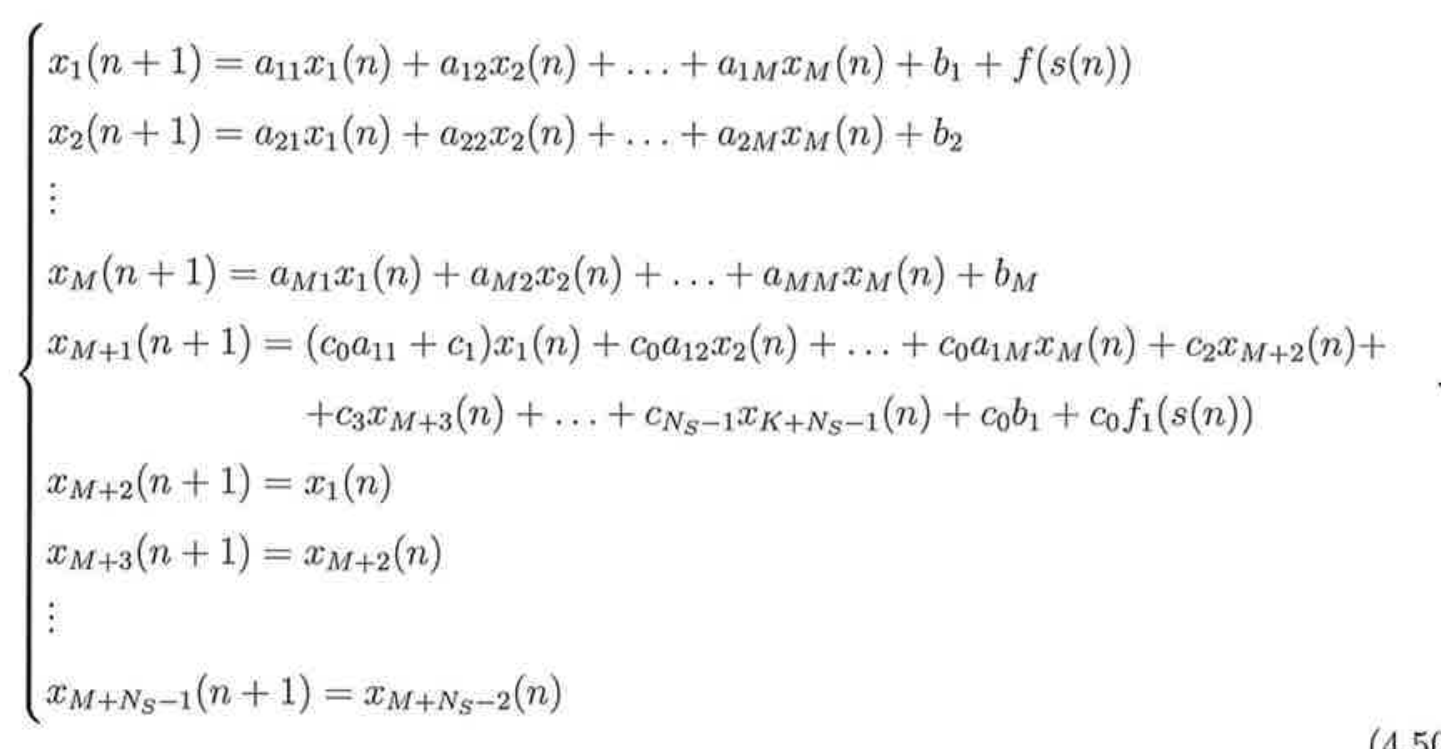

A matriz de sincronismo associada a (4.50) tem dimensão $M^{\prime} \times M^{\prime}$ com

$$
M^{\prime}=\left(M+N_{S}-1\right)
$$

e é dada por

$$
\boldsymbol{A}_{4}^{\prime}=\left[\begin{array}{ccccccccc}
a_{11} & a_{12} & \cdots & a_{1 M} & 0 & 0 & \cdots & 0 & 0 \\
a_{21} & a_{22} & \cdots & a_{2 M} & 0 & 0 & \cdots & 0 & 0 \\
\vdots & \vdots & \vdots & \vdots & \vdots & \vdots & \vdots & \vdots & \vdots \\
a_{M 1} & a_{M 2} & \cdots & a_{M M} & 0 & 0 & \cdots & 0 & 0 \\
\left(c_{0} a_{11}+c_{1}\right) & c_{0} a_{12} & \cdots & c_{0} a_{1 M} & 0 & c_{2} & \cdots & c_{N_{S}-2} & c_{N_{S}-1} \\
1 & 0 & \cdots & 0 & 0 & 0 & \cdots & 0 & 0 \\
0 & 0 & \cdots & 0 & 0 & 1 & \cdots & 0 & 0 \\
\vdots & \vdots & \vdots & \vdots & \vdots & \vdots & \ddots & \vdots & \vdots \\
0 & 0 & \cdots & 0 & 0 & 0 & \cdots & 1 & 0
\end{array}\right] .
$$

ou

$$
\boldsymbol{A}_{4}^{\prime}=\left[\begin{array}{ccc}
\boldsymbol{A} & & \mathbf{0}_{M \times\left(N_{S}-1\right)} \\
& \mathbf{v}_{1 \times M^{\prime}} & \\
& \mathbf{u}_{1 \times M^{\prime}} & \\
0_{\left(N_{S}-3\right) \times(M+1)} & I_{\left(N_{S}-3\right) \times\left(N_{S}-3\right)} & 0_{\left(N_{S}-3\right) \times 1}
\end{array}\right],
$$

sendo

$$
\mathbf{v}=\left[\begin{array}{lllllllll}
\left(c_{0} a_{11}+c_{1}\right) & c_{0} a_{12} & \ldots & c_{0} a_{1 K} & 0 & c_{2} & \ldots & c_{N_{S}-2} & c_{N_{S}-1}
\end{array}\right]
$$

$\mathrm{e} \mathbf{u}=\left[\begin{array}{lllll}1 & 0 & 0 & \ldots & 0\end{array}\right]$ 
Os autovalores $\lambda_{m}^{\prime}, 1 \leq m \leq M+N_{S}-1$, de $A_{4}^{\prime}$, são as raízes da equação em $\lambda$ $\operatorname{det}\left(\lambda \boldsymbol{I}-\boldsymbol{A}_{4}^{\prime}\right)=\left|\begin{array}{ccccccccc}\left(\lambda-a_{11}\right) & a_{12} & \cdots & a_{1 M} & 0 & 0 & \cdots & 0 & 0 \\ a_{21} & \left(\lambda-a_{22}\right) & \cdots & a_{2 M} & 0 & 0 & \cdots & 0 & 0 \\ \vdots & \vdots & \vdots & \vdots & \vdots & \vdots & \vdots & \vdots & \vdots \\ a_{M 1} & a_{M 2} & \cdots & \left(\lambda-a_{M M}\right) & 0 & 0 & \cdots & 0 & 0 \\ \left(c_{0} a_{11}+c_{1}\right) & c_{0} a_{12} & \cdots & c_{0} a_{1 M} & \lambda & c_{2} & \cdots & c_{N_{S}-2} & c_{N_{S}-1} \\ 1 & 0 & \cdots & 0 & 0 & \lambda & \cdots & 0 & 0 \\ 0 & 0 & \cdots & 0 & 0 & 1 & \cdots & 0 & 0 \\ \vdots & \vdots & \vdots & \vdots & \vdots & \vdots & \ddots & \vdots & \vdots \\ 0 & 0 & \cdots & 0 & 0 & 0 & \cdots & 1 & \lambda\end{array}\right|_{(4.55)}$

Calculando o determinante a partir da expansão por cofatores da coluna $M+1$ da matriz, (4.55) torna-se

$$
\operatorname{det}\left(\lambda \boldsymbol{I}-\boldsymbol{A}_{4}^{\prime}\right)=\lambda\left|\begin{array}{cccccccc}
\left(\lambda-a_{11}\right) & a_{12} & \cdots & a_{1 M} & 0 & \cdots & 0 & 0 \\
a_{21} & \left(\lambda-a_{22}\right) & \cdots & a_{2 M} & 0 & \cdots & 0 & 0 \\
\vdots & \vdots & \vdots & \vdots & \vdots & \vdots & \vdots & \vdots \\
a_{M 1} & a_{M 2} & \cdots & \left(\lambda-a_{M M}\right) & 0 & \cdots & 0 & 0 \\
1 & 0 & \cdots & 0 & \lambda & \cdots & 0 & 0 \\
0 & 0 & \cdots & 0 & 1 & \cdots & 0 & 0 \\
\vdots & \vdots & \vdots & \vdots & \vdots & \ddots & \vdots & \vdots \\
0 & 0 & \cdots & 0 & 0 & \cdots & 1 & \lambda
\end{array}\right|=0 .
$$

Usando a expansão por cofatores mais $N_{S}-2$ vezes, sempre a partir da última coluna, a equação (4.56) torna-se

$$
\begin{aligned}
\operatorname{det}\left(\lambda \boldsymbol{I}-\boldsymbol{A}_{4}^{\prime}\right) & =\lambda^{\left(N_{S}-1\right)}\left|\begin{array}{cccc}
\left(\lambda-a_{11}\right) & a_{12} & \cdots & a_{1 M} \\
a_{21} & \left(\lambda-a_{22}\right) & \cdots & a_{2 M} \\
\vdots & \vdots & (\lambda-\cdots) & \vdots \\
a_{M 1} & a_{M 2} & \cdots & \left(\lambda-a_{M M}\right)
\end{array}\right| \\
& =\lambda^{\left(N_{S}-1\right)} \operatorname{det}(\lambda \boldsymbol{I}-\boldsymbol{A})=0 .
\end{aligned}
$$

Portanto, os $M+N_{S}-1$ autovalores de $\boldsymbol{A}_{4}^{\prime}$ são $\lambda_{m}^{\prime}=\lambda_{m}, 1 \leq m \leq M$, e $\lambda_{M+1}^{\prime}=$ $\lambda_{M+2}^{\prime}=\ldots=\lambda_{M+N_{S}-1}^{\prime}=0$. Assim, o Teorema 4.1 está demonstrado para $N_{S}>3 \mathrm{e}$ conclui-se sua demonstração. 
Como importante corolário do Teorema 4.1, tem-se

Corolário 4.1. O sistema mestre-escravo (4.30)-(4.31) sincroniza completamente independentemente dos filtros utilizados, desde que os autovalores da matriz $\boldsymbol{A}$ satisfaçam (4.5).

Concluindo, se o sistema mestre-escravo original sincroniza, os filtros não afetam esse sincronismo, dado que os autovalores não nulos da nova matriz de sincronismo são os mesmos do GSC original. Esse corolário generaliza o resultado obtido em [25] para o mapa de Hénon $\boldsymbol{f}_{H}(\cdot)$.

Note-se que nada está se afirmando sobre a natureza do sinal transmitido $s(n)$ : ele pode deixar de ser caótico, tornando-se periódico, ou mesmo divergir dependendo dos filtros utilizados, mas o sincronismo e o funcionamento do SCBC da Figura 4.8 estão garantidos, independentemente dos filtros $H_{S}(\omega)$

\subsubsection{Formatação da mensagem e noise filtering}

Uma vez demonstrado o funcionamento do SCBC da Figura 4.8, são necessárias algumas considerações levando-se em conta a transmissão de mensagens digitais utilizando-se sinais de banda limitada. Do lado transmissor $m(n)$ tem que ser formatado de forma a ter o espectro contido dentro da faixa de frequências desejada para o sinal caótico. Do lado do receptor, dado que o sinal transmitido é limitado em banda, pode-se utilizar um filtro sintonizador de forma a eliminar as componentes do ruído fora da faixa do sinal, melhorando-se assim a SNR e reduzindo a BER.

Essas questões são tratadas de forma resumida nessa seção. Os principais resultados foram detalhados em [65].

Considera-se

$$
m(n)=\sum_{i=0}^{+\infty} d_{i} p(n-L i)
$$

sendo

$$
p(n)=\left\{\begin{array}{ll}
1, & 0 \leq n<L-1 \\
0, & \text { caso contrário }
\end{array},\right.
$$

um pulso retangular de $L$ amostras e $d_{i}$ uma sequência binária formada por valores \pm 1 . Na Figura 4.12(a)-(d) mostram-se alguns exemplos da mensagem $m(n)$ formatada pelo pulso retangular $p(n)$ para uma sequência $d_{i}$ formada por +1 s e -1 s alternados. 


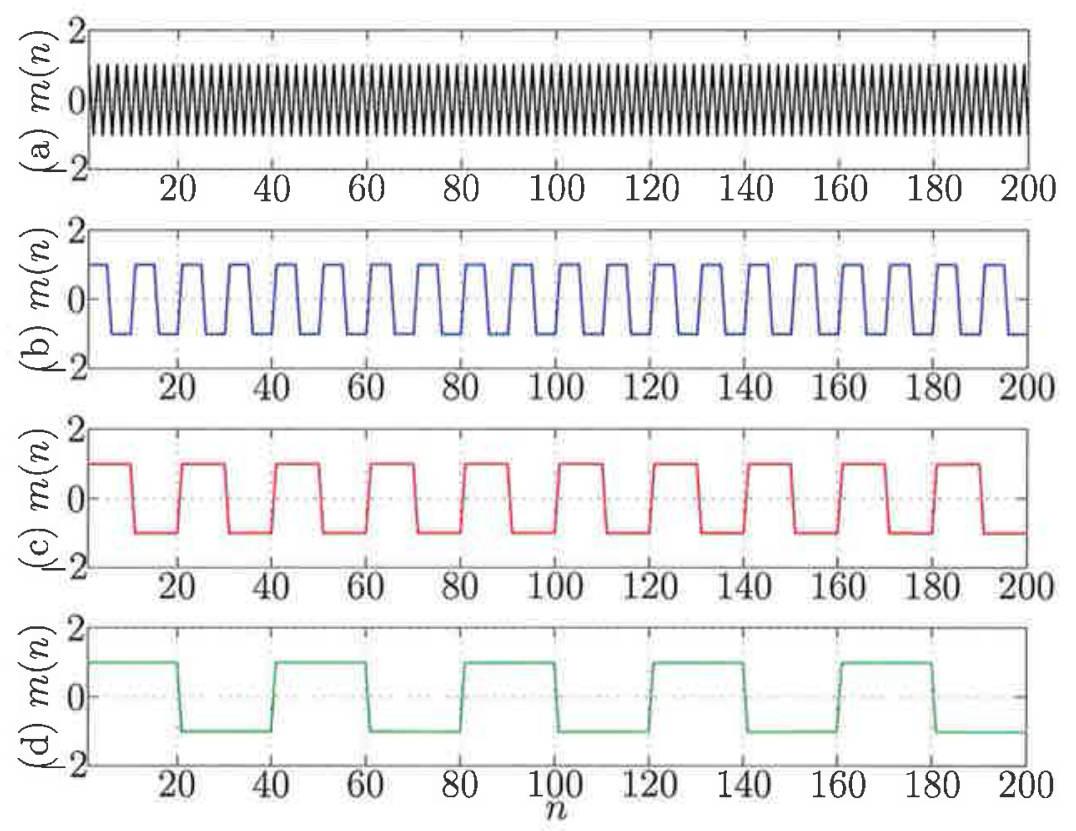

Figura 4.12: Mensagem $m(n)$ (4.58) para uma sequência $d_{i}$ formada por $+1 \mathrm{~s}$ e $-1 \mathrm{~s}$ alternados com: (a) $L=1$, (b) $L=5$, (c) $L=10$ e (d) $L=20$. Fonte: [65].

Pode-se mostrar [65] que, para $d_{i}$ equiprovável, a DEP de $m(n)$ é dada por

$$
M(\omega)=\frac{1}{L}\left[\frac{\sin \left(\frac{\omega L}{2}\right)}{\sin \left(\frac{\omega}{2}\right)}\right]^{2} .
$$

Alguns exemplos de $M(\omega)$, para diferentes valores de $L$, são mostrados na Figura 4.13(a).

(a)

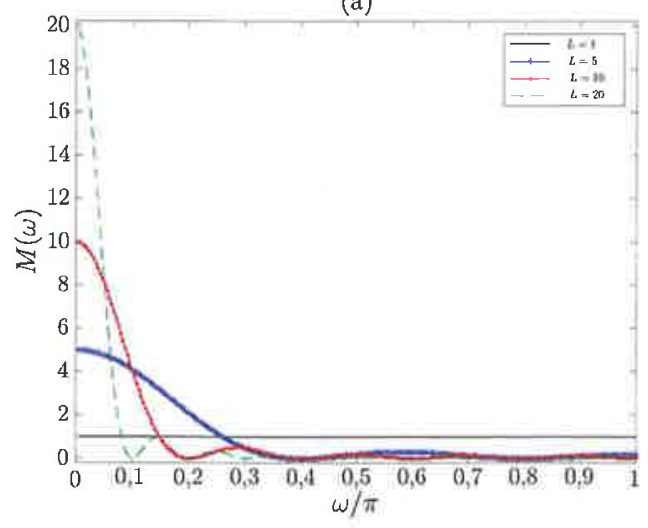

(b)

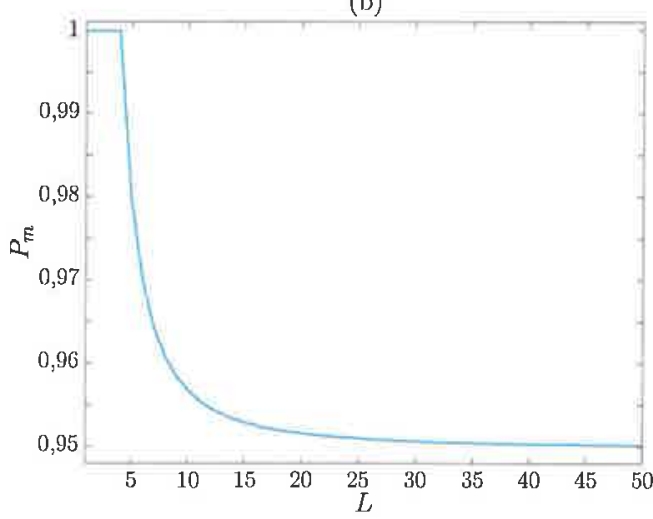

Figura 4.13: (a) DEP $M(\omega)$ de $m(n)$ e (b) Fração da potência de $m(n), P_{m}$, concentrada no intervalo $\left[0, B_{M}\right]$ em função de $L$. Fonte: [65].

Considera-se a banda essencial de $M(\omega), B_{M}$, como sendo a frequência em que ocorre 
o segundo nulo de $M(\omega)$. De (4.59),

$$
B_{M}=\frac{4 \pi}{L}
$$

Na Figura 4.13(b) mostra-se que a fração da potência de $m(n)$, concentrada entre 0 e $B_{M}$

$$
P_{m}=\frac{1}{\pi} \int_{0}^{B_{M}} M(\omega) d \omega
$$

é superior a $95 \%$, para todo $L$, coerente com a definição de banda essencial utilizada no Capítulo 3, (3.5). Com essa escolha, para que $m(n)$ tenha certa banda essencial, $B_{M}$, deve-se tomar

$$
L=\left\lceil\frac{4 \pi}{B_{m}}\right\rceil .
$$

Com $m(n)$ formato dessa maneira e utilizando-se o SCBC da Figura 4.8 com a função de codificação linear

$$
s(n)=(1-\gamma) x_{M+1}(n)+\gamma m(n),
$$

que é a mesma utilizada na Seção 4.2.1, (4.20), pode-se de fato limitar a banda do sinal transmitido $s(n)$ fazendo-se com que $m(n)$ tenha banda essencial menor ou igual a $\omega_{S}$, a frequência de corte do filtro inserido na realimentação do sistema. Assim, faz-se

$$
L=\left\lceil\frac{4 \pi}{\omega_{S}}\right\rceil .
$$

Para se obter a sequência binária estimada, $\widehat{d}_{i}$ no receptor a partir da mensagem recuperada $\widehat{m}(n)$, utiliza-se o decisor ótimo pelo critério máximo a posteriori [18], que nesse caso, consiste em calcular

$$
S_{i}=\sum_{n=i L}^{(i+1) L-1} \widehat{m}(n)
$$

e decidir

$$
\widehat{d_{i}}= \begin{cases}1, & S_{i}>0 \\ -1, & S_{i}<0\end{cases}
$$

Como $s(n)$ é limitado em banda e o ruído no canal $w(n)$, tem sua potência igualmente distribuída em todas as frequências, é interessante utilizar-se um filtro sintonizador, $H_{T}(\omega)$, na entrada do receptor de forma a eliminar as componentes do ruído nas frequências acima da banda essencial de $s(n)$.

Para ilustrar o processo de sintonização, mostra-se na Figura 4.14 o módulo da resposta em frequência de um sintonizador, $H_{T}(\omega)$, com frequência de corte $\omega_{T}=0,38 \pi$ e as 
DEPs normalizadas do ruído no canal $W(\omega)$ e do sinal transmitido $S(\omega)$ para $\omega_{S}=0,2 \pi$, $L=20$ e $\mathrm{SNR}=20 \mathrm{~dB}$. Nota-se que na faixa de rejeição do filtro a potência do ruído é dominante.

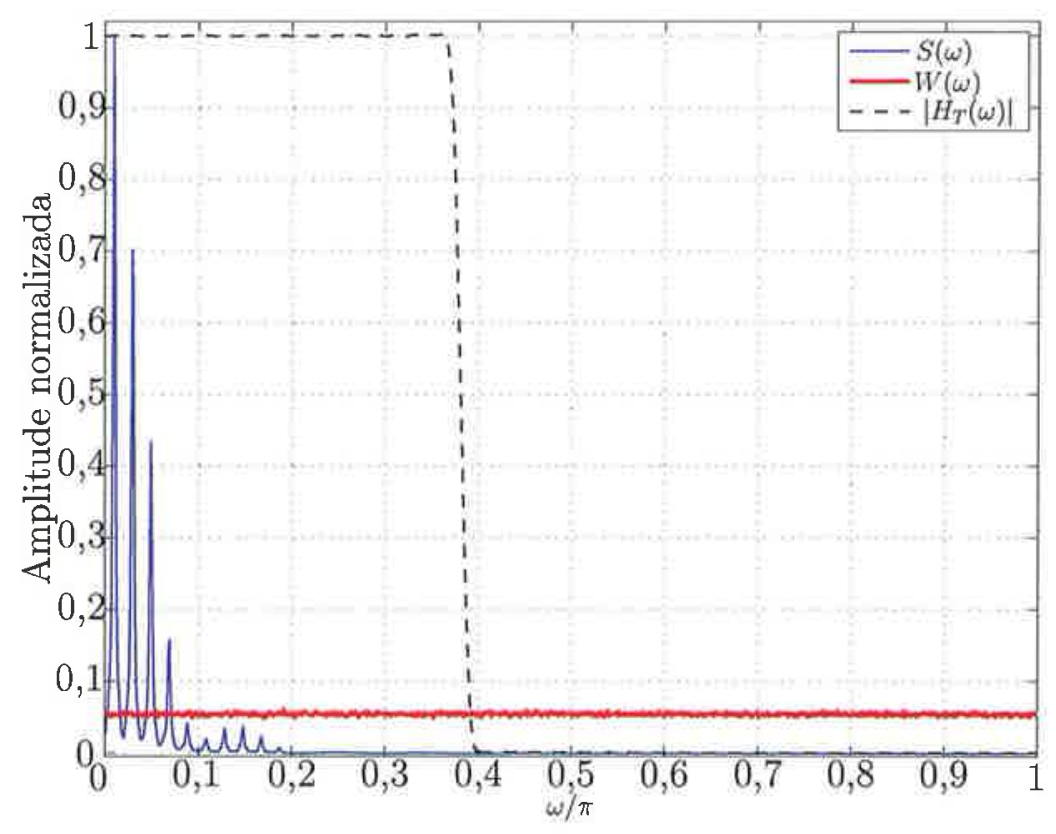

Figura 4.14: Exemplo de atuação do filtro sintonizador, eliminando componentes fora da banda de $s(n)$. Fonte: [65].

Os acréscimos ao SCBC da Figura 4.8 descritos nessa seção são mostrados na Figura 4.15 .

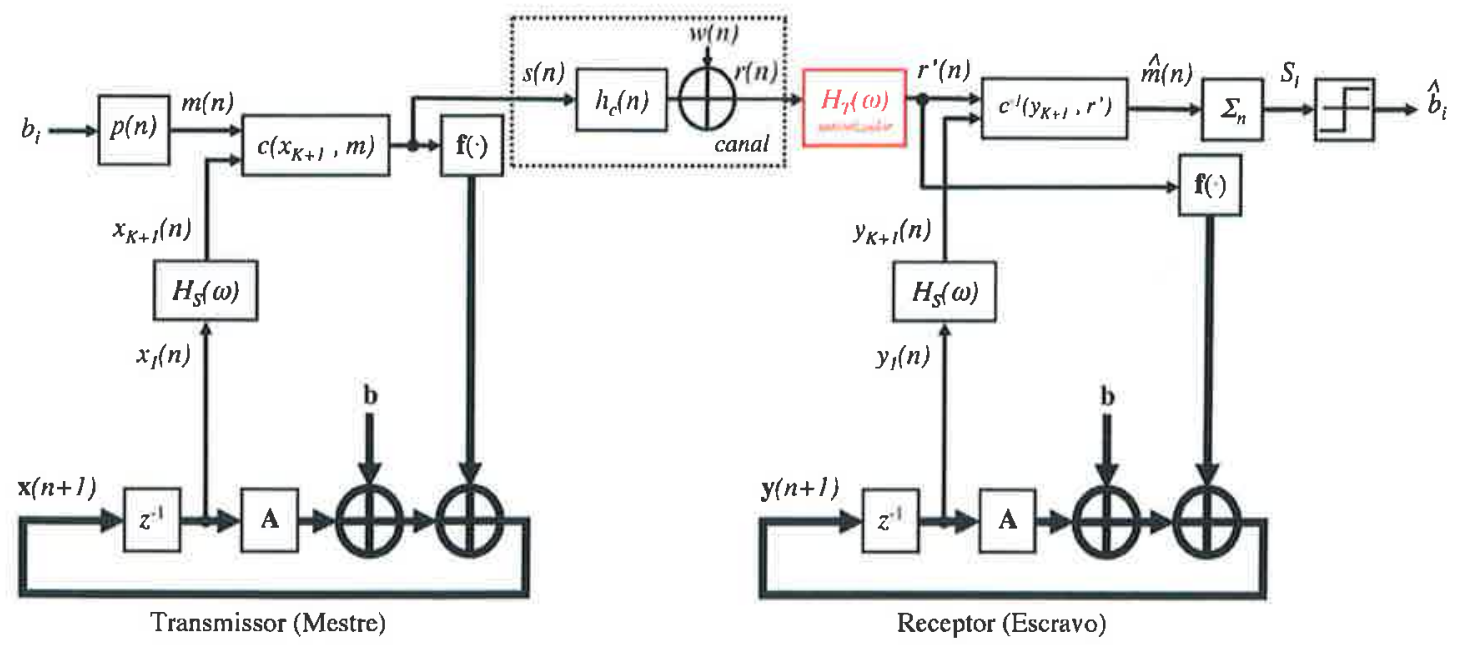

Figura 4.15: SCBC de banda limitada da Figura 4.8 adaptado para mensagens binárias. Fonte: [65].

Uma questão relevante é a escolha da frequência de corte $\omega_{T}$ do filtro sintonizador 
$H_{T}(\omega)$. Trata-se dessa questão, de forma numérica, para um caso particular em [65]. Especificamente, considerou-se canal AWGN fixando-se a frequência de corte dos filtros $H_{S}(\omega)$ em $\omega_{S}=0,2 \pi$. Para garantir-se uma transição abrupta entre a faixa de passagem e de rejeição tomou-se o número de coeficientes de $H_{S}(\omega)$ e $H_{T}(\omega)$ igual a 200. Utiliza-se a função de codificação (4.63) com $\gamma=0,3$ e $\boldsymbol{f}_{H}(\cdot)$ como GSC com $a=0,9$ e $b=0,3$.

Na Figura 4.16(a) mostram-se os valores de BER obtidos como função de $\omega_{T}$ para $\mathrm{SNR}=10 \mathrm{~dB}$. Por um lado, dado que a frequência de corte dos filtros $H_{S}(\omega)$ é $\omega_{S}=0,2 \pi$, verifica-se que para $\omega_{T}<0,2 \pi$ os valores da BER aumentam abruptamente, visto que componentes relevantes de $r(n)$ são atenuadas pelo sintonizador. A partir de $\omega_{T} \approx 0,4 \pi$ a BER aumenta suavemente com $\omega_{T}$, o que indica que não há componente relevante de $r(n)$ acima dessa frequência e aumentar a banda do sinal recebido apenas acrescenta ruído. Assim, a frequência de corte ótimo, $\omega_{T_{o}}$, para o filtro sintonizador deve estar entre $0,2 \pi \mathrm{e}$ $0,4 \pi$. Numericamente, determina-se que o valor de $\omega_{T_{o}}$ que leva à menor BER para essa situação específica é

$$
\omega_{T o} \approx 0,38 \pi
$$

que é indicado na. Figura 4.16(a).

(a)

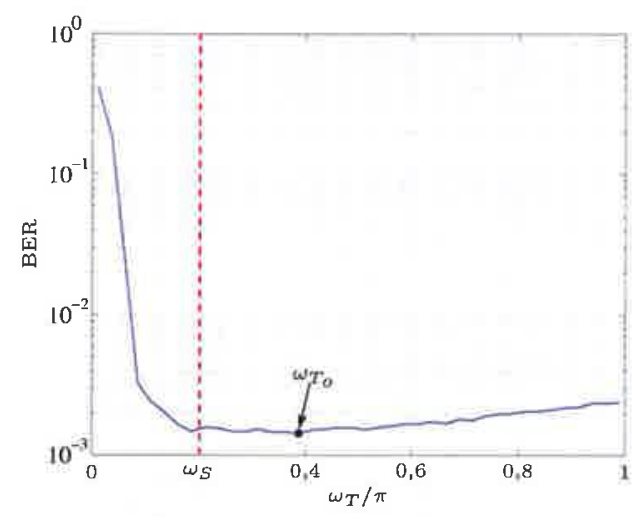

(b)

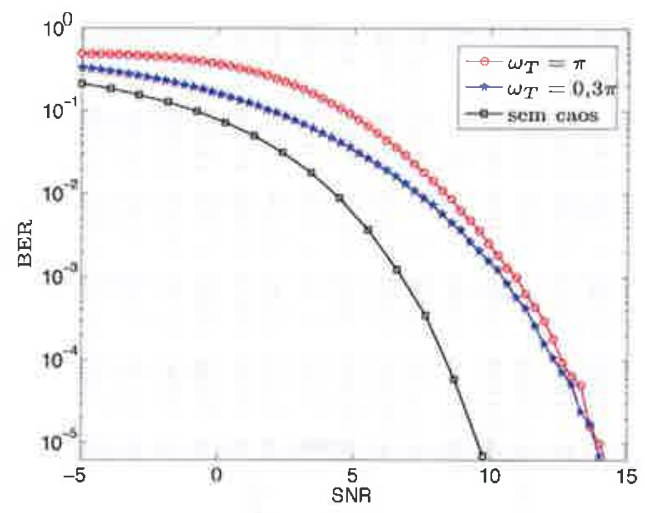

Figura 4.16: (a) BER em função de $\omega_{T}$ para uma SNR de $10 \mathrm{~dB}$; (b) BER em função da SNR para $\omega_{T}=\pi$ (sem sintonizador) e para $\omega_{T}=0,3 \pi$. A curva para o caso ótimo sem caos (4.22) também é mostrada. Fonte: [65].

Na Figura 4.16(b) compara-se o desempenho em termos de BER para os casos com sintonizador ótimo, $\omega_{T_{o}}=0,38 \pi$, e sem o filtro sintonizador, ou seja, $\omega_{T}=\pi$. Observase que há vantagem na utilização do sintonizador para valores de SNR menores do que aproximadamente SNR $=12 \mathrm{~dB}$. Desta forma, o filtro sintonizador está eliminando de fato o ruído acima da banda do sinal transmitido. Para efeito de comparação, o resultado ótimo do caso sem caos, (4.22) também é mostrado. 


\subsubsection{Condições para manutenção do caos}

Um problema relevante, porém raramente abordada na literatura de sistemas dinâmicos aplicados a problemas de comunicações, diz respeito à influência da introdução da mensagem na característica caótica do sinal transmitido. Para SCBCs em que ocorre a realimentação da mensagem no transmissor, como o analisado aqui, esse problema é especialmente importante. Por exemplo, mostrou-se em [29] que, sob certas condições, o sistema da Figura 4.1, quando se utiliza como GSC o mapa de Ikeda $f_{I k}(\cdot)$ deixa de gerar sinais caóticos.

No SCBC de banda limitada discutido nessa seção, o problema torna-se ainda mais complicado porque, além da introdução da mensagem $m(n)$, um filtro FIR $H_{S}(\omega)$ é inserido na malha de realimentação do transmissor. O Teorema 4.1 e o Corolário 4.1 garantem apenas que haverá sincronização entre o transmissor e o receptor, independentemente da escolha de $H_{S}(\omega)$ e da mensagem enviada. Porém, não há nenhuma garantia de que os sinais continuam caóticos, podendo perder a DSCI, tornarem-se periódicos ou mesmo divergir.

Como visto nas Seções 2.2 e 2.3, para verificar se os sinais transmitidos são caóticos, é necessário calcular o maior expoente de Lyapunov do sistema transmissor da Figura 4.15, o que parece desafiante analiticamente pelo fato da ordem do sistema depender do comprimento de $H_{S}(\omega)$ e da característica, em geral aleatória, da mensagem $m(n)$.

Nos últimos anos, o autor e seus colaboradores obtiveram alguns resultados numéricos interessantes para esse problema, que foram publicados nos artigos [25, 100] e na tese [65]. Alguns desses resultados são apresentados a seguir, no intuito de ilustrar o problema e sua complexidade. Preferiu-se não entrar em detalhes nos algoritmos envolvidos no cálculo do maior expoente de Lyapunov, que estão descritos nas referências citadas.

Considera-se como GSC o mapa de Hénon $f_{H}(\cdot)(2.20)$ com $b=0,3$, a função de codificação (4.20) e $m(n)$ na forma (4.58).

Com essas escolhas, o sistema analisado aqui pode ser escrito como [100]

$$
x(n+1)=\left[\begin{array}{l}
x_{1}(n+1) \\
x_{2}(n+1) \\
x_{3}(n+1)
\end{array}\right]=\left[\begin{array}{c}
a-s^{2}(n)+0,3 x_{2}(n) \\
x_{1}(n) \\
\sum_{j=0}^{N_{S}-1} c_{j} x_{1}(n+1-j)
\end{array}\right]
$$

$\operatorname{com} s(n)$ dado por

$$
s(n)=c\left(x_{3}(n), m(n)\right)=(1-\gamma) x_{3}(n)+\gamma m(n) .
$$

Para $\gamma=0$, o sistema não depende da mensagem aleatória $m(n)$, sendo portanto 
determinista. Dessa forma, $h$ pode ser calculado utilizando-se a técnica do mapa tangente [1, p.199-203]. Aborda-se primeiramente esse caso.

Para a estimação do maior expoente de Lyapunov utilizou-se $10^{4}$ pontos da órbita com condições iniciais aleatórias.

Caso $N_{S}=1$ e $\gamma=0$

Nesse caso, $h_{S}(n)$ é um simples ganho $c_{0}$ e a mensagem não influencia o sinal transmitido.

Na Figura 4.17(a) mostra-se o maior expoente de Lyapunov, $h$, e o diagrama de bifurcação de (4.68) para $0<a \leq 1,4$ e $c_{0}=1$, isto é, o sistema sem a presença do filtro, o mapa de Hénon "puro". Nota-se que, após um intervalo de bifurcações periódicas há uma faixa de valores, $1,1 \leq a \leq 1,2$ e $1,25 \leq a \leq 1,4$, para os quais observa-se a geração de sinais caóticos, dado que $h>0$. Em particular, para $a=1,4$, como usualmente utilizado na literatura [1, p. 201], obtém-se caos.
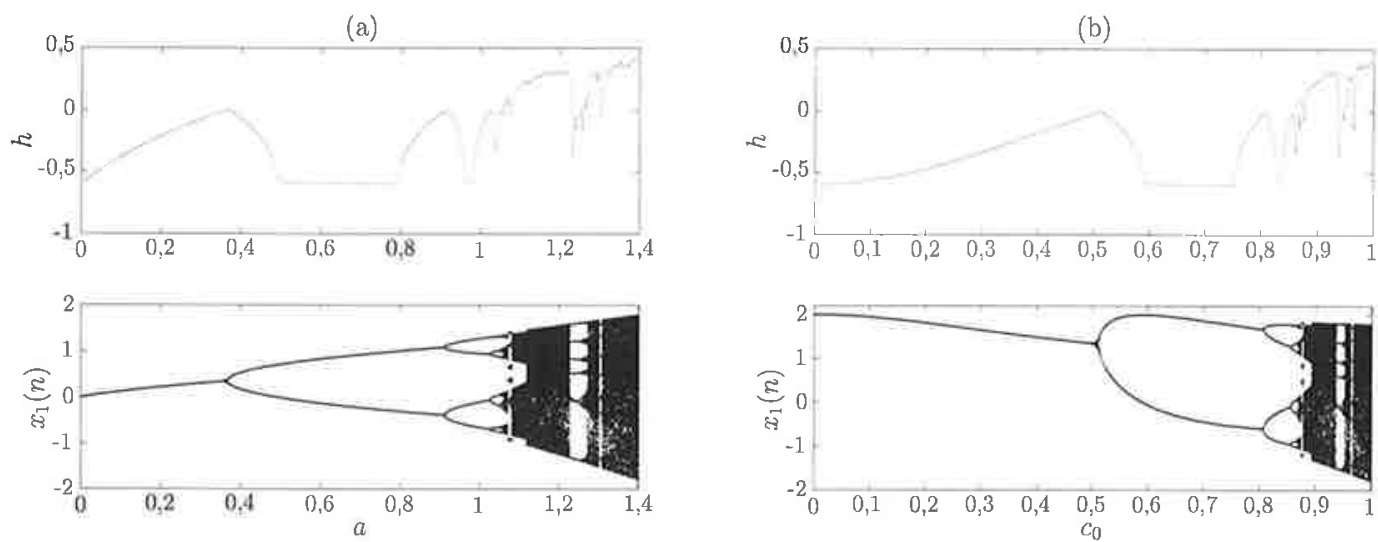

Figura 4.17: Maior expoente de Lyapunov $h$ e diagrama de bifurcação para o mapa (4.68) com $N_{S}=1$ e $\gamma=0$ : (a) em função de $a$ com $c_{0}=1$ e (b) em função de $c_{0}$ com $a=1,4$. Fonte: [100].

Na Figura 4.17(b), fixa-se $a=1,4$, que para o mapa "puro" gera órbitas caóticas e varia-se o coeficiente do filtro $c_{0}$. Ambos os gráficos da Figura 4.17(b) são versões distorcidas daqueles apresentados na Figura 4.17(a). Claramente observa-se que o valor do coeficiente do filtro, $c_{0}$, altera as propriedades caóticas do sistema de Hénon original. Nesse caso é possível obter caos para $0,87 \leq c_{0} \leq 0,92$ e $c_{0}>0,97$, regiões em que $h>0$. Notese que mesmo nesse caso simples, a inclusão do filtro $H_{S}(\omega)$ já afeta significativamente as propriedades dinâmicas dos sinais gerados. Pode-se obter um sinal periódico, com qualquer período desejado escolhendo-se o valor de $c_{0}$ adequado. 
Caso $N_{S}=2$ e $\gamma=0$

No caso $N_{S}=2, h_{S}(n)$ possui dois coeficientes, $c_{0}$ e $c_{1}$. Na Figura 4.18 mostram-se regiões em que o maior expoente de Lyapunov $h$ do sistema (4.68) é positivo ou negativo no plano $c_{0} \times c_{1}$, para $a=1,4$. As regiões azuis (mais escuras) representam $h<0$, ou seja órbitas não-caóticas, enquanto as regiões amarelas (mais claras) têm $h>0$, ou seja, geram-se sinais caóticos. As regiões brancas representam órbitas divergentes.

(a)

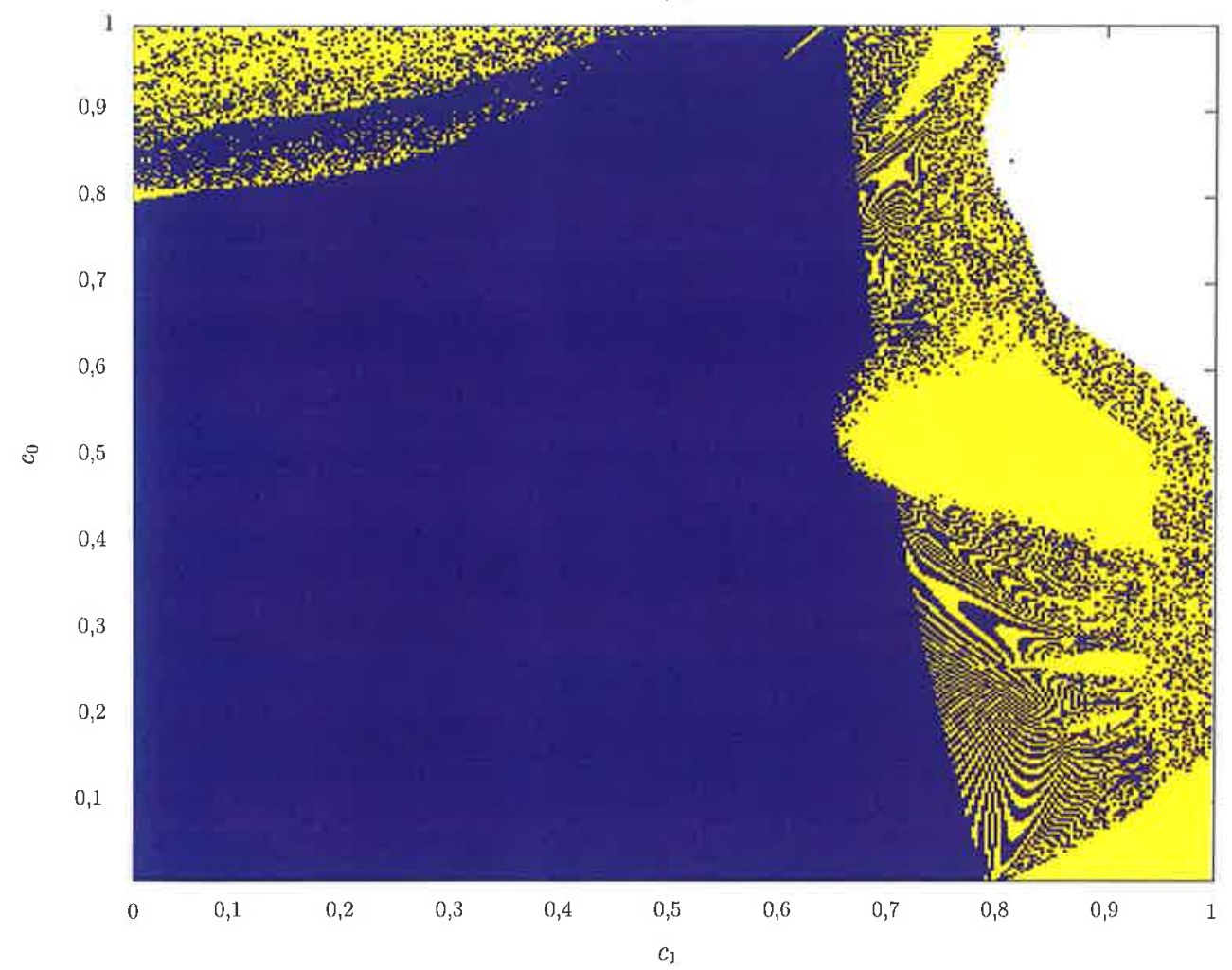

Figura 4.18: Maior expoente de Lyapunov $h$ para (4.68) $\operatorname{com} N_{S}=2, \gamma=0$ e $a=1,4$. As regiões roxas (escuras) representam $h>0$ e as regiões amarelas (claras) representam $h<0$. Nas regiões brancas as órbitas divergem Fonte: [100].

Para $c_{0}<0,6$ e $c_{1}<0,6$ o sistema gera sinais periódicos, enquanto que, para $c_{0}>0,7$ e $c_{1}>0,7$ é possivel obter sinais caóticos, em função dos coeficientes do filtro, para combinações específicas de $c_{0}$ e $c_{1}$. Entretanto, se $c_{0}>0,85$ e $c_{1}>0,85$ as órbitas divergem como mostra a área branca da Figura 4.18.

Observando-se a área da. Figura 4.18 em que $0,6 \leq c_{1} \leq 1$, notam-se alguns padrões complicados entre as regiões que apresentam caos e aquelas que não apresentam essa condição, parecendo haver aí uma estrutura fractal [1, Cap. 4]. Nessa região, pequenas variações nos valores de cada coeficiente podem mudar completamente a dinâmica dos sinais gerados. 
Esses resultados, sem dúvida, merecem uma análise mais detalhada não só numérica, mas também analítica, sendo assunto de trabalho presente do autor e de seus colaboradores.

Caso $N_{S} \geq 3$ e $\gamma=0$

Esse caso foi apresentado em [25].

Como o número de coeficientes aumenta, fica inviável uma análise em função da variação individual deles. Opta-se por uma abordagem em termos da resposta em frequência. Considera-se que $H_{S}(\omega)$ é um filtro FIR passa-baixas com $N_{S}$ coeficientes e frequência de corte $\omega_{S}$ e faz-se a análise em função desses parâmetros.

Nas Figuras 4.19(a) e 4.19(b) mostram-se gráficos de $h$ em função de $\omega_{S}$ e de $N_{S}$, respectivamente. Nesse último toma-se a média dos expoentes obtidos usando-se 10 condições iniciais para cada $N_{S}$ e $\omega_{S}$. As barras verticais em cada ponto do gráfico medem o desvio padrão em torno da média do valor do expoente de Lyapunov.
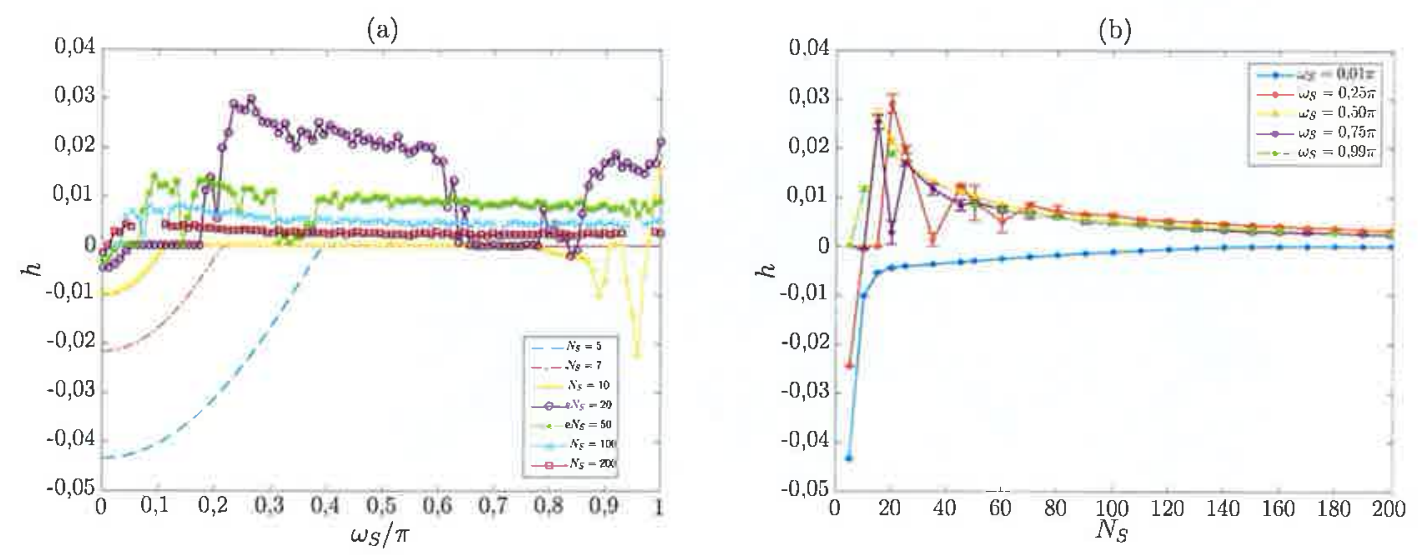

Figura 4.19: Maior expoente de Lyapunov $h$ para o sistema (4.68) em função (a) da frequência de corte $\omega_{S}$ e (b) do número de coeficientes $N_{S}$ do filtro. Pontos não marcados indicam que as órbitas divergem para o par $N_{S}, \omega_{S}$.

Da Figura 4.19(a) nota-se que para $N_{S}>10$ há um intervalo maior de $\omega_{C}$ para as quais os sinais gerados são caóticos. Em contrapartida, para $N_{S} \leq 10, h \leq 0$ para quase todos os valores de $\omega_{c}$.

Dos gráficos da Figura 4.19(b) conclui-se que para $N_{S}>45$ e $\omega_{S} \geq 0,25$, os sinais gerados são caóticos. Nota-se também a convergência dos valores de $h$ para os valores de $\omega_{S}$ simulados.

De modo geral, os resultados mostrados na Figura 4.19 permitem inferir que o sistema transmite sinais caóticos para filtros com $N_{S}$ alto e $\omega_{S}$ não muito baixa.

Para ilustrar esses resultados, mostram-se na Figura 4.20 exemplos de gráficos de 
$x_{1}(n)$ para casos em que (a) $h<0$, (b) $h \approx 0$, (c) $h>0$ e (d) as órbitas divergem. Os resultados claramente coincidem com o esperado, obtendo-se aperiodicidade e DSCI apenas no caso (c).
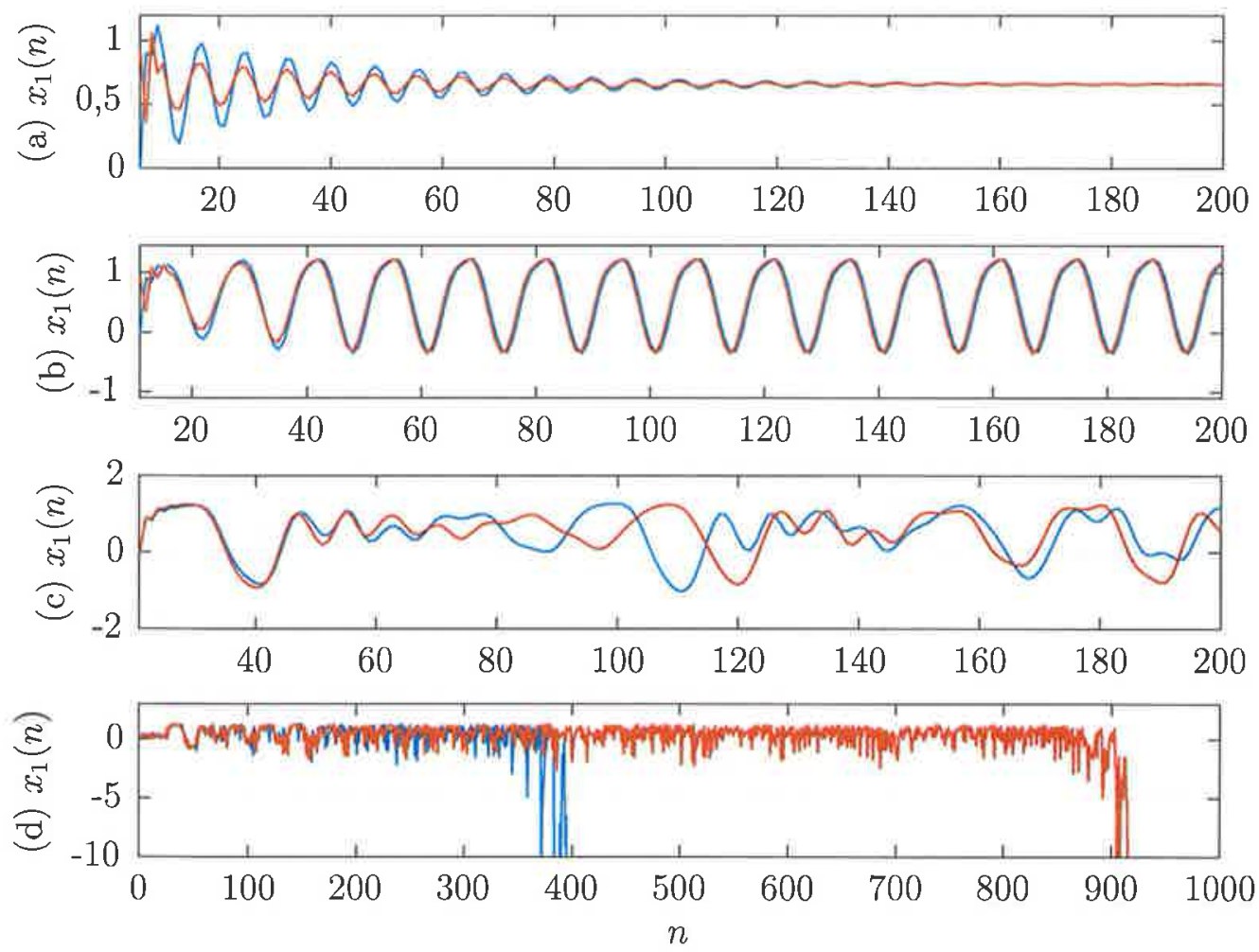

Figura 4.20: Gráficos de $x_{1}(n)$ do sistema (4.68) para duas condições iniciais diferentes e (a) $N_{S}=5, \omega_{S}=0,25 \pi(h \approx-0,02) ;\left(\right.$ b) $N_{S}=10, \omega_{S}=0,25 \pi(h \approx 0)$; (c) $N_{S}=20$, $\omega_{S}=0,25 \pi(h \approx 0,03)$; e (d) $N_{S}=25, \omega_{S}=0,99 \pi$ (órbitas divergentes).

\section{Caso $\gamma \neq 0$}

Para $\gamma \neq 0$, a mensagem $m(n)$ afeta os sinais gerados. Claramente esse é o caso de maior interesse prático, mas também o mais complicado já que insere um componente aleatório no sistema (4.68). Para se definir e calcular $h$ é necessário recorrer à teoria de sistemas dinâmicos aleatórios [111]. Devido à ergodicidade do sistema dinâmico, as propriedades dinâmicas podem ser deduzidas a partir de uma única realização de $m(n)$ suficientemente longa [111]. Utiliza-se novamente a técnica do mapa tangente, tratando-se $m(n)$ como se fosse um parâmetro do sistema que varia amostra a amostra $[29,56,64]$.

Nas Figuras 4.21(a) e (b), mostram-se os valores de $h$ calculados para o sistema (4.68) para $N_{S}=1$ e $c_{0}=1$, ou seja, no caso sem filtro, em função de $\gamma$. Considera-se (a) $a=1,4$ e (b) $a=0,9$. Para cada $\gamma$ é mostrada uma média de $h$ calculada para 10 condições iniciais 
e realizações de $m(n)$ diferentes juntamente com barras de erro.

(a)

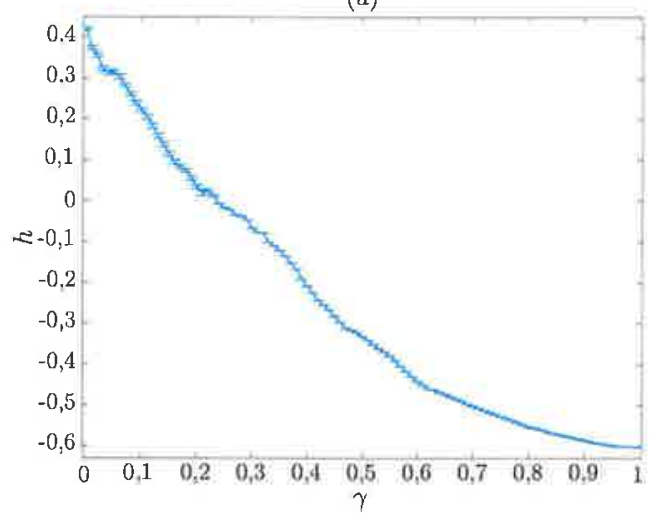

(b)

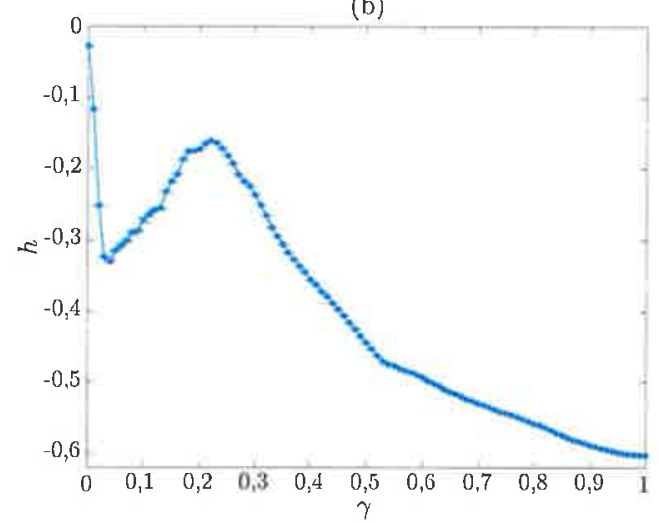

Figura 4.21: Maior expoente de Lyapunov para o sistema (4.68) em função de $\gamma$ para: (a) $a=1,4$ e (b) $a=0,9$. Fonte: [65].

Os resultados mostram que, para $a=1,4$, somente há geração de sinais caóticos quando $\gamma<0$,22. Já para $a=0,9$, para todos os valores de $\gamma$ os sinais gerados não são caóticos. Nota-se então a relevância de se verificar se uma dada proposta de SCBC de fato transmite sinais caóticos, como foi apontado, para um sistema diferente, em [29].

Gráficos de $x_{1}(n)$ nas condições da Figura 4.21(a) são mostrados na Figura 4.22, para (a) $\gamma=0,2(h \approx 0,02)$ e (b) $\gamma=0,3(h \approx-0,08)$.

Os sinais na Figura 4.22 apresentam o comportamento esperado: apenas o caso (a) apresenta DSCI. A aperiodicidade presente no gráfico (b) é devida simplesmente à aperiodicidade de $m(n)$. A DSCI não está presente, o que não é evidente observando-se apenas uma realização de $x_{1}(n)$.

Essa questão do "caos aparente" em SCBCs foi explorada pelos autor e seus colaboradores em [29]. O fato de que a função de codificação (4.69) gera sinais caóticos apenas para valores baixos de $\gamma$ foi analisada em detalhes em [56]. Nesse último artigo propõe-se uma função de codificação alternativa que gera sinais caóticos para um conjunto maior de parâmetros.

Nas Figuras 4.23(a) e (b), mostram-se os expoentes de Lyapunov, para o sistema (4.68) com $a=0,9$, em função de $\gamma$, para diversos valores de $N_{S}$. Em (a) $\omega_{S}=0,5 \pi$ e $L=8$; em (b) $\omega_{S}=0,2 \pi$ e $L=20$. O valor de $L$, é escolhido de acordo com (4.64) de modo que $s(n)$ tenha banda essencial $\omega_{S}$.

Pelas curvas das Figuras 4.23(a) e (b) nota-se novamente que um valor de $\gamma>0,3$ faz com que o comportamento caótico desapareça.

De forma geral, simulações mostram que o SCBC da Figura 4.15, com a função de codificação (4.69) transmite sinais caóticos quando se utiliza o mapa $\boldsymbol{f}_{H}(\cdot)$ para $a=0,9$, 

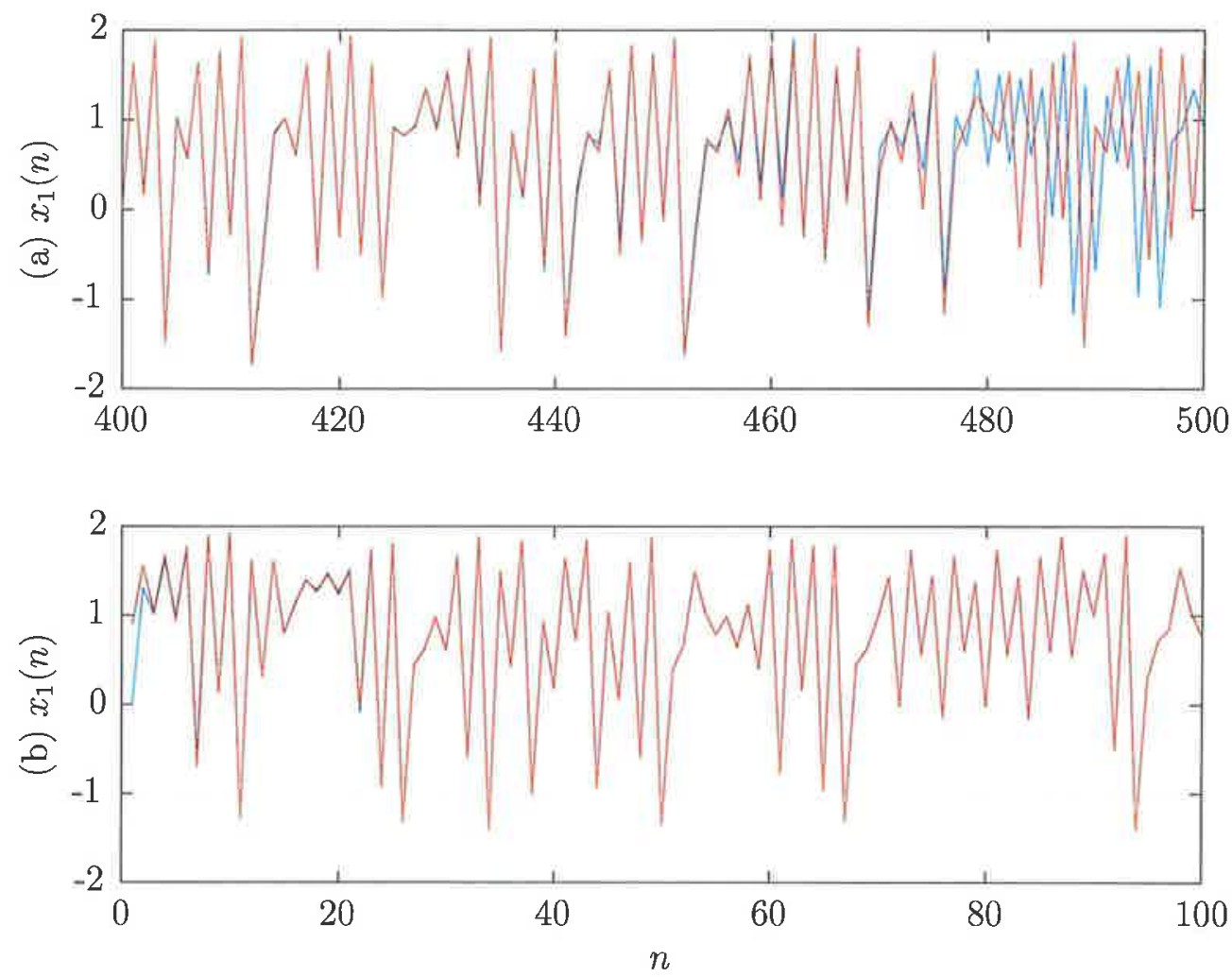

Figura 4.22: Gráficos de $x_{1}(n)$ nas condições da Figura 4.21(a) para duas condições iniciais diferentes: (a) $\gamma=0,2(h \approx 0,02)$ e $(b) \gamma=0,3(h \approx-0,08)$. Fonte: [65].
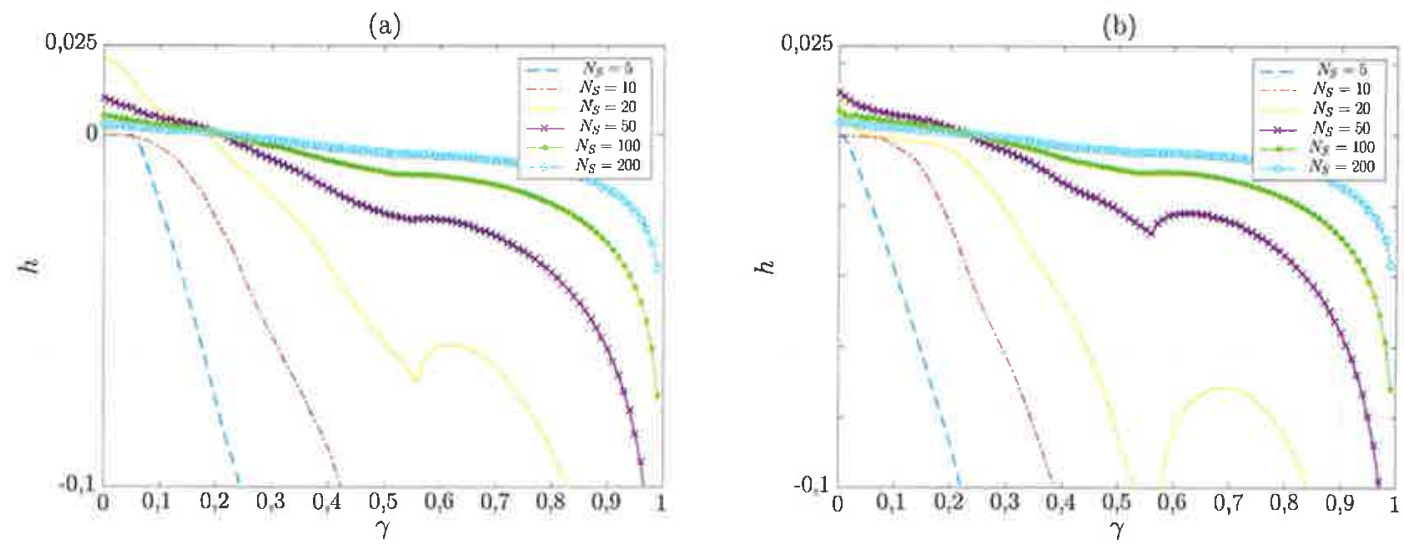

Figura 4.23: Maior expoentes de Lyapunov de (4.68), em função de $\gamma$, para $a=0,9$ e diversos valores de $N_{S}$ : (a) $\omega_{S}=0,5 \pi$ e $L=8$; (b) $\omega_{S}=0,2 \pi$ e $M=20$. Fonte: [65].

$\gamma<0,2, N_{S}>45$ e $\omega_{S}>0,1[65]$.

Os resultados apresentados nessa seção, a respeito da natureza caótica dos sinais transmitidos, ainda são preliminares e necessitam de melhor sistematização e análise. São assuntos de pesquisa atual do autor e de seus colaboradores e deverão gerar publicações 
relevantes nos próximos anos.

\subsubsection{Conclusões}

Na Seção 4.3 apresentou-se uma discussão sobre a adaptação do SCBC mostrado na Figura 4.1 para a transmissão de sinais com banda essencial bem determinada. Limitar a banda dos sinais transmitidos é fundamental em aplicações práticas. Para sistemas sem fio em geral, apenas uma faixa de frequências está disponível para um dado sistema de comunicação. Mesmo em sistemas cabeados, em que não há necessidade de particionamento do canal, trabalhar com sinais limitados em frequência é essencial, já que os canais transmitem bem apenas determinadas faixas [81].

Esse problema começou a ser estudado pelo autor ainda em seu mestrado, para sistemas de tempo contínuo [93] por sugestão de seu orientador, Prof. Max Gerken. O assunto foi retomado já em 2009 tendo gerado diversos resultados relevantes, discutidos aqui.

A solução proposta para a geração de sinais caóticos com banda essencial bem definida, utilizando-se filtros FIR no transmissor e receptor é inicialmente apresentada e na Subseção 4.3.1 mostrou-se que o sincronismo caóticos nos sistemas transmissor e receptor independe dos coeficientes dos filtros utilizados.

Pensando na transmissão de mensagens binárias, $m(n)$ precisa ser formatado adequadamente para que o espectro do sinal transmitido tenha a banda essencial desejada. Além disso, pensando-se em canal AWGN é possível utilizar um filtro sintonizador na entrada do receptor de forma a eliminar o ruído fora de banda. Esses aspectos foram tratados na Subseção 4.3.2.

Por fim, na Subseção 4.3.3 tratou-se de como a inclusão dos filtros e da mensagem afetam as propriedades dinâmicas do GSC. Pelos resultados numéricos apresentados, pode-se notar que o problema parece bastante complicado. A inclusão da mensagem e dos filtros pode fazer com que desapareça a característica DSCI dos sinais transmitidos.

Em resumo, mostrou-se a viabilidade de se transmitir sinais caóticos em canais de banda limitada. Há uma série de problemas ainda em aberto, especialmente em relação a dependência do expoente de Lyapunov com os coeficientes dos filtros e com a mensagem.

Outra questão relevante é a realização em hardware desses sistemas e a forma como as imprecisões inerentes a essas realizações afetarão a sincronização. Nesse sentido, nos próximos anos, pretende-se implementar o SCBC da Figura 4.15 utilizando-se eletrônica definida por software $[112,113]$. 


\subsection{Desempenho em canais dispersivos e equalização}

Até aqui, considerou-se apenas canais AWGN. Pensando-se em aplicações práticas, é fundamental analisar também o desempenho do SCBC da Figura 4.1 em canais dispersivos e variantes no tempo.

Para estudar essa questão, o autor juntou-se a Magno T. M. Silva, professor do Laboratório de Processamento de Sinais (LPS) da EPUSP, especialista em processamento digital de sinais e filtragem adaptativa. Juntos, orientaram a tese de doutoramento de Renato Candido [64] que versa sobre a equalização para o SCBC da Figura 4.1. Atualmente, o Renato Candido está realizando estágio pós-doutoral no LPS com o Prof. Magno e os estudos continuam.

Os resultados obtidos até o momento foram publicado nos artigos $[28,29,37,44,53$, 101]. Alguns desses resultados são descritos de forma resumida nessa seção.

\subsubsection{Formulação do problema de equalização}

Em sistemas de comunicação convencionais, é usual considerar-se um equalizador no receptor de forma a mitigar a interferência intersimbólica (ISI - Intersymbol Interference) introduzida pelo canal $[18,114,115]$. Esquemas de equalização aplicados a SCBCs têm sido propostos na literatura para diferentes abordagens de codificação de mensagens [116120]. Porém, nenhum desses trabalhos aborda casos semelhantes ao SCBC da Figura 4.1, em que a mensagem codificada é realimentada no GSC.

Em [28], propõe-se um equalizador adaptativo para o SCBC da Figura 4.1 usando-se o mapa de Hénon $f_{H}(\cdot)$ como GSC e $m(n)$ binário, $m(n) \in\{-1,+1\}$. Na Figura 4.24 mostra-se o esquema de equalização proposto.

Assume-se um equalizador adaptativo com $N_{e q}$ coeficientes, com vetor regressor de entrada

$$
\boldsymbol{r}(n)=\left[\begin{array}{llll}
r(n) & r(n-1) & \cdots & r\left(n-N_{e q}+1\right)
\end{array}\right]^{T}
$$

e saída

$$
\widehat{s}(n)=\boldsymbol{r}^{T}(n) \boldsymbol{v}(n-1)
$$

sendo

$$
\boldsymbol{v}(n)=\left[\begin{array}{llll}
v_{0}(n) & v_{1}(n) & \cdots & v_{N_{e q}-1}(n)
\end{array}\right]^{T}
$$

o vetor de coeficientes do equalizador no instante $n$.

O objetivo do equalizador é eliminar a ISI introduzida pelo canal e recuperar o sinal transmitido $s(n)$ admitindo-se um atraso fixo de $\Delta$ amostras. Como critério de equalização 


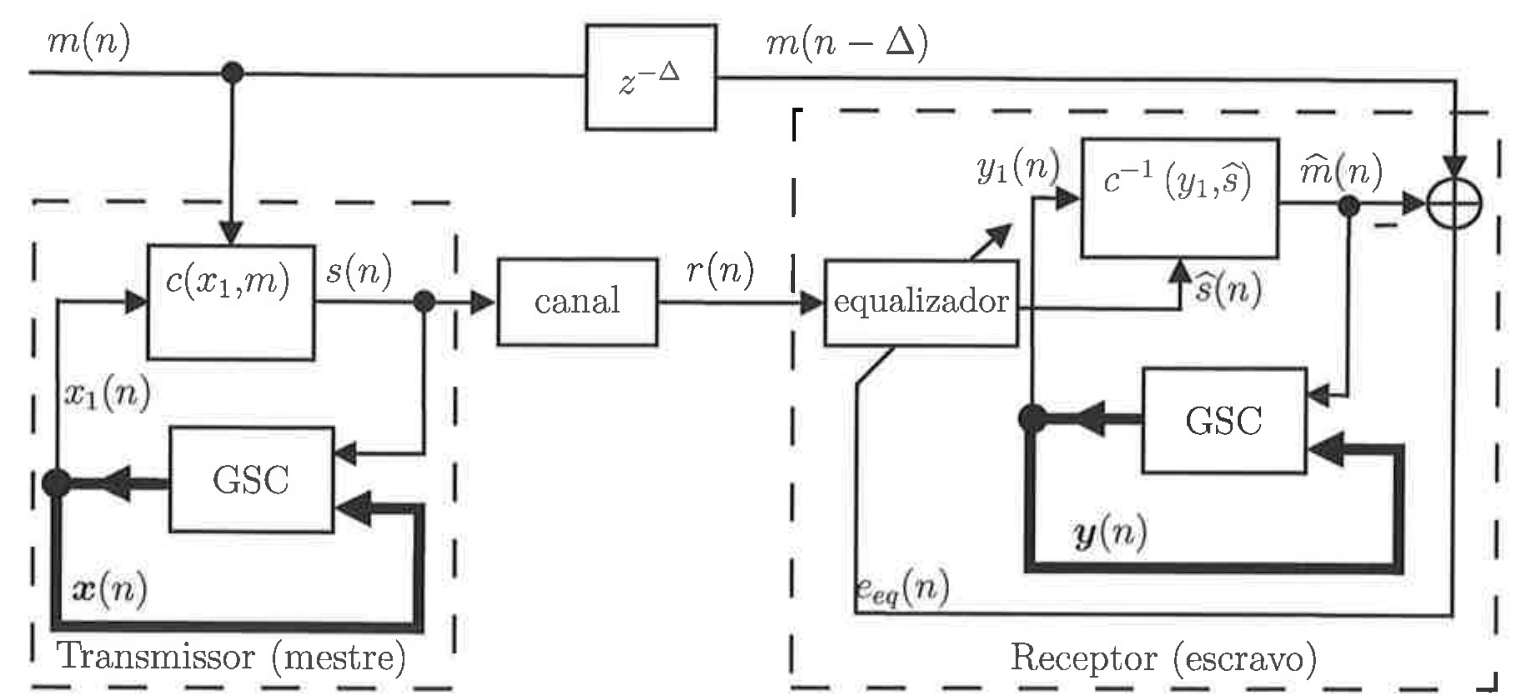

Figura 4.24: Esquema de equalização proposto para o sistema da Figura 4.1. Fonte: [28].

utiliza-se o erro de estimação

$$
e_{e q}(n) \triangleq m(n-\Delta)-\widehat{m}(n)
$$

Assume-se que há uma sequência de treinamento $m(n-\Delta)$ conhecida de antemão no receptor. Nesse caso, o equalizador trabalha no modo de treinamento e atualiza seus coeficientes de modo supervisionado, usando $e_{e q}(n)$ em conjunto com o algoritmo adaptativo. Durante o funcionamento em regime, quando se está de fato transmitindo uma mensagem por meio de $m(n)$, o receptor obviamente não tem acesso prévio a $m(n-\Delta)$ e essa sequência é substituída pela saída de um dispositivo de decisão. Nesse caso, o equalizador trabalha no modo conhecido como decisão direta. Devido à variância no tempo do canal de comunicação, uma comutação entre esse dois modos é necessária sempre que o erro quadrático médio atinge um limiar pré-determinado $[18,114,115]$. Apesar dessa comutação ocorrer constantemente na prática, aqui só será considerado o modo de treinamento. A comutação entre modo de treinamento e decisão direta para o SCBC em estudo é abordada de forma preliminar em [101] e ainda está em estudo.

Como função de codificação, considera-se $[44,121]$

$$
s(n)=c\left(x_{1}(n), m(n)\right)=x_{1}(n) \cdot m(n)
$$

que leva à função de decodificação

$$
\widehat{m}(n)=c^{-1}\left(y_{1}(n), \widehat{s}(n)\right)=\frac{\widehat{s}(n)}{y_{1}(n)},
$$


supondo $y_{1}(n) \neq 0$ para todo $n$.

Essa escolha leva a uma interessante propriedade quando se utiliza $\boldsymbol{f}_{H}(\cdot)$ como GSC: para uma mensagem polar binária $(m(n)= \pm 1)$, de (4.74),

$$
s^{2}(n)=x_{1}^{2}(n)
$$

Assim, de (4.10) e (4.14), $\boldsymbol{x}(n+1)$ não depende de $m(n)$ e, portanto, a mensagem não perturba o GSC. Assim, o sinal transmitido é de fato caótico desde que os sinais gerados pelo GSC sejam caóticos. Como foi visto na Subseção 4.3.3, esse não é sempre o caso quando se utiliza, por exemplo, a função de codificação linear (4.20).

\subsubsection{O algoritmo NLMS caótico}

Algoritmos de gradiente estocástico atualizam os coeficientes de um equalizador adaptativo pela relação

$$
\boldsymbol{v}(n)=\boldsymbol{v}(n-1)-\rho \nabla_{\boldsymbol{v}} \widehat{J}(n),
$$

sendo $\rho$ o passo de adaptação e $\nabla_{v} \widehat{J}(n)$ o vetor gradiente da função de custo instantânea a ser minimizada.

Usando (4.77), o vetor de coeficientes $\boldsymbol{v}(n-1)$ é atualizado na direção oposta à do gradiente de $\widehat{J}(n)$, que é uma função do erro de estimação. Diferentes funções levam a algoritmos com diferentes propriedades como taxa de convergência, custo computacional e capacidade de rastreamento, entre outras $[114,115]$.

Para se obter uma versão do algoritmo de mínimos quadrados (LMS - Least Mean Squares) para adaptar o equalizador no esquema da Figura 4.24, define-se a seguinte função custo instantânea

$$
\widehat{J}(n)=e_{e q}^{2}(n)=[m(n-\Delta)-\widehat{m}(n)]^{2}
$$

Calculando o gradiente de $\widehat{J}(n)$ em relação ao vetor $\boldsymbol{v}(n-1)$, obtém-se

$$
\nabla_{\boldsymbol{v}} \widehat{J}(n)=2 e_{e q}(n) \frac{\partial e_{e q}(n)}{\partial \boldsymbol{v}(n-1)}=-2 e_{e q}(n) \frac{\partial \widehat{m}(n)}{\partial \boldsymbol{v}(n-1)} .
$$

Levando-se em conta o equalizador (4.71) no esquema da Figura 4.24, (4.75) pode ser reescrita como

$$
\widehat{m}(n)=\frac{\widehat{s}(n)}{y_{1}(n)}=\frac{r^{T}(n) \boldsymbol{v}(n-1)}{y_{1}(n)} .
$$


Usando (4.80) e assumindo que $y_{1}(n)$ não depende de $\boldsymbol{v}(n-1)$, obtém-se

$$
\nabla_{\boldsymbol{v}} \widehat{J}(n)=-2 \frac{e_{e q}(n)}{y_{1}(n)} \frac{\partial \widehat{s}(n)}{\partial \boldsymbol{v}(n-1)}=-2 \frac{e_{e q}(n)}{y_{1}(n)} \boldsymbol{r}(n)
$$

Assim, substituindo (4.81) em (4.77) e tomando $\mu=2 \rho$ como passo de adaptação, chega-se à equação de atualização do algoritmo LMS caótico ${ }^{1}$ (cLMS - chaotic LMS) dada por

$$
\boldsymbol{v}(n)=\boldsymbol{v}(n-1)+\mu \frac{e_{e q}(n)}{y_{1}(n)} \boldsymbol{r}(n)
$$

Um problema bem conhecido do algoritmo LMS diz respeito à escolha do passo de adaptação $\mu$ de forma a permitir um erro médio quadrático em regime aceitável e ainda garantir sua estabilidade $[114,115]$. Usar algoritmos de passo variável torna essa escolha mais simples. Além disso, esses algoritmos podem superar em desempenho seus equivalentes não normalizados, principalmente quando as estatísticas do sinal de entrada mudam rapidamente. Esse é o caso do algoritmo LMS normalizado (NLMS - Normalized LMS) $[114,115]$.

Para obter uma versão normalizada do cLMS, define-se primeiramente o erro a posteriori

$$
e_{p}(n) \triangleq m(n-\Delta)-\frac{\boldsymbol{r}^{T}(n) \boldsymbol{v}(n)}{y_{1}(n)}
$$

Usando (4.82), $e_{p}(n)$ pode ser reescrita como

$$
e_{p}(n)=m(n-\Delta)-\frac{\boldsymbol{r}^{T}(n)\left[\boldsymbol{v}(n-1)+\mu \frac{e_{e q}(n)}{y_{1}(n)} \boldsymbol{r}(n)\right]}{y_{1}(n)}=e_{e q}(n)\left[1-\mu \frac{\|\boldsymbol{r}(n)\|^{2}}{y_{1}^{2}(n)}\right] \text {. }
$$

Para forçar $e_{p}(n)=0$ a cada iteração $n$, seleciona-se

$$
\mu(n)=\frac{y_{1}^{2}(n)}{\|\boldsymbol{r}(n)\|^{2}}
$$

Introduzido um passo de adaptação fixo $\widetilde{\mu}$ para controlar a taxa de convergência e um fator de regularização $\delta$ para prevenir a divisão por zero no cálculo de $\mu(n)$ e substituindo o passo de adaptação resultante em (4.82), obtém-se o algoritmo NLMS caótico (cNLMS - chaotic NLMS):

$$
\boldsymbol{v}(n)=\boldsymbol{v}(n-1)+\frac{\tilde{\mu}}{\delta+\|\boldsymbol{r}(n)\|^{2}} y_{1}(n) e_{e q}(n) \boldsymbol{r}(n)
$$

\footnotetext{
${ }^{1}$ Usa-se o termo caótico para os algoritmos deduzidos nos trabalhos publicados para distingui-los das versōes originais dos algoritmos LMS e LMS normalizado (NLMS - Normalized LMS) [114, 115]. O uso do termo não implica comportamento caótico por parte dos algoritmos.
} 
Pode-se mostrar [28] que o cNLMS é estável se $\widetilde{\mu}$ for escolhido no intervalo

$$
0<\widetilde{\mu}<2,
$$

ou seja, para esses valores de $\widetilde{\mu}$, o algoritmo não diverge.

Note que o cNLMS depende não apenas do erro de estimação $e_{e q}(n)$, mas também de $y_{1}(n)$. Como $y_{1}(n)$ depende não linearmente de $\widehat{s}(n-1)$, o cNLMS é uma versão não linear do NLMS.

Para evitar a divisão por um valor próximo de zero no cálculo de $\widehat{m}(n)$, substitui-se (4.75) por

$$
\widehat{m}(n)=\operatorname{sign}\left[\widehat{s}(n) y_{1}(n)\right]
$$

quando $\left|y_{1}(n)\right|<\varepsilon$, sendo $\varepsilon$ uma constante positiva pequena.

De forma a garantir a estabilidade do algoritmo e evitar grandes erros quando $y_{1}(n)$ é grande, introduz-se um limite superior para $\left|y_{1}(n)\right|$, isto é, se $\left|y_{1}(n)\right|>Y$, faz-se $y_{1}(n) \leftarrow Y \operatorname{sign}\left[y_{1}(n)\right]$ sendo $Y$ uma constante positiva. Em [28] utiliza-se $Y=100$.

O algoritmo cNLMS descrito é resumido na Tabela 4.1.

\subsubsection{Resultados de simulações}

Para ilustrar o comportamento do algoritmo cNLMS, mostram-se algumas simulações realizadas assumindo $a=1,4$ e $b=0,3$. Os vetores de estado dos sistemas transmissor e receptor foram inicializados com $\boldsymbol{x}(0)=\left[\begin{array}{ll}0 & 0\end{array}\right]^{T}$ e $\boldsymbol{y}(0)=\left[\begin{array}{ll}0,1 & -0,1\end{array}\right]^{T}$, respectivamente. Outras inicializações também possibilitam bons resultados em termos de sincronismo quando o equalizador é capaz de eliminar razoavelmente bem a ISI. Além disso, o equalizador foi inicializado com $\boldsymbol{v}(0)=0$ e, para comparação, também se considera o sistema da Figura 4.24 sem o equalizador, para o qual $\widehat{s}(n)=r(n)$.

Como medida de desempenho, considera-se o erro médio quadrático em excesso (EMSE - Excess Mean-Square Error) [114, 115] definido como

$$
\mathrm{EMSE} \triangleq \mathbb{E}\left[e_{a}^{2}(n)\right]
$$

com o erro a priori $e_{a}(n)$ definido como

$$
e_{a}(n)=\boldsymbol{r}^{T}(n)\left[\boldsymbol{v}_{o}-\boldsymbol{v}(n-1)\right]
$$

sendo $\boldsymbol{v}_{o}$ a solução de Wiener $[114,115]$, dada por

$$
\boldsymbol{v}_{\circ}=\boldsymbol{R}^{-1} \boldsymbol{g}
$$


Tabela 4.1: Algoritmo cNLMS. Fonte: [28].

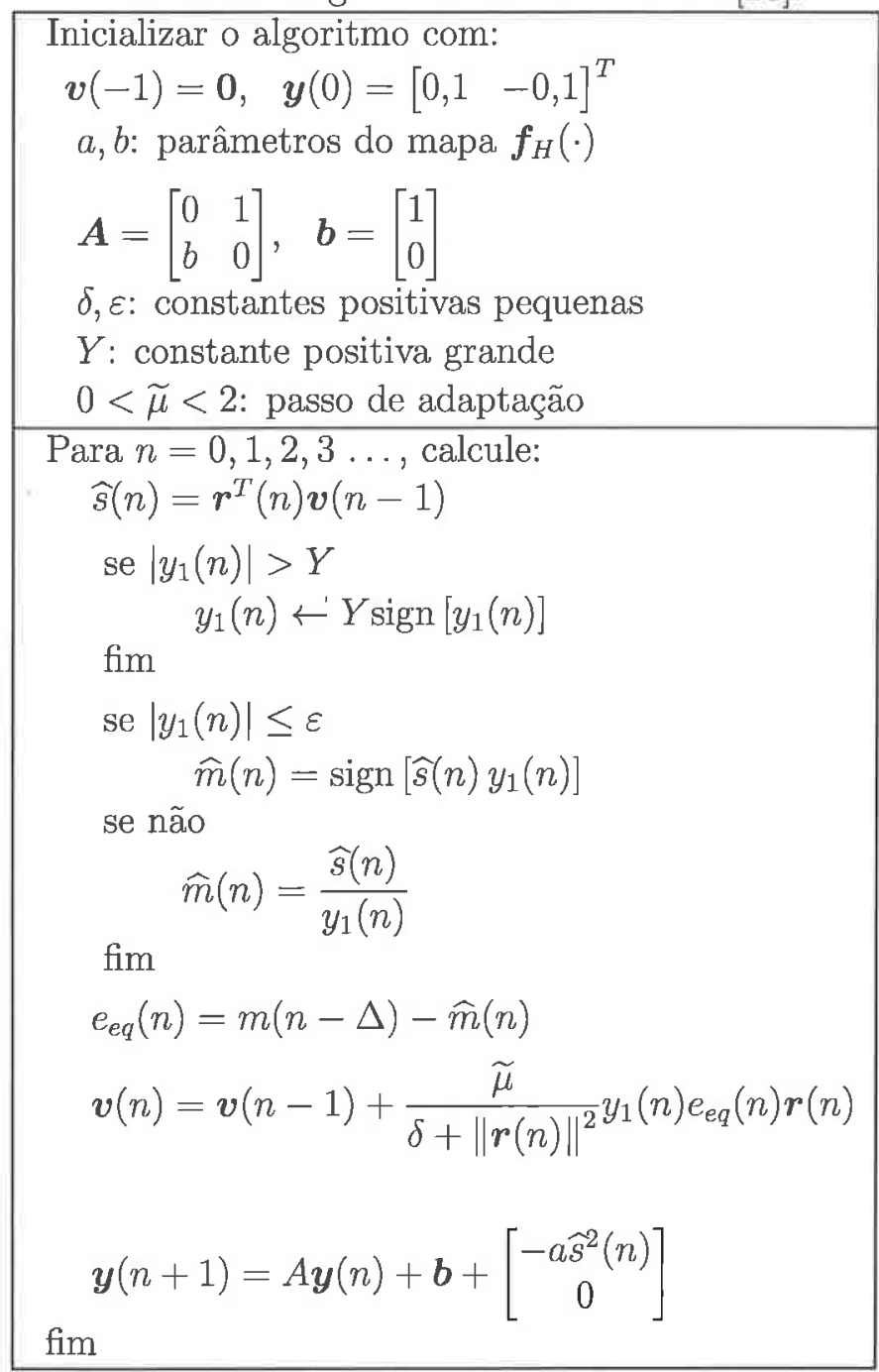

em que $\boldsymbol{R}=\mathbb{E}\left[\boldsymbol{r}(n) \boldsymbol{r}^{T}(n)\right]$ é a matriz de autocorrelação do sinal na entrada do equalizador e $\boldsymbol{g}=\mathrm{E}\{s(n-\Delta) \boldsymbol{r}(n)\}$ é a correlação cruzada entre o vetor regressor de entrada e o sinal de treinamento transmitido. Como a maioria dos filtros adaptativos convergem na média para a solução de Wiener (4.91), ela é considerada como uma referência para a medida de desempenho do cNLMS. O EMSE mede o quanto $\mathbb{E}\{\widehat{J}(n)\}$ excede o seu mínimo devido à adaptação. Se o algoritmo convergir para a solução de Wiener, o EMSE será nulo. Como é usual na área, costuma-se representar o EMSE em decibels (dB),

$$
\operatorname{EMSE}(\mathrm{dB})=10 \log (\mathrm{EMSE})
$$

Também considera-se a BER como outra medida de desempenho. Nesse caso, desprezam-se os primeiros $3 \times 10^{5}$ bits para aguardar a convergência do equalizador e utilizam-se $10^{6}$ bits no seu cálculo. A BER obtida com a solução de Wiener é considerada como limite 
inferior para o esquema proposto.

Na Tabela 4.2 [64] listam-se os canais utilizados nas simulações relatadas aqui.

Tabela 4.2: Canais de comunicação utilizados nas simulações. Fonte: [64].

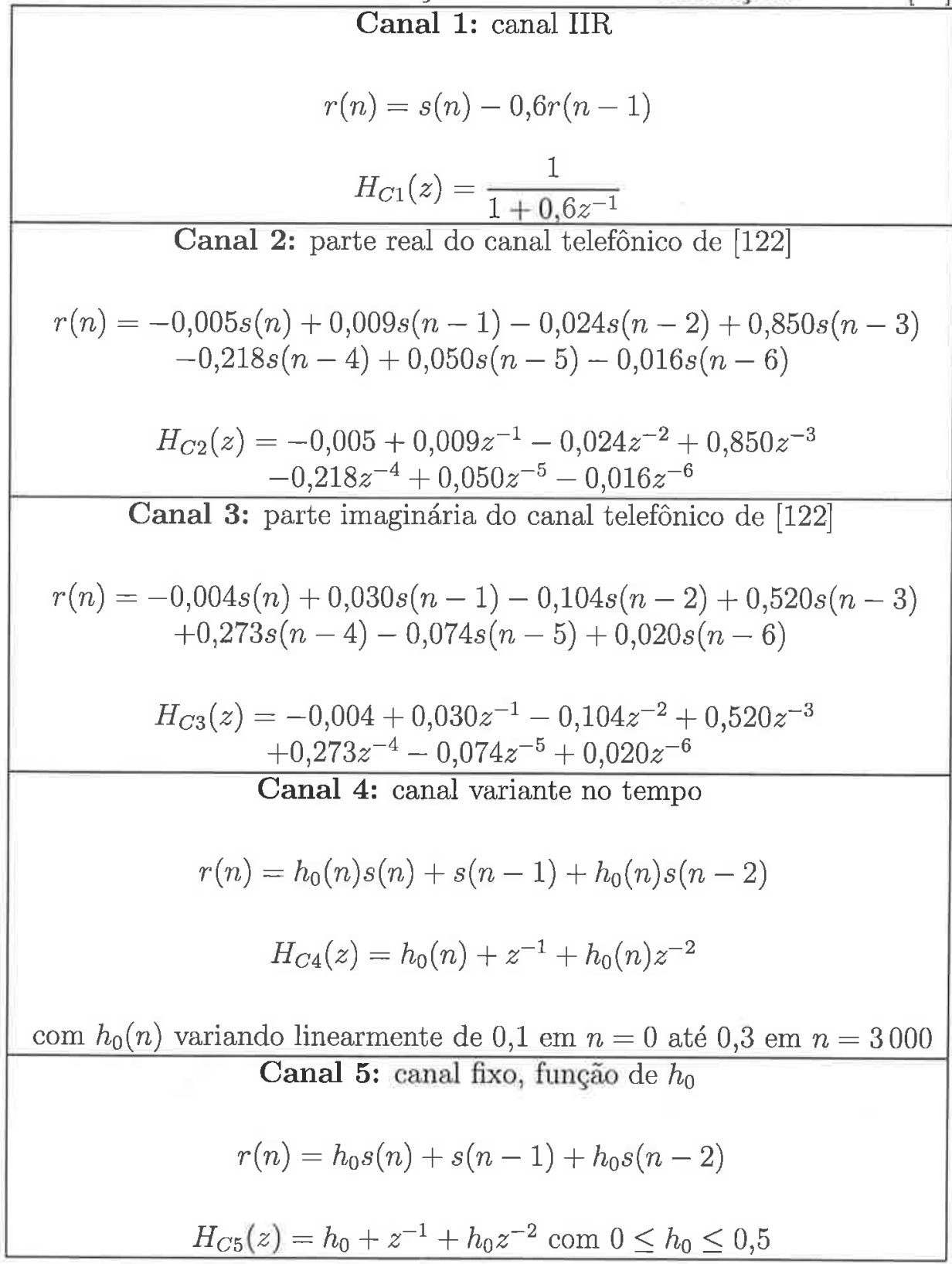

Primeiramente assume-se que $m(n) \equiv 1 \mathrm{e}$, consequentemente, de (4.74), $s(n)=x_{1}(n)$. Considera-se o canal IIR $H_{C 1}(z)$. Como esse canal é um filtro IIR só-polos [84], é possível a equalização perfeita na ausência de ruído. Nesse caso simples,

$$
\boldsymbol{v}_{o}=\left[\begin{array}{ll}
1 & 0,6
\end{array}\right]^{T}
$$

Apesar de não haver transmissão de informação entre transmissor e receptor nessa si- 
tuação, com essa simulação mostra-se que o equalizador tem um papel essencial em permitir a sincronização caótica.

$O$ efeito do canal $H_{C 1}(z)$ pode ser observado comparando-se os atratores reconstruídos utilizando-se $s(n)$ e $r(n)$. Devido à ação do canal, as características dinâmicas do sinal $s(n)=x_{1}(n)$ são perdidas, como pode-se observar comparando-se os atratores dos gráficos (a) e (b) da Figura 4.25. No gráfico (c), é possível notar que o equalizador foi capaz de eliminar o efeito do canal, recuperando um atrator similar ao original.
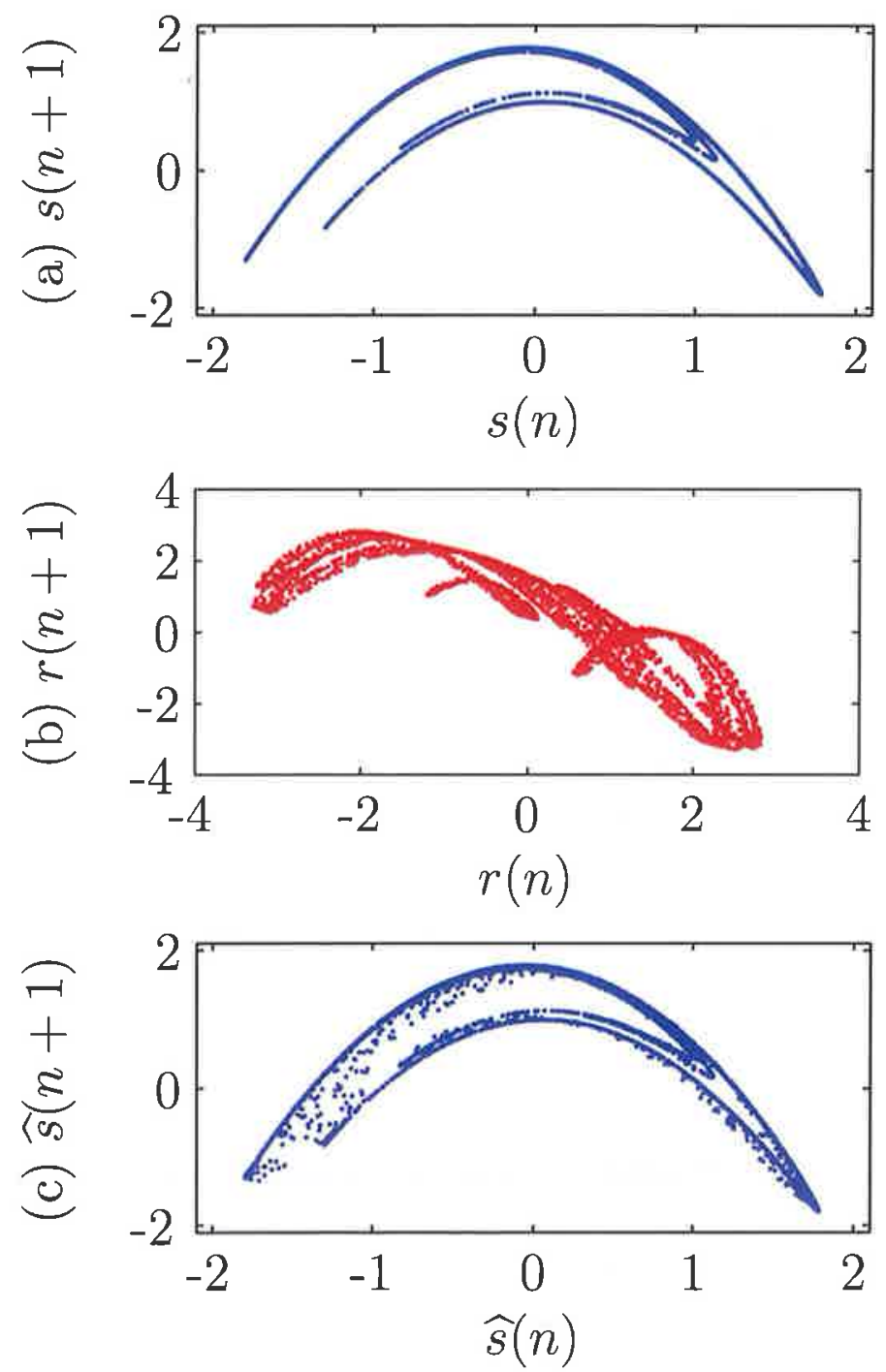

Figura 4.25: Atrator no sistema receptor reconstruído utilizando o sinal: (a) transmitido $s(n)$, (b) recebido $r(n)$ (c) recuperado com o equalizador cNLMS $\widehat{s}(n)$ no caso $m(n) \equiv 1$; $N_{e q}=2 ; \Delta=0$; canal $H_{C 1}(z)$. Fonte: [28].

A sequência $\widehat{m}(n)$ estimada com o equalizador cNLMS é mostrada na Figura 4.26(b). O valor médio dos dois coeficientes e o EMSE ao longo das iterações, estimado a partir de $10^{3}$ realizações são mostrados, respectivamente, nos gráficos (c) e (e) da mesma figura. 

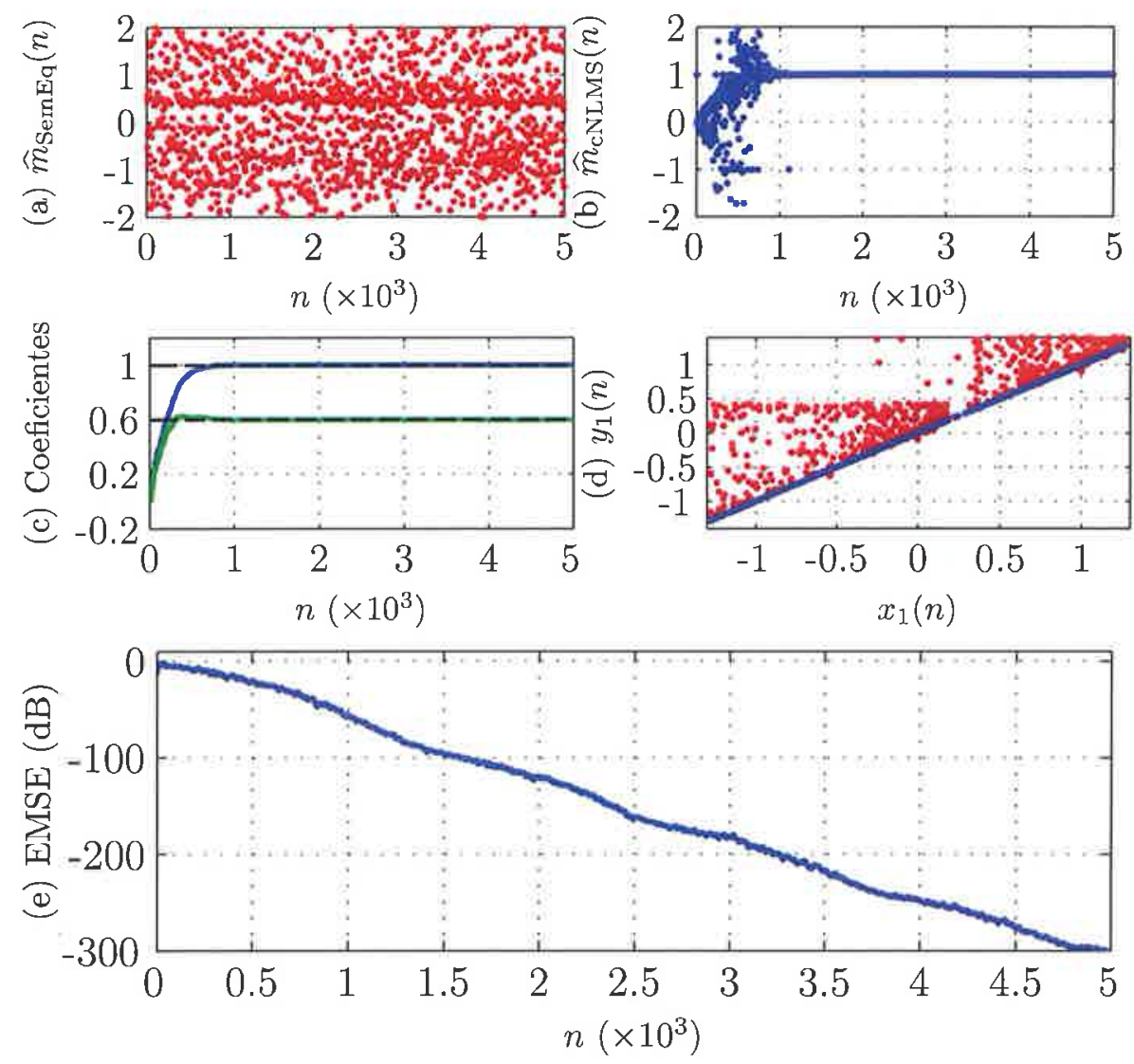

Figura 4.26: Mensagem recuperada (a) sem equalizador; (b) com o cNLMS ( $\widetilde{\mu}=0,005$, $\delta=10^{-5}, \varepsilon=0,1$ ); (c) Média dos coeficientes do cNLMS e solução de Wiener (linhas tracejadas); (d) $y_{1}(n) \times x_{1}(n)$ : pontos em vermelho para $0<n \leq 2000$ e pontos azuis para $n>2000$ (e) EMSE Estimado; média de $10^{3}$ realizações; $N_{e q}=2 ; \Delta=0$; canal $H_{C 1}(z)$. Fonte: [28].

Pode-se observar que os coeficientes do equalizador tendem a $\boldsymbol{v}_{o}$ de (4.93), como mostrado pelas linhas tracejadas na Figura 4.26(c). Além disso, o equalizador está funcionando como esperado já que a solução elimina a ISI permitindo a sincronização dos sistemas transmissor e receptor, como confirmado pela Figura 4.26(d), já que para $n>2000$, o gráfico de $y_{1}(n) \times x_{1}(n)$ torna-se próximo à reta diagonal do $1^{\circ}$ e $3^{\circ}$ quadrantes. Não há sincronização e a mensagem não pode ser recuperada sem equalizador, como pode ser visto na Figura 4.26(a).

Nas simulações seguintes, assume-se a transmissão de sequências aleatórias equiprováveis $m(n) \in\{-1,1\}$. Considera-se novamente o canal $H_{C 1}(z)$ com $\Delta=0$ e ausência de ruído. A sequência estimada pelo equalizador cNLMS e o erro depois do dispositivo de decisão, ambos para uma realização, são mostrados nos gráficos (b) e (c) da Figura 4.27. A média dos dois coeficientes e o EMSE ao longo das iterações, estimado a partir da média amostral sobre $10^{3}$ realizações são mostrados, respectivamente, nos gráficos (d) 
e (e).
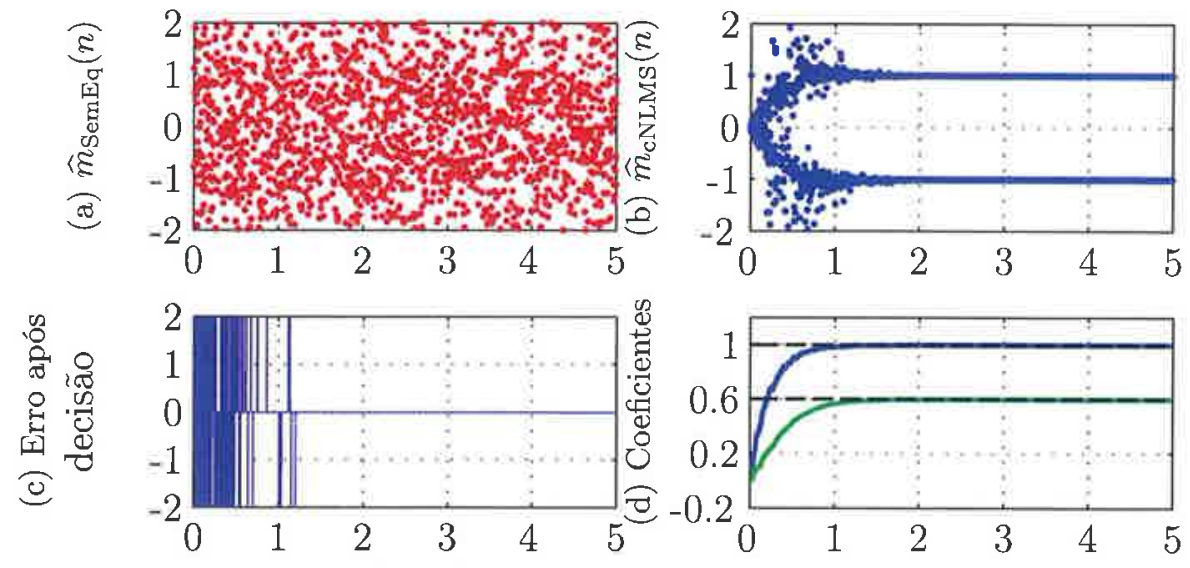

$$
n\left(\times 10^{3}\right)
$$

$n\left(\times 10^{3}\right)$

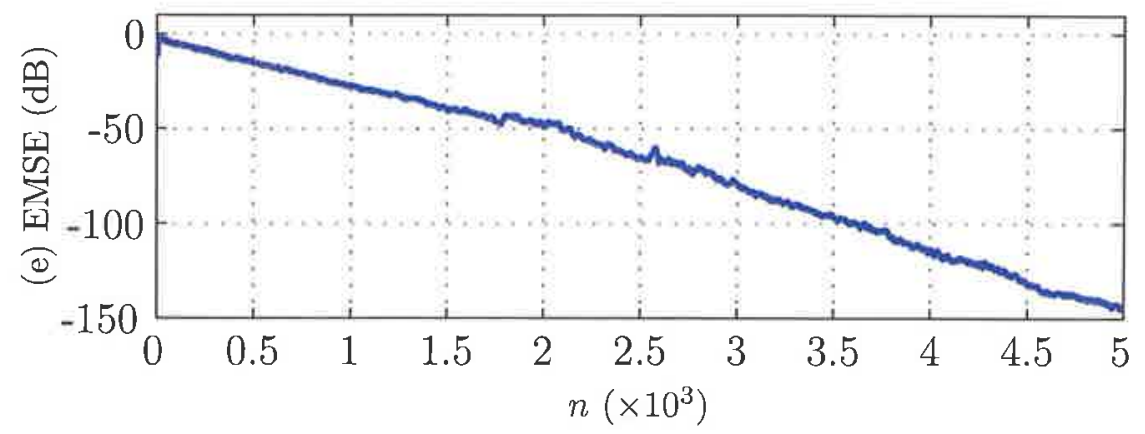

Figura 4.27: Mensagem recuperada (a) sem equalizador e (b) usando cNLMS $(\widetilde{\mu}=0,005$, $\delta=10^{-5}, \varepsilon=0,1$; (c) Erro depois da decisão; (d) Média dos coeficientes do cNLMS e solução de Wiener (linhas tracejadas); (e) EMSE estimado; média de $10^{3}$ realizações; $N_{e q}=2 ; \Delta=0$; canal $H_{C 1}(z)$. Fonte: [28].

Novamente, os coeficientes do equalizador se aproximam de $\boldsymbol{v}_{o}(4.93)$ e o equalizador recupera de forma apropriada a sequência transmitida, o que pode ser confirmado pelos erros depois do dispositivo de decisão mostrados no gráfico (c). A comunicação é completamente perdida no caso sem equalizador, como mostrado na Figura 4.27(a).

O efeito do canal de comunicação também pode ser observado por meio dos atratores reconstruídos usando os sinais transmitidos e recebidos. Eles são mostrados nos gráficos (a) e (b) da Figura 4.28. Devido ao efeito do canal, as características da dinâmica do sinal transmitido são bastante modificadas, como pode ser observado no gráfico (b). No gráfico (c), é possível notar que o equalizador foi capaz de eliminar o efeito do canal, recuperando novamente um atrator similar ao original.

Em seguida, verifica-se o comportamento do equalizador no caso em que a uma variação abrupta no canal. Para isso, considera-se o seguinte cenário na ausência de ruído: inicialmente, $s(n)$ é transmitido pelo canal $H_{C 2}(z)$. Então, em $n=30 \times 10^{3}$, esse canal é mudado de forma abrupta para $H_{C 3}(z)$. Para ambos os canais, utiliza-se um equalizador 

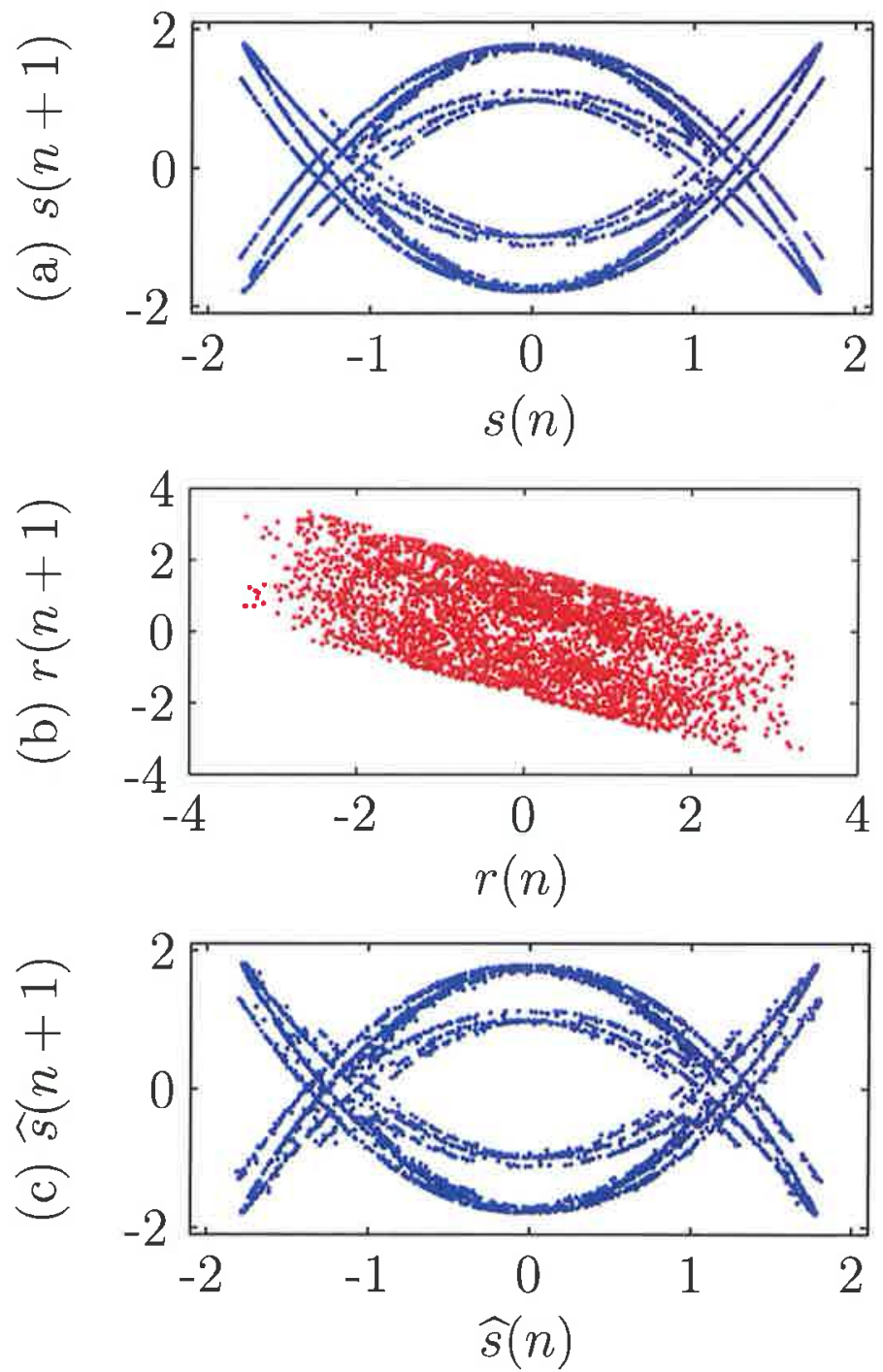

Figura 4.28: Atrator reconstruído usando o sinal: (a) transmitido; (b) recebido e (c) recuperado com o equalizador quando $m(n)$ é uma sequência binária aleatória. Os parâmetros são os mesmos da Figura 4.25. Fonte: [28].

com $N_{e q}=25$ coeficientes e um atraso de $\Delta=12$ amostras.

Os resultados para esse cenário são mostrados na Figura 4.29.

Como pode-se notar, os coeficientes do equalizador cNLMS convergem para a solução de Wiener [115], cujos coeficientes são mostrados em linhas tracejadas na Figura 4.29(d). É relevante notar que o cNLMS é capaz de acompanhar a variação abrupta no canal, alcançando o regime permanente novamente. O equalizador desempenha o importante papel de mitigar a ISI já que o desempenho do sistema sem o equalizador é consideravelmente pior, como pode ser observado na Figura 4.29(a).

Para verificar o comportamento do equalizador em um canal variante no tempo, 

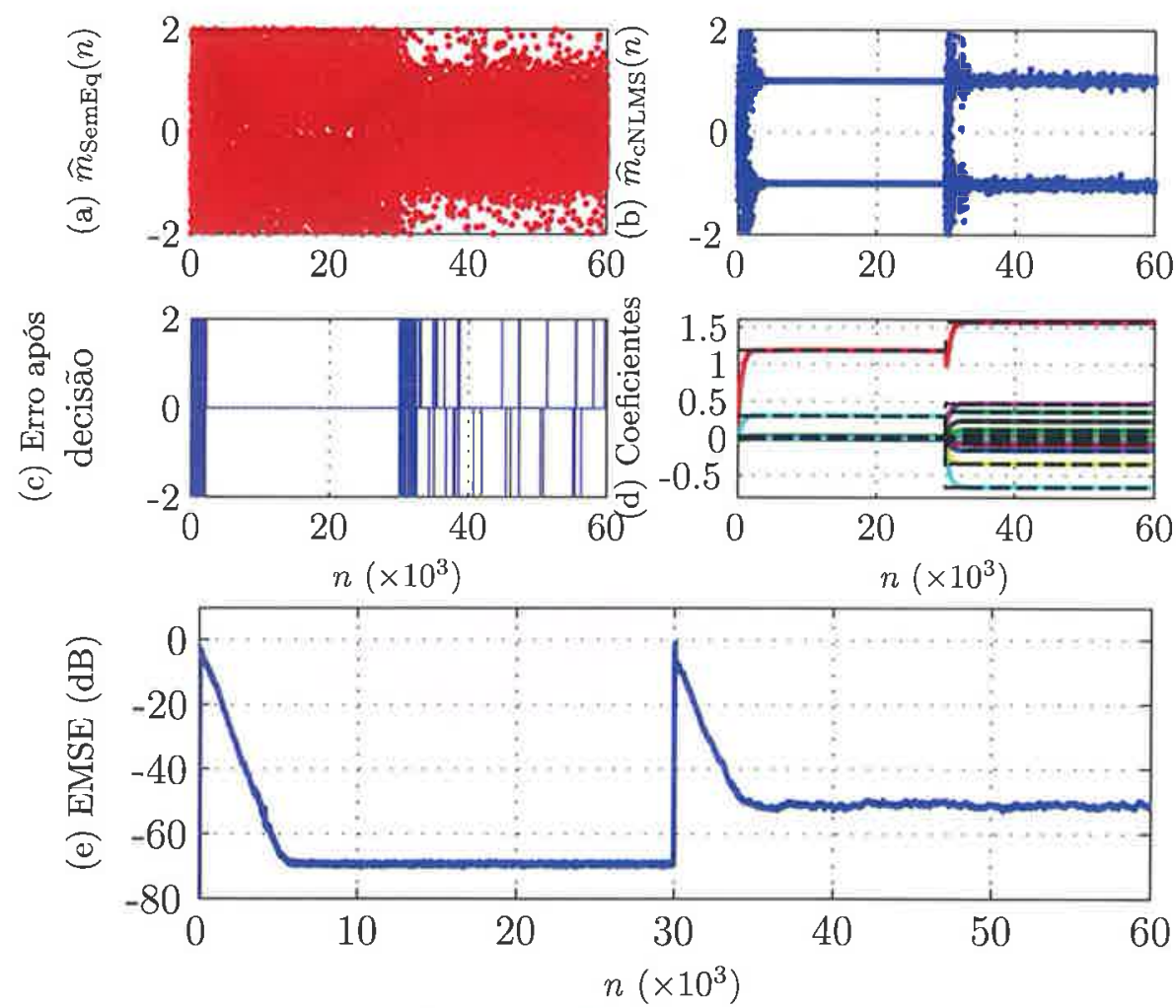

Figura 4.29: Mensagem recuperada (a) sem equalizador e (b) com o equalizador cNLMS $\left(\widetilde{\mu}=0,25 ; \delta=10^{-5} ; \varepsilon=0,1 ; N_{e q}=25 ; \Delta=12\right.$ ); (c) Erro após decisão; (d) Média dos coeficientes do equalizador e solução de Wiener (linhas tracejadas); (e) EMSE estimado; média de $10^{3}$ realizações; variação abrupta do Canal $H_{C 2}(z)$ para o $H_{C 3}(z)$ em $n=$ $30 \times 10^{3}$. Fonte: [28].

considerou-se a transmissão de $s(n)$ pelo canal $H_{C 4}(z)$. Os resultados para esse cenário são mostrados na Figura 4.30.

Nota-se que o equalizador é capaz de se adaptar conforme o canal varia, obtendo-se boas estimações da solução de Wiener instantânea, mostrada pelas linhas tracejadas na Figura 4.30(d).

Para avaliar a robustez da sincronização caótica com relação à ISI, obtém-se curvas de BER do SCBC para o canal $H_{C 5}(z)$ na ausência de ruído com $N_{e q}=21$ e $\Delta=11$. Eles são mostrados na Figura 4.31. Note-se que no caso sem equalizador, o atraso deve-se somente ao canal. Assim, comparou-se a sequência recuperada com $m(n-\Delta)$, para $\Delta=1$ nesse caso. Quanto menor o valor de $h_{0}$, menor a ISI introduzida pelo canal.

Pode-se observar que o cNLMS elimina praticamente os efeitos do canal, obtendo-se uma equalização quase perfeita $\left(\mathrm{BER}<10^{-6}\right.$ ) para $0 \leq h_{0} \leq 0,2$. Além disso, atinge-se a solução de Wiener para todos os valores de $h_{0}$, superando de longe o caso sem equalizador para todos os valores de $h_{0}$ considerados. Note que mesmo uma mínima imperfeição do 

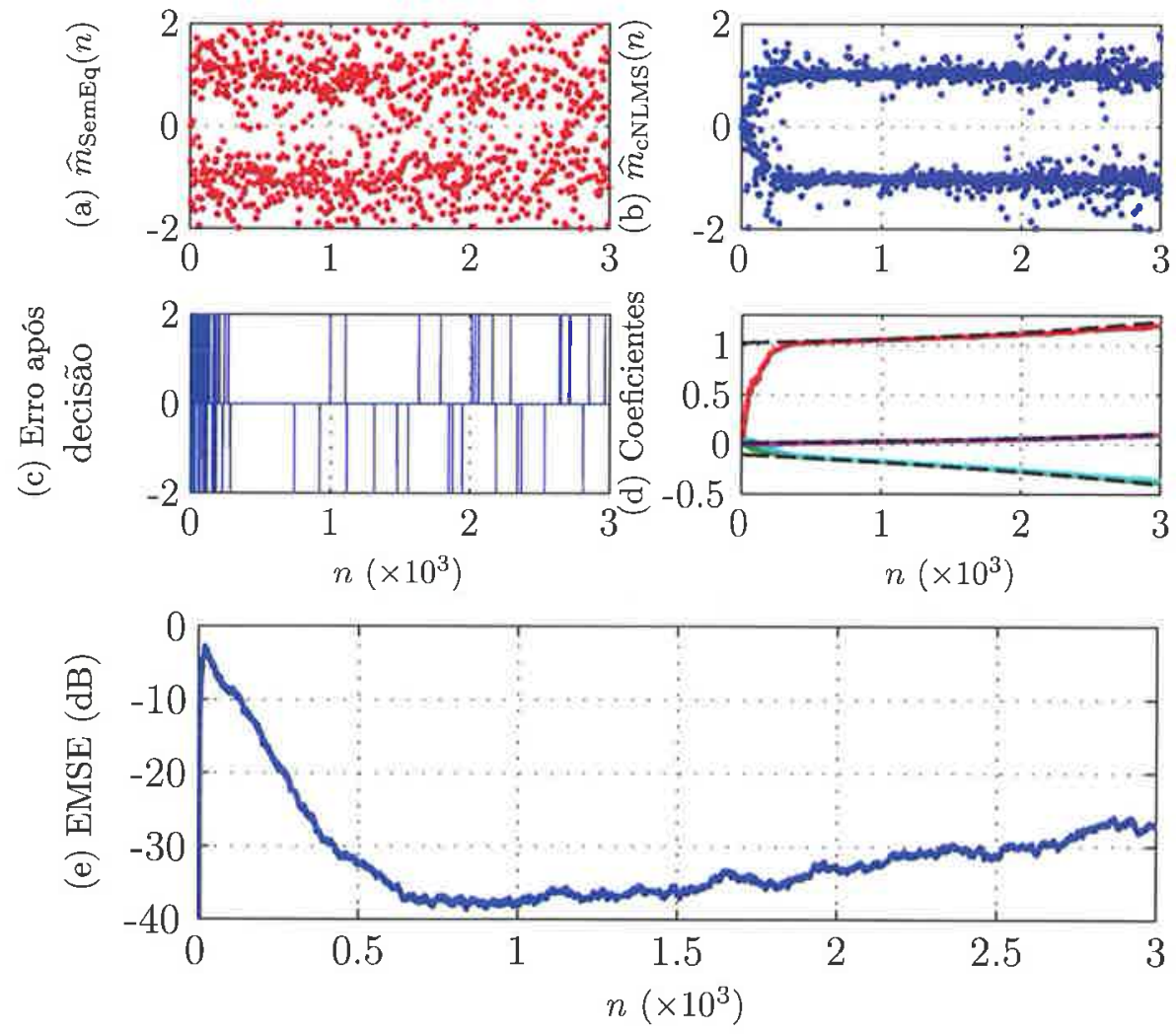

Figura 4.30: Mensagem recuperada (a) sem equalizador e (b) com o equalizador cNLMS $\left(\widetilde{\mu}=0,1, \delta=10^{-5}, \varepsilon=0,1 ; N_{e q}=5 ; \Delta=3\right.$ ); (c) Erro após decisão; (d) Média dos coeficientes do equalizador e solução de Wiener (linhas tracejadas); (e) EMSE estimado; média de $10^{3}$ realizações; Canal $H_{C 4}(z)$, variante no tempo. Fonte: [28].

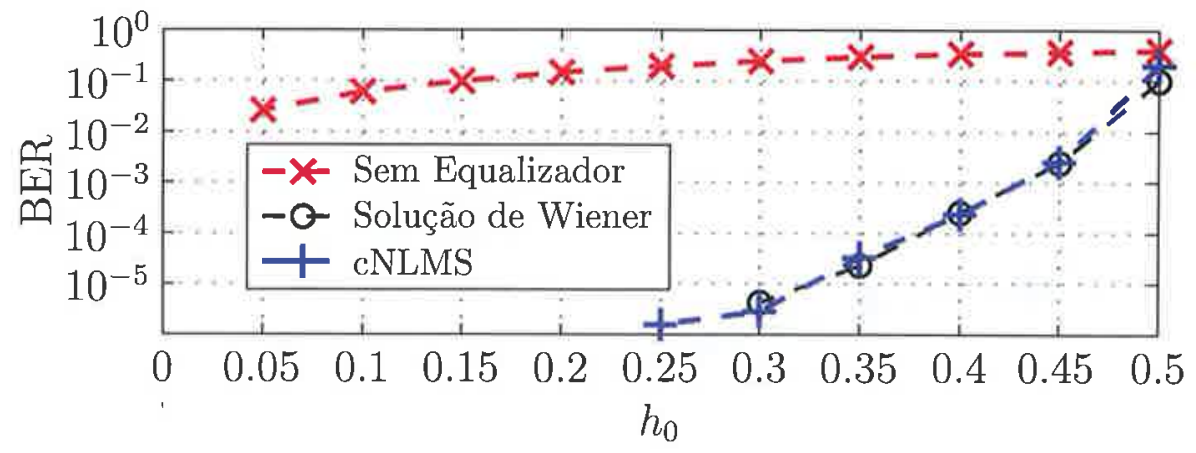

Figura 4.31: BER para o canal $H_{C 5}(z)$ em função de $h_{0}$ na ausência de ruído; cNLMS $\operatorname{com} \widetilde{\mu}=0,05 ; \delta=10^{-5} ; \varepsilon=0,1 ; N_{e q}=21 ; \Delta=11$. Fonte: [28].

canal (por exemplo, $h_{0}=0,05$ ) é suficiente para se perder completamente a mensagem transmitida. Assim, o equalizador é de fato essencial para permitir a comunicação. No caso $h_{0}=0,5$, o canal apresenta um nulo espectral profundo e, ao invés de um equalizador linear transversal, deve ser empregado um equalizador com realimentação de decisão para 
se eliminar os efeitos do canal $[114,115]$.

Para ilustrar a sensibilidade ao ruído da sincronização caótica e do esquema de equalização, acrescenta-se AWGN ao sinal na saída do canal $H_{C 5}(z)$ de foma a se obter uma SNR de $60 \mathrm{~dB}$. As curvas de BER para esse caso são mostradas na Figura 4.32.

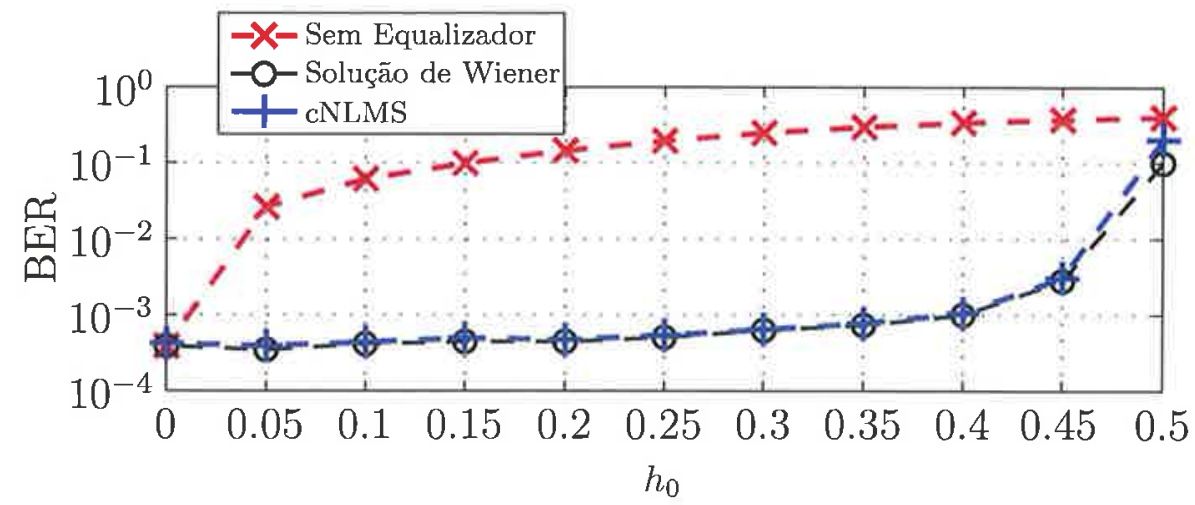

Figura 4.32: BER para o canal $H_{C 5}(z)$ em função de $h_{0}$ com SNR $=60 \mathrm{~dB}$; cNLMS com $\widetilde{\mu}=0,05 ; \delta=10^{-5} ; \varepsilon=0,1 ; N_{e q}=21 ; \Delta=11$. Fonte: [28].

Como o equalizador tenta eliminar apenas ISI, não tendo nenhum influência sobre o ruído introduzido, os valores de BER são maiores do que os da Figura 4.31, principalmente quando a ISI é pequena. Mesmo para o canal ideal $\left(h_{0}=0\right)$, não é possível recuperar perfeitamente a mensagem e tem-se uma BER de aproximadamente $8 \times 10^{-4}$. Nesse caso, como esperado, os casos com e sem equalizador fornecem o mesmo resultado.

Assumindo-se novamente o canal $H_{C 5}(z)$ com $h_{0}(n)=0,25$, obtém-se curvas de BER em função da SNR, que são mostradas na Figura 4.33 .

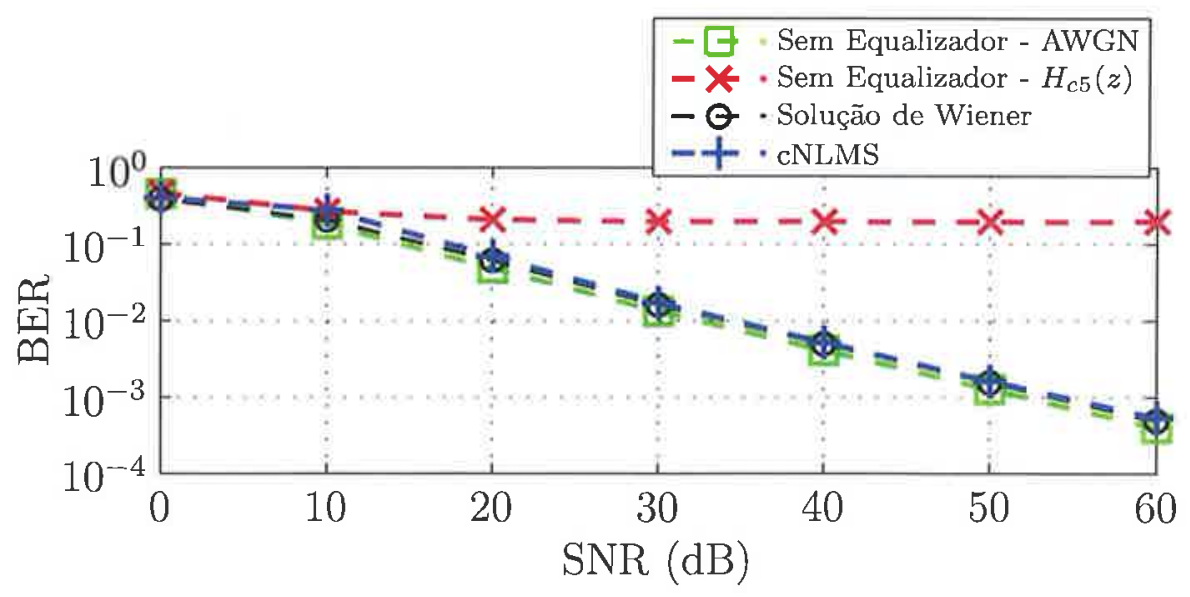

Figura 4.33: BER para o canal AWGN não dispersivo e para o Canal $H_{C 5}(z)$ com $h_{0}=$ 0,25 , em função da SNR; cNLMS com $\widetilde{\mu}=0,05 ; \delta=10^{-5} ; \varepsilon=0,1 ; N_{e q}=21 ; \Delta=11$. Fonte: [28]. 
Para efeito de comparação, incluiu-se também a curva de BER para um canal AWGN não dispersivo, obtido com o sistema da Figura 4.24 sem equalizador. Essa curva de BER funciona como limite de desempenho para a equalização em um canal ruidoso e dispersivo. Pode-se observar que a BER obtida com o algoritmo cNLMS está próxima da solução de Wiener e ambas próximas da BER para canal AWGN. Novamente, a ausência do equalizador em canal dispersivo leva a valores de BER proibitivos. É importante enfatizar que, para que o SCBC da Figura 4.24 seja viável na presença de ruído é necessário que o transmissor codifique o sinal $s(n)$ usando um código corretor de erros antes da transmissão $[18]$.

\subsubsection{Conclusões e outros trabalhos envolvendo equalização}

Nessa seção, expôs-se a proposta de um esquema de equalização supervisionada, baseada no algoritmo NLMS, para o SCBC da Figura 4.1. Simulações em diferentes cenários mostram que o algoritmo proposto permite a sincronização caótica e a transmissão de mensagens mesmo em canais não ideais. Os resultados apresentados aqui foram publicados originalmente em [28].

Desde então, o autor juntamente com o Prof. Magno T. M. Silva e o pós-doutorando Renato Candido obtiveram outros resultados relevantes. Entre eles pode-se destacar:

1. Em [44], os autores usam esquema similar ao apresentado aqui, mas agora utilizando o mapa de Ikeda $f_{I k}(\cdot)(2.21)$ como GSC. A motivação inicial para essa escolha é o fato de que esse mapa poder servir de modelo em problemas de cavidade em lasers $[1,74]$. Como uma das principais possibilidades práticas de SCBCs é em comunicações óticas [19], pensou-se ser relevante essa investigação. Obteve-se resultados interessantes, mostrando a viabilidade do esquema do cNLMS nesse cenário.

2. Em [29] mostra-se que, para o mapa $f_{I k}(\cdot)$, a função de codificação (4.74) pode levar à perda das propriedades caóticas dos sinais transmitidos. Isso ocorre devido ao ponto fixo atrator desse mapa, mostrado na Figura 2.8. Mostra-se também que uma versão modificada da função de codificação linear (4.69) permite a geração de sinais caóticos para alguns valores de $\gamma$.

3. Em [56] propõe-se uma nova função de codificação que permite, usando o mapa de Hénon como GSC, obter melhores valores de BER e uma maior faixa de parâmetros em que se obtém $s(n)$ caótico.

4. Em [101] esboça-se um esquema que permite a comutação entre a transmissão de sinais convencionais e caóticos e também entre equalização assistida ou cega, dependendo das condições do canal de comunicação. Simulações iniciais mostraram a 
viabilidade do sistema. Esse estudo está em andamento e deverá gerar um artigo a ser publicado em periódico ao longo de 2017.

\subsection{Conclusões, pesquisas em andamento e trabalhos futuros associados}

Nas últimas décadas apareceram inúmeras propostas de SCBCs na literatura. Porém, depois de mais de 25 anos das primeiras propostas [2, 3, 92, 105], o autor desconhece sistemas práticos que usem as propriedades dos sinais caóticos. Uma explicação para tanto, detectada pelo autor no início dos anos 2000, é o fato de que boa parte dessas propostas se limitar a situações ideais, sem se preocupar em como esses sistemas se comportariam em situações realísticas, ou seja, na presença de ruído, limitação em banda, atrasos, etc.

Assim, iniciou o seu interesse em estudar SCBCs nessas condições. Particularmente, nos últimos 10 anos escolheu sistemas que utilizam o sincronismo caótico, conhecidos como coerentes. Nesses sistemas, as propriedades dos GSCs são de fato utilizadas na codificação de informação. Essa situação contrasta com os sistemas ditos não coerentes como o CSK e o DCSK [90], em que não é necessário o sincronismo caótico. A informação é codificada na energia de trechos do sinal transmitido ou na correlação entre esses trechos. Uma crítica que o autor comumente faz a esses sistemas é que eles teriam desempenho virtualmente idêntico caso os sinais caóticos fossem substituídos por trechos de sinais aleatórios.

Nesse capítulo, descreveu-se uma versão em tempo discreto do SCBC proposto por $\mathrm{Wu}$ e Chua e estudou-se separadamente diversos aspectos do comportamento desse sistema perante condições não ideais do canal. O SCBC foi apresentado na Seção 4.1. A seguir, na Seção 4.2 estuda-se seu desempenho em canal AWGN para uma particular função de codificação e diversos mapas diferentes. A questão de tornar o SCBC passível de utilização em canais de banda limitada é discutida em diversos aspectos ao longo da Seção 4.3. Por fim, a questão da equalização para canais dispersivos é abordada na Seção 4.4.

Os trabalhos apresentados nesse capítulo fazem parte de uma dissertação de mestrado [62] e duas teses de doutorado [64, 65] e foram publicados em 4 artigos de periódicos [28$30,95]$ e em diversos artigos em anais de congressos.

O tema continua sendo assunto de pesquisa do orientador, em colaboração com seus colegas e alunos. Diversas possibilidades de trabalhos presentes e futuros foram colocadas ao longo do capítulo. De forma geral, três tópicos gerais parecem ser bastante relevantes. 


\section{SCBCs e sistemas de comunicação convencionais}

Um pré-requisito fundamental para a continuidade das pesquisas com os SCBCs é descobrir e demonstrar numericamente aplicações em que os SCBCs superem as soluções atualmente em uso ou em desenvolvimento.

Claramente, o uso de sinais caóticos da forma como discutida nesse capítulo impede, em princípio, o uso do receptor ótimo em sistemas de comunicações digitais, o filtro casado [81]. Assim, seu desempenho em termos de BER em canal AWGN será sempre inferior ao dos sistemas convencionais. É necessário encontrar então alguma outra vantagem dos SCBCs de forma que justifique seu uso, mesmo com o desempenho em termos de BER desfavorável.

É usual afirmar que a transmissão de sinais caóticos acrescenta segurança ao sistema na camada física, veja por exemplo $[19,121]$. Mas o autor desconhece qualquer demonstração quantitativa desse aumento tão apregoado.

O fato de os sinais caóticos poderem ser de banda larga, torna os SCBCs candidatos a sistemas de espalhamento espectral, como indica, por exemplo, [4, 7, 123]. Assim, eles poderiam apresentar as vantagens desses últimos como, por exemplo, resistência a jamming e bom desempenho em canais com multipercurso [81]. Mas, novamente, não há nenhuma situação do conhecimento do autor, em que se possa apontar os sinais caóticos como tendo desempenho melhor do que as alternativas já em uso na prática.

Resultados mais recentes, como $[124,125]$ mostram a robustez das propriedades dinâmicas dos sinais caóticos transmitidos, mais especificamente dos expoentes de Lyapunov, em canais com multipercurso. Usando-se dessa invariância poderia se transmitir informação a taxas baixas em situações de baixa SNR. Mais estudos precisam ser feitos no sentido de propor SCBC digitais que utilizem de forma eficiente essa propriedade e de se mostrar que poderiam ser uma alternativa válida em algumas situações.

O sentimento do autor ć que, enquanto não se conseguir de fato demonstrar quantitativamente situações efetivas em que vale a pena utilizar-se os SCBCs, esse assunto será apenas um problema matemático interessante.

\section{SCBCs usando sincronismo de rede de osciladores e sincronismo de fase}

Uma possibilidade de melhorar a robustez do sincronismo caótico na presença de AWGN é utilizar redes de mapas no transmissor e no receptor, no lugar de um único mapa como feito nesse capítulo. Estudos nesse sentido foram inicializados pelo autor em colaboração com o Prof. Antonio M. Baptista da Universidade Estadual de Ponta Grossa [126]. Nesse trabalho detectou-se numericamente um aumento na robustez do sincronismo 
com o número de mapas acoplados utilizados no transmissor e no receptor.

Nos estudos relatados no capítulo, sempre se considerou o sincronismo completo ou idêntico [102] entre sistemas mestre-escravo. Uma alternativa que pode ser relevante para sistemas de comunicação, é considerar-se apenas a sincronização de fase [127] entre osciladores caótico, como forma de transmitir informações. Outra possibilidade, é estudar esse tipo de sincronismo como forma de armazenamento dinâmico de informação, como proposto em [127].

Nessa linha, um assunto que tem atraído a atenção de pesquisadores de múltiplas áreas é a propagação de informações e a sincronização em redes complexas $[128,129]$. Como muitos dos sistemas de comunicação modernos podem ser modelados como redes desse tipo, analisar questões envolvendo esse tema pode ter relevância prática. Alguns dos assuntos que pretende-se pesquisar nos próximos anos visando aplicações em SCBC são: sincronia seletiva [130], computing reservoir [131] e a propagação de informação em redes complexas [132].

\section{Implementação em hardware dos SCBCs estudados}

Apesar da quantidade de resultados obtidos, eles baseiam-se sobretudo em análises teóricas e simulações numéricas. A falta de resultados experimentais e não apenas numéricos, tem sido uma crítica constante ao trabalho desse autor.

Nos próximos anos, tem-se a intenção de pesquisar com mais ênfase a implementação prática em hardware dos SCBCs descritos nesse capítulo principalmente por meio de software defined electronics $[112,113]$. Essa implementação deve ajudar a responder uma série de perguntas de natureza prática. Por exemplo, qual o comportamento dos transmissores descritos e da sincronização caótica quando utiliza-se precisão finita nos cálculos. 


\section{Capítulo 5}

\section{Notas finais}

Nesse texto procurou-se fazer um recorte dos principais resultados de pesquisa alcançados pelo autor nos últimos 10 anos, ou seja, no período que vai do final do seu doutoramento em 2006 até o presente.

Em todas as pesquisas relatadas, busca-se fundir recursos de duas áreas do conhecimento geralmente tratadas de forma isolada: Processamento Digital de Sinais (PDS) e Sistemas de Comunicação de um lado e Sistemas Dinâmicos e Teoria do Caos de outro. Com sua formação básica associada à primeira área e seu grande interesse na segunda, o autor buscou aplicar as técnicas de uma em outra desde sua graduação. Assim, surgiram resultados que pensa-se serem contribuições relevantes para ambas. Tanto é que foram publicados em periódicos tanto da área de PDS e comunicações (por exemplo, IEEE Communication Letters, Signal Processing) quanto da área de Sistemas Dinâmicos (por exemplo, Communications in Nonlinear Science and Numerical Simulation, Chaos, Solitons \& Fractals).

Após uma breve introdução no Capítulo 1, faz-se uma revisão sobre sinais caóticos em tempo discreto no Capítulo 2. Nessa revisão estabeleceu-se boa parte da notação utilizada no restante do texto além de ter o objetivo de tornar o texto autocontido.

Os resultados de pesquisa são apresentados nos dois capítulos seguintes. Buscandose adotar uma notação unificada e consistente, sistematizam-se criticamente resultados apresentados em 4 dissertações de mestrado [40, 60, 62, 63] e 2 teses de doutorado [64, 65] e publicados em 12 artigos de periódicos listados no JCR [13, 21-31], em 6 capítulos de livro [32-37] e em 22 artigos completos em anais de congressos.

No Capítulo 3, deduz-se a DEP para os sinais caóticos gerados pelos mapas tenda inclinada $f_{I}(\cdot)$ e de Bernoulli $f_{B}(\cdot)$. Obtém-se também a banda essencial para as órbitas em função dos parâmetros dos mapas. Os resultados são obtidos usando formalmente definições utilizadas para processos estocásticos. Vale destacar que diversos autores utili- 
zaram as técnicas apresentadas para obter a DEP de outros mapas, por exemplo $[85,86]$. Trabalhos atuais e futuros são descritos na Seção 3.4 .

No Capítulo 4 estudam-se diversos aspectos práticos do SCBC de tempo discreto definido na Seção 4.1. Analisa-se seu desempenho em canal AWGN, propõe-se o uso de filtros FIR para adaptá-lo a canais limitados em banda e o uso de equalizadores. Trabalhos atuais e futuros são descritos na Seção 4.5 .

Espera-se que o presente texto tenha apresentado de forma consistente as pesquisas realizadas no período e o rumo que se pretende tomar nos próximos anos. Tem-se a expectativa de continuar avançando nos estudos desses temas, buscando aplicações de fato prática para os SCBCs.

Ressalta-se que os trabalhos apresentados não esgotam a produção do autor no período, que também realizou pesquisas envolvendo, entre outros assuntos, sinais neuronais [133-135] e redes complexas [136-138]. 


\section{Referências Bibliográficas}

[1] K. T. Alligood, T. D. Sauer, and J. A. Yorke, Chaos. Textbooks in Mathematical Sciences, Springer, 2000.

[2] L. M. Pecora and T. L. Carroll, "Synchronization in chaotic systems," Physical Review Letters, vol. 64, pp. 821-824, feb 1990.

[3] E. Ott, C. Grebogi, and J. A. Yorke, "Controlling chaos," Physical Review Letters, vol. 64, pp. 1196-1199, mar 1990.

[4] M. P. Kennedy, G. Setti, and R. Rovatti, eds., Chaotic Electronics In Telecommunications. Boca Raton, FL, USA: CRC Press, 2000.

[5] M. P. Kennedy and G. Kolumbán, "Digital communications using chaos," Signal Processing, vol. 80, pp. 1307-1320, jul 2000.

[6] S. Tsekeridou, V. Solachidis, N. Nikolaidis, A. Nikolaidis, A. Tefas, and I. Pitas, "Statistical analysis of a watermarking system based on Bernoulli chaotic sequences," Signal Processing, vol. 81, pp. 1273-1293, jun 2001.

[7] F. C. M. Lau and C. K. Tse, Chaos-Based Digital Communication Systems. Berlin: Springer-Verlag GmbH, 2003.

[8] P. Stavroulakis, ed., Chaos Applications in Telecommunications. Boca Raton, FL, USA: CRC Press, 2005.

[9] M. Eisencraft, R. R. F. Attux, and R. Suyama, eds., Chaotic Signals in Digital Communications (Electrical Engineering 80 Applied Signal Processing Series). CRC Press, 2013.

[10] G. Kaddoum, "Wireless chaos-based communication systems: A comprehensive survey," IEEE Access, vol. 4, pp. 2621-2648, 2016.

[11] X. Li, C. Li, and I.-K. Lee, "Chaotic image encryption using pseudo-random masks and pixel mapping," Signal Processing, vol. 125, pp. 48-63, aug 2016.

[12] L. M. Pecora and T. L. Carroll, "Synchronization of chaotic systems," Chaos: An Interdisciplinary Journal of Nonlinear Science, vol. 25, p. 097611, sep 2015. 
[13] L. Monteiro, A. Lisboa, and M. Eisencraft, "Route to chaos in a third-order phaselocked loop network," Signal Processing, vol. 89, pp. 1678-1682, aug 2009.

[14] R. de F. Attux and J. Romano, "Chaotic phenomena in adaptive blind equalisers," IEE Proceedings - Vision, Image, and Signal Processing, vol. 150, p. 360, 152003.

[15] T. Endo and L. Chua, "Chaos from phase-locked loops," IEEE Transactions on Circuits and Systems, vol. 35, pp. 987-1003, Aug 1988.

[16] B. A. Harb and A. Harb, "Chaos and bifurcation in a third-order phase locked loop," Chaos, Solitons 8 Fractals, vol. 19, pp. 667-672, feb 2004.

[17] M. S. Tavazoei and M. Haeri, "Chaos in the APFM nonlinear adaptive filter," Signal Processing, vol. 89, pp. 697-702, may 2009.

[18] S. Haykin and M. Moher, Communication Systems. John Wiley \& Sons Inc., 5th ed., 2009 .

[19] A. Argyris, D. Syvridis, L. Larger, V. Annovazzi-Lodi, P. Colet, I. Fischer, J. GarcíaOjalvo, C. R. Mirasso, L. Pesquera, and K. A. Shore, "Chaos-based communications at high bit rates using commercial fibre-optic links," Nature, vol. 438, pp. 343-346, nov 2005.

[20] D. Syvridis, "Optical chaos encoded communications: Solutions for today and tomorrow," in 2009 IEEE LEOS Annual Meeting Conference Proceedings, IEEE Lasers and Electro-Optics Society (LEOS) Annual Meeting, pp. 759-760, IEEE Photon Soc, IEEE, oct 2009.

[21] M. Eisencraft and L. A. Baccalá, "The Cramer-Rao bound for initial conditions estimation of chaotic orbits," Chaos, Solitons $\mathcal{E}$ Fractals, vol. 38, pp. 132-139, oct 2008 .

[22] M. Eisencraft and D. M. Kato, "Spectral properties of chaotic signals with applications in communications," Nonlinear Analysis: Theory, Methods $\&$ Applications, vol. 71, pp. e2592-e2599, dec 2009.

[23] M. Eisencraft, R. D. Fanganiello, and L. A. Baccala, "Synchronization of discretetime chaotic systems in bandlimited channels," Mathematical Problems in Engineering, vol. 2009, pp. 1-12, 2009.

[24] M. Eisencraft, D. Kato, and L. Monteiro, "Spectral properties of chaotic signals generated by the skew tent map," Signal Processing, vol. 90, pp. 385-390, jan 2010.

[25] M. Eisencraft, R. D. Fanganiello, and L. H. A. Monteiro, "Chaotic synchronization in discrete-time systems connected by bandlimited channels," IEEE Communications Letters, vol. 15, pp. 671-673, jun 2011. 
[26] M. Eisencraft and A. Batista, "Discrete-time chaotic systems synchronization performance under additive noise," Signal Processing, vol. 91, pp. 2127-2131, aug 2011.

[27] M. Eisencraft, R. Fanganiello, J. Grzybowski, D. Soriano, R. Attux, A. Batista, E. Macau, L. Monteiro, J. Romano, R. Suyama, and T. Yoneyama, "Chaos-based communication systems in non-ideal channels," Communications in Nonlinear Science and Numerical Simulation, vol. 17, pp. 4707-4718, dec 2012.

[28] R. Candido, M. Eisencraft, and M. T. Silva, "Channel equalization for synchronization of chaotic maps," Digital Signal Processing, vol. 33, pp. 42-49, oct 2014.

[29] R. Candido, D. C. Soriano, M. T. Silva, and M. Eisencraft, "Do chaos-based communication systems really transmit chaotic signals?," Signal Processing, vol. 108, pp. 412-420, mar 2015.

[30] R. T. Fontes and M. Eisencraft, "A digital bandlimited chaos-based communication system," Communications in Nonlinear Science and Numerical Simulation, vol. 37, pp. 374-385, aug 2016.

[31] R. A. Costa, M. B. Loiola, and M. Eisencraft, "Correlation and spectral properties of chaotic signals generated by a piecewise-linear map with multiple segments," Signal Processing, vol. 133, pp. 187-191, apr 2017.

[32] J. M. V. Grzybowski, M. Eisencraft, and E. E. N. Macau, "Chaos-based communication systems: Current trends and challenges," in Applications of Chaos and Nonlinear Dynamics in Engineering - Vol. 1 (S. Banerjee, M. Mitra, and L. Rondoni, eds.), vol. 71 of Understanding Complex Systems, pp. 203-230, Springer Nature, 2011.

[33] M. Eisencraft and L. A. Baccalá, "Applying estimation techniques to chaos-based digital communications," in Chaotic Systems (E. Tlelo-Cuautle, ed.), pp. 255-280, InTech, feb 2011.

[34] R. D. Fanganiello, R. T. Fontes, M. Eisencraft, and L. H. A. Monteiro, "Chaotic communications in bandlimited channels," in Chaotic Signals in Digital Communications (M. Eisencraft, R. R. F. Attux, and R. Suyama, eds.), CRC Press, Inc., 2013.

[35] G. A. Abib, M. Eisencraft, and A. M. Batista, "Using coupled maps to improve synchronization performance," in Chaotic Signals in Digital Communications (M. Eisencraft, R. Attux, and R. Suyama, eds.), CRC Press, Inc., 2013.

[36] D. Soriano, M. B. Loiola, M. Eisencraft, V. B. Olivatto, J. M. T. Romano, and R. R. F. Attux, "Denoising chaotic time series using an evolutionary state estimation approach," in Chaotic Signals in Digital Communications, CRC Press, 2013. 
[37] R. Candido, M. Eisencraft, and M. T. M. Silva, "Channel equalization for chaotic communications systems," in Chaotic Signals in Digital Communications (M. Eisencraft, R. Attux, and R. Suyama, eds.), CRC Press, Inc., 2013.

[38] M. Eisencraft and L. A. Baccalá, "Estimating the initial condition of chaotic orbits: Performance bounds," in CHAOS'06: A preprints volume, vol. 39, (Reims), pp. 281285, Elsevier BV, 2006.

[39] D. M. Kato and M. Eisencraft, "On the power spectral density of chaotic signals generated by skew tent maps," in 2007 International Symposium on Signals, Circuits and Systems, vol. 1, pp. $1-4$, Institute of Electrical and Electronics Engineers (IEEE), jul 2007.

[40] F. S. Netto and M. Eisencraft, "Spread spectrum digital communication system using chaotic pattern generator," in The 10th Experimental Chaos Conference, vol. 1, (Catania), pp. 1-7, Universitá degli Studi di Catania, 2008.

[41] M. Eisencraft and M. A. do Amaral, "Estimation of nonuniform invariant density chaotic signals with applications in communications," in Proceedings of the 2nd IFAC meeting related to analysis and control of chaotic systems, vol. 42, (London), pp. 116-121, Elsevier BV, 2009.

[42] M. Eisencraft, M. A. do Amaral, and C. A. Lima, "Estimation of chaotic signals with applications in communications," in Preprints of the 15th IFAC Symposium on System Identification, vol. 42, (Saint-Malo), pp. 126-131, Elsevier BV, 2009.

[43] D. C. Soriano, G. A. Abib, M. Eisencraft, R. Attux, and R. Suyama, "Using an evolutionary denoising approach to improve the robustness of chaotic synchronization," in Proceedings of the third IFAC CHAOS Conference, vol. 45, pp. 35-39, International Federation of Automatic Control (IFAC), Elsevier BV, jun 2012.

[44] R. Candido, M. Eisencraft, and M. T. M. Silva, "Channel equalization for synchonization of Ikeda maps," in Proc. of $21^{\text {st }}$ European Signal Processing Conference (EUSIPCO'2013), (Marrakesh, Marocco), 2013.

[45] R. T. Fontes and M. Eisencraft, "Noise filtering in bandlimited digital chaos-based communication systems," in 22nd European Signal Processing Conference, EUSIPCO 2014, Lisbon, Portugal, September 1-5, 2014, pp. 406-410, 2014.

[46] G. A. Abib and M. Eisencraft, "On the performance of a digital chaos-based communication system in noisy channels," in Proceedings of the 1st IFAC Conference on Modelling, Identification and Control of Nonlinear Systems (MICNON 2015), vol. 1, (Saint-Petersburg, Russia), pp. 1-6, IFAC - International Federation of Automatic Control, 2015. 
[47] D. M. Kato and M. Eisencraft, "Caracterização espectral de sinais caóticos," in Anais do XXV Simpósio Brasileiro de Telecomunicações (SBrT'07), vol. 1, pp. 1-5, Sociedade Brasileira de Telecomunicações, 2007.

[48] M. Eisencraft and L. A. Baccalá, "Modulações digitais usando portadoras caóticas: uma análise comparativa," in Anais do XXV Simpósio Brasileiro de Telecomunicações, (Recife), pp. 1-6, Sociedade Brasileira de Telecomunicações, Sept. 2007.

[49] D. M. Kato and M. Eisencraft, "Caracterização espectral de sinais caóticos: resultados analíticos," in Anais do XXVI Simpósio Brasileiro de Telecomunicações, (Rio de Janeiro), pp. 1-6, Sociedade Brasileira de Telecomunicações, 2008.

[50] F. S. Netto and M. Eisencraft, "Sequências pseudoaleatórias usando caos para sistemas de espalhamento espectral," in Anais do 80 Congresso Brasileiro de Dinâmica, Controle e Aplicaçôes DINCON'09, (Baurú), pp. 1-8, SBMAC e UNESP, 2009.

[51] D. M. Kato and M. Eisencraft, "Análise espectral de órbitas do mapa de Maneville," in Anais do 80 Congresso Brasileiro de Dinâmica, Controle e Aplicaçôes DINCON'09, (Baurú), pp. 1-7, SBMAC e UNESP, 2009.

[52] R. T. Fontes, M. Eisencraft, and L. H. A. Monteiro, "Sistemas de comunicaçaõo digital usando sinais caóticos em canais de banda limitada," in Anais da X Conferência Brasileira de Dinâmica, Controle e Aplicações (DINCON), vol. 1, pp. 160-163, Brazilian Society for Computational and Applied Mathematics (SBMAC), 2011.

[53] R. Candido, M. Eisencraft, and M. T. M. Silva, "Equalização de canais de comunicação para a sincronização de mapas," in Proceeding Series of the Brazilian Society of Computational and Applied Mathematics (DINCON), vol. 1, Brazilian Society for Computational and Applied Mathematics (SBMAC), oct 2013.

[54] G. A. Abib and M. Eisencraft, "Desempenho de sistema de comunicacção digital caótico em canal com ruído," in Proceeding Series of the Brazilian Society of Computational and Applied Mathematics (DINCON), vol. 1, Brazilian Society for Computational and Applied Mathematics (SBMAC), oct 2013.

[55] G. A. Abib and M. Eisencraft, "Sobre o desempenho em canal com ruído de um sistema de comunicação baseado em caos," in SBrT 2013, Sociedade Brasileira de Telecomunicações, Sociedade Brasileira de Telecomunicações, 2013.

[56] R. Candido, M. T. M. Silva, and M. Eisencraft, "Uma nova codificação para sistemas de comunicação caóticos," in Proceeding Series of the Brazilian Society of Computational and Applied Mathematics (DINCON), Brazilian Society for Computational and Applied Mathematics (SBMAC), aug 2016. 
[57] R. A. D. Costa, M. Bellezo, and M. Eisencraft, "Análise espectral de sinais caóticos gerados pelo mapa de Bernoulli com $r$ segmentos," in Proceeding Series of the Brazilian Society of Computational and Applied Mathematics (DINCON), pp. 1-7, Brazilian Society for Computational and Applied Mathematics (SBMAC), aug 2016.

[58] R. A. Costa, M. B. Loiola, and M. Eisencraft, "Caracterização espectral de sinais caóticos gerados pelo mapa de Bernoulli com 2 e 3 segmentos," in Anais do XXXIII Simpósio Brasileiro de Telecomunicações (SBrT 2015), pp. 1-5, SBrT, 2015.

[59] R. T. Fontes and M. Eisencraft, "Conditions for synchronizing a master-slave bandlimited chaos-based communication system," in 2015 International Workshop on Telecommunications (IWT), vol. 1, (Santa Rita do Sapucaí), pp. 1-4, Institute of Electrical and Electronics Engineers (IEEE), jun 2015.

[60] D. M. Kato, "Análise espectral de sinais caóticos gerados por mapas unidimensionais," Master's thesis, Programa de Pós-graduação em Engenharia Elétrica Universidade Presbiteriana Mackenzie, 2008.

[61] F. S. Netto, "Geradores de sequências pseudoaleatórias usando caos em sistemas de espalhamento espectral," Master's thesis, Universidade Presbiteriana Mackenzie Mestrado em Engenharia Elétrica, 2009.

[62] G. A. Abib, "Desempenho em canal com ruído de um sistema de comunicação baseado em caos," Master's thesis, Universidade Federal do ABC - Mestrado em Engenharia da Informação, 2013.

[63] R. A. Costa, "Caracterização temporal e espectral de sinais caóticos gerados por mapas unidimensionais," Master's thesis, Universidade Federal do ABC - Mestrado em Engenharia da Informação, 2015.

[64] R. Candido, A questão da equalização em sistemas de comunicação que utilizam sinais caóticos. PhD thesis, Escola Politécnica, Universidade de São Paulo (Doutorado em Engenharia Elétrica), 2014.

[65] R. T. Fontes, Sistema de comunicação digital em banda limitada baseado em sincronismo caótico. PhD thesis, Universidade de São Paulo, 2017.

[66] M. Eisencraft, "Sistemas de comunicação utilizando sinais caóticos," Master's thesis, Escola Politécnica da Universidade de São Paulo, 2001.

[67] M. Eisencraft, Contribuições da teoria da estimação para modulações digitais que utilizam sinais caóticos. PhD thesis, Escola Politécnica, Universidade de São Paulo, 2006. 
[68] D. C. Soriano, F. I. Fazanaro, R. Suyama, J. R. Oliveira, R. Attux, and M. K. Madrid, "A method for Lyapunov spectrum estimation using cloned dynamics and its application to the discontinuously-excited Fitzhugh-Nagumo model," Nonlinear Dynamics, vol. 67, pp. 413-424, mar 2011.

[69] T.-Y. Li and J. A. Yorke, "Period three implies chaos," The American Mathematical Monthly, vol. 82, p. 985, dec 1975.

[70] R. L. Devaney, An Introduction to Chaotic Dynamical Systems. Addison-Wesley studies in nonlinearity, Westview, 2003.

[71] D. F. Drake and D. B. Williams, "Linear, random representations of chaos," IEEE Transactions on Signal Processing, vol. 55, pp. 1379-1389, apr 2007.

[72] A. Kisel, H. Dedieu, and T. Schimming, "Maximum likelihood approaches for noncoherent communications with chaotic carriers," IEEE Transactions on Circuits and Systems I: Fundamental Theory and Applications, vol. 48, pp. 533-542, may 2001.

[73] M. Hénon, "A two-dimensional mapping with a strange attractor," Communications in Mathematical Physics, vol. 50, pp. 94-102, 1976.

[74] K. Ikeda, "Multiple-valued stationary state and its instability of the transmitted light by a ring cavity system," Optics Communications, vol. 30, no. 2, pp. 257 261, 1979 .

[75] D. L. Hitzl and F. Zele, "An exploration of the Hénon quadratic map," Physica D: Nonlinear Phenomena, vol. 14, pp. 305-326, mar 1985.

[76] A. Lasota and M. C. Mackey, Probabilistic Properties of Deterministic Systems. Cambridge University Press, 1985.

[77] G. Setti, G. Mazzini, R. Rovatti, and S. Callegari, "Statistical modeling of discretetime chaotic processes-basic finite-dimensional tools and applications," Proceedings of the IEEE, vol. 90, pp. 662-690, may 2002.

[78] O. Michel and P. Flandrin, "Application of methods based on higher-order statistics for chaotic time series analysis," Signal Processing, vol. 53, pp. 133-148, sep 1996.

[79] H. Sakai and H. Tokumaru, "Autocorrelations of a certain chaos," IEEE Transactions on Acoustics, Speech, and Signal Processing, vol. 28, pp. 588-590, oct 1980.

[80] P. Stoica and R. L. Moses, Spectral Analysis of Signals. Prentice Hall, 2005.

[81] B. P. Lathi and Z. Ding, Modern Digital and Analog Communication Systems (The Oxford Series in Electrical and Computer Engineering). The Oxford Series in Electrical and Computer Engineering, Oxford University Press, 2009. 
[82] H. Papadopoulos and G. Wornell, "Maximum-likelihood estimation of a class of chaotic signals," IEEE Transactions on Information Theory, vol. 41, pp. 312-317, Jan 1995.

[83] A. V. Oppenheim, Sinais e Sistemas. Pearson, 2010.

[84] A. V. Oppenheim and R. W. Schafer, Discrete-Time Signal Processing. Upper Saddle River, NJ, USA: ADDISON WESLEY PUB CO INC, 3rd ed., 2009.

[85] K. Feltekh, Z. B. Jemaa, D. Fournier-Prunaret, and S. Belghith, "Border collision bifurcations and power spectral density of chaotic signals generated by onedimensional discontinuous piecewise linear maps," Communications in Nonlinear Science and Numerical Simulation, vol. 19, pp. 2771-2784, aug 2014.

[86] K. Feltekh, D. Fournier-Prunaret, and S. Belghith, "Analytical expressions for power spectral density issued from one-dimensional continuous piecewise linear maps with three slopes," Signal Processing, vol. 94, pp. 149-157, jan 2014.

[87] R. A. Costa, M. B. Loiola, and M. Eisencraft, "Spectral properties of chaotic signals generated by the Bernoulli map," Journal of Engineering Science and Technology Review, vol. 8, no. 2, pp. 12-16, 2015.

[88] P. Peebles, Probability, Random Variables, and Random Signal Principles. McGrawHill Science/Engineering/Math, 2000.

[89] R. A. da Costa and M. Eisencraft, "Spectral properties of the orbits of the Hénon map," in Proceedings of the 6th International Conference on Nonlinear Science and Complexity, pp. 1-3, SWGE Sistemas, 2016.

[90] G. Kolumban, M. Kennedy, and L. Chua, "The role of synchronization in digital communications using chaos. II. chaotic modulation and chaotic synchronization," IEEE Transactions on Circuits and Systems I: Fundamental Theory and Applications, vol. 45, no. 11, pp. 1129-1140, 1998.

[91] Y. Pomeau and P. Manneville, "Intermittent transition to turbulence in dissipative dynamical systems," Communications in Mathematical Physics, vol. 74, pp. 189197, jun 1980.

[92] C. W. Wu and L. O. Chua, "A simple way to synchronize chaotic systems with applications to secure communication systems," International Journal of Bifurcation and Chaos, vol. 03, pp. 1619-1627, dec 1993.

[93] M. Eisencraft and M. Gerken, "Comunicação utilizando sinais caóticos: Influência de ruído e de limitação em banda," in Anais do XVIII Simpósio Brasileiro de Telecomunicações., (Gramado), Sociedade Brasileira de Telecomunicações, 2000. 
[94] G. A. Abib and M. Eisencraft, "Comportamento de sistemas de comunicação digital usando sinais caóticos em meio ruidoso," in Anais do I WPOSINFO - I Workshop da Pós-Graduação em Engenharia da Informação, (Santo André), pp. 1-2, UFABC, 2011.

[95] G. A. Abib and M. Eisencraft, "Comportamento de sistemas de comunicação digital usando sinais caóticos em canal com ruído," Revista de Tecnologia da Informação e Comunicação, vol. 1, pp. 27-32, apr 2012.

[96] G. A. Abib and M. Eisencraft, "Performance of digital chaos-based communication systems in a noisy environment," in 12th Experimental Chaos and Complexity Conference, vol. 1, (Ann Arbor, Michigan), pp. 50-50, University of Michigan, 2012.

[97] R. D. Fanganiello, M. Eisencraft, and L. H. A. Monteiro, "Conditions for the synchronization of band-limited discrete-time chaotic systems," in Book of Abstracts of the 11th Experimental Chaos $\& 3$ Complexity Conference, vol. 1, (Lille), pp. 141-141, Université Lille 1 Sciences et Technologies, 2010.

[98] R. D. Fanganiello, M. Eisencraft, and L. H. A. Monteiro, "Conditions for the synchronization of band-limited discrete-time chaotic systems," in Dynamics Days South America 2010 - International Conference on Chaos and Nonlinear Dynamics - Book of Abstracts and Program, (São José dos Campos), pp. 84-85, INPE, 2010.

[99] R. D. Fanganiello, M. Eisencraft, and L. H. A. Monteiro, "Synchronization conditions for a bandlimited discrete-time chaotic system," in Proceedings - Extended Abstracts of the Dynamics Days South America 2010 - International Conference on Chaos and Nonlinear Dynamics, (São José dos Campos), pp. 1-2, INPE, 2010.

[100] R. T. Fontes and M. Eisencraft, "Chaotic properties of the Hénon map with a linear filter," in Proceedings of the 6th International Conference on Nonlinear Science and Complexity, pp. 1-3, SWGE Sistemas, 2016.

[101] R. Candido, M. T. M. Silva, and M. Eisencraft, "A switching scheme between conventional and chaos-based communication systems," in Proceedings of the 6th International Conference on Nonlinear Science and Complexity, pp. 1-3, SWGE Sistemas, 2016.

[102] S. Boccaletti, J. Kurths, G. Osipov, D. Valladares, and C. Zhou, "The synchronization of chaotic systems," Physics Reports, vol. 366, pp. 1-101, aug 2002.

[103] R. P. Agarwal, Difference Equations and Inequalities: Theory, Methods, and Applications (Pure and Applied Mathematics : a Series of Monographs and Textbooks, Vol 1), vol. 155 of Monographs and Textbooks in Pure and Applied Mathematics. New York: Marcel Dekker Inc, 1992. 
[104] K. M. Cuomo and A. V. Oppenheim, "Circuit implementation of synchronized chaos with applications to communications," Physical Review Letters, vol. 71, pp. 65-68, Jul 1993.

[105] K. Cuomo, A. Oppenheim, and S. Strogatz, "Synchronization of Lorenz-based chaotic circuits with applications to communications," IEEE Transactions on Circuits and Systems II: Analog and Digital Signal Processing, vol. 40, pp. 626-633, Oct 1993.

[106] C. Williams, "Chaotic communications over radio channels," IEEE Transactions on Circuits and Systems I: Fundamental Theory and Applications, vol. 48, pp. 13941404 , dec 2001.

[107] B. Schrauwen, D. Verstraeten, and J. M. V. Campenhout, "An overview of reservoir computing: theory, applications and implementations," in The European Symposium on Artificial Neural Networks, pp. 471-482, 2007.

[108] N. F. Rulkov and L. S. Tsimring, "Synchronization methods for communication with chaos over band-limited channels," International Journal of Circuit Theory and Applications, vol. 27, pp. 555-567, nov 1999.

[109] V. K. Ingle and J. G. Proakis, Digital Signal Processing Using MATLAB. Cengage Learning, 2011.

[110] D. Lay, Linear Algebra and Its Applications. Pearson Education, 2011.

[111] L. Arnold, Random Dynamical Systems. Springer Monographs in Mathematics, Springer-Verlag GmbH, 1998.

[112] G. Kolumban, T. I. Krebesz, and F. C. M. Lau, "Theory and application of software defined electronics: Design concepts for the next generation of telecommunications and measurement systems," IEEE Circuits and Systems Magazine, vol. 12, pp. 8--34, Secondquarter 2012.

[113] G. Kolumbán, T. Krébesz, C. K. Tse, and F. C. M. Lau, "Basics of communications using chaos," in Chaotic Signals in Digital Communications (M. Eisencraft, R. Attux, and R. Suyama, eds.), ch. 4, pp. 111-141, CRC Press, Inc., 2013.

[114] S. O. Haykin, Adaptive Filter Theory. Prentice Hall, 2013.

[115] A. H. Sayed, Adaptive Filters. IEEE Computer Soc., 2008.

[116] H. Leung, "System identification using chaos with application to equalization of a chaotic modulation system," IEEE Transactions on Circuits and Systems I: Fundamental Theory and Applications, vol. 45, pp. 314-320, mar 1998. 
[117] M. Ciftci and D. Williams, "A novel channel equalizer for chaotic digital communications systems," in 1999 IEEE International Conference on Acoustics, Speech, and Signal Processing. Proceedings. ICASSP99 (Cat. No.99CH36258), vol. 3, pp. 13011304 vol.3, Institute of Electrical and Electronics Engineers (IEEE), Mar 1999.

[118] Z. Zhu and H. Leung, "Adaptive blind equalization for chaotic communication systems using extended-Kalman filter," IEEE Transactions on Circuits and Systems I: Fundamental Theory and Applications, vol. 48, pp. 979-989, aug 2001.

[119] J. Feng, C. K. Tse, and F. C. M. Lau, "Reconstruction of chaotic signals with application to channel equalization in chaos-based communication systems," International Journal of Communication Systems, vol. 17, pp. 217-232, apr 2004.

[120] C. Vural and G. Çetinel, "Blind equalization of single-input single-output FIR channels for chaotic communication systems," Digital Signal Processing, vol. 20, pp. 201211, jan 2010 .

[121] M. Feki, B. Robert, G. Gelle, and M. Colas, "Secure digital communication using discrete-time chaos synchronization," Chaos, Solitons 8 Fractals, vol. 18, pp. 881890, nov 2003.

[122] G. Picchi and G. Prati, "Blind equalization and carrier recovery using a "stop-andgo" decision-directed algorithm," IEEE Transactions on Communications, vol. 35, pp. 877-887, sep 1987.

[123] W. M. Tam, F. C. M. Lau, and C. K. Tse, Digital Communications with Chaos. Elsevier Science, 2010.

[124] H.-P. Ren, M. S. Baptista, and C. Grebogi, "Wireless communication with chaos," Physical Review Letters, vol. 110, p. 184101, apr 2013.

[125] H.-P. Ren, M. S. . Baptista, and C. Grebogi, "Robustness of chaos to multipath propagation media," in Chaotic Signals in Digital Communications (M. Eisencraft, R. Attux, and R. Suyama, eds.), ch. 16, pp. 423-437, CRC Press, 2013.

[126] A. M. Batista and M. Eisencraft, "Comparing single and coupled maps synchronization perfomance under additive noise," in Dynamics Days South America 2010 - International Conference on Chaos and Nonlinear Dynamics - Book of Abstracts and Program, (São José dos Campos), pp. 93-93, INPE, 2010.

[127] R. Follmann, E. Rosa, E. E. N. Macau, and J. R. C. Piqueira, "Identifying phase synchronous regimes in non-coherent and multiple scroll attractor systems," International Journal of Bifurcation and Chaos, vol. 23, p. 1350179, nov 2013. 
[128] S. Boccaletti, V. Latora, Y. Moreno, M. Chavez, and D. Hwang, "Complex networks: Structure and dynamics," Physics Reports, vol. 424, pp. 175-308, feb 2006.

[129] M. Newman, Networks. New York, NY, USA: Oxford University Press, 2010.

[130] A. Zlotnik, R. Nagao, I. Z. Kiss, and J.-S. Li, "Phase-selective entrainment of nonlinear oscillator ensembles," Nature Communications, vol. 7, p. 10788, mar 2016.

[131] M. Lukoševičius, H. Jaeger, and B. Schrauwen, "Reservoir computing trends," KI - Künstliche Intelligenz, vol. 26, pp. 365-371, may 2012.

[132] M. S. Baptista, R. M. Szmoski, R. F. Pereira, and S. E. de Souza Pinto, "Chaotic, informational and synchronous behaviour of multiplex networks," Scientific Reports, vol. 6, p. 22617, mar 2016.

[133] J. N. S. S. Filho, M. Eisencraft, R. Suyama, E. T. Fonoff, and M. D. Miranda, "The use of least squares lattice algorithm in the parameterization and sorting of action potentials signals," in Bioelectronics, Biomedical, and Bioinspired Systems and Nanotechnology $V$ (Á. B. Rodríguez-Vázquez, R. Adelung, R. A. CarmonaGalán, G. Liñán-Cembrano, and C. Ronning, eds.), (Prague), pp. 80680Q-80680Q 7, SPIE-Intl Soc Optical Eng, may 2011.

[134] P. H. S. Rodrigues, M. Eisencraft, and M. D. Miranda, "Identificação de sistemas aplicada à parametrização do potencial de ação de neurônios," in Anais do SBrT 2011: XXIX Simpósio Brasileiro de Telecomunicações, (Curitiba), pp. 1-2, Sociedade Brasileira de Telecomunicações, 2011.

[135] R. A. Castellani, "Um estudo sobre a detecção de spikes em sinais neuronais," Master's thesis, Universidade Federal do ABC - Mestrado em Engenharia da Informação, 2014.

[136] A. L. D. Camargo and M. Eisencraft, "Mapeamento de séries financeiras em redes complexas," in Conferência Brasileira de Dinâmica, Controle e Aplicações (DINCON 2015), vol. 1, (Natal), pp. 1-7, Brazilian Society for Computational and Applied Mathematics (SBMAC), aug 2016.

[137] A. L. de Camargo, "Mapeamento de séries financeiras em redes complexas," Master's thesis, Universidade Federal do ABC (Mestrado em Engenharia da Informação), 2016.

[138] A. L. Camargo and M. Eisencraft, "Relation between autocorrelation sequence and average shortest-path length in a time serie to network mapping," in Proceedings of the 6th International Conference on Nonlinear Science and Complexity, pp. 1-4, SWGE Sistemas, 2016. 